\title{
The Development of a High Temperature Supercritical Carbon Dioxide Corrosion Test Rig
}

by

\author{
Ryan Gregory Petrusenko, B.Eng
}

\author{
A thesis submitted to \\ the Faculty of Graduate and Postdoctoral Affairs \\ in partial fulfillment of \\ the requirements for the degree of \\ Master of Applied Science
}

Ottawa-Carleton Institute for Mechanical and Aerospace Engineering

Department of Mechanical and Aerospace Engineering Carleton University

Ottawa, Ontario, Canada

May 2011

(C) 2011

Ryan Gregory Petrusenko 
Library and Archives

Canada

Published Heritage

Branch

395 Wellington Street

Ottawa ON K1A 0N4

Canada
Bibliothèque et

Archives Canada

Direction du

Patrimoine de l'édition

395 , rue Wellington

Ottawa ON K1A 0N4

Canada
Your file Votre référence

ISBN: 978-0-494-83048-2

Our file Notre référence

ISBN: 978-0-494-83048-2
NOTICE:

The author has granted a nonexclusive license allowing Library and Archives Canada to reproduce, publish, archive, preserve, conserve, communicate to the public by telecommunication or on the Internet, loan, distribute and sell theses worldwide, for commercial or noncommercial purposes, in microform, paper, electronic and/or any other formats.

The author retains copyright ownership and moral rights in this thesis. Neither the thesis nor substantial extracts from it may be printed or otherwise reproduced without the author's permission.
AVIS:

L'auteur a accordé une licence non exclusive permettant à la Bibliothèque et Archives Canada de reproduire, publier, archiver, sauvegarder, conserver, transmettre au public par télécommunication ou par l'Internet, prêter, distribuer et vendre des thèses partout dans le monde, à des fins commerciales ou autres, sur support microforme, papier, électronique et/ou autres formats.

L'auteur conserve la propriété du droit d'auteur et des droits moraux qui protège cette thèse. $\mathrm{Ni}$ la thèse ni des extraits substantiels de celle-ci ne doivent être imprimés ou autrement reproduits sans son autorisation.
In compliance with the Canadian Privacy Act some supporting forms may have been removed from this thesis.

While these forms may be included in the document page count, their removal does not represent any loss of content from the thesis.
Conformément à la loi canadienne sur la protection de la vie privée, quelques formulaires secondaires ont été enlevés de cette thèse.

Bien que ces formulaires aient inclus dans la pagination, il n'y aura aucun contenu manquant.

\section{Canadä}




\begin{abstract}
The supercritical carbon dioxide $\left(\mathrm{S}-\mathrm{CO}_{2}\right)$ Brayton cycle represents a highly efficient means of power conversion; however, owing to its novelty, material compatibility with $\mathrm{CO}_{2}$ at the operating conditions dictated by this cycle is still relatively unknown. As part of a collaborative research effort, a high temperature, $\mathrm{S}-\mathrm{CO}_{2}$ corrosion test rig was designed and assembled for use up to $750^{\circ} \mathrm{C}$ at $15.0 \mathrm{MPa}$ or $700^{\circ} \mathrm{C}$ at 25.0 MPa. Functional testing was carried out at $15.0 \mathrm{MPa}$ to determine and validate the necessary furnace set points that would give near uniform temperature distributions of $550,600,650,700$, and $721^{\circ} \mathrm{C}$. Temperature variation across the usable length of the specimen boat was maintained to within a 12.3 to $16.8^{\circ} \mathrm{C}$ window for all nine trials conducted. Preliminary commissioning at $25.0 \mathrm{MPa}$ also indicated that fluid temperatures were almost $40^{\circ} \mathrm{C}$ lower than those measured at $15.0 \mathrm{MPa}$ using equivalent furnace set points.
\end{abstract}




\section{Acknowledgements}

First and foremost, I would like to thank my advisor, Dr. Henry Saari, for his continuous support, both morally and financially, throughout the duration of this project; despite numerous setbacks and challenges his thoughtful guidance and direction was greatly appreciated.

I would also like to express my gratitude to CanmetENERGY of Natural Resources Canada for the funding provided. Also, many thanks to all those from the Zero Emissions Technology (ZET) group at the Ottawa Research Centre in Bells Corners that were involved in some capacity throughout the project. Chris Gareau and Dave Faguy deserve my sincere appreciation for their patience, diligence, and assistance with the overall assembly of the test rig. As well, both Dr. Kourosh Zanganeh and Carlos Salvador are worthy of acknowledgement for their help integrating this project into the existing infrastructure of the Vertical Combustor (VC) building.

Finally, I wish to thank my parents, family, and friends for their encouragement, in addition to Kyla for her help in editing this thesis. 


\section{Table of Contents}

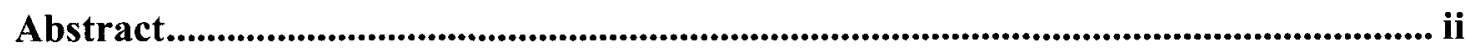

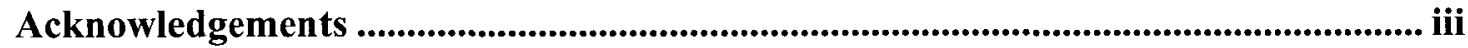

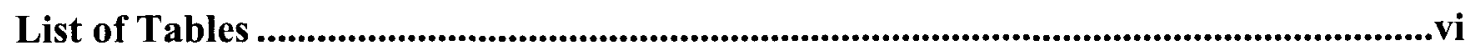

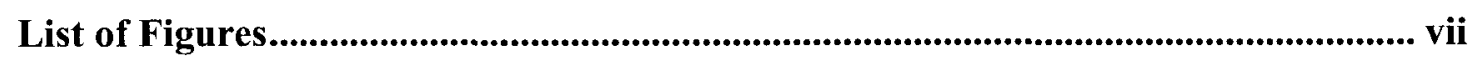

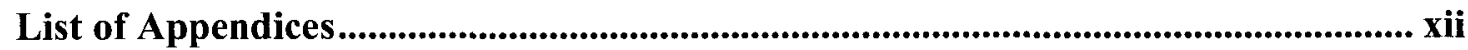

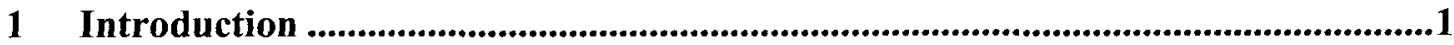

1.1 Demand for Advanced Power Conversion Cycles ......................................... 1

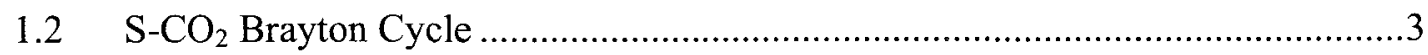

1.3 High Temperature S- $\mathrm{CO}_{2}$ Corrosion ........................................................... 7

1.4 Objective and Organization of Thesis ...........................................................

2 Literature Review - High Temperature, $\mathrm{S}-\mathrm{CO}_{2}$ Corrosion Testing.....................10

$2.1 \quad$ A Primer on High Temperature Materials........................................................ 10

2.2 Modes of High Temperature Corrosion ........................................................ 16

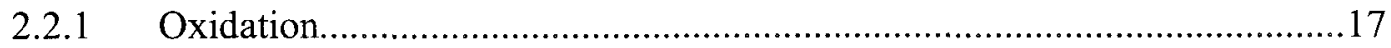

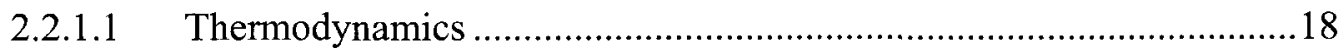

2.2.1.2 Kinetics of Oxide Formation and Growth .........................................21

2.2.1.3 Desired High Temperature Oxide Scales .........................................25

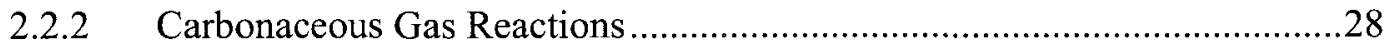

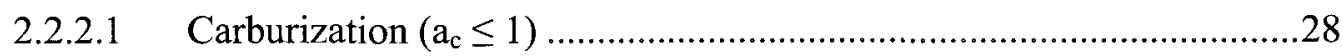

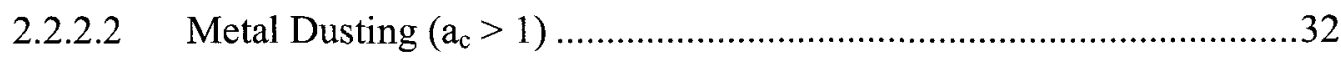

2.2.2.3 Protection Against Carbon Attack ...................................................33

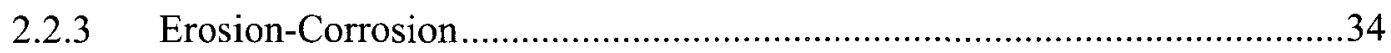

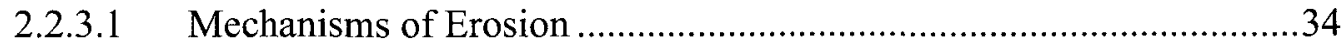

2.2.3.2 High Temperature Corrosion Interaction ............................................37

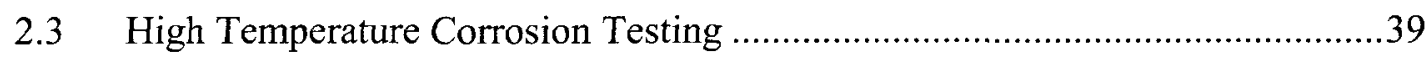

2.3.1 Erosion-Corrosion Rig Testing ...................................................... 40

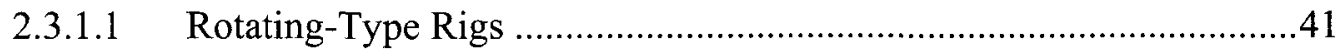

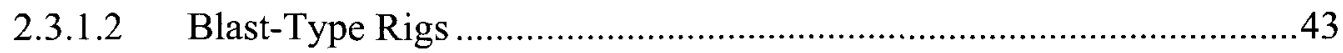

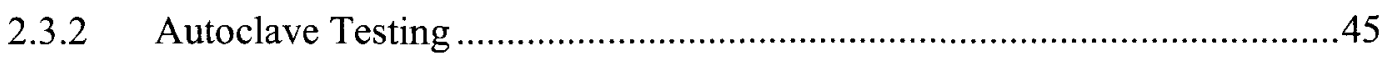

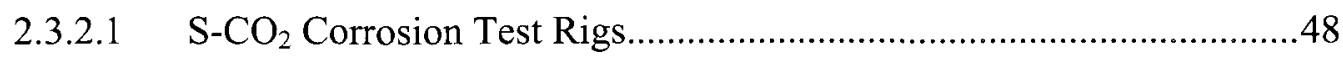




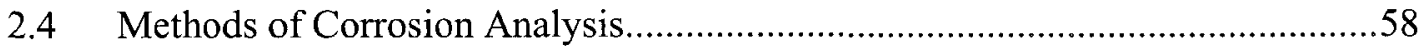

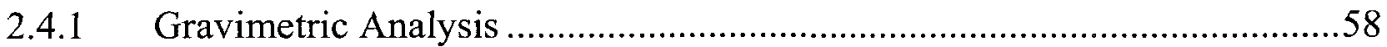

2.4.2 Microscopic and Spectroscopic Analyses..............................................59

2.5 Metallic Corrosion in High Temperature $\mathrm{CO}_{2}$ Environments ............................60

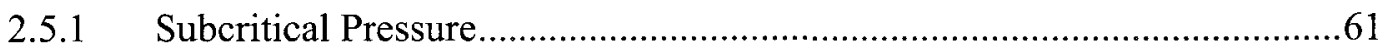

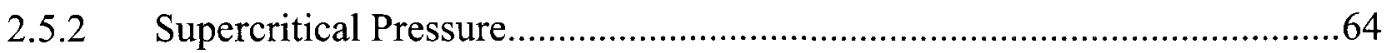

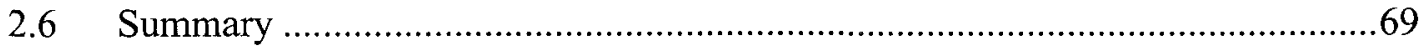

3 Thesis Objectives and Outline .........................................................................70

4 Design of the Carleton-NRCan S-CO $\mathrm{CO}_{2}$ Corrosion Test Rig .................................71

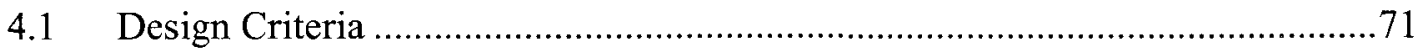

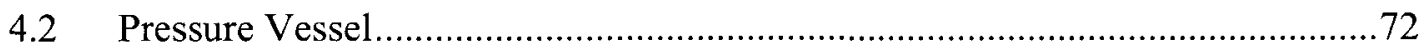

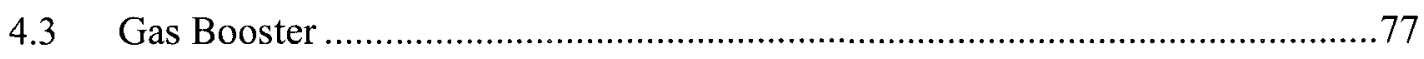

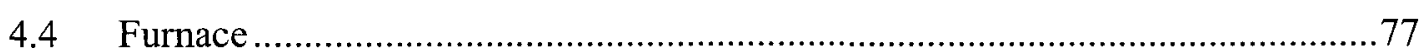

4.5 Integrated Safety Features.................................................................... 78

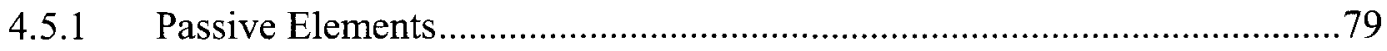

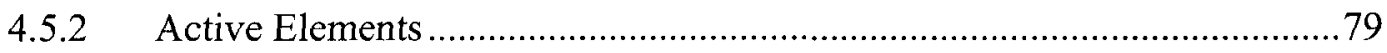

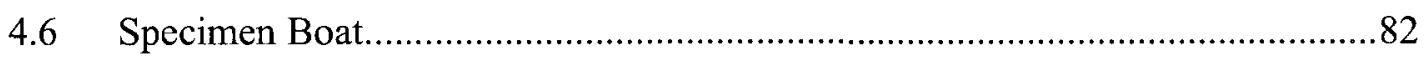

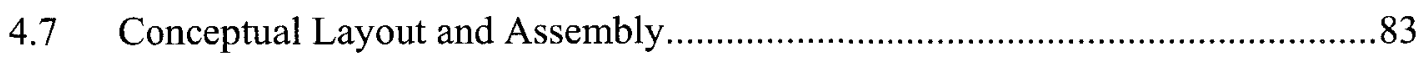

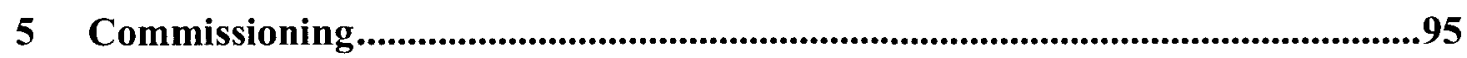

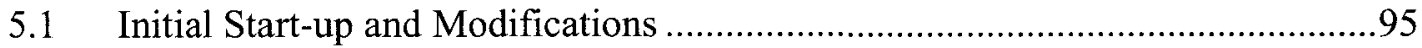

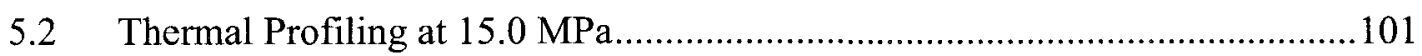

5.3 Pressure Effects on Performance.............................................................. 111

6 Summary and Conclusions ...................................................................................114

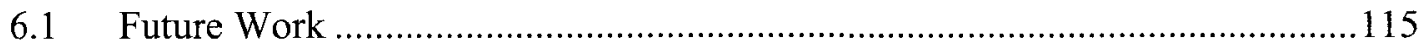

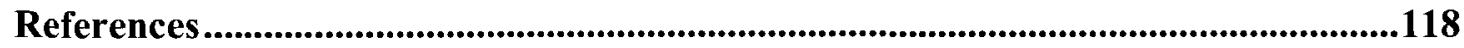




\section{List of Tables}

Table 2-1: Compositions of some common nickel-base superalloys $[40,43]$

Table 2-2: The roles of selected alloying elements in nickel-base superalloys $[39,40] .12$

Table 2-3: Test conditions used for high temperature, $\mathrm{S}-\mathrm{CO}_{2}$ corrosion studies ..........65

Table 4-1: Activation pressures to remedy an overpressurization ..............................80

Table 4-2: Maximum impurity content of BOC Canada Ltd. standard grade bulk

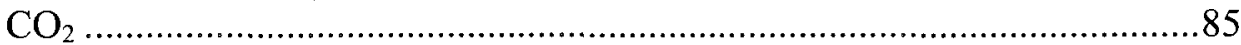

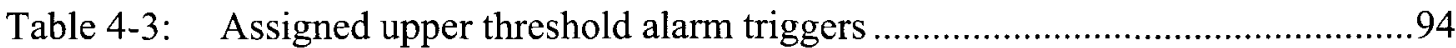

Table 5-1: Heated zone set points to give uniform temperature distributions ..............103

Table 5-2: $\quad$ Summary of the thermal profiling trials conducted at $15.0 \mathrm{MPa} \ldots \ldots \ldots \ldots . . . .108$ 


\section{List of Figures}

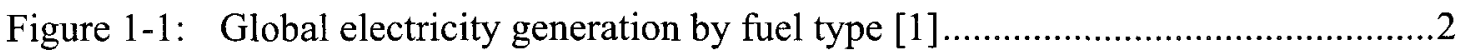

Figure 1-2: $\quad \mathrm{CO}_{2}$ phase diagrams for the (a) pressure-temperature plane, and (b) density-pressure plane [16].

Figure 1-3: Marked differences in turbine size among the advanced power cycles [6]....5

Figure 1-4: T-s diagram for the $\mathrm{S}-\mathrm{CO}_{2}$ recompression cycle. Adapted from [6] .... 6

Figure 1-5: An efficiency comparison of the $\mathrm{S}-\mathrm{CO}_{2}$, helium Brayton, and supercritical Rankine cycles between 350 and $950^{\circ} \mathrm{C}$. Reproduced from [6]

Figure 2-1: The relationship between creep-rupture life and $\gamma^{\prime}$ volume fraction [40]....13

Figure 2-2: Creep-rupture strength as a function of combined Al and Ti content [39]...13

Figure 2-3: Possible morphologies of grain boundary carbides: (a) favourable discrete, globular type [39], (b) unfavourable continuous film [44], and

(c) unfavourable discontinuous, cellular type [44]

Figure 2-4: Evolution of cast turbine blade grain structure: equiaxed polycrystalline (left), columnar grain directionally solidified (centre), and single crystal directionally solidified (right) [39]

Figure 2-5: Ellingham diagram for the oxidation of selected metals [47].

Figure 2-6: Lattice defects typical of (a) n-type and (b) p-type oxides. Interstitial species represent excesses and sub-lattice vacancies represent deficiencies. Adapted from [47]

Figure 2-7: Evolution of a metallic oxide layer at high temperature: (a) metal-oxidant reaction at the metal surface, (b) nucleation of a thin oxide film, (c) oxide film growth controlled by diffusion, (d) possible emergence of oxide layer defects and separation from the metal substrate, and (e) subsequent loss of protectiveness. Reproduced from [46]

Figure 2-8: Common oxidation rate laws, with the associated protective (P), temporarily protective (TP), or non-protective (NP) behaviour noted in parentheses. 
Figure 2-9: Parabolic oxidation rate constants for metals pertinent to superalloy composition as a function of temperature. Reproduced from [46]

Figure 2-10: Oxide scale development on a Ni-Cr-Al alloy: (a) nickel-rich oxides appear first at the alloy-gas interface, (b) lower oxygen activity beneath the external scale promotes discontinuous $\mathrm{Cr}_{2} \mathrm{O}_{3}$ and $\mathrm{Al}_{2} \mathrm{O}_{3}$ formation, (c) continuous $\mathrm{Cr}_{2} \mathrm{O}_{3}$, and (d) finally $\mathrm{Al}_{2} \mathrm{O}_{3}$ subscales result with the progression of time. Reproduced from [47]

Figure 2-11: Ellingham diagram for transition metal carbides [57]

Figure 2-12: Stability diagram for the $\mathrm{Cr}-\mathrm{O}-\mathrm{C}$ system at $620^{\circ} \mathrm{C}$. Reproduced from [45]

Figure 2-13: Effect of carburization on room temperature, mechanical properties of nickel-base superalloys [59]

Figure 2-14: Metal dusting mechanism of a $\mathrm{Cr}_{2} \mathrm{O}_{3}$-forming, nickel-base alloy: (a) carbon diffusion into the substrate initiated at $\mathrm{Cr}_{2} \mathrm{O}_{3}$ scale defect, (b) formation of internal carbides $\left(\mathrm{M}_{7} \mathrm{C}_{3}\right.$ and $\left.\mathrm{M}_{23} \mathrm{C}_{6}\right)$ and local carbonsupersaturation of substrate, (c) graphite nucleation and inward growth, and (d) outgrowth of 'coke' corrosion product. Reproduced from [55]......33

Figure 2-15: Erosion mechanisms for ductile and brittle materials: (a) low angle surface abrasion, (b) high angle, low velocity surface fatigue, (c) excessive plastic deformation at high angle, medium velocity, (d) surface melting due to high velocity impact, and (e) brittle fracture. Adapted from $[61]$.

Figure 2-16: Effect of particle impact angle on the erosion rate of ductile and brittle materials.

Figure 2-17: Erosion-corrosion interaction regimes. Adapted from [64]

Figure 2-18: Whirling arm erosion-corrosion test rig [69]

Figure 2-19: Centrifugal erosion-corrosion test rig [68]

Figure 2-20: Gas jet erosion-corrosion test rig [72]

Figure 2-21: Wind tunnel-type erosion-corrosion test rig [67]

Figure 2-22: Effect of internal pressure on the minimum required wall thickness for a pressure vessel of circular cross-section.

Figure 2-23: Stress-temperature curves for high temperature boiler materials [74] 
Figure 2-24: Chevron Oil Field Research Company $\mathrm{S}-\mathrm{CO}_{2}$ corrosion test rig [23] 49

Figure 2-25: Sandia National Laboratories S- $\mathrm{CO}_{2}$ corrosion test rig [24] .50

Figure 2-26: INL single specimen, $\mathrm{S}-\mathrm{CO}_{2}$ corrosion test rig. Adapted from [11] .52

Figure 2-27: INL multi-specimen, $\mathrm{S}-\mathrm{CO}_{2}$ corrosion test rig. Adapted from [11] .52

Figure 2-28: Tokyo Institute of Technology $\mathrm{S}-\mathrm{CO}_{2}$ corrosion test rig. Adapted from [33].

Figure 2-29: MIT low pressure $\mathrm{S}-\mathrm{CO}_{2}$ corrosion test rig. Reproduced from [38] .55

Figure 2-30: MIT high pressure $\mathrm{S}-\mathrm{CO}_{2}$ corrosion test rig. Reproduced from [38] .........56

Figure 2-31: UW-Madison $\mathrm{S}-\mathrm{CO}_{2}$ corrosion test rig. Adapted from [36].....

Figure 2-32: CEA S- $\mathrm{CO}_{2}$ corrosion test rig [78]

Figure 2-33: Surface interaction with an incident electron beam [47] 60

Figure 2-34: Multi-layered oxide $\left(\mathrm{Fe}_{3} \mathrm{O}_{4}\left|\mathrm{SiO}_{2}\right| \mathrm{FeCr}_{2} \mathrm{O}_{4}\right)$ that formed on a ferritic stainless steel following 1060 hour exposure to $\mathrm{CO}_{2}$ at $520^{\circ} \mathrm{C}$ and 4.0 $\mathrm{MPa}[31]$

Figure 2-35: Post-breakaway oxidation rate as a function of temperature [27] .62

Figure 2-36: Intergranular attack of $\mathrm{IN}-617$ following 175 hour exposure to $\mathrm{CO}_{2}$ at $1000^{\circ} \mathrm{C}$ and $7.0 \mathrm{MPa}[11]$

Figure 2-37: Characterization of 410J3-SS oxide structure following 1000 hour exposure to $\mathrm{S}-\mathrm{CO}_{2}$ at $600^{\circ} \mathrm{C}$ and $20.0 \mathrm{MPa}$ [33]

Figure 2-38: Cumulative mass gains of various alloys following a 3000 hour exposure to $\mathrm{S}-\mathrm{CO}_{2}$ at $650^{\circ} \mathrm{C}$ and $20.7 \mathrm{MPa}$ at UW-Madison. Reproduced from [36].

Figure 2-39: Cumulative mass gains of nickel-base superalloys following exposure to $\mathrm{S}-\mathrm{CO}_{2}$ at various test conditions [38]

Figure 4-1: Stress-temperature curves for pressure vessel material candidates. Generated with ASME data provided by Moore [83]

Figure 4-2: Maximum allowable internal pressure-metal temperature curve for the pressure vessel as per the ASME B31.3-2008 Process Piping code 
Figure 4-3: Grayloc ${ }^{\circledR}$ connector prior to (left) and following (right) tightening. Adapted from [87]

Figure 4-4: $\quad$ Working drawing of the $\mathrm{IN}-625$ pressure vessel $[84]$.............................76

Figure 4-5: Furnace dimensions and heated zone locations ................................... 78

Figure 4-6: Overpressurization protection flowchart ...................................... 80

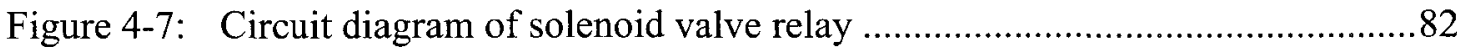

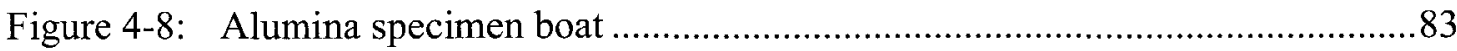

Figure 4-9: $\quad$ P\&ID for Carleton-NRCan high temperature $\mathrm{S}-\mathrm{CO}_{2}$ corrosion test rig .......84

Figure 4-10: Carleton-NRCan high temperature $\mathrm{S}^{-\mathrm{CO}_{2}}$ corrosion test rig ...................85

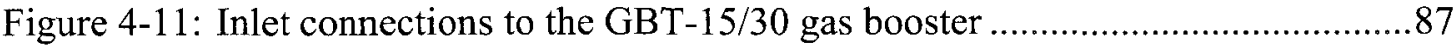

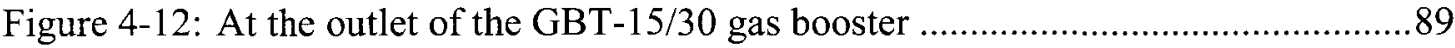

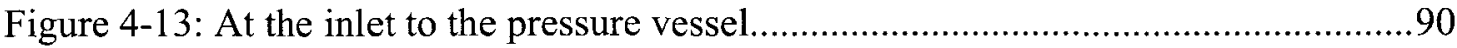

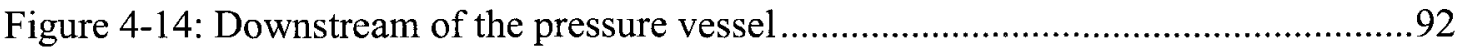

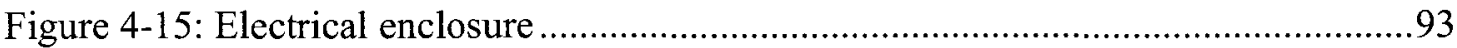

Figure 4-16: Thermocouple locations along the length of the pressure vessel ................93

Figure 5-1: Location of thermocouples within the pressure vessel (hatched) ................96

Figure 5-2: Initial temperature distribution at 15.0 MPa for furnace set points of

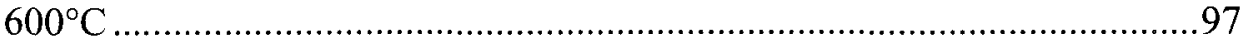

Figure 5-3: Heat reflector positioning within the pressure vessel (hatched) ..................98

Figure 5-4: Heat reflectors attached to the profile probe sheath ..................................98

Figure 5-5: Effectiveness of the heat reflectors on raising fluid temperature at 15.0 $\mathrm{MPa}$ for furnace set points of $600^{\circ} \mathrm{C}$

Figure 5-6: Change in metal temperature following the addition of the heat reflectors at $15.0 \mathrm{MPa}$ for furnace set points of $600^{\circ} \mathrm{C}$

Figure 5-7: Temperature distributions for $550,600,650$, and $700^{\circ} \mathrm{C}$ using the established furnace set points 
Figure 5-8: Validation of the furnace set points to give $550^{\circ} \mathrm{C}$ at $15.0 \mathrm{MPa}$..............106

Figure 5-9: Validation of the furnace set points to give $600^{\circ} \mathrm{C}$ at $15.0 \mathrm{MPa} \ldots \ldots \ldots \ldots . . .106$

Figure 5-10: Validation of the furnace set points to give $650^{\circ} \mathrm{C}$ at $15.0 \mathrm{MPa} \ldots \ldots \ldots \ldots . . .107$

Figure 5-11: Validation of the furnace set points to give $700^{\circ} \mathrm{C}$ at $15.0 \mathrm{MPa} \ldots \ldots \ldots \ldots . . . . .107$

Figure 5-12: Temperature distribution using furnace set points of $\left[800^{\circ} \mathrm{C}\left|750^{\circ} \mathrm{C}\right| 800^{\circ} \mathrm{C}\right]$ at $15.0 \mathrm{MPa}$

Figure 5-13: Pressure variations at $15.0 \mathrm{MPa}$ over a 10 hour period at $650^{\circ} \mathrm{C} \ldots \ldots \ldots \ldots . . .110$

Figure 5-14: Temperature variations at $650^{\circ} \mathrm{C}$ over a 10 hour period at $15.0 \mathrm{MPa} \ldots \ldots . .110$

Figure 5-15: Differences in metal temperature at 25.0 $\mathrm{MPa}$ from $15.0 \mathrm{MPa}$ for equivalent furnace set points

Figure 5-16: Temperature distributions using fixed furnace set points of $\left[685^{\circ} \mathrm{C}\left|610^{\circ} \mathrm{C}\right| 645^{\circ} \mathrm{C}\right]$ at 15.0 and $25.0 \mathrm{MPa}$

Figure 5-17: Temperature distributions using fixed furnace set points of $\left[725^{\circ} \mathrm{C}\left|640^{\circ} \mathrm{C}\right| 690^{\circ} \mathrm{C}\right]$ at 15.0 and $25.0 \mathrm{MPa}$

Figure 5-18: Thermal response of $\mathrm{T}-15$ from room temperature to fixed furnace set points of $\left[685^{\circ} \mathrm{C}\left|610^{\circ} \mathrm{C}\right| 645^{\circ} \mathrm{C}\right]$ at 15.0 and $25.0 \mathrm{MPa}$ 


\section{List of Appendices}

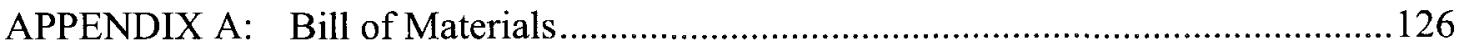

APPENDIX B: Representative Thermal Profiles of the Pressure Vessel......................129 


\section{$1 \quad$ Introduction}

\subsection{Demand for Advanced Power Conversion Cycles}

The International Energy Agency (IEA) estimates that the global electricity demand will increase $76 \%$ between 2007 and 2030. This marked growth is a direct result of the continued development and maturation of non-Organization for Economic Co-operation and Development (OECD) economies. Assuming, albeit highly unlikely, that no changes are made to existing governmental energy policies, Figure 1-1 shows that fossil fuels will supplement the majority of this increase in electricity generation [1]. The combustion of fossil fuels, however, has an adverse effect on the environment and potentially the climate because of the emissions that are produced. At the very least, efficiency gains must be made to the design and operation of fossil fuel-based, electrical power plants, either by increasing their operating conditions or utilizing improved combustion technologies. The capture and sequestration of carbon emissions would also lessen the environmental impact of fossil fuel combustion but not remove it entirely. Current carbon dioxide $\left(\mathrm{CO}_{2}\right)$ capture processes though are energy-intensive and may actually decrease the electrical output of a power plant once implemented [2]. Reducing the role of fossil fuels in the energy production aggregate represents a more complete solution to an environmentally-conscience energy source. Nuclear energy has the potential to offset this reduced role.

With the intent of achieving the mainstream use of nuclear energy, the GenerationIV International Forum (GIF) was established to facilitate research and development efforts of future nuclear energy systems. Six reactor designs were chosen by the GIF that 
were deemed to offer the most promise in areas such as sustainability, economic competitiveness, safety, and proliferation resistance and physical protection. In addition, the supercritical Rankine steam cycle, helium Brayton cycle, and supercritical carbon dioxide $\left(\mathrm{S}-\mathrm{CO}_{2}\right)$ Brayton cycle were selected as the electric power conversion systems to complement the Generation-IV reactors [3-5]. The inherent advantages of the $\mathrm{S}-\mathrm{CO}_{2}$ Brayton cycle, in comparison to the other cycles mentioned, will be briefly discussed in the section to follow.

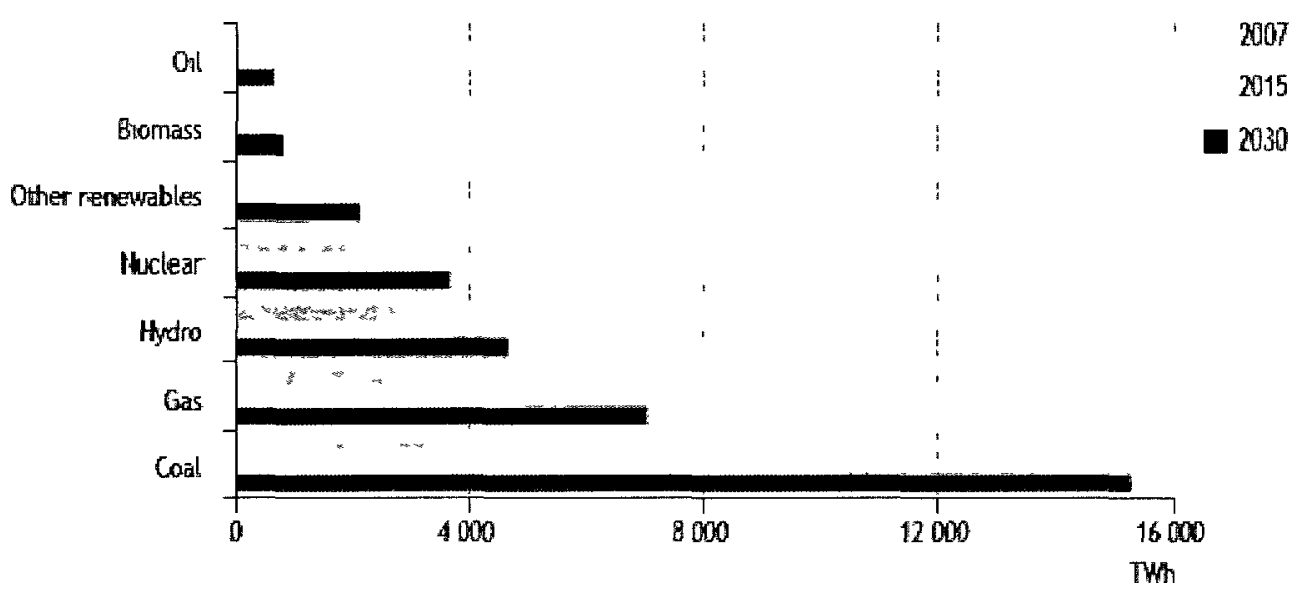

Figure 1-1: Global electricity generation by fuel type [1]

The $\mathrm{S}-\mathrm{CO}_{2}$ cycle was originally envisioned to be used as the power conversion system in both the lead-cooled fast reactor (LFR) and sodium-cooled fast reactor (SFR) because of their intermediate $\left(550^{\circ} \mathrm{C}\right)$ core outlet temperature. More recent developments [4,6-11] have also suggested the favourable application of this cycle to other advanced reactor concepts, in particular the gas-cooled fast reactor (GFR), molten salt reactor (MSR), and very high temperature reactor (VHTR). Outside the nuclear field, the S-CO cycle is being actively researched as an alternative to the traditional steam and organic 
Rankine cycles used in concentrated solar [12,13] and nuclear ship propulsion [6] systems. In fossil fuel-based, cogeneration installations, the $\mathrm{S}-\mathrm{CO}_{2}$ cycle is also being considered as a possible bottoming cycle option for waste heat recovery [14].

\section{$1.2 \quad \mathrm{~S}-\mathrm{CO}_{2}$ Brayton Cycle}

The $\mathrm{S}-\mathrm{CO}_{2}$ cycle is intended to operate as a closed system and exclusively above the critical point of $\mathrm{CO}_{2}$; i.e., above $31.03^{\circ} \mathrm{C}(304.18 \mathrm{~K})$ and $7.38 \mathrm{MPa}(73.8 \mathrm{bar})$ [15]. Carbon dioxide phase diagrams are shown in Figure 1-2 for both the pressuretemperature and density-pressure planes. Above the critical point, liquid and gaseous phases become indistinguishable - represented in Figure 1-2a by dashed phase boundaries - and $\mathrm{CO}_{2}$ exists as a homogenous, supercritical fluid phase. At temperatures and pressures far exceeding those that define the critical point, $\mathrm{S}-\mathrm{CO}_{2}$ fluid behaviour approximates that of an ideal gas. Only near the critical point do fluid properties, such as density, viscosity, and specific heat capacity, exhibit large gradients with small changes in temperature $[6,16]$. Figure $1-2 \mathrm{~b}$ illustrates how significant this temperature sensitivity is on the density, and hence the compressibility, of $\mathrm{S}-\mathrm{CO}_{2}$.

Exploiting the low compressibility of $\mathrm{CO}_{2}$, in the vicinity of its critical point, is what gives the $\mathrm{S}-\mathrm{CO}_{2}$ cycle a distinct advantage over the ideal gas, helium Brayton cycle; the extremely low critical point of helium $\left(-267.95^{\circ} \mathrm{C}\right)$ [17] makes it impracticable to benefit from these same real gas properties. Consequently, the $\mathrm{S}-\mathrm{CO}_{2}$ cycle uses only $30 \%$ of its total turbine work for compression as opposed to the $45 \%$ needed by the helium cycle. This reduced compressor work eliminates the need for intercooling, 
decreasing the overall plant footprint, complexity, and cost $[6,8,18-22]$. Figure 1-3 depicts the extremely compact turbomachinery of the $\mathrm{S}-\mathrm{CO}_{2}$ cycle in relation to the helium Brayton and supercritical Rankine steam cycles.
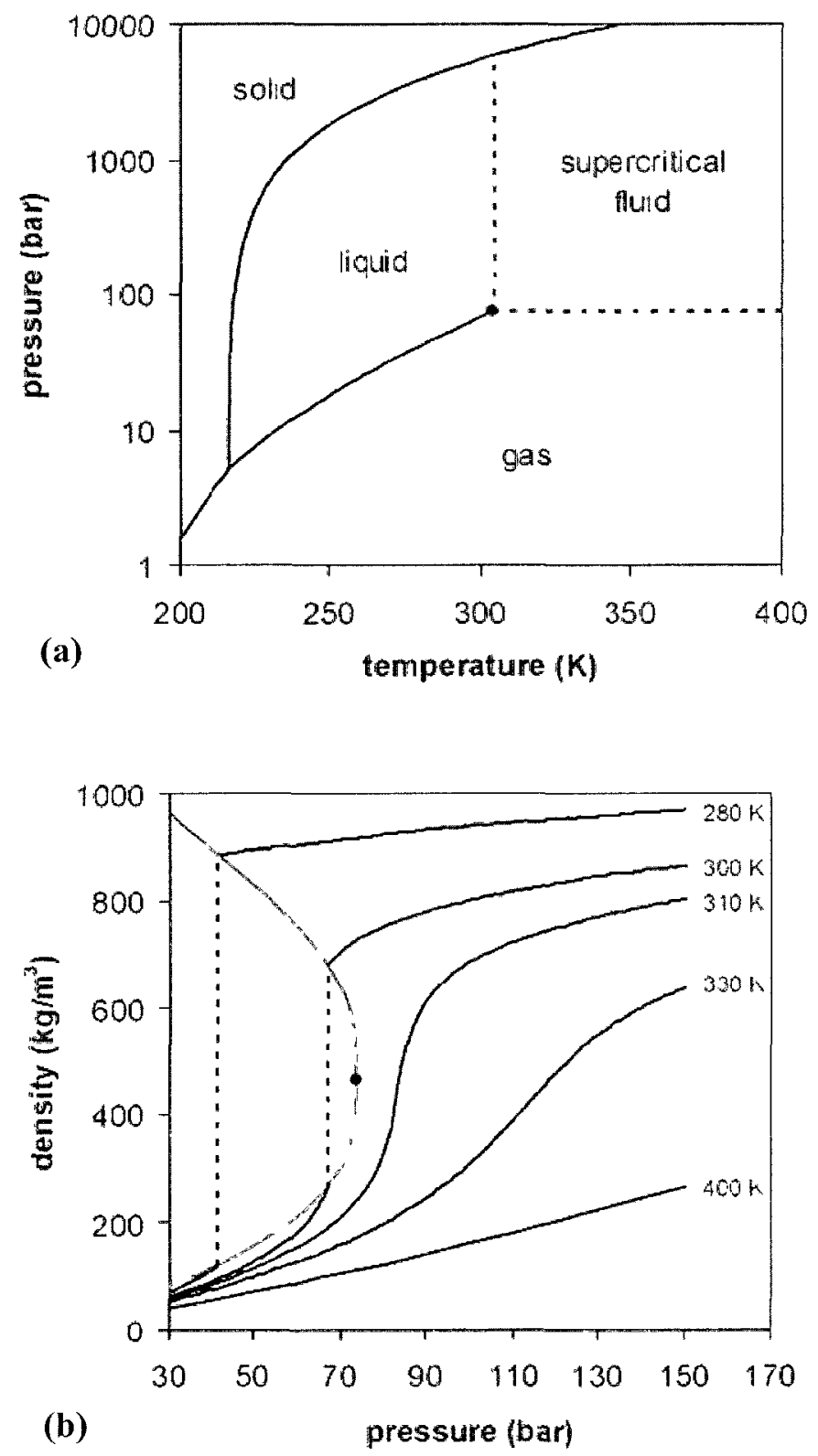

Figure 1-2: $\mathrm{CO}_{2}$ phase diagrams for the (a) pressure-temperature plane, and (b) density-pressure plane [16] 


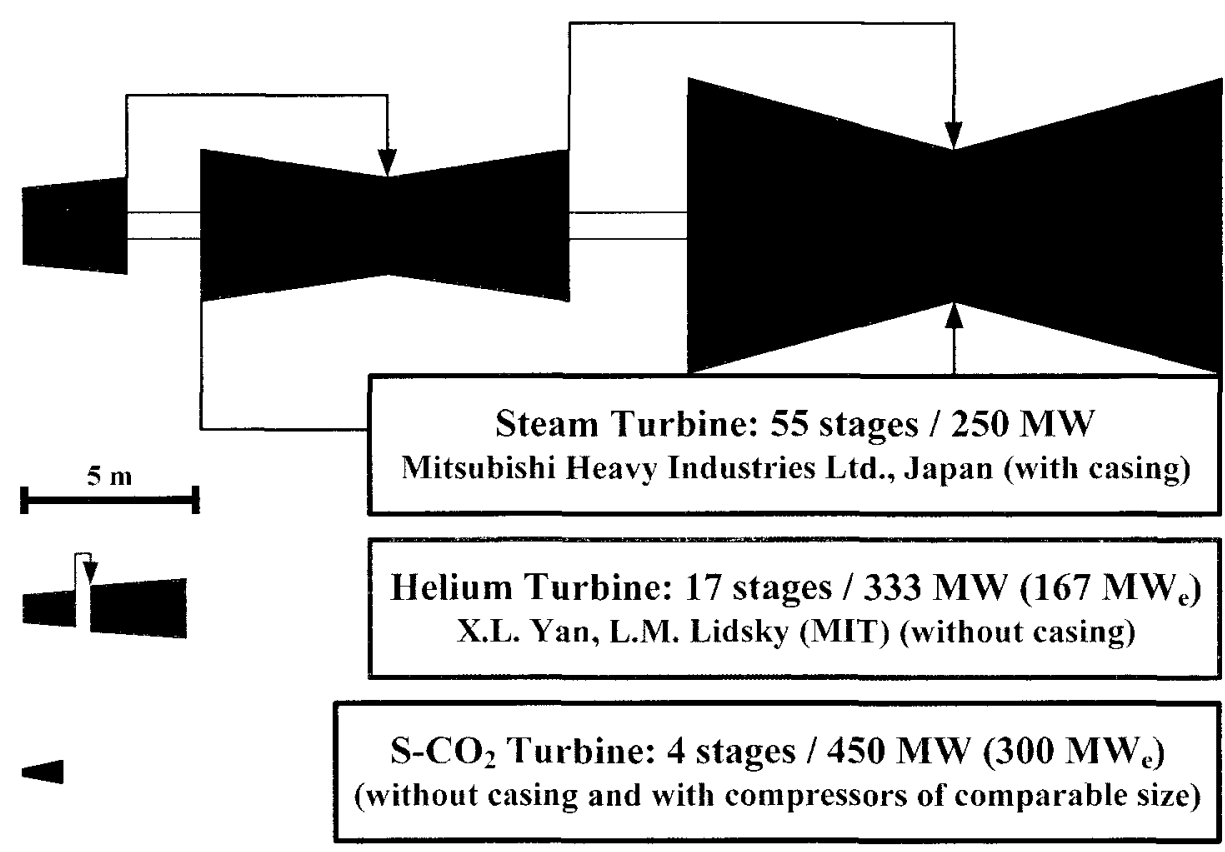

Figure 1-3: Marked differences in turbine size among the advanced power cycles [6]

The proposed turbine inlet conditions for the $\mathrm{S}-\mathrm{CO}_{2}$ and helium Brayton cycles differ considerably as well. Using a thermal efficiency of $45 \%$ as a benchmark between cycles, the $\mathrm{S}-\mathrm{CO}_{2}$ recompression cycle (the most efficient of all the layouts investigated) needs only $550^{\circ} \mathrm{C}$ and $20.0 \mathrm{MPa}$ to attain this level compared to the $750^{\circ} \mathrm{C}$ (closer to $800^{\circ} \mathrm{C}$ if all losses are considered) and 8.0 MPa required by the helium Brayton cycle [6]. Figure 1-4 provides a temperature-entropy ( $\mathrm{T}-\mathrm{s}$ ) diagram for the $\mathrm{S}-\mathrm{CO}_{2}$ recompression cycle, illustrating how heat rejection is minimized (or efficiency is improved) with the addition of another compressor before the pre-cooler. The higher operating temperature of the helium cycle imposes a significant demand on both component cooling and material requirements $[6-8,18,19]$. In terms of material strength and creep resistance, the higher operating pressure of the $\mathrm{S}-\mathrm{CO}_{2}$ recompression cycle is less problematic at the 
lower turbine inlet temperature (TIT). Furthermore, a higher operating pressure reduces the detrimental effects that fractional pressure drops have on cycle efficiency. Thermal efficiencies for the supercritical Rankine cycle and both Brayton cycles are plotted in Figure 1-5 for TITs between 350 and $950^{\circ} \mathrm{C}$, inclusively. For TITs above $550^{\circ} \mathrm{C}$, the $\mathrm{S}-\mathrm{CO}_{2}$ recompression cycle is the most advantageous of the three cycles considered; this is promising for even greater efficiency gains once confidence is acquired at lower the initial operating temperature. Although the Rankine cycle appears to have superiority over the $\mathrm{S}-\mathrm{CO}_{2}$ recompression cycle at lower temperatures, the added plant complexity and auxiliaries required to do so lead to a higher capital investment $[6-8,19]$.

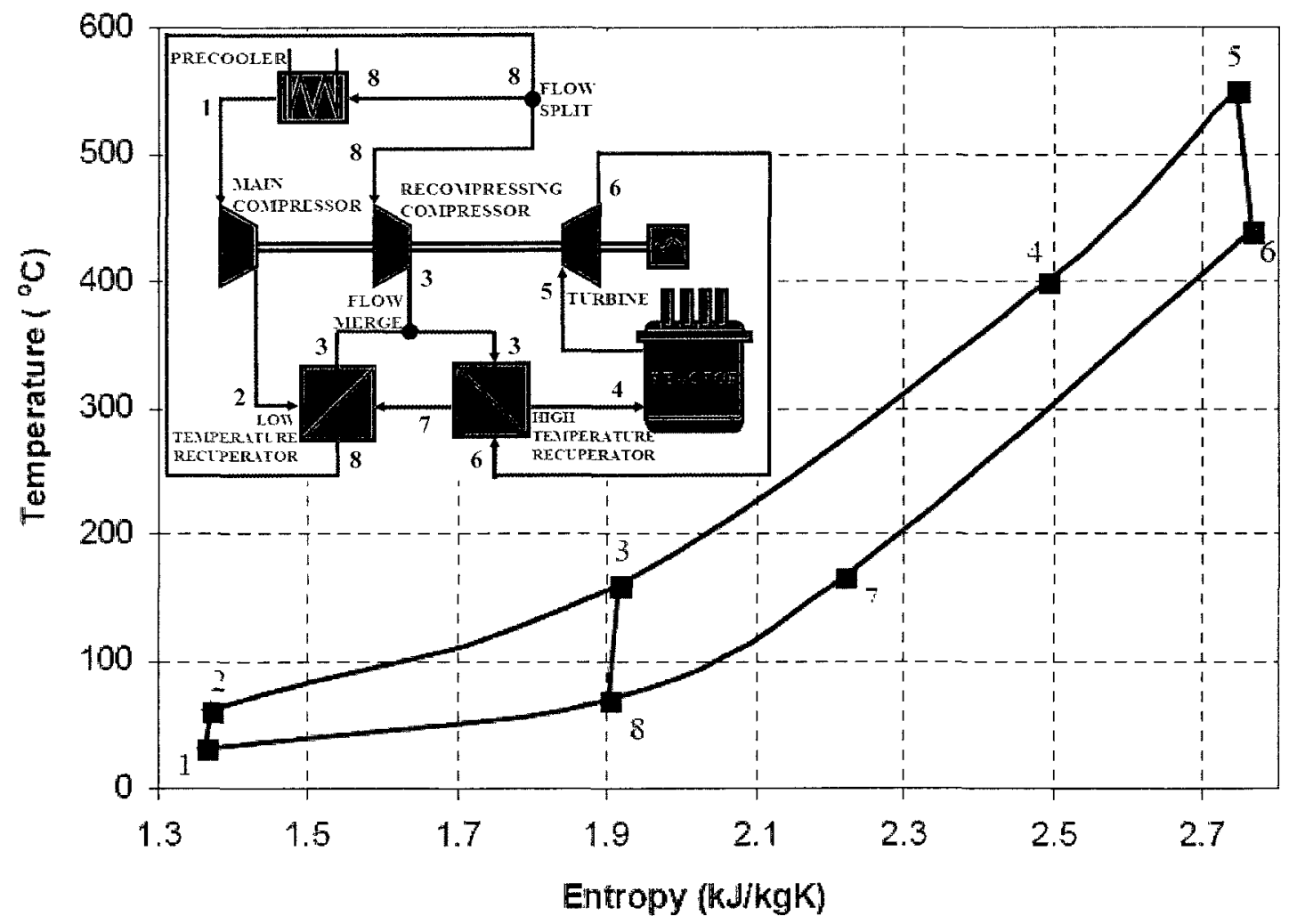

Figure 1-4: T-s diagram for the $\mathrm{S}-\mathrm{CO}_{2}$ recompression cycle. Adapted from [6] 


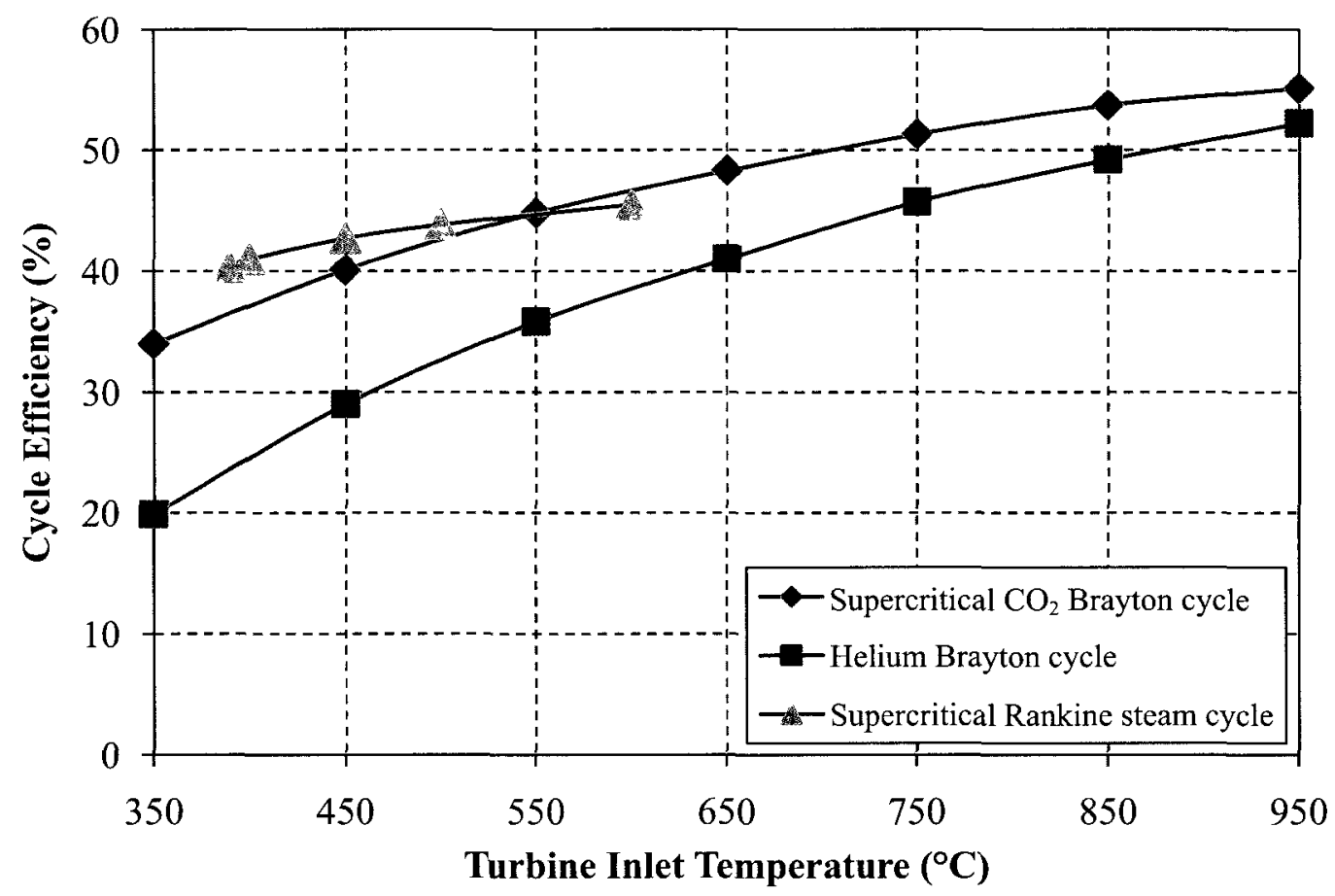

Figure 1-5: An efficiency comparison of the $\mathrm{S}-\mathrm{CO}_{2}$, helium Brayton, and supercritical Rankine cycles between 350 and $950^{\circ} \mathrm{C}$. Reproduced from [6]

\subsection{High Temperature $\mathrm{S}-\mathrm{CO}_{2}$ Corrosion}

While the $\mathrm{S}-\mathrm{CO}_{2}$ Brayton cycle offers merit in achieving high thermal efficiencies, the novelty of this cycle poses a unique challenge relating to material selection - the compatibility of materials with $\mathrm{CO}_{2}$ at the temperature and pressure combination dictated by the $\mathrm{S}-\mathrm{CO}_{2}$ recompression cycle is relatively unknown. For the most part, $\mathrm{CO}_{2}$ corrosion studies originating from the oil and gas industry involve carbon steels and gas compositions (high sulphur and water content) [23] that are likely never to be used or encountered within a S-CO 2 cycle. Moreover, the small fraction of corrosion tests conducted at supercritical conditions, with relatively pure $\mathrm{CO}_{2}$, and prior to the 
realization of the $\mathrm{S}-\mathrm{CO}_{2}$ cycle were done so at rather low temperatures $\left(54\right.$ to $238^{\circ} \mathrm{C}$ ) $[24,25]$. Experience with the British Magnox and advanced gas reactor (AGR) program can provide more relevant insight into material interaction with high temperature $\mathrm{CO}_{2}$ but only at subcritical pressures - the maximum being about 5.3 $\mathrm{MPa}$. Apart from some reactor-specific alloys [26], corrosion data obtained as a result of this nuclear program was primarily for mild and stainless steels [27-32].

The ability to conduct accelerated laboratory corrosion testing in a high temperature, $\mathrm{S}-\mathrm{CO}_{2}$ environment is warranted yet still only possible at a small number of institutions worldwide. Preliminary results published by these institutions correlate well with what was observed in the AGR program despite the differences in pressure. Regarding corrosion resistance, austenitic stainless steels still outperform their ferritic counterparts mainly because of greater chromium (Cr) content [33-37]. Repeated testing at supercritical conditions is required to determine what effect, if any, pressure has on the formation and protectiveness of oxide layers. Although these $\mathrm{S}-\mathrm{CO}_{2}$ studies focused predominantly on the corrosion behaviour of steels, the nickel-base superalloys that were tested also demonstrated excellent corrosion resistance [34,36,38]. Corrosion data relating to this family of superalloys however needs to be expanded, as they represent the logical material choice for the $\mathrm{S}-\mathrm{CO}_{2}$ turbomachinery and heat exchangers. Additionally, the duration of future $\mathrm{S}-\mathrm{CO}_{2}$ corrosion tests will also need to increase to properly characterize the corrosion mechanisms involved and assess the long-term stability of oxide layers. 


\subsection{Objective and Organization of Thesis}

In a collaborative effort between Carleton University and CanmetENERGY of Natural Resources Canada (NRCan), the development and optimization of a $100 \mathrm{MW}_{\mathrm{e}}$, $\mathrm{S}-\mathrm{CO}_{2}$ advanced Brayton cycle has been initiated. As part of the overall scope of this project, a long-term, $\mathrm{S}-\mathrm{CO}_{2}$ corrosion study is required to evaluate the corrosion behaviour of selected structural materials. The main objective of this thesis is therefore to design, construct, and commission a $\mathrm{S}-\mathrm{CO}_{2}$ corrosion test loop that will be used to conduct this study.

In the subsequent chapter, an introduction to high temperature corrosion mechanisms and testing methods is presented at the outset to accompany a review of past and current high temperature $\mathrm{CO}_{2}$ corrosion studies. The specific objectives of this thesis are outlined in Chapter 3. Chapter 4 describes the design and assembly of the S-CO corrosion test loop while its commissioning is detailed in Chapter 5. Finally, Chapter 6 summarizes the work carried out for this project, draws upon the major conclusions, and lays out recommendations for future work. 


\section{$2 \quad$ Literature Review - High Temperature, $\mathrm{S}-\mathrm{CO}_{2}$ Corrosion Testing}

This chapter provides a detailed review of high temperature metal corrosion in a $\mathrm{S}-\mathrm{CO}_{2}$ environment. An overview of high temperature materials, exclusively the nickelbase class of superalloys, is first presented. Following this, the thermodynamic and kinetic principles of high temperature corrosion are explained. While several modes of high temperature corrosion are recognized, only those that seem apt for a carbon-rich atmosphere and closed-cycle gas turbine application will be discussed. High temperature corrosion tests are then described, in addition to the methods used to both quantify and evaluate the extent of corrosion. Finally, a survey detailing metallic interaction with a $\mathrm{CO}_{2}$-rich environment concludes this chapter. This survey begins with high temperature corrosion investigations conducted at subcritical $\mathrm{CO}_{2}$ pressures and ends with the most recent corrosion studies related to the $\mathrm{S}-\mathrm{CO}_{2}$ Brayton cycle.

\subsection{A Primer on High Temperature Materials}

High temperature materials, more commonly referred to as superalloys, consist of nickel-, nickel-iron-, and cobalt-base alloy systems. At service temperatures above $540^{\circ} \mathrm{C}$, superalloys possess high creep-rupture strength and exhibit a considerable resistance to thermo-mechanical fatigue, oxidation, and corrosion [39-42]. This primer however will focus only on the metallurgical aspects (namely the composition, microstructures, processing methods, and surface protection) of nickel-base superalloys, due to their prevalence in current gas turbine applications. The reader is directed to work by Donachie [39] for a more comprehensive discussion of all the superalloy classes. 
Nominal compositions of some representative nickel-base superalloys are given in Table 2-1. The controlled alloying elements - possibly as many as fourteen - that comprise the listed superalloys have a major influence on the phase structures that form as well as the mechanical properties and environmental protection that they impart. Thus, each element can be classified as having one or more of the following roles within the nickel-base superalloy: matrix strengthener, intermetallic precipitate former, carbide former, grain boundary strengthener, or surface stabilizer $[39,40]$. Table 2-2 summarizes the specific roles of the various alloying elements.

Table 2-1: Compositions of some common nickel-base superalloys $[40,43]$

\begin{tabular}{|c|c|c|c|c|c|c|c|c|c|c|c|c|}
\hline \multirow[b]{2}{*}{ Alloy } & \multicolumn{12}{|c|}{ Nominal Composition (wt. \%, bal. Ni) } \\
\hline & $\mathrm{Cr}$ & $\mathrm{Co}$ & Mo & W & $\mathrm{Ta}$ & $\operatorname{Re}$ & $\mathrm{Ru}$ & $\mathrm{Nb}$ & $\mathrm{Al}$ & $\mathrm{Ti}$ & Hf & $\mathrm{C}$ \\
\hline \multicolumn{13}{|c|}{ Wrought Superalloys } \\
\hline Waspaloy & 19.5 & 13.5 & 4.3 & - & - & - & - & - & 1.3 & 3.0 & - & 0.08 \\
\hline Udimet 720 & 17.9 & 14.7 & 3.0 & 1.3 & - & - & - & - & 2.5 & 5.0 & - & 0.04 \\
\hline \multicolumn{13}{|c|}{ Conventionally Cast Alloys } \\
\hline Mar-M246 & 8.3 & 10.0 & 0.7 & 10.0 & 3.0 & - & - & - & 5.5 & 1.0 & 1.50 & 0.14 \\
\hline IN-713LC & 12.0 & - & 4.5 & - & - & - & - & 2.0 & 5.9 & 0.6 & - & 0.16 \\
\hline \multicolumn{13}{|c|}{ Directionally Solidified Alloy } \\
\hline IN-792 & 12.4 & 9.2 & 1.9 & 3.9 & 4.2 & - & - & - & 3.5 & 3.9 & - & 0.07 \\
\hline \multicolumn{13}{|c|}{ First-Generation Single-Crystal Alloys } \\
\hline PWA 1480 & 10.0 & 5.0 & - & 4.0 & 12.0 & - & - & - & 5.0 & 1.5 & - & - \\
\hline CMSX-2 & 8.0 & 5.0 & 0.6 & 8.0 & 6.0 & - & - & - & 5.6 & 1.0 & - & - \\
\hline \multicolumn{13}{|c|}{ Second-Generation Single-Crystal Alloys } \\
\hline PWA 1484 & 5.0 & 10.0 & 2.0 & 6.0 & 9.0 & 3.0 & - & - & 5.6 & - & 0.10 & - \\
\hline CMSX-4 & 6.5 & 9.6 & 0.6 & 6.4 & 6.5 & 3.0 & - & - & 5.6 & 1.0 & 0.10 & - \\
\hline \multicolumn{13}{|c|}{ Third-Generation Single-Crystal Alloy } \\
\hline CMSX-10 & 2.0 & 3.0 & 0.4 & 5.0 & 8.0 & 6.0 & - & - & 5.7 & 0.2 & 0.03 & - \\
\hline \multicolumn{13}{|c|}{ Fourth-Generation Single-Crystal Alloy } \\
\hline TMS-162 & 2.9 & 5.8 & 3.9 & 5.8 & 5.6 & 4.9 & 6.0 & - & 5.8 & - & 0.09 & - \\
\hline
\end{tabular}


Table 2-2: The roles of selected alloying elements in nickel-base superalloys $[39,40]$

\begin{tabular}{|c|c|c|c|c|c|c|c|c|c|c|c|c|c|c|}
\hline \multirow{2}{*}{ Purpose } & \multicolumn{14}{|c|}{ Alloying Element } \\
\hline & $\mathrm{Cr}$ & $\mathrm{Co}$ & Mo & W & $\mathrm{Fe}$ & $\mathrm{Re}$ & $\mathrm{Ta}$ & $\mathrm{Nb}$ & $\mathrm{Al}$ & $\mathrm{Ti}$ & Hf & $\mathrm{C}$ & $\mathrm{B}$ & $\mathrm{Zr}$ \\
\hline Matrix Strengthener & $X$ & $\mathrm{X}$ & $X$ & $X$ & $X$ & $X$ & & & & & & & & \\
\hline $\begin{array}{l}\text { Intermetallic } \\
\text { Precipitate Former }\end{array}$ & & & & & & & $X$ & $\mathrm{X}$ & $X$ & $\mathrm{X}$ & & & & \\
\hline Carbide Former & $\mathrm{X}$ & & $\mathrm{X}$ & $\mathrm{X}$ & & & $X$ & $\mathrm{X}$ & & $X$ & $\mathrm{X}$ & & & \\
\hline $\begin{array}{l}\text { Grain Boundary } \\
\text { Strengthener }\end{array}$ & & & & & & & & & & & $\mathrm{X}$ & $\mathrm{X}$ & $X$ & $\mathrm{X}$ \\
\hline Surface Stabilizer & $\mathrm{X}$ & & & & & & & & $\mathrm{X}$ & & & & & \\
\hline
\end{tabular}

Nickel-base superalloys consist of a face-centred cubic (FCC) gamma (austenitic) matrix together with several secondary phases. The coherent, intermetallic gamma prime $\left(\gamma^{\prime}\right)$ phase and the carbides are, for the scope of this review, considered to be the most relevant secondary phases. The $\gamma^{\prime}$-phase constitutes the ordered, $\mathrm{Ni}_{3}(\mathrm{Al}, \mathrm{Ti})$ compounds that nucleate within the austenitic matrix from an initial solution heat treatment and evolve with subsequent aging heat treatment(s). The presence of the $\gamma^{\prime}$-phase distorts the austenitic matrix so as to impede the movement of dislocations and hence conferring strength to the superalloy; the volume fraction, particle size, and morphology of the $\gamma^{\prime}$-phase all dictate to what extent this strengthening mechanism occurs [39,40,42]. All three factors are controlled by the aluminium and titanium contents of the superalloy and the heat treatments it has been subjected to [39]. Figure 2-1 illustrates the creep-rupture behaviour of a nickel-base superalloy as a function of its $\gamma^{\prime}$ volume fraction. Beyond an optimum volume fraction of approximately $70 \%$, further increases in $\gamma^{\prime}$ volume fraction 
actually reduce creep-rupture life [40]. Similarly, Figure 2-2 shows an increase in creeprupture strength with greater aluminium and titanium contents.

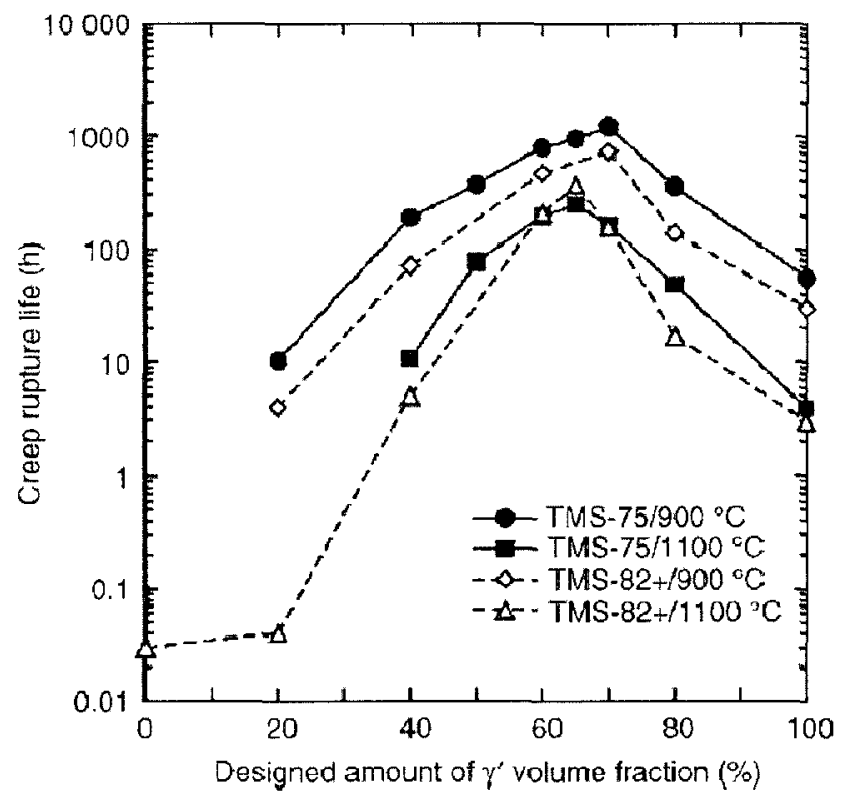

Figure 2-1: The relationship between creep-rupture life and $\gamma^{\prime}$ volume fraction [40]

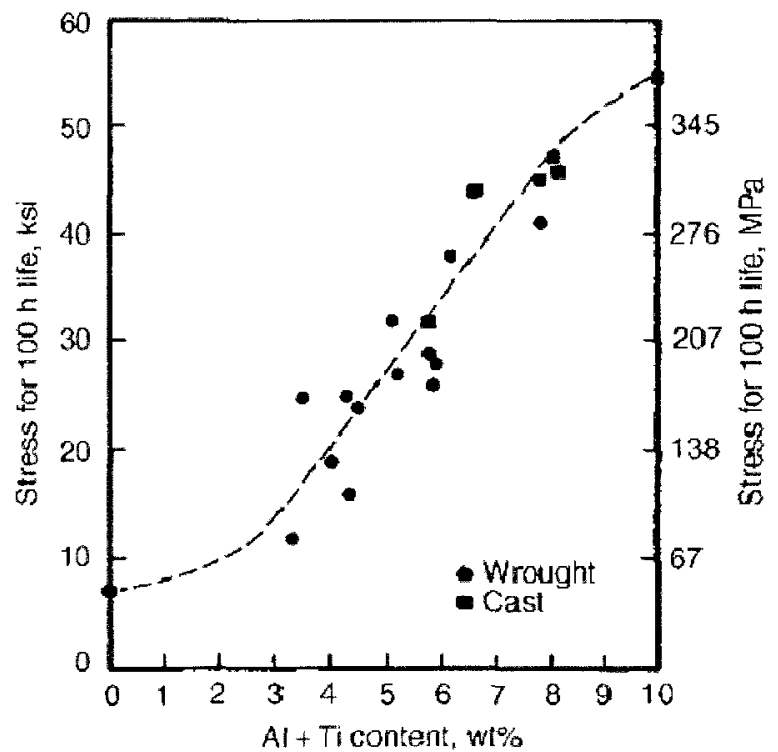

Figure 2-2: Creep-rupture strength as a function of combined $\mathrm{Al}$ and Ti content [39] 


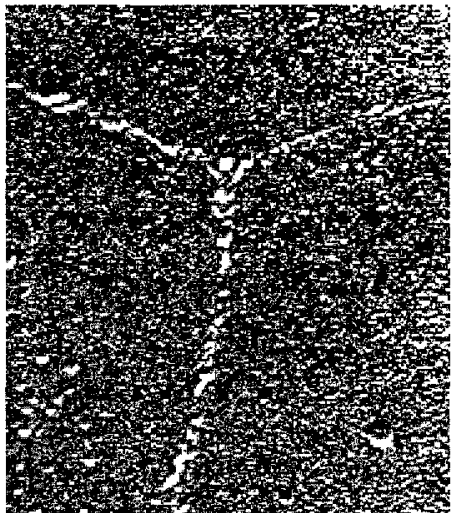

(a)

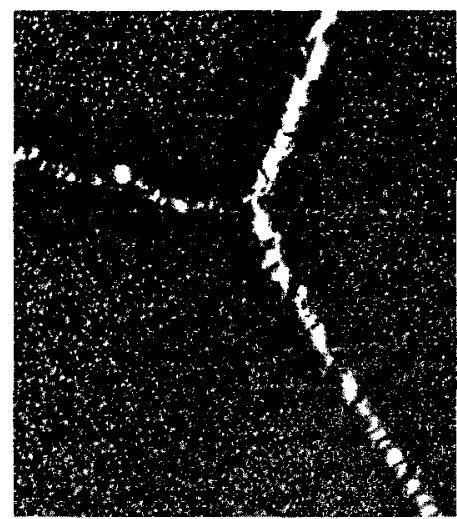

(b)

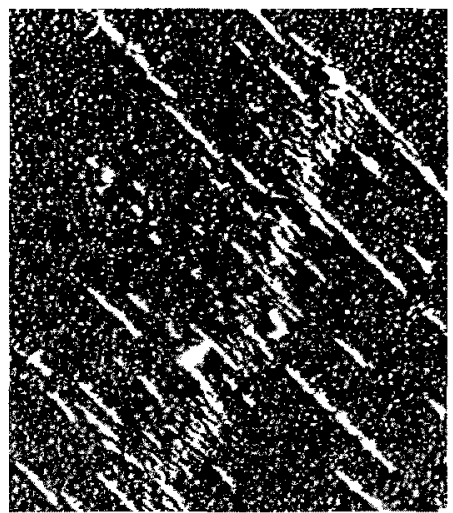

(c)

Figure 2-3: Possible morphologies of grain boundary carbides: (a) favourable discrete, globular type [39], (b) unfavourable continuous film [44], and

(c) unfavourable discontinuous, cellular type [44]

Carbide species that readily form in these superalloys, either at grain boundaries or within the grains, include $\mathrm{MC}, \mathrm{M}_{23} \mathrm{C}_{6}, \mathrm{M}_{6} \mathrm{C}$, and $\mathrm{M}_{7} \mathrm{C}_{3}$, where $\mathrm{M}$ denotes a refractory metal atom. The carbon content of the superalloy as well as the temperature and duration of its thermal exposure (be it via heat treatment or through service) affect what carbide type will form. Grain boundary carbides, specifically their morphology, have a significant effect on creep-rupture behaviour. Discrete globular $\mathrm{M}_{23} \mathrm{C}_{6}$ carbides prevent premature failure by inhibiting grain boundary sliding and allowing adjacent grains to retain enough ductility to accommodate this redistribution of stress. Carbides that precipitate as continuous films or discontinuous, cellular formations however are detrimental to creep-rupture life $[39,41,43]$. These distinct, grain boundary carbide morphologies are shown above in Figure 2-3. Other functions that carbides have in nickel-base superalloys are to provide secondary strengthening to the austenitic matrix and bind to impurity elements that would otherwise degrade mechanical properties [39]. 
Nickel-base superalloys are processed in both wrought and cast forms; notable differences in the size, morphology, and orientation of the grains exist between the two processing methods [41]. Wrought superalloys typically possess excellent tensile strength and low-cycle-fatigue (LCF) resistance on account of their finer-sized grains. Conversely, the coarser grain sizes of cast superalloys enhance high temperature, creeprupture properties $[39,40,42,43]$. Further benefits to creep-rupture properties are possible if directionally solidified (DS) casting techniques are employed. At elevated temperature, metal fracture occurs intergranularly - often initiated at grain boundaries oriented perpendicular to the direction of applied loading [39]. With control over grain orientation through DS casting, transverse grain boundaries can be removed from the superalloy to extend creep-rupture life. Depicted in Figure 2-4, the logical progression of turbine blade microstructures - from polycrystalline (PC) to columnar grain directionally solidified (CGDS) and finally single crystal directionally solidified (SCDS) - reiterates the improved high temperature performance that was realized first with the elimination of transverse grain boundaries and then grain boundaries altogether.

To protect against material degradation, nickel-base superalloys are intentionally alloyed with elements that form thermodynamically-stable oxides - primarily chromia $\left(\mathrm{Cr}_{2} \mathrm{O}_{3}\right)$ and alumina $\left(\mathrm{Al}_{2} \mathrm{O}_{3}\right)$ [41]. These oxides develop into continuous, adherent surface films, which act to isolate the superalloy from its surrounding environment. Compared to an applied diffusion, overlay, or thermal barrier coating system, the $\mathrm{Cr}_{2} \mathrm{O}_{3}$ and $\mathrm{Al}_{2} \mathrm{O}_{3}$ oxide layers are also regenerative in nature; that is, even with spallation, these oxide layers are ultimately restored by consuming additional alloying species from the 
austenitic matrix. This regenerative ability however can be damaging to mechanical properties, as both chromium and aluminium contribute to strengthening mechanisms of the nickel-base superalloy. Overlay and thermal barrier coatings do offer the added benefits of being specially tailored to suit a particular service environment and significantly reducing metal temperatures, respectively $[39,40]$. The premise behind oxidation is explained in greater detail in the succeeding section.

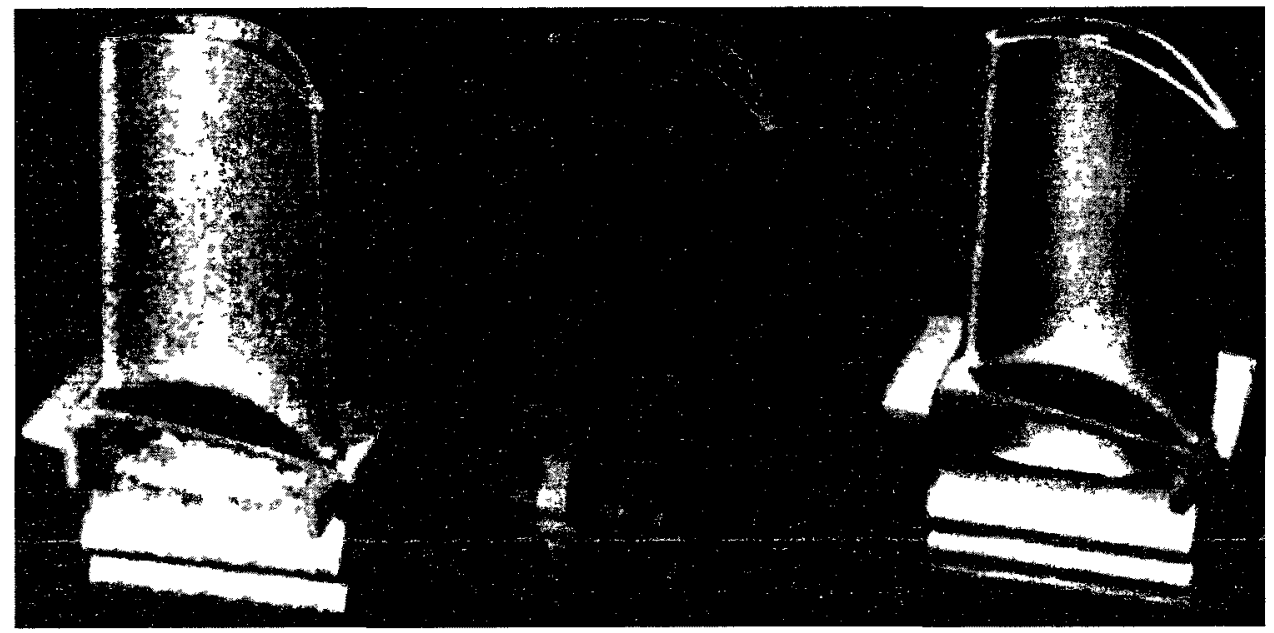

Figure 2-4: Evolution of cast turbine blade grain structure: equiaxed polycrystalline (left), columnar grain directionally solidified (centre), and single crystal directionally solidified (right) [39]

\subsection{Modes of High Temperature Corrosion}

High temperature (above $500^{\circ} \mathrm{C}$ ) corrosion can be regarded as the non-galvanic, electrochemical reaction between a metal and non-metal, whose interfacial anode and cathode are separated by a layer or film of reaction product $[45,46]$. While oxidation is the most prevalent mode of high temperature corrosion, other modes - such as nitridation, carburization and metal dusting, halogenation, sulfidation, erosion-corrosion, 
and molten salt deposition - are also possible depending on the atmospheric composition that the metal is exposed to. For the context of this review however, only the principles of oxidation, carburization and metal dusting, and erosion-corrosion will be considered. Exclusion of the remaining high temperature corrosion modes follows from the logic that although contaminant species will inevitably exist within the $\mathrm{S}-\mathrm{CO}_{2}$ fluid, their trace levels are unlikely to be the controlling corrosion mechanism(s). This section summarizes the detailed high temperature corrosion reviews conducted by Lai [45]; Shreir [46]; Birks, Meier, and Pettit [47]; and Kofstad [48].

\subsubsection{Oxidation}

Oxidation is potentially the most beneficial form of high temperature corrosion because, if properly exploited, the ensuing oxide layer or scale serves as an effective barrier to subsequent metal attack. However if this same oxide layer proves to be thermodynamically unstable or prone to cracking, porosity, and spallation, the protection it provides may be compromised or absent altogether $[46,47]$. Perhaps of even greater interest is that environments that are otherwise devoid of molecular oxygen $\left(\mathrm{O}_{2}\right)$ and therefore have extremely low oxygen activities, such as one composed primarily of $\mathrm{CO}_{2}$, can still support oxidation. This section provides an understanding behind the basic thermodynamics responsible for whether an oxide layer will form and, if so, the kinetics that determine at what rate it will evolve. To complement these oxidation fundamentals, the selective oxidation of high temperature materials, specifically $\mathrm{Cr}_{2} \mathrm{O}_{3}$ - and $\mathrm{Al}_{2} \mathrm{O}_{3}$ forming nickel-base superalloys, will conclude this discussion. 


\subsubsection{Thermodynamics}

The synthesis of a metallic oxide $\left(\mathrm{M}_{\mathrm{x}} \mathrm{O}_{\mathrm{y}}\right)$ from a metal $(\mathrm{M})$ and a single gaseous oxidant, $\mathrm{O}_{2}$ for simplicity, can be represented by a reaction of the general form:

$$
\frac{2 x}{y} \mathrm{M}(\mathrm{s})+\mathrm{O}_{2}(\mathrm{~g}) \leftrightarrow \frac{2}{y} \mathrm{M}_{x} \mathrm{O}_{y}(\mathrm{~s})
$$

Whether or not this reaction indeed tends to be product-favouring, that is, proceeds from left to right, is indicated by its change in Gibbs free energy $(\Delta \mathrm{G})$. By definition, $\Delta \mathrm{G}$ characterizes the algebraic sum of the first and second laws of thermodynamics for an isothermal (constant temperature) and isobaric (constant pressure) process. Thus, the Gibbs free energy change of Equation 2.1 at absolute temperature, $\mathrm{T}$, is expressed as:

$$
\Delta G=\Delta G^{\circ}+R_{u} T \cdot \ln \left(\frac{a_{\mathrm{M}_{x} \mathrm{O}_{y}}^{2 / y}}{a_{\mathrm{M}}^{2 x / y} \cdot a_{\mathrm{O}_{2}}}\right)
$$

where $\Delta G^{\circ}$ is the standard-state Gibbs free energy of formation, $R_{u}$ is the universal gas constant, and a is the chemical activity of the indicated species.

Commonly the metal and oxide activities are taken as unity under the assumption that both are pure solids and therefore, due to their small molar volumes, are insensitive to pressure. Furthermore, if the oxidant behaves as an ideal gas, its activity can be assumed equivalent to its partial pressure, $\mathrm{P}_{\text {oxidant }}$, in the given atmosphere but normalized to standard pressure $[45,46,48]$. However for significant deviations from ideal gas behaviour, such as in the supercritical regime, fugacity must be used in lieu of partial pressure to accurately quantify gas concentrations. Incorporating these simplifications at equilibrium $(\Delta \mathrm{G}=0)$, Equation 2.2 can be rearranged to give the dissociation pressure of 
the oxide, $\mathrm{P}_{\mathrm{O}_{2}}^{\text {diss }}$, or the ambient oxygen partial pressure above which oxidation of the metal is possible:

$$
P_{\mathrm{O}_{2}}^{\text {diss }}=\exp \left(\frac{\Delta G^{\circ}}{R_{u} T}\right)
$$

Over a desired temperature range, a convenient means to assess the relative, thermodynamic stabilities of various oxides, and, similarly, the products of other metal/non-metal reactions, is with the use of an Ellingham diagram [45-48]. An Ellingham diagram, in its simplest form, plots $\Delta \mathrm{G}^{\circ}$ per mole of oxidant consumed as a function of temperature. Apart from the noble metals and away from extreme temperature, metals are naturally disposed to oxide formation [46] and Equation 2.1, consequently, proceeds from left to right. Increasingly negative values of $\Delta \mathrm{G}^{\circ}-$ tantamount to moving from the top to bottom of the diagram - are indicative of the difficulty in which an oxide can be reduced [45-48]; i.e., its thermodynamic stability. Regarding alloys, the Ellingham diagram provides initial insight into which constituent element's oxidation will predominate and thus which phase diagram to use to describe the variation in oxide structure [47]. Figure 2-5 shows both $\mathrm{Cr}_{2} \mathrm{O}_{3}$ and $\mathrm{Al}_{2} \mathrm{O}_{3}$ curves to fall below that of nickel(II) oxide (NiO), explaining why in nickel-base superalloys a $\mathrm{NiO}$ oxide layer is not favoured, at least not for the long term. Also noteworthy of Figure 2-5 are the partial pressure nomograms or ancillary scales surrounding the Ellingham diagram. These nomograms give the dissociation pressure of the oxide either directly, by $\mathrm{P}_{\mathrm{O}_{2}}$, or indirectly, via the equilibrium ratio of carbon monoxide $(\mathrm{CO})$ to $\mathrm{CO}_{2}$ for the following reaction: 


$$
\mathrm{CO}_{2}(\mathrm{~g}) \leftrightarrow \mathrm{CO}(\mathrm{g})+\frac{1}{2} \mathrm{O}_{2}(\mathrm{~g})
$$

What can be concluded from either nomogram is that the formation of $\mathrm{Cr}_{2} \mathrm{O}_{3}$ and $\mathrm{Al}_{2} \mathrm{O}_{3}$ are very difficult to prevent [46] - at $550^{\circ} \mathrm{C}, \mathrm{Cr}_{2} \mathrm{O}_{3}$ and the more thermodynamically stable $\mathrm{Al}_{2} \mathrm{O}_{3}$ need $\mathrm{P}_{\mathrm{O}_{2}}$ of only $10^{-38}$ atm and $10^{-60}$ atm, respectively, to form.

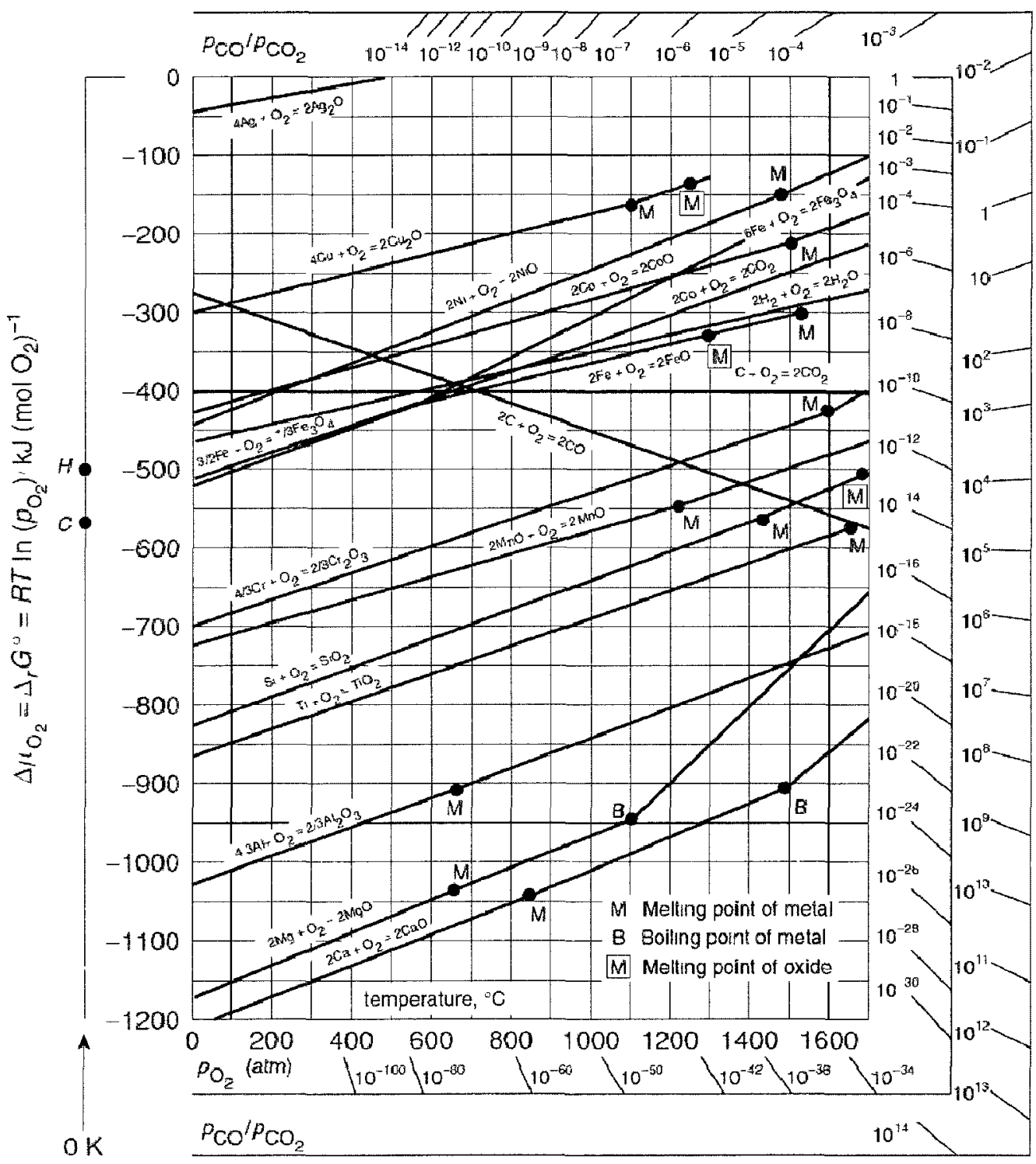

Figure 2-5: Ellingham diagram for the oxidation of selected metals [47] 


\subsubsection{Kinetics of Oxide Formation and Growth}

The mechanisms and rates of oxide evolution are as equally important as the underlying thermodynamics in terms of the level of protection that an oxide layer will impart to its substrate. At elevated temperature, metallic oxides can typically be classified as non-stoichiometric ionic compounds, meaning that their metal-to-oxygen atom ratio differs slightly from what their chemical formula would imply. Point defects vacancies on cationic $\left(\mathrm{M}^{\mathrm{n}+}\right)$ and anionic $\left(\mathrm{O}^{2-}\right)$ sub-lattices and ions occupying interstittal positions - allow for such deviations from stoichiometric composition and, in conjunction with electronic defects, preserve the overall electrical neutrality of the oxide $[46,47]$. Free electrons and electron holes (higher valency cations) constitute these electronic defects and give the metallic oxide either a negative-type (n-type), for the former, or a positive-type (p-type), for the latter, semiconductive behaviour [49]. Figure 2-6 distinguishes between the two semiconductor types, showing either a metal excess or oxygen deficit for an n-type oxide (Figure 2-6a) and a metal deficit or oxygen excess for a p-type oxide (Figure 2-6b).

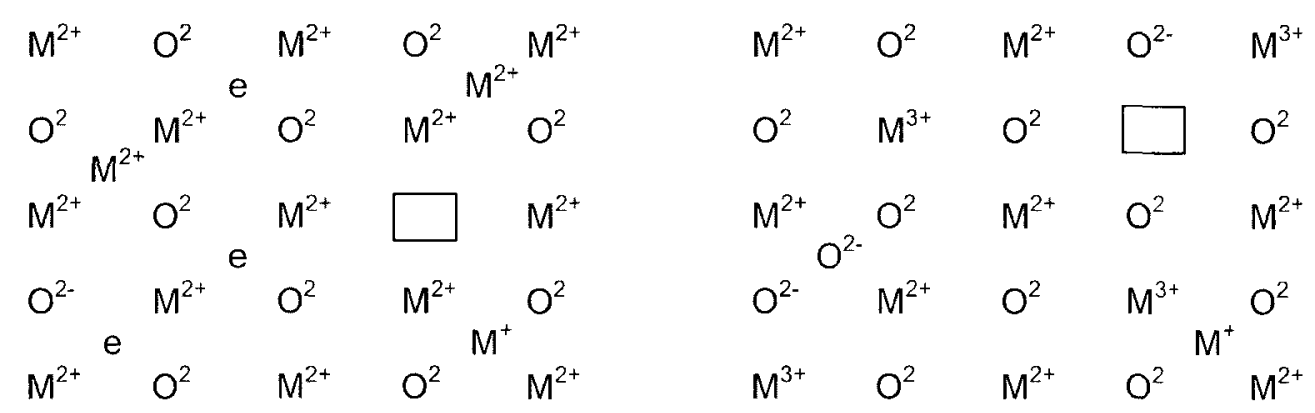

(a)

Figure 2-6: Lattice defects typical of (a) n-type and (b) p-type oxides. Interstitial species represent excesses and sub-lattice vacancies represent deficiencies.

Adapted from [47] 
Together, the crystalline and electronic defects previously described are, for the most part, responsible for oxide growth via diffusion; a phase boundary process, such as the dissociation and adsorption of a molecular oxidant, establishes the other principal growth mechanism [48]. Depending on the mechanism and ambient temperature, oxidation kinetics may conform to one or some combination of the linear, parabolic, and logarithmic rate laws and can be easily measured by a change in mass per unit area $\left(\frac{\Delta \mathrm{m}}{\mathrm{A}}\right)$ [45-48]. A simplified representation of high temperature oxidation, in which the rate controlling step transitions first from a phase boundary process to ionic and electronic diffusion through the growing oxide layer, is illustrated below in Figure 2-7.

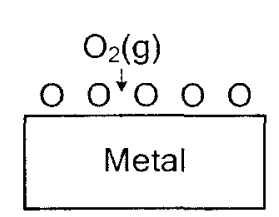

(a)

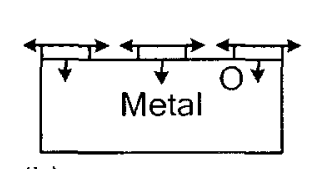

(b)

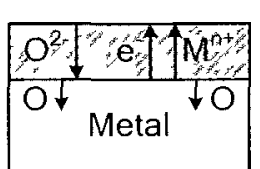

(c)

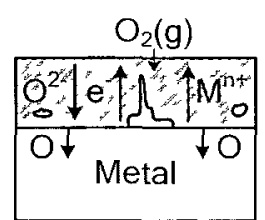

(d)

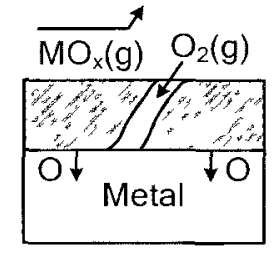

(e)

Figure 2-7: Evolution of a metallic oxide layer at high temperature: (a) metal-oxidant reaction at the metal surface, (b) nucleation of a thin oxide film, (c) oxide film growth controlled by diffusion, (d) possible emergence of oxide layer defects and separation from the metal substrate, and (e) subsequent loss of protectiveness. Reproduced from [46]

Initially (Figure 2-7a) $\mathrm{O}_{2}$ molecules collide with and are adsorbed on the metal surface. Islands of oxide then rapidly develop (Figure 2-7b) in accordance with Equation 2.1 and spread laterally over the metal until a continuous, thin layer forms. Chemical and electrical potential gradients are established across this layer and, in conjunction with the intrinsic crystalline defects of the oxide, promote the diffusion of ions and electrons 
through it (Figure 2-7c). As a result, the thickness of this oxide layer increases, with its direction of growth - either inward from the metal-oxide interface or outward from the oxide-gas interface - contingent on whether anion or cation migration is favoured $[46,48]$. A complete understanding behind oxide transport properties is beyond the scope of this review but can be found in either Shreir [46], Birks et al. [47], or Toft Sørensen [49]. Microvoids and cracks may begin to appear within the oxide layer (Figure 2-7d) as a means to alleviate or redistribute stresses induced during growth or from thermal exposure. If these cracks propagate completely through its thickness (breakaway oxidation) or the oxide is easily vaporized, virgin metal is once again exposed, leading to further metal attack (Figure 2-7e) [46,48].

The preceding oxidation process exemplifies linear (during initial formation and potentially again, if the oxide layer fails) and parabolic (when solid-state diffusion predominates) rate behaviour, with both rate equations and their combination, along with the logarithmic rate equation, plotted in Figure 2-8. Of these three elementary rate equations, only the linear reaction rate remains constant with time and thus independent of oxide thickness [45]. Oxide growth or loss (e.g. volatilization) consistent with linear behaviour is likely related to a phase boundary process [46] and may be represented by:

$$
\left(\frac{\Delta m}{A}\right)=k_{L} t
$$

where $\mathrm{k}_{L}$ and $\mathrm{t}$ denote the linear rate constant and time, respectively.

Protective barriers form when oxidation kinetics follow either a parabolic,

$$
\left(\frac{\Delta m}{A}\right)^{2}=k_{P} t+C
$$


or logarithmic time dependence,

$$
\left(\frac{\Delta m}{A}\right)=k_{\log } \cdot \log \left(t+t_{o}\right)+A
$$

where $k_{P}, k_{\log }, C, t_{0}$, and $A$ all represent constants. In each case, reaction rates tend to decrease and stabilize with the progression of time. The logarithmic rate equation however is usually only applicable to the low temperature $\left(<400^{\circ} \mathrm{C}\right)$ oxidation of metals and is often difficult to substantiate with a single growth mechanism [47].

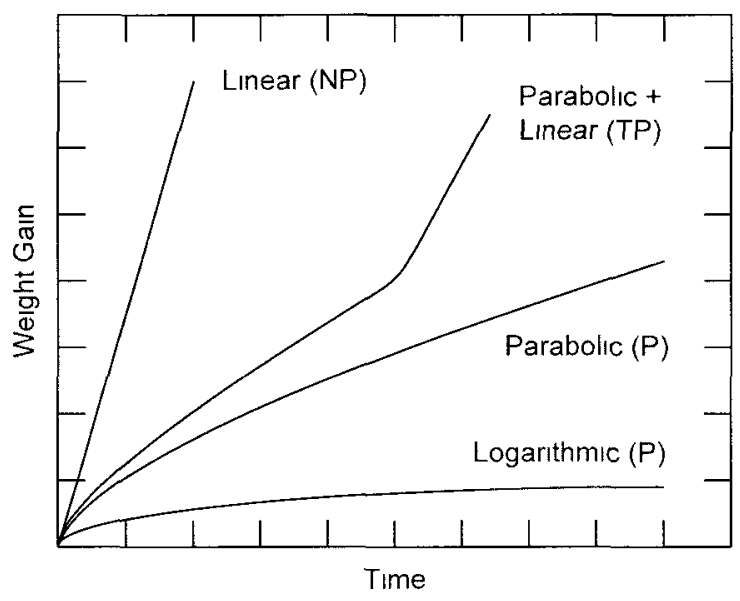

Figure 2-8: Common oxidation rate laws, with the associated protective (P), temporarily protective (TP), or non-protective (NP) behaviour noted in parentheses.

Using the applicable molar volume, molar mass, and composition of the oxide, together with the measured change in specimen mass, the ordinate of Figure 2-8 can be just as easily transformed into either the oxide thickness or the depth of metal penetration. In fact, the volumetric ratio of oxide produced to metal consumed - termed the Pilling-Bedworth ratio (PBR) - serves as a preliminary assessor of the protectiveness of a given oxide layer. A PBR less than unity is generally indicative of a porous oxide layer or one that fails to fully cover the metal surface. Conversely, a compact and 
protective oxide layer is assumed to form when the PBR exceeds unity, although an accumulation of compressive growth stresses could lead to unwanted cracking and spallation [46-48]. Other factors however, such as the oxide-substrate adherence, must ultimately be considered when quantifying the protection of an oxide layer.

\subsubsection{Desired High Temperature Oxide Scales}

Up to $900^{\circ} \mathrm{C}$, the attractiveness of both $\mathrm{Cr}_{2} \mathrm{O}_{3}$ and $\mathrm{Al}_{2} \mathrm{O}_{3}$ oxide scales is not only attributed to their thermodynamic stability but also to their slow growth rates and low coefficients of thermal expansion [46-48]. Chromia, however, becomes increasingly susceptible to oxidation above $900^{\circ} \mathrm{C}$ and at high $\mathrm{P}_{\mathrm{O}_{2}}$, resulting in the formation of volatile chromium trioxide $\left(\mathrm{CrO}_{3}\right)$ :

$$
\mathrm{Cr}_{2} \mathrm{O}_{3}(\mathrm{~s})+\frac{3}{2} \mathrm{O}_{2}(\mathrm{~g}) \rightarrow 2 \mathrm{CrO}_{3}(\mathrm{~g})
$$

A competing effort between the evaporation of $\mathrm{CrO}_{3}$ and ionic diffusion through the thinner $\mathrm{Cr}_{2} \mathrm{O}_{3}$ oxide layer leads to an overall increase in oxidation rate $[46,47]$. Figure 2-9 summarizes the parabolic oxidation rate constants of $\mathrm{Cr}_{2} \mathrm{O}_{3}$ and $\mathrm{Al}_{2} \mathrm{O}_{3}$, in addition to the base metals that form the three superalloy classes, as a function of temperature. For the hatched region defining the oxidation kinetics of $\mathrm{Cr}_{2} \mathrm{O}_{3}$, a sharp increase in slope of its lower bound marks the abovementioned effect of $\mathrm{CrO}_{3}$ formation.

While $\mathrm{Cr}_{2} \mathrm{O}_{3}$ may lack the extreme thermal stability of $\mathrm{Al}_{2} \mathrm{O}_{3}$, it does have a rhombohedral crystal structure identical to that of $\alpha-\mathrm{Al}_{2} \mathrm{O}_{3}$, the most stable polymorph of $\mathrm{Al}_{2} \mathrm{O}_{3}$. All other metastable or transition phases, $\gamma-, \delta$-, and $\theta-\mathrm{Al}_{2} \mathrm{O}_{3}$ being the most common, eventually transform to $\alpha-\mathrm{Al}_{2} \mathrm{O}_{3}$ when heated above a critical temperature. The 
magnitude of this temperature and also the rate of phase transformation are largely influenced by the base metal of an alloy, alloying additions such as the rare earths (RE), $\mathrm{Cr}$, and $\mathrm{Ti}$, and the presence of an isotypic phase [50]. In a binary alloy system consisting of a nickel base and either chromium or aluminium as the solute element, considerable solute content - at least $18 \mathrm{wt} . \% \mathrm{Cr}$ or $17 \mathrm{wt} . \% \mathrm{Al}$ - is required to preclude internal oxidation and the formation of complex, less protective, spinel $\mathrm{Ni}(\mathrm{Cr}, \mathrm{Al})_{2} \mathrm{O}_{4}$ oxides. When both elements are combined to form an alloy of $\mathrm{Ni}-\mathrm{Cr}-\mathrm{Al}$ composition, protective $\mathrm{Al}_{2} \mathrm{O}_{3}$ oxide scales can be achieved with $\mathrm{Al}$ contents as low as 5 wt. \% due in part to the 'gettering' effect of chromium [46,47]. Figure 2-10 characterizes the transient to steady-state oxidation of a Ni-Cr-Al alloy with time.

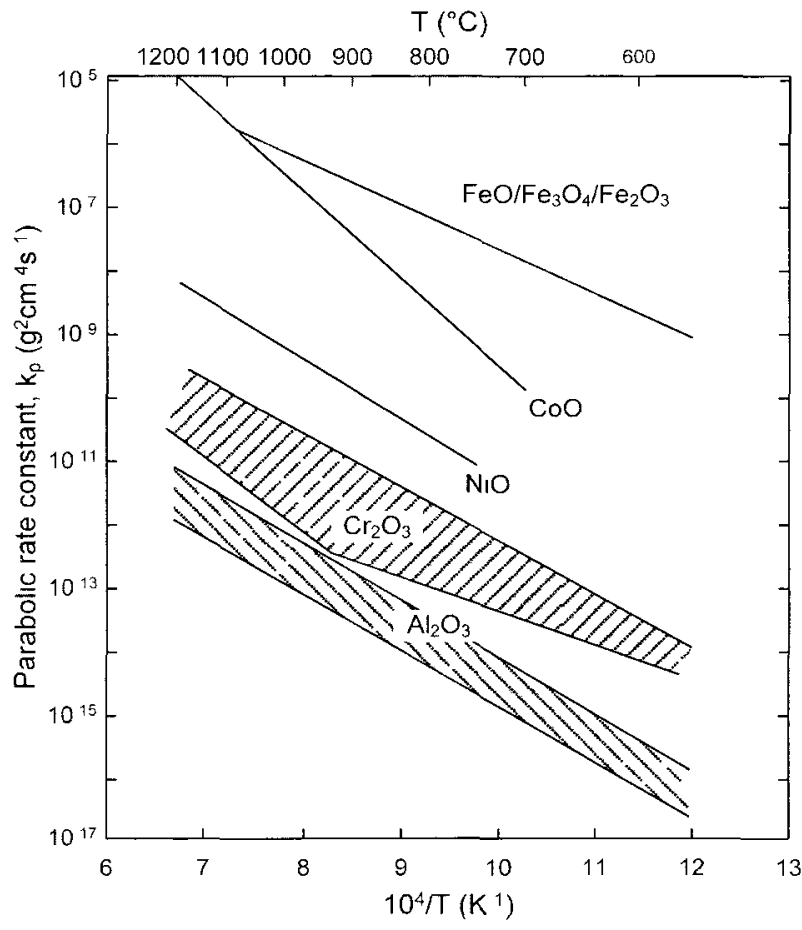

Figure 2-9: Parabolic oxidation rate constants for metals pertinent to superalloy composition as a function of temperature. Reproduced from [46] 
(a)

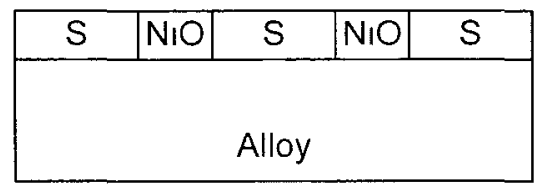

(b)

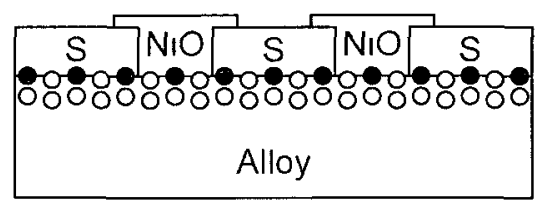

(c)

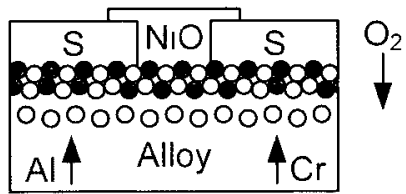

(d)

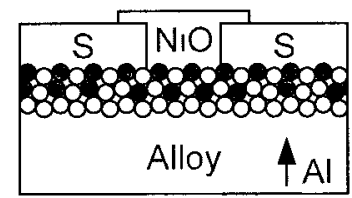

- $\mathrm{Cr}_{2} \mathrm{O}_{3} \quad \mathrm{Al}_{2} \mathrm{O}_{3} \quad \mathrm{~S} \mathrm{NI}(\mathrm{Cr}, \mathrm{Al})_{2} \mathrm{O}_{4}$

Figure 2-10: Oxide scale development on a Ni-Cr-Al alloy: (a) nickel-rich oxides appear first at the alloy-gas interface, (b) lower oxygen activity beneath the external scale promotes discontinuous $\mathrm{Cr}_{2} \mathrm{O}_{3}$ and $\mathrm{Al}_{2} \mathrm{O}_{3}$ formation, (c) continuous $\mathrm{Cr}_{2} \mathrm{O}_{3}$, and (d) finally $\mathrm{Al}_{2} \mathrm{O}_{3}$ subscales result with the progression of time. Reproduced from [47]

The abundance of nickel in the alloy initially encourages the formation of oxides that are predominantly nickel-based $-\mathrm{NiO}$ and $\mathrm{Ni}(\mathrm{Cr}, \mathrm{Al})_{2} \mathrm{O}_{4}-$ at the alloy-gas interface (Figure 2-10a). Internal, isolated pockets of $\mathrm{Cr}_{2} \mathrm{O}_{3}$ and $\mathrm{Al}_{2} \mathrm{O}_{3}$ develop below this nickelbased external scale (Figure 2-10b) on account of their thermodynamic stability at lower oxygen activities. With sufficient $\mathrm{Cr}$ content, a continuous $\mathrm{Cr}_{2} \mathrm{O}_{3}$ subscale ensues (Figure 2-10c), further decreasing oxygen activity within the alloy and blocking previous diffusion paths to the surface. Given enough time, $\mathrm{Al}_{2} \mathrm{O}_{3}$ becomes continuous underneath this duplex scale (Figure 2-10d) and protects the alloy from subsequent oxidation [47]. 


\subsubsection{Carbonaceous Gas Reactions}

When carbon also comprises the oxidant (e.g. $\mathrm{CO}_{2}$ ), the high temperature, metalgas interaction becomes slightly more complex than it would be with $\mathrm{O}_{2}$ alone. In addition to a metallic oxide, $\mathrm{CO}$ is also formed as a product of the oxidation reaction. For a $\mathrm{CO}_{2}$ atmosphere with trace levels of $\mathrm{CO}, \mathrm{H}_{2}$, and $\mathrm{H}_{2} \mathrm{O}$, Gibbs et al. [51] and Pritchard et al. [52] have suggested that carbon activity $\left(\mathrm{a}_{\mathrm{C}}\right)$ is controlled by the disproportionation of $\mathrm{CO}$ as per the Boudouard reaction,

$$
2 \mathrm{CO}(\mathrm{g}) \leftrightarrow \mathrm{C}(\mathrm{s})+\mathrm{CO}_{2}(\mathrm{~g})
$$

or via the synthesis gas reaction,

$$
\mathrm{CO}(\mathrm{g})+\mathrm{H}_{2}(\mathrm{~g}) \leftrightarrow \mathrm{C}(\mathrm{s})+\mathrm{H}_{2} \mathrm{O}(\mathrm{g})
$$

Carbon (C) ingress into an alloy can affect oxide scale formation, morphology, and adhesion, because of the precipitation of carbides (carburization) $[53,54]$, as well as disintegrate the alloy entirely (metal dusting), if the local $a_{C}$ is high enough $[55,56]$. This section summarizes carburization $\left(\mathrm{a}_{\mathrm{C}} \leq 1\right)$ and metal dusting $\left(\mathrm{a}_{\mathrm{C}}>1\right)$ mechanisms as applicable to nickel-base superalloys, in addition to what is done to protect against carbon attack.

\subsubsection{Carburization $\left(a_{c} \leq 1\right)$}

Binary metallic carbides $\left(\mathrm{M}_{\mathrm{x}} \mathrm{C}_{\mathrm{y}}\right)$ are just as easily formed as oxides, assuming that the ambient carbon activity supports the metal-carbon reaction $[45,57]$. With the same thermodynamic concepts outlined in Section 2.2.1.1 also applicable to carbide formation, an Ellingham diagram can be constructed to represent the comparative, temperature- 
dependent stabilities of assorted carbides. Such a diagram is shown in Figure 2-11 for metallic carbides specific to nickel-base superalloy compositions.

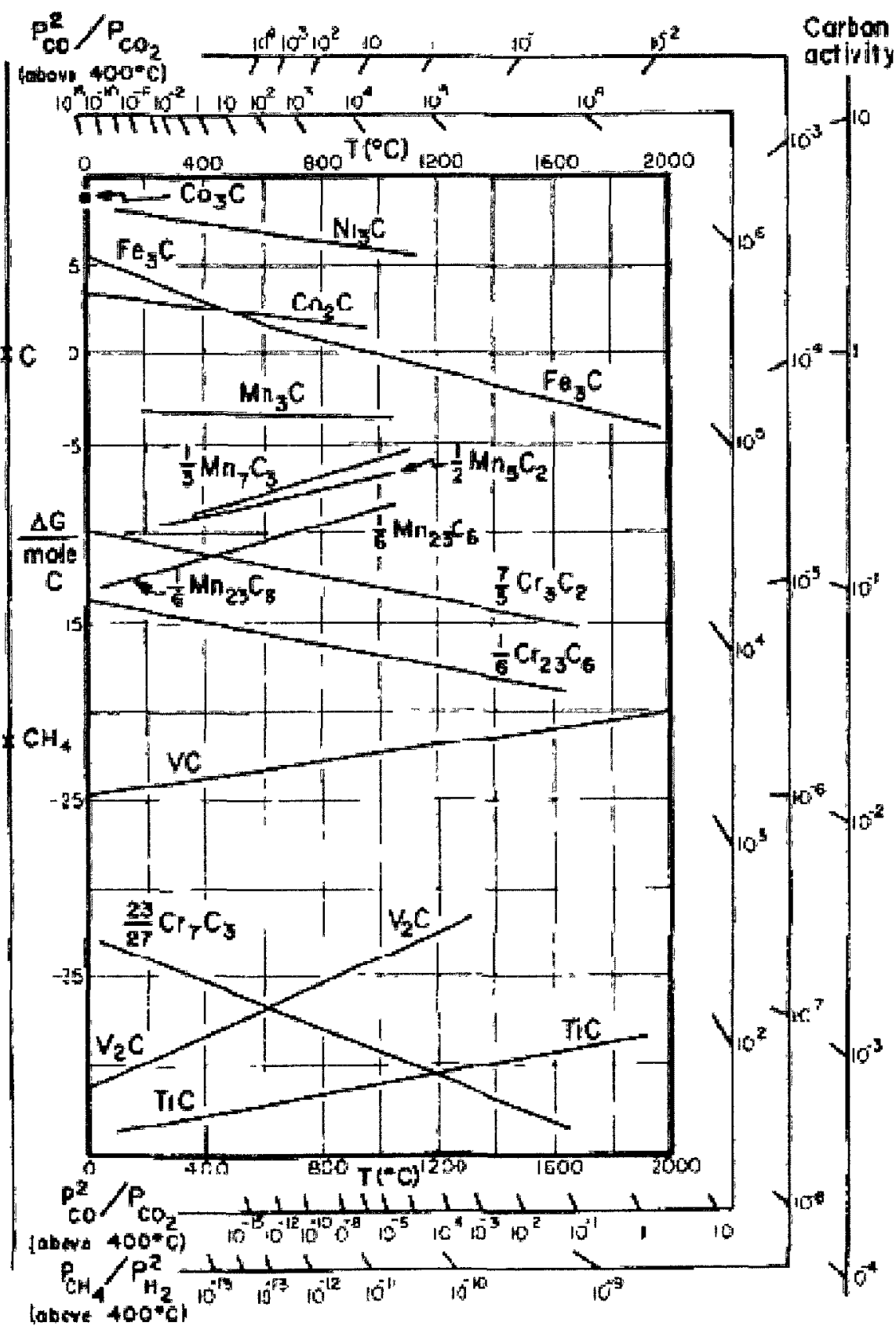

Figure 2-11: Ellıngham diagram for transition metal carbides [57] 
In the absence of a protective oxide layer, nickel and, by extension, its alloys are catalytic to the carbon-producing reactions described by Equations 2.9 and 2.10 [53]. Thus, carbon atoms adsorb on the exposed surface and, facilitated by the disinclination of nickel carbide $\left(\mathrm{Ni}_{3} \mathrm{C}\right)$ to precipitate $(\Delta \mathrm{G}>0)$, diffuse into the nickel matrix. The ensuing metal-carbon reaction produces internal $\mathrm{Cr}$ and, to a lesser extent, other refractory carbides that nucleate both at grain boundaries and within the grains themselves $[54,58]$. Chromium-based carbides $\left(\mathrm{Cr}_{23} \mathrm{C}_{6}, \mathrm{Cr}_{7} \mathrm{C}_{3}\right.$, and $\left.\mathrm{Cr}_{3} \mathrm{C}_{2}\right)$ however can be particularly harmful to an alloy that relies on the formation of a $\mathrm{Cr}_{2} \mathrm{O}_{3}$ scale for protection against metal attack; these carbides consume $\mathrm{Cr}$ from the nickel matrix that would otherwise be used to form the protective oxide layer [45]. A stability diagram for a $\mathrm{Cr}-\mathrm{O}-\mathrm{C}$ system at $620^{\circ} \mathrm{C}$ is depicted in Figure 2-12 and shows that carbide formation only becomes preferential with extremely low oxygen partial pressures; i.e. $\mathrm{P}_{\mathrm{O}_{2}} \leq 10^{-35}$ atm.

Carbide morphology - controlled by the gaseous carbon activity, exposure temperature, and alloy composition - obviously has a direct bearing on how carburization will affect mechanical properties at service conditions $[53,54]$. Creep-rupture life, for example, may be slightly improved with the precipitation of finely dispersed carbides (low temperature and $\mathrm{a}_{\mathrm{C}}$ ) or severely impaired by the formation of continuous carbide films at the grain boundaries (high temperature and $\mathrm{a}_{\mathrm{C}}$ ) [45]. The effect of carburization on room temperature, mechanical properties however is almost always deleterious, regardless of carbide morphology [59]. Figure 2-13 reveals significant decreases in both tensile strength and ductility, with increasing carbon content, for two nickel-base superalloys at room temperature; pre-carburization data is included for contrast. 


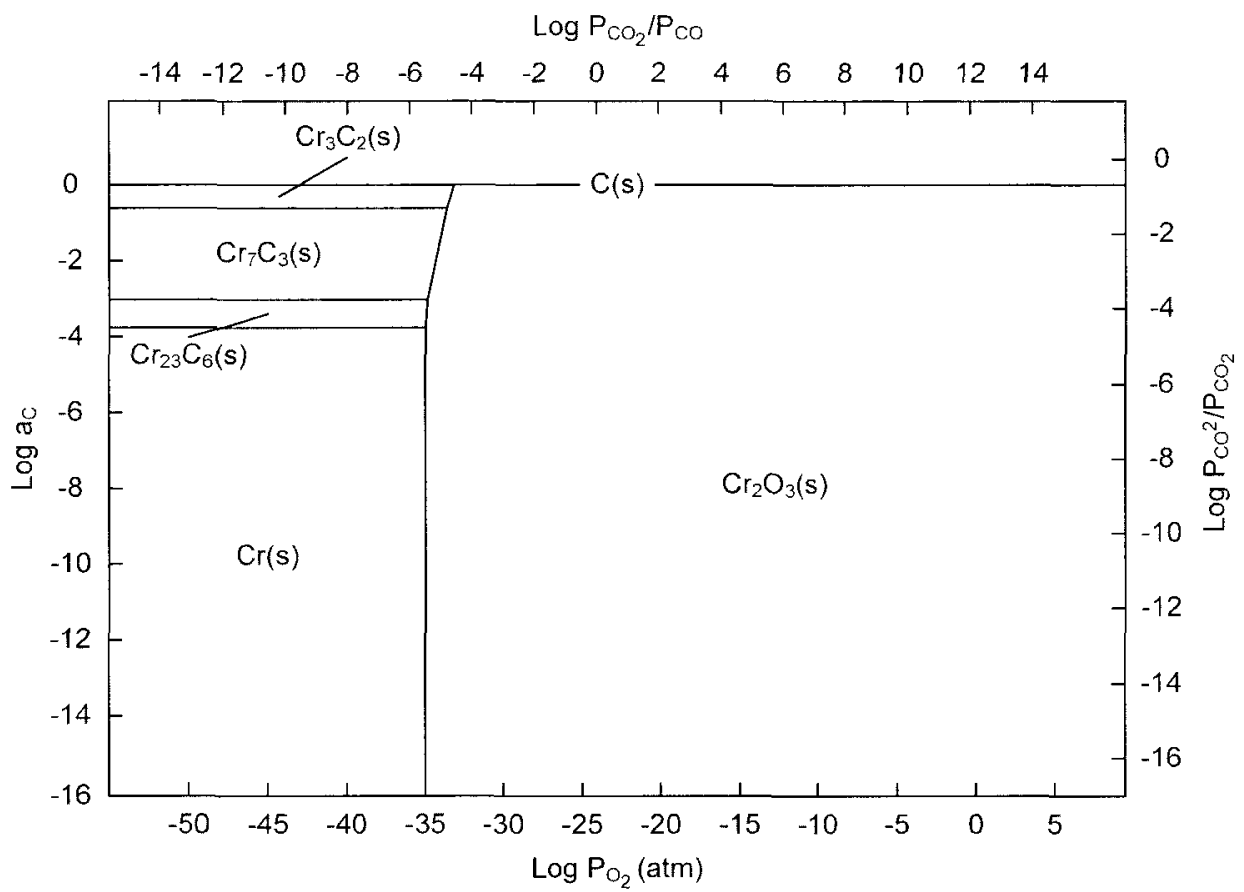

Figure 2-12: Stability diagram for the Cr-O-C system at $620^{\circ} \mathrm{C}$. Reproduced from [45]

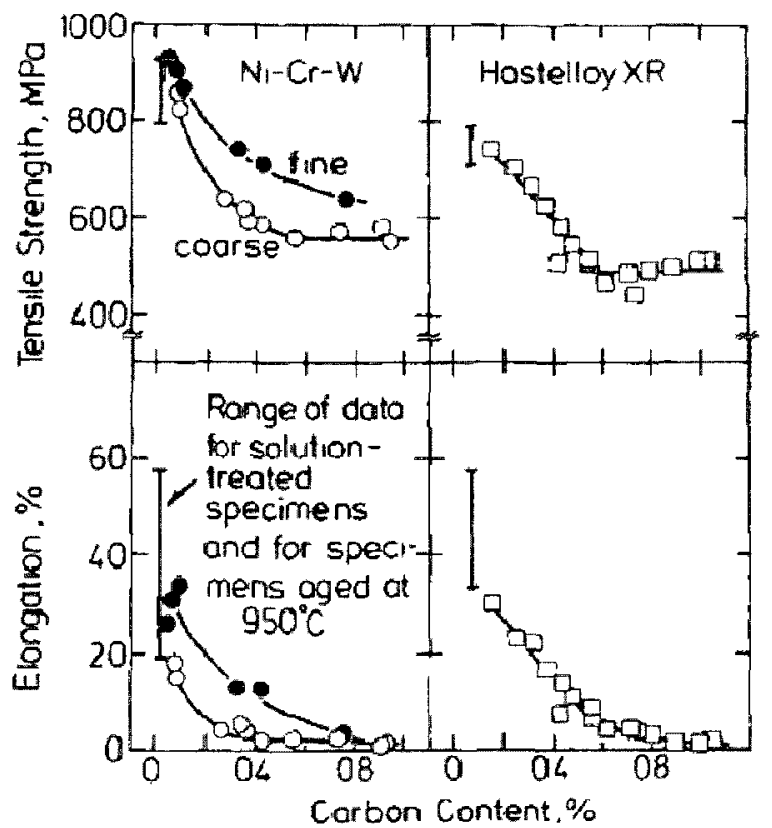

Figure 2-13: Effect of carburization on room temperature, mechanical properties of nickel-base superalloys [59] 


\subsubsection{Metal Dusting $\left(a_{c}>1\right)$}

Metal dusting, or catastrophic carburization, occurs when susceptible materials coincidentally the base metals of superalloys - are exposed to gaseous carbon activities greater than unity at temperatures between 400 and $800^{\circ} \mathrm{C}[45,55]$. Graphite nucleation and growth on or within these alloys is favoured because of the carbon-supersaturated environment and inevitably leads to their destruction. The subsequent corrosion product (termed 'coke') consists of disintegrated metal and graphitic carbon in addition to oxides and carbides, depending on the alloy composition [53,55]. Figure 2-14 provides a schematic representation of the metal dusting phenomenon for a $\mathrm{Cr}_{2} \mathrm{O}_{3}$-forming, nickelbase alloy.

Carbon dissolution into a nickel-base alloy (Figure 2-14a) initiates at a defect or void in its protective $\mathrm{Cr}_{2} \mathrm{O}_{3}$ oxide layer and, accordingly, a zone of finely dispersed, internal carbides $\left(\mathrm{M}_{7} \mathrm{C}_{3}\right.$ and $\left.\mathrm{M}_{23} \mathrm{C}_{6}\right)$ develops beneath it (Figure 2-14b). Until now, metal dusting and carburization mechanisms are identical. What differentiates the two beyond this point is that the higher $a_{c}$ associated with metal dusting allows this carbide zone to become supersaturated with carbon over time. Graphite nucleates on the still-exposed substrate surface, assuming the oxide layer was unable to properly heal, and grows inward into the carbon-rich zone and dendritically along surrounding grain boundaries (Figure 2-14c). Moreover, metal grains encapsulated by graphite tend to separate from the bulk metal because of the compressive stresses attributed to an expansion in volume. The outward growth of coke (Figure 2-14d) results in the uptake of metal, carbides, and oxides from the substrate, leaving behind hemispherical pits when it breaks away $[55,60]$. 


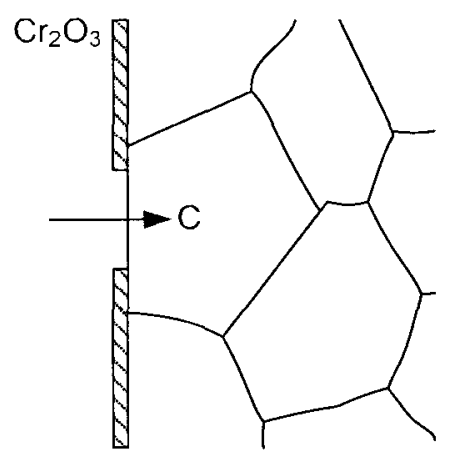

(a)

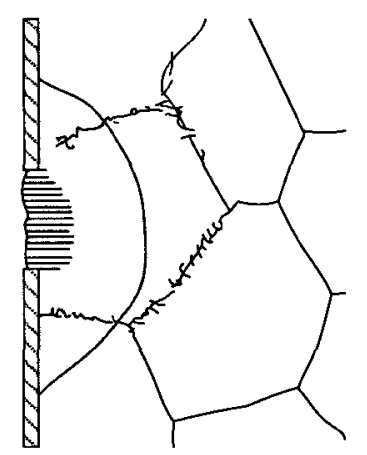

(c)

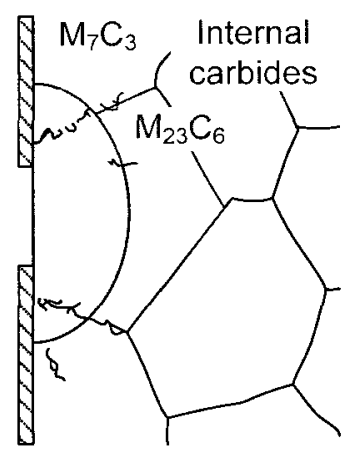

(b)

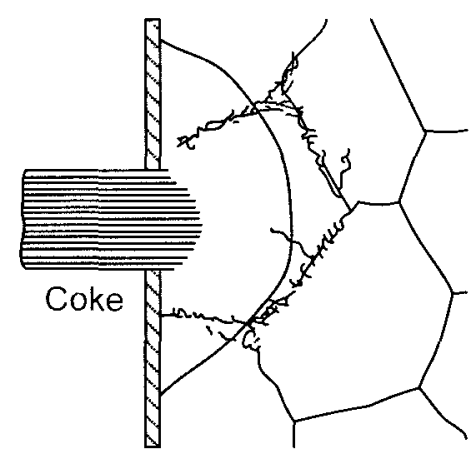

(d)

Figure 2-14: Metal dusting mechanism of a $\mathrm{Cr}_{2} \mathrm{O}_{3}$-forming, nickel-base alloy: (a) carbon diffusion into the substrate initiated at $\mathrm{Cr}_{2} \mathrm{O}_{3}$ scale defect, (b) formation of internal carbides $\left(\mathrm{M}_{7} \mathrm{C}_{3}\right.$ and $\left.\mathrm{M}_{23} \mathrm{C}_{6}\right)$ and local carbon-supersaturation of substrate, (c) graphite nucleation and inward growth, and (d) outgrowth of 'coke' corrosion product.

Reproduced from [55]

\subsubsection{Protection Against Carbon Attack}

Carbon attack is prevented, or at the very least hindered, by the application or formation of a barrier impervious to carbon diffusion, such as a coating system or oxide scale [58], or the introduction of gaseous hydrogen sulphide $\left(\mathrm{H}_{2} \mathrm{~S}\right)[45,55]$ into the process environment. The low carbon solubility in $\mathrm{Cr}_{2} \mathrm{O}_{3}$ and $\mathrm{Al}_{2} \mathrm{O}_{3}$ scales as well as $\mathrm{Cr}$ and Al-based coatings makes them ideal candidates for carbon barriers, assuming that they remain adherent to the substrate and free of porosity. Protection imparted by 
sulphur is slightly different from the former mechanism, given that sulphur atoms adsorb on the alloy surface and interfere with carbon-releasing reactions directly rather than establish a protective barrier $[45,55]$. Too high a sulphur content in the process environment though can also be harmful and lead to degradation by sulphidation.

\subsubsection{Erosion-Corrosion}

Since most practical gaseous environments contain suspended particles, erosioncorrosion can be regarded as the most realistic of all the high temperature corrosion modes. Under that same rationale however, the simultaneous surface degradation by both mechanical and chemical means gives erosion-corrosion the potential to be one of the most aggressive modes as well [45]. Erosion, for the context of this discussion, applies only to surface degradation by solid particle impingement and not by tribological (friction) wear or cavitation. This section first gives a brief overview on the mechanisms of erosion and concludes with a description of the established erosion-corrosion regimes.

\subsubsection{Mechanisms of Erosion}

Erosion mechanisms broadly correspond to either the ability (ductile response) or inability (brittle response) of a surface to absorb and dissipate the kinetic energy of an impinging particle [61-63]. At high temperature, metals will most always exhibit a ductile response, a stark contrast to the brittle nature of such corrosion products as oxide scales and coke deposits. Figure 2-15 shows erosion mechanisms for both ductile and brittle materials in response to a particle impact. The ductile mechanism can be further 
expanded to illustrate what effect impact angle (the angle measured from the surface to the particle's trajectory) and particle velocity have on surface degradation. Other contributing factors to the erosion rate of a material include the size, shape, hardness, and mass flux of the erodent [61].

DUCTILE

RESPONSE

(a)

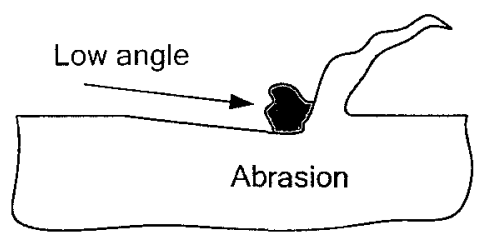

(b)
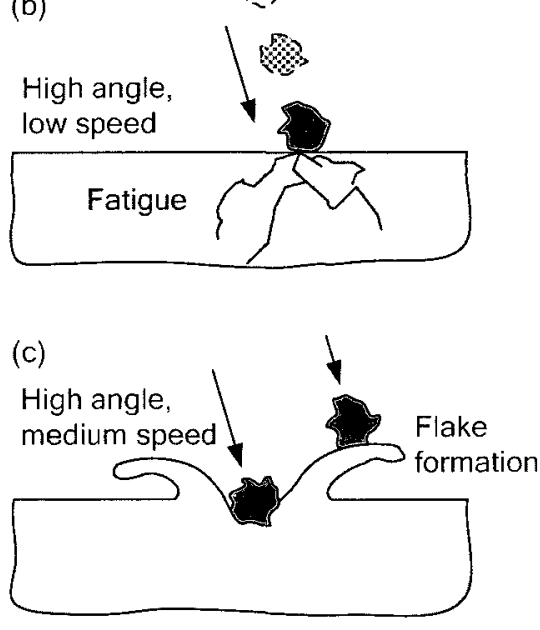

(d)

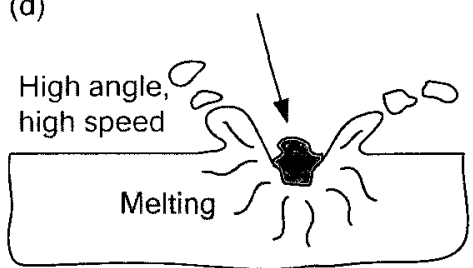

BRITTLE RESPONSE

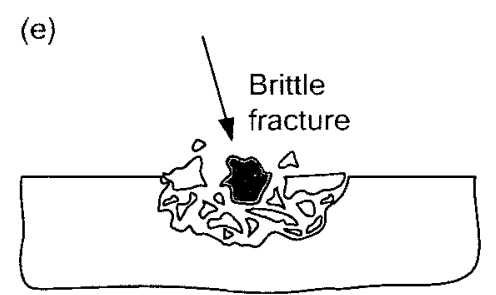

Figure 2-15: Erosion mechanisms for ductile and brittle materials: (a) low angle surface abrasion, (b) high angle, low velocity surface fatigue, (c) excessive plastic deformation at high angle, medium velocity, (d) surface melting due to high velocity impact, and (e) brittle fracture. Adapted from [61] 
At low impact angles and above a threshold particle velocity, the erodent cuts into the surface of a ductile material (Figure 2-15a) of lesser or equal hardness. Surface gouging and subsequent material loss only intensify as particle velocity is increased, although this relationship between erosion rate and velocity is not shown explicitly in Figure 2-15. As the impact angle approaches 90 degrees, surface damage attributed to particle impingement transitions from channels or grooves to impact craters. At low velocity but high impact angle, plastic deformation is minimal, yet the repetitive bombardment of erodent produces highly localized surface fractures and ultimately leads to fatigue (Figure 2-15b). Plastic deformation becomes increasingly exaggerated (Figure 2-15c), as does surface melting and re-solidification (Figure 2-15d) with even greater particle velocities [61]. However, unlike the ductile mechanism of erosion, the brittle response to particle impact is characterized by negligible plastic deformation; the coalescence of subsurface cracks and subsequent spallation (Figure 2-15e) are responsible for material removal [63].

Ductile and brittle erosion responses are typified in Figure 2-16 as a function of impact angle. The erosion rate of a ductile material reaches a maximum when surface cutting predominates (i.e. an impact angle between 20 and 30 degrees) and decreases rapidly as the particle trajectory becomes normal to the surface. Conversely, for a brittle material, the maximum erosion rate occurs when the particle impacts the surface at 90 degrees $[62,63]$. Furthermore, overall erosion resistance is specific to the material and not to the controlling erosion mechanism; i.e., $\mathrm{Al}_{2} \mathrm{O}_{3}$ (brittle) is superior to both annealed aluminum (ductile) and graphite (brittle) in terms of erosion resistance [61]. 


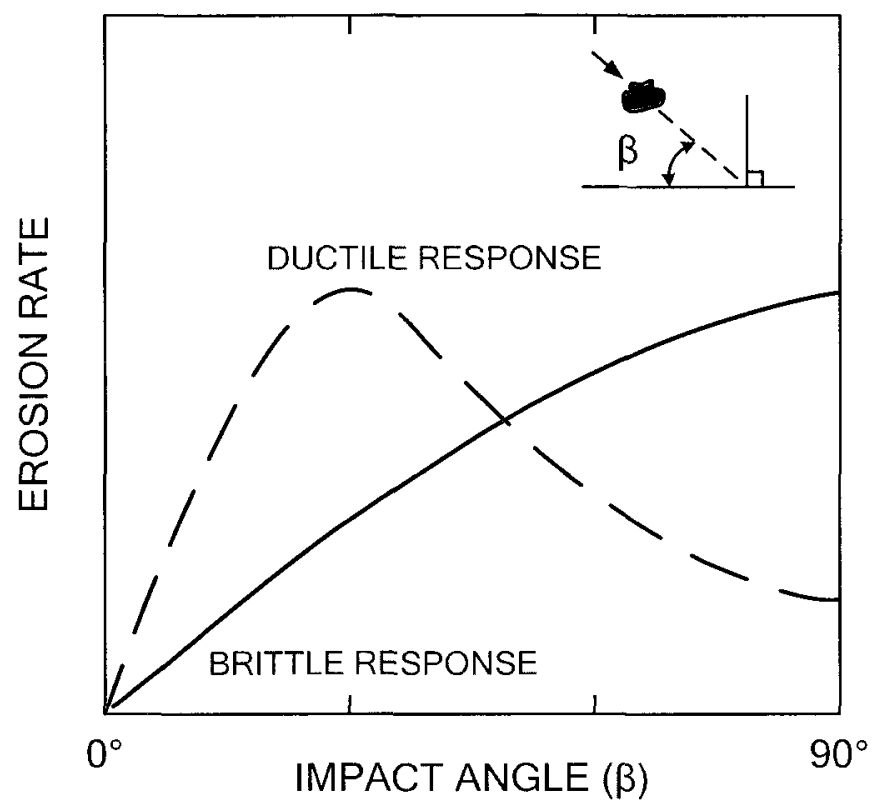

Figure 2-16: Effect of particle impact angle on the erosion rate of ductile and brittle materials

\subsubsection{High Temperature Corrosion Interaction}

Depending on the relative intensities of erosion and corrosion, their combined effect on surface degradation can be categorized into one of four regimes. These regimes are represented schematically in Figure 2-17 and, listed in order of increasing erosion rate or decreasing corrosion rate, include: pure corrosion, erosion-enhanced corrosion, oxidation-affected erosion, and pure erosion. For each regime (excluding pure erosion), diffusion-controlled oxidation is assumed to be the dominant corrosion process [64].

The pure corrosion regime, as its name would imply, is unaffected by the presence of an erodent. Only in the erosion-enhanced regime does the synergistic effect of erosive and corrosive processes on surface attack first become obvious. Moreover, this regime itself encompasses three unique modes - termed types I, II, and III - of erosion-corrosion 
interaction. For type I erosion-enhanced corrosion, erosive thinning of the oxide scale leads to an overall increase in oxidation rate. However, an eventual balance between erosion and oxidation rates is established and the scale thickness remains constant. In some instances, scale thickness may actually increase because of particle impingement, a feature typical of type II erosion-enhanced corrosion. Rishel et al. [64] has postulated this behaviour to be a result of one or both of the following mechanisms: (i) elements (e.g. Al) that would otherwise selectively oxidize and form slow growing, protective oxides scales (e.g. $\mathrm{Al}_{2} \mathrm{O}_{3}$ ) are removed from the matrix by the erodent, or (ii) the number of short-circuit diffusion pathways in the oxide scale are increased by impact-induced cracking. Lastly, type III erosion-enhanced corrosion can be viewed upon as an extension of type I, except that both the intensity and irregularity (either in particle size or impact frequency) of erosion have increased; the oxide scale becomes incoherent, allowing the erodent to now deform the substrate [64].

When erosion prevails over corrosion to become the dominant mode of surface degradation, the oxidation-affected erosion regime is befitting to describe the erosioncorrosion interaction. Successive particle impacts occur and remove material much faster than the oxide scale can grow laterally over the exposed substrate. Consequently, a complex, conglomerate of corrosion product, erodent, and metal develops in lieu of the oxide scale. The final erosion-corrosion regime - the pure erosion regime - occurs in the absence of an oxidant or at temperatures too low to facilitate scale formation $[47,64]$. Metal recession therefore proceeds according to the ductile erosion response presented in Section 2.2.3.1. 


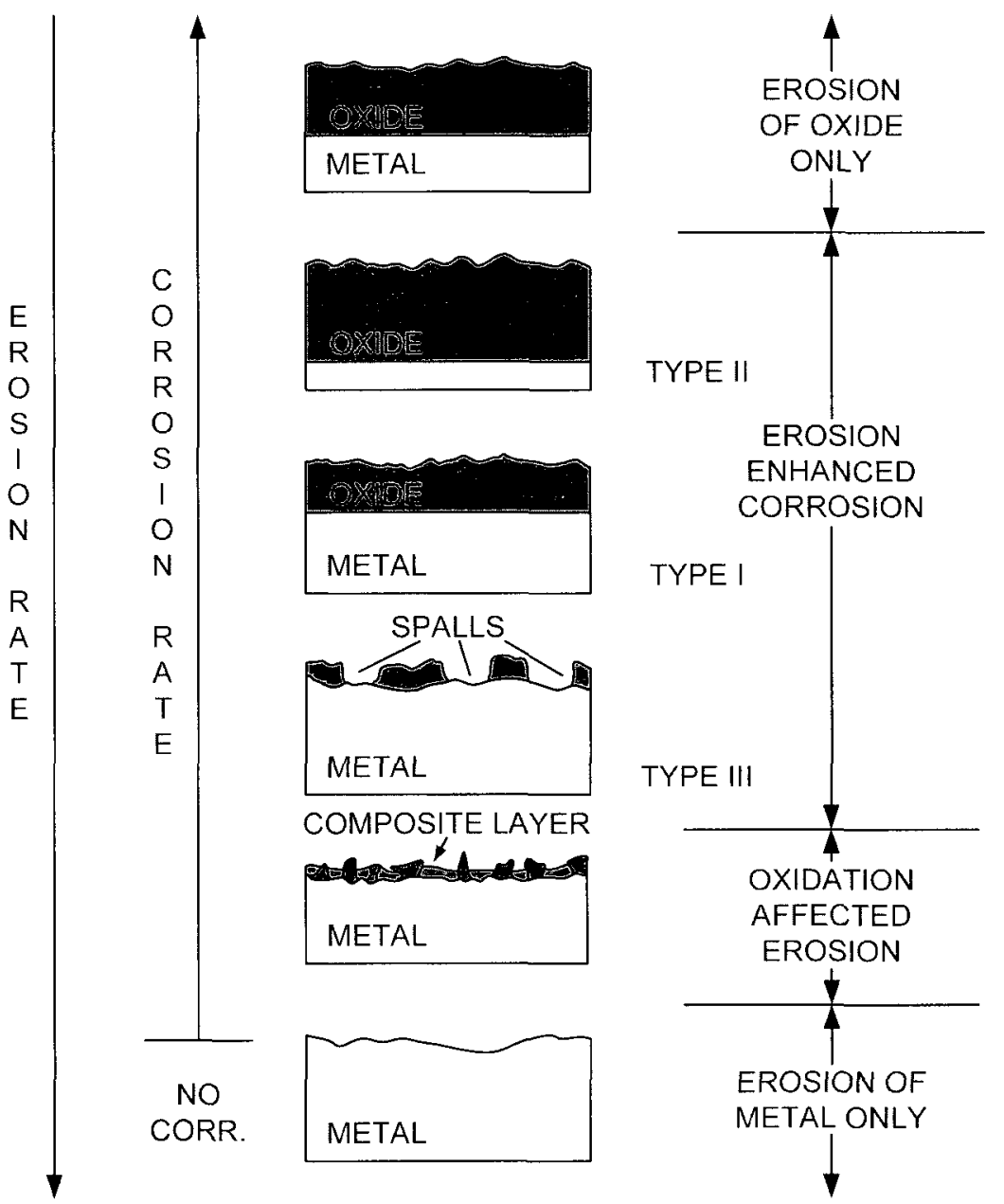

Figure 2-17: Erosion-corrosion interaction regimes. Adapted from [64]

\subsection{High Temperature Corrosion Testing}

Ideally, high temperature corrosion testing would be carried out in the intended service environment to give the most meaningful material response. However, when such a task proves impractical, frequently because of the costs or safety implications involved, laboratory corrosion test rigs serve as effective alternatives in which to approximate service conditions [65]. Additionally, the control afforded by laboratory test 
rigs over such process variables as temperature, pressure, flowrate, environmental composition, exposure time, and entrained particulate, allows for a methodological approach in determining how each will influence corrosion behaviour. Very rarely though, if ever, are the quantitative results (e.g. corrosion rates) obtained through laboratory testing directly exchangeable with the real-world application; instead, these results help to rank and identify suitable candidate materials $[65,66]$. This section will discuss laboratory corrosion test rigs as related to high temperature (purposely gas turbine) applications and summarize the autoclave-based, $\mathrm{S}-\mathrm{CO}_{2}$ corrosion systems that have been built to date.

\subsubsection{Erosion-Corrosion Rig Testing}

Erosion-corrosion test rigs capable of producing intermediate to high velocity particle impacts at elevated temperature can be classified into one of two groups: the rotating-type or the blast-type [67]. These groups coincide with how contact between the specimen(s) and erodent (typically silicon dioxide, $\mathrm{Al}_{2} \mathrm{O}_{3}$, or ash) is initiated - either indirectly from the rotary action of a motor or from particles entrained within the gas itself $[67,68]$. Despite their obvious differences in operation, the main components comprising each type of erosion-corrosion test rig are essentially the same: a unit to hold erodent, either in the form of a hopper or fluidized bed, and subsequent system to collect it; a gas-particle mixer; and a test chamber, which is usually enclosed by a furnace. 


\subsubsection{Rotating-Type Rigs}

The rotating-type class of erosion-corrosion test rigs, whose negligible gas velocities make them apposite to testing in harsh gas compositions, include the whirling arm [69] and centrifugal designs [68]. Both designs can also accommodate multiple specimens simultaneously, allowing for time-efficient testing of different materials under identical conditions or one material at various impingement angles.

Even when compared to its centrifugal counterpart, the whirling arm test rig is unique because the erodent, in addition to the corrosive gas, remains effectively static relative to a stationary reference frame. Specimens are mounted to an 'arm' or holder which, in turn, is rotated though a fluidized bed or stream to encourage particle interaction [67]. Accordingly, the particle impact velocity (limited to approximately $30 \mathrm{~m} / \mathrm{s}$ ) becomes a function of the rotational speed of the arm and at what radial distance the specimens are mounted from its axis of rotation [69]. A process flow diagram of a whirling arm test rig used in high-sulphur, low-oxygen environments is shown in Figure 2-18, although other gaseous compositions could be easily interchanged.

Centrifugal erosion-corrosion rigs, as depicted in Figure 2-19, use a centrallylocated, rotating nozzle to eject erodent at specimens. Specimens are positioned to encircle the perforated base of the nozzle and particle impact velocity, analogous to the rotating arm design, is governed by its rotational speed [68]. Impact velocities and loading rates of up to $200 \mathrm{~m} / \mathrm{s}$ and $0.6 \mathrm{~kg} / \mathrm{m}^{2} \mathrm{~s}$, respectively, are possible with the centrifugal rig, but quantifying the total mass of erodent that has impacted with the specimens becomes convoluted if various impingement angles are tested at once [67]. 


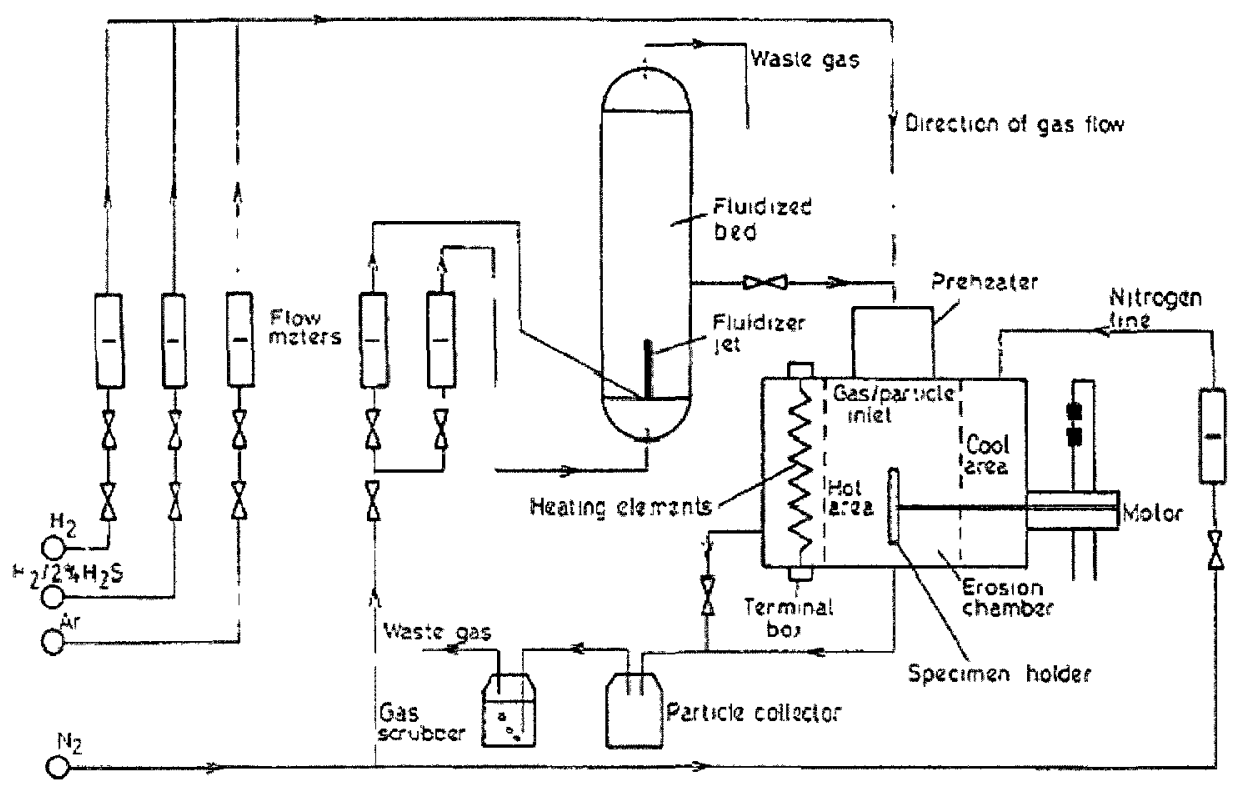

Figure 2-18: Whirling arm erosion-corrosion test rig [69]

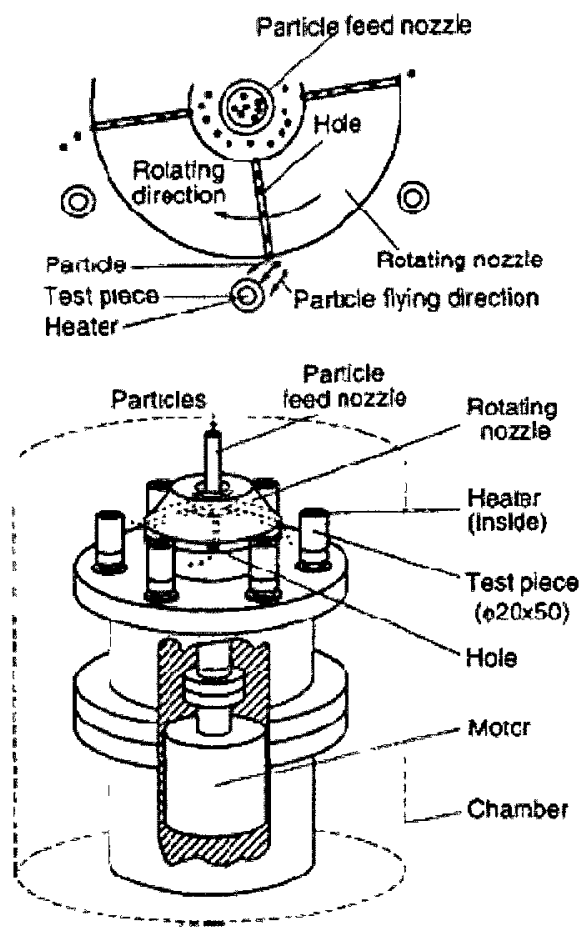

Figure 2-19: Centrifugal erosion-corrosion test rig [68] 


\subsubsection{Blast-Type Rigs}

Erosion-corrosion test rigs utilizing pressurized gas to accelerate the erodent represent the most common configuration used at research institutions and in industry due to their simple construction and inexpensive operation [67]. Regardless of their prevalence, gas jet and high velocity rigs are not capable of the same degree of particle velocity uniformity that can be achieved with the rotating-type designs.

For the gas jet, blast-type test rig, the erodent is introduced to a pressurized reactive gas, accelerated via aerodynamic drag force through a convergent nozzle and accelerator tube, and directed at a single specimen or stage of specimens [70,71]. A schematic representation of such a rig is provided in Figure 2-20. Contrary to the rotating-type rigs, particle velocity - typically limited to $40 \mathrm{~m} / \mathrm{s}$ [67] - is dictated by the pressure differential established between the gas carrier and the test chamber as well as the length and diameter of the accelerator tube; to a lesser extent, both particle size and shape, in addition to the temperature at the accelerator tube outlet, also influence particle velocity [71]. The reactive gas stream may also be supplied from the exhaust of a combustor (referred to as a burner rig in this arrangement), with erodent injected into the attendant air or fuel supply prior to combustion or into the exhaust gas stream following combustion [67]. Likewise, burner rigs are imperative to the study of hot corrosion mechanisms and understanding the deposition behaviour of molten salts.

High velocity, high temperature wind tunnels draw many parallels to the gas jet, blast-type test rigs but on a much larger scale. Erodent is typically injected far upstream of the test specimen(s) and accelerated by the high velocity gas in a constant area duct. 
The outcome is an erodent-laden gas stream spanning the entire cross-section of the duct, which acts to preserve the aerodynamic characteristics of the fluid field [71]; i.e., the erosion-corrosion interaction is more representative of what would be seen in service as opposed to that induced by a localized gas jet. Compared to high velocity burner rigs, the wind tunnel configuration can achieve comparable particle velocities (approximately $300 \mathrm{~m} / \mathrm{s})$ at similar test temperatures $\left(1100^{\circ} \mathrm{C}\right)$ but only at a fraction of the operating cost [67]. Figure 2-21 illustrates a wind tunnel erosion-corrosion test rig whose gas stream is supplied by the exhaust of a can combustor.

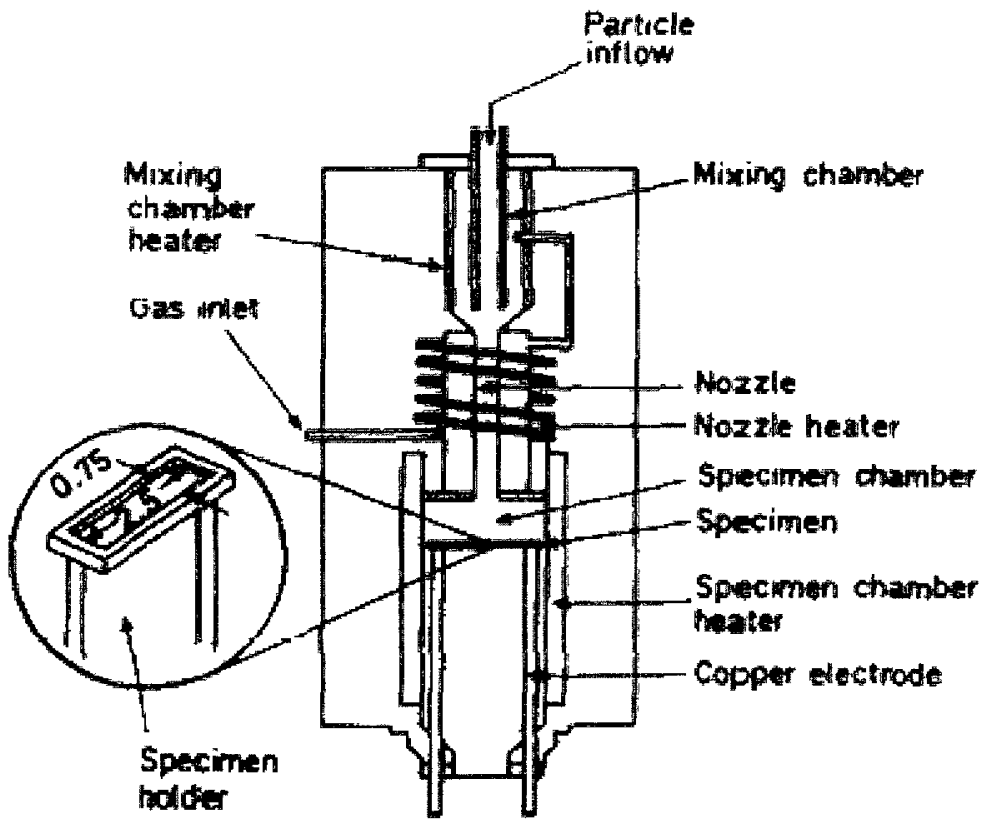

Figure 2-20: Gas jet erosion-corrosion test rig [72] 


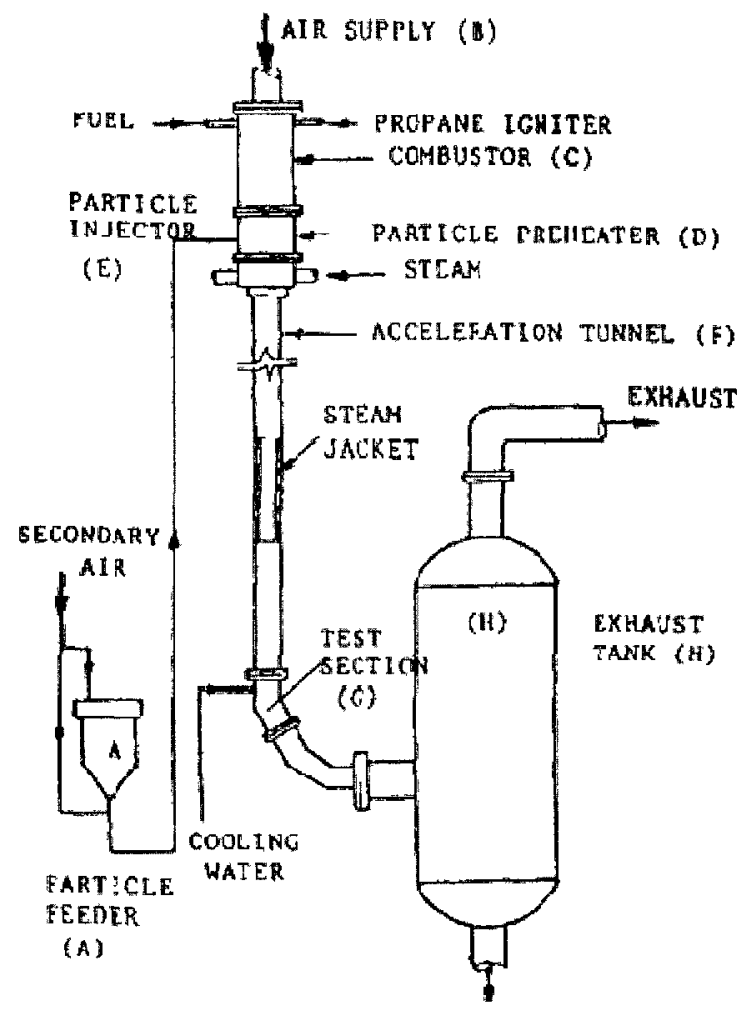

Figure 2-21: Wind tunnel-type erosion-corrosion test rig [67]

\subsubsection{Autoclave Testing}

High temperature, autoclave test systems emphasize the chemical, rather than the mechanical, response to the simulated service environment and therefore have no cause to accelerate erodent and generate high velocity impingements. Whether these systems are intended to be operated under static, once-through, or recirculating conditions, each will employ some form of a metallic, usually cylindrical, pressure vessel [65], either to hold test specimens or to function as one (in the case of a pipe). Here, the inclusion of a pressure vessel permits corrosion studies to be conducted well above standard pressure, something that most erosion-corrosion test rigs are not capable of. Exactly what 
combination of internal pressure and temperature the vessel can safely be subjected to is determined by its cross-sectional dimensions and construction material.

Pressure vessels used in autoclave corrosion test systems tend to limit their capacity to between 0.5 and $5.0 \mathrm{~L}$ to minimize the associated material costs [65]. Figure 2-22 shows the general relationship between the internal pressure $(\mathrm{P})$ of a pressure vessel and the minimum required wall thickness $(t)$ to contain it, normalized to the maximum allowable material stress $\left(\sigma_{\max }\right)$ and internal radius $\left(\mathrm{r}_{\mathrm{i}}\right)$, respectively. Regardless of whether the internal or external radius of the vessel is fixed, wall thickness increases exponentially in response to increasing internal pressure; for the former, the vessel can become quite cumbersome as its pressure approaches $\sigma_{\max }$ whereas for the latter, internal volume is significantly reduced. Often, the overall length of the pressure vessel is extended to maintain a workable internal volume yet still preserve a sensible external diameter [65].

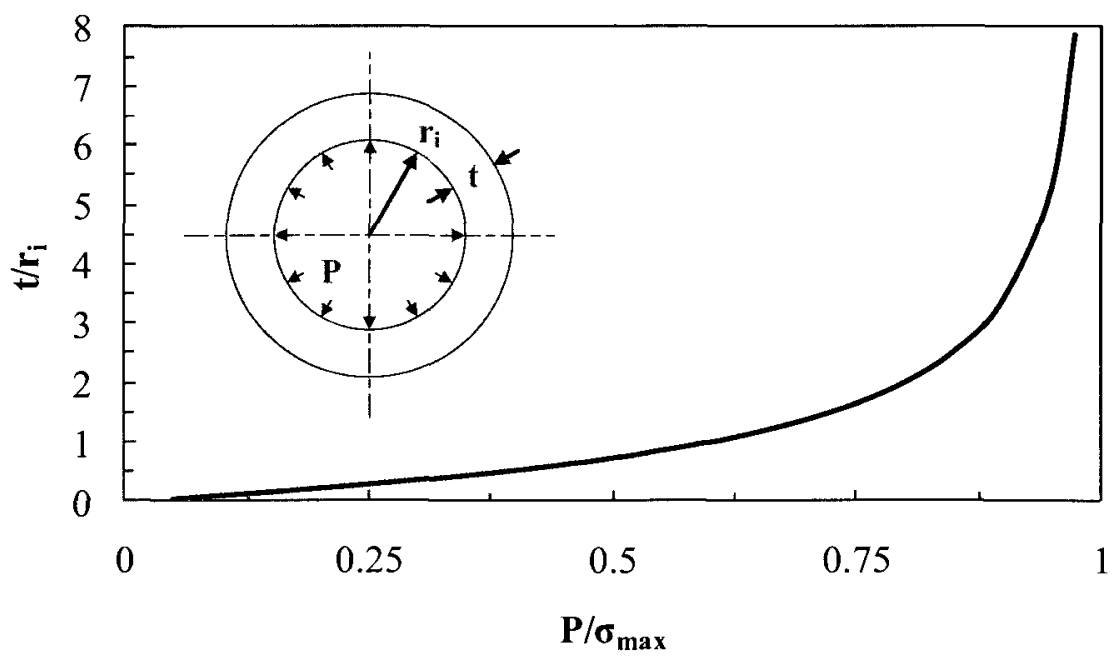

Figure 2-22: Effect of internal pressure on the minimum required wall thickness for a pressure vessel of circular cross-section 
Caution should be exercised when selecting the pressure vessel material(s) if the metal temperature is likely to exceed $550^{\circ} \mathrm{C}$. Figure $2-23$ provides maximum allowable stress versus temperature curves for alloys used in current fossil boilers and those expected to be integral to emerging ultra-supercritical water power plants; i.e., materials which must retain their mechanical properties (e.g. creep-rupture strength and fracture toughness) at intermediate to high temperatures while at the same time resist corrosive attack. As expected, nickel-based alloys outperform both ferritic and austenitic stainless steels at these service temperatures and are fit to serve as either the shell or seal material for a pressure vessel. By contrast, non-metallic seal materials, such as elastomers and plastics, are generally ill-suited for high pressure applications and also degrade rapidly between 150 and $250^{\circ} \mathrm{C}$ [73]. Particularly aggressive test environments may even warrant the application of a compatible ceramic liner to the bore of the pressure vessel $[65]$.

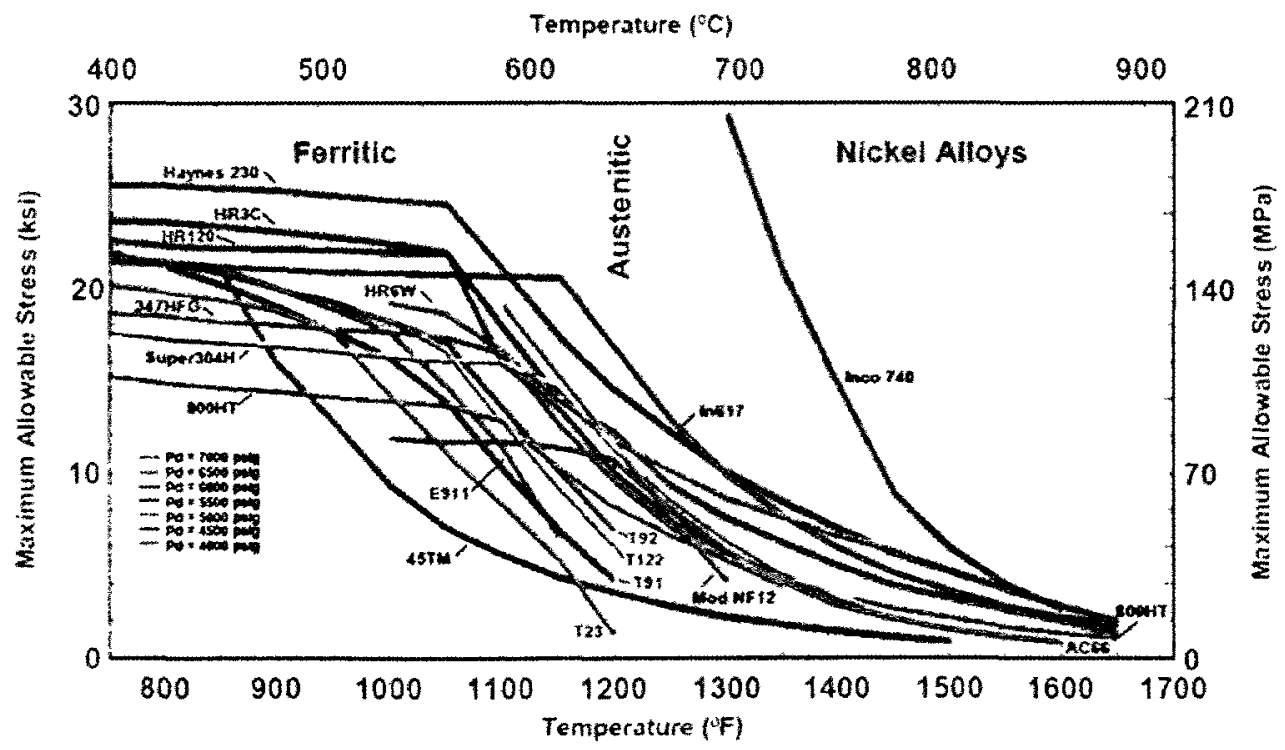

Figure 2-23: Stress-temperature curves for high temperature boiler materials [74] 


\subsubsection{1 $\mathrm{S}-\mathrm{CO}_{2}$ Corrosion Test Rigs}

The majority of $\mathrm{S}-\mathrm{CO}_{2}$ corrosion test rigs (and exclusively those with high temperature capabilities) have just recently emerged with the advent of $\mathrm{S}-\mathrm{CO}_{2}$ Brayton cycles; earlier corrosion test rigs evolved when $\mathrm{S}-\mathrm{CO}_{2}$ was being considered for oil recovery endeavours [23] and as an industrial solvent [24]. All S- $\mathrm{CO}_{2}$ test rigs however, at least those published in open literature, have been based on the autoclave design (either at static or low flowing conditions) and exist or once existed at the following institutions: the Chevron Oil Field Research Company [23], Sandia National Laboratories [24], Idaho National Laboratory (INL) [11], Tokyo Institute of Technology [33,75], Massachusetts Institute of Technology (MIT) [34,35,38,76], University of Wisconsin-Madison (UW-Madison) [36], and the Commissariat à l'Énergie Atomique (CEA) [37]. Only Sridharan of UW-Madison has initiated the development of a test loop to investigate flow-assisted corrosion mechanisms in high temperature, $\mathrm{S}-\mathrm{CO}_{2}$ environments [77]. This section will review the $\mathrm{S}-\mathrm{CO}_{2}$ corrosion facilities listed above in chronological order.

One of the earliest references to a test rig dedicated to studying material compatibility with $\mathrm{S}-\mathrm{CO}_{2}$ originated at the Chevron Oil Field Research Company shortly before 1972 [23]. A novel enhanced oil recovery effort at the time, Chevron proposed to inject high pressure $\mathrm{CO}_{2}(16.5 \mathrm{MPa})$ into spent wells to restore reservoir pressure; hence, the construction of a laboratory corrosion test rig was necessitated to replicate the conditions that would be encountered within these $\mathrm{CO}_{2}$ pipelines. As depicted in Figure 2-24, the Chevron test rig consisted of three pressure vessels - large enough to accommodate test specimens $304.8 \mathrm{~mm}$ (12.0 in.) in diameter - which were arranged to 
form two independent, recirculating test loops. Together, an air-driven gas booster pump and nitrogen-charged accumulator delivered dry $\mathrm{CO}_{2}$ (at $13.9 \mathrm{MPa}$ ) to both loops, where it was heated and then circulated at fluid velocities of 762 to $1016 \mathrm{~mm} / \mathrm{min}(30.0$ to 40.0 in./min). Provisions in the overall design also allowed for impurity species, such as water and $\mathrm{H}_{2} \mathrm{~S}$, to be easily incorporated into the $\mathrm{S}-\mathrm{CO}_{2}$, if so desired. Each test loop, however, was limited to just $17.3 \mathrm{MPa}$ - in fact, safety relief valves and rupture discs would activate at 15.3 and $16.0 \mathrm{MPa}$, respectively, to protect against inadvertent overpressurization - and could only reach a maximum temperature of $54^{\circ} \mathrm{C}$.

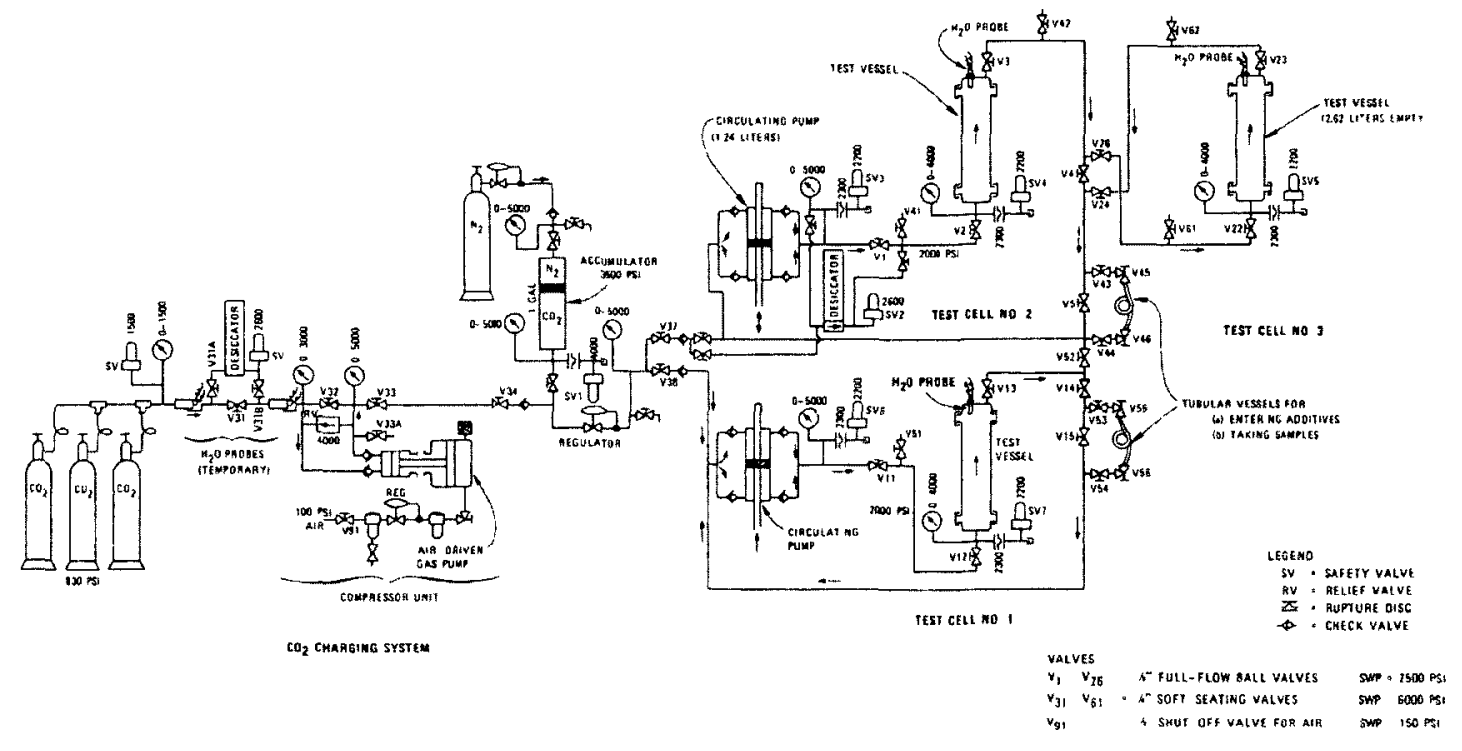

Figure 2-24: Chevron Oil Field Research Company S-CO $\mathrm{CO}_{2}$ corrosion test rig [23]

In 1994, Sandia National Laboratories designed and assembled a static, S- $\mathrm{CO}_{2}$ corrosion test rig to complement research related to using $\mathrm{S}-\mathrm{CO}_{2}$ as an industrial solvent [24]. A process flow diagram of the Sandia design is shown in Figure 2-25. Compression to the desired $\mathrm{CO}_{2}$ test pressure $(24.2 \mathrm{MPa})$ was achieved using a two- 
stage, gas booster pump arrangement to prevent, or at the very least minimize, problems (pump hesitation and surging) associated with a low $\mathrm{CO}_{2}$ supply pressure. Specimens were suspended from a glass support stand inside an $1.8 \mathrm{~L}$ sample vessel which, because of the temperature-controlled water bath used to heat it, was inherently limited to temperatures under $100^{\circ} \mathrm{C}$ (i.e. the boiling point of water at standard pressure). Upon depressurization of the sample vessel to atmosphere, a $1.0 \mathrm{~L}$ recovery vessel acted as an intermediary to collect co-solvent (e.g. water and other alcohols) that would condense as the solubility in $\mathrm{CO}_{2}$ decreased with pressure. The entire corrosion test system including both sample and recovery vessels, as well as the tubing and fittings - was fabricated from 316-grade stainless steel (316-SS) and ultimately restricted to test pressures below $34.6 \mathrm{MPa}$.

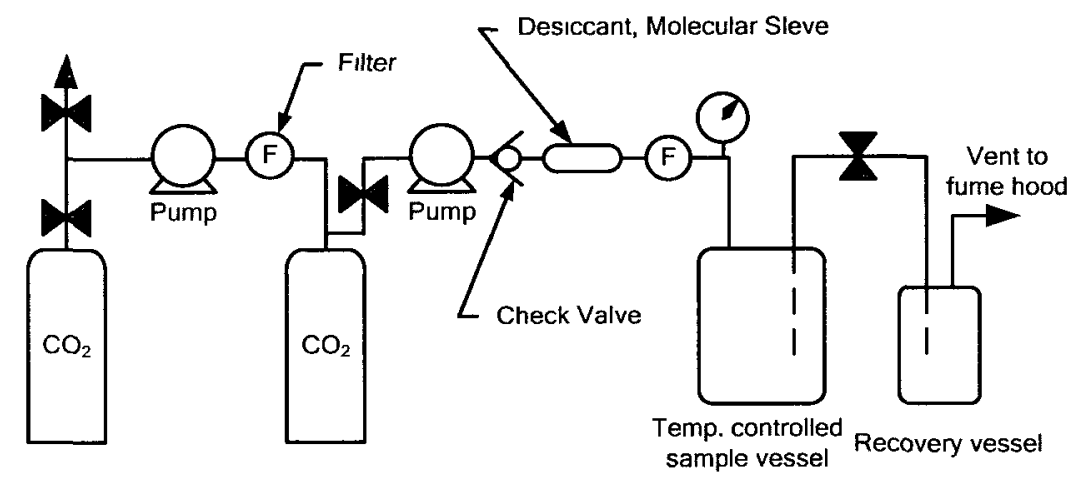

Figure 2-25: Sandia National Laboratories $\mathrm{S}-\mathrm{CO}_{2}$ corrosion test rig [24]

Between 2002 and 2005, the INL conducted an extensive research initiative to develop a S-CO $\mathrm{CO}_{2}$ Brayton cycle that could be applied to the VHTR [11]. Two test rigs were created as part of this initiative that would mark the beginning of a series of high temperature, $\mathrm{S}-\mathrm{CO}_{2}$ corrosion test rigs. The first corrosion test rig, while somewhat 
unconventional in its configuration, used water-cooled connections to convert a tubular test specimen into a functioning segment of high pressure pipe. Figure 2-26 shows a schematic of this initial design, with the test specimen supplied with $\mathrm{CO}_{2}$ from a high precision syringe pump and surrounded by a resistance tube furnace. In using the watercooled connections, the ends of the specimen were kept at a considerably lower temperature than its center, adding axial-varying, thermal stresses to the mechanical stresses already induced at the bore. Test conditions (i.e. pressure and temperature) were specific to the specimen material, even though this once-through test rig was capable of delivering $\mathrm{CO}_{2}$ at $21.0 \mathrm{MPa}$ and $25 \mathrm{~mL} / \mathrm{min}$ and heating it to $1100 \pm 5^{\circ} \mathrm{C}$, prior to throttling to atmosphere.

The second corrosion test rig built by the INL was in fact just an adaptation of their initial design, replacing the single tubular test specimen with five, thick-walled, 304grade stainless steel (304-SS) pipes. Each pipe measured $1.2 \mathrm{~m}$ (47.2 in.) in length, had an internal diameter (ID) of $11 \mathrm{~mm}(0.43 \mathrm{in}$.$) , and used a wall thickness that could$ withstand an internal pressure of $7.0 \mathrm{MPa}$ at $1000^{\circ} \mathrm{C}$ for 10,000 hours. Multiple specimens could be inserted into these pipes and tested simultaneously, although the use of 304-SS at elevated temperature left them prone to creep and in one instance resulted in a rupture. Figure 2-27 illustrates the layout of this corrosion test rig, complete with a gas sampling system (a mass spectrometer as well as $\mathrm{O}_{2}$ and $\mathrm{CO} / \mathrm{CO}_{2}$ meters), and confirms its likeness to its predecessor. Both corrosion test rigs have since been decommissioned following the conclusion of this $\mathrm{S}-\mathrm{CO}_{2}$ initiative. 


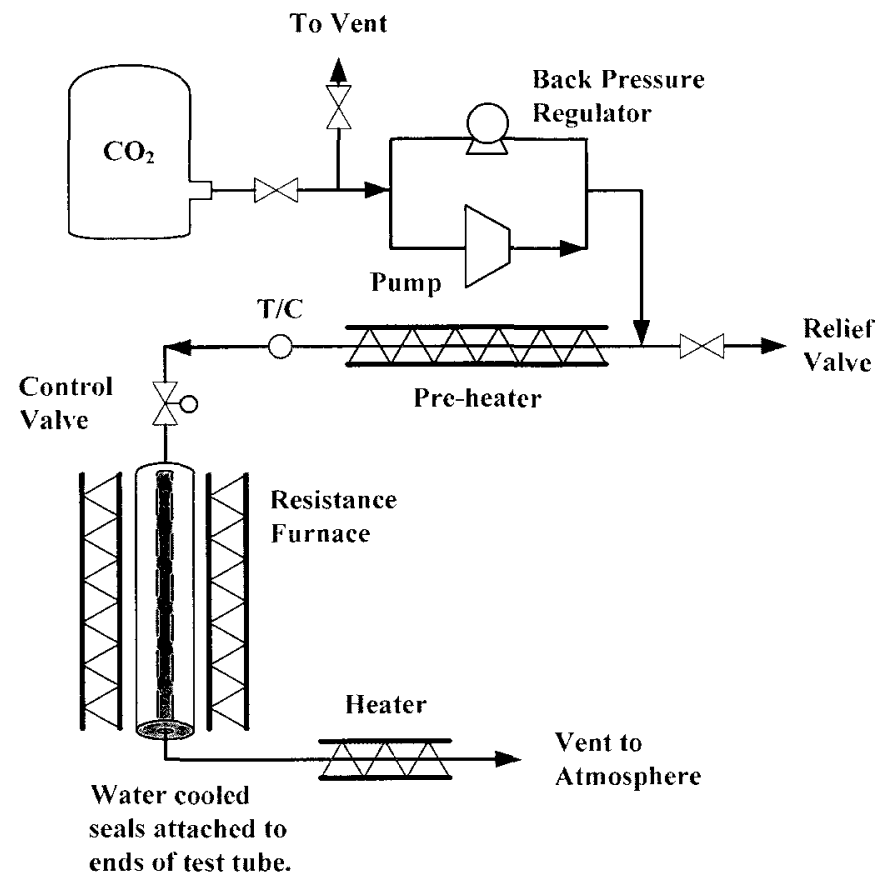

Figure 2-26: INL single specimen, $\mathrm{S}-\mathrm{CO}_{2}$ corrosion test rig. Adapted from [11]

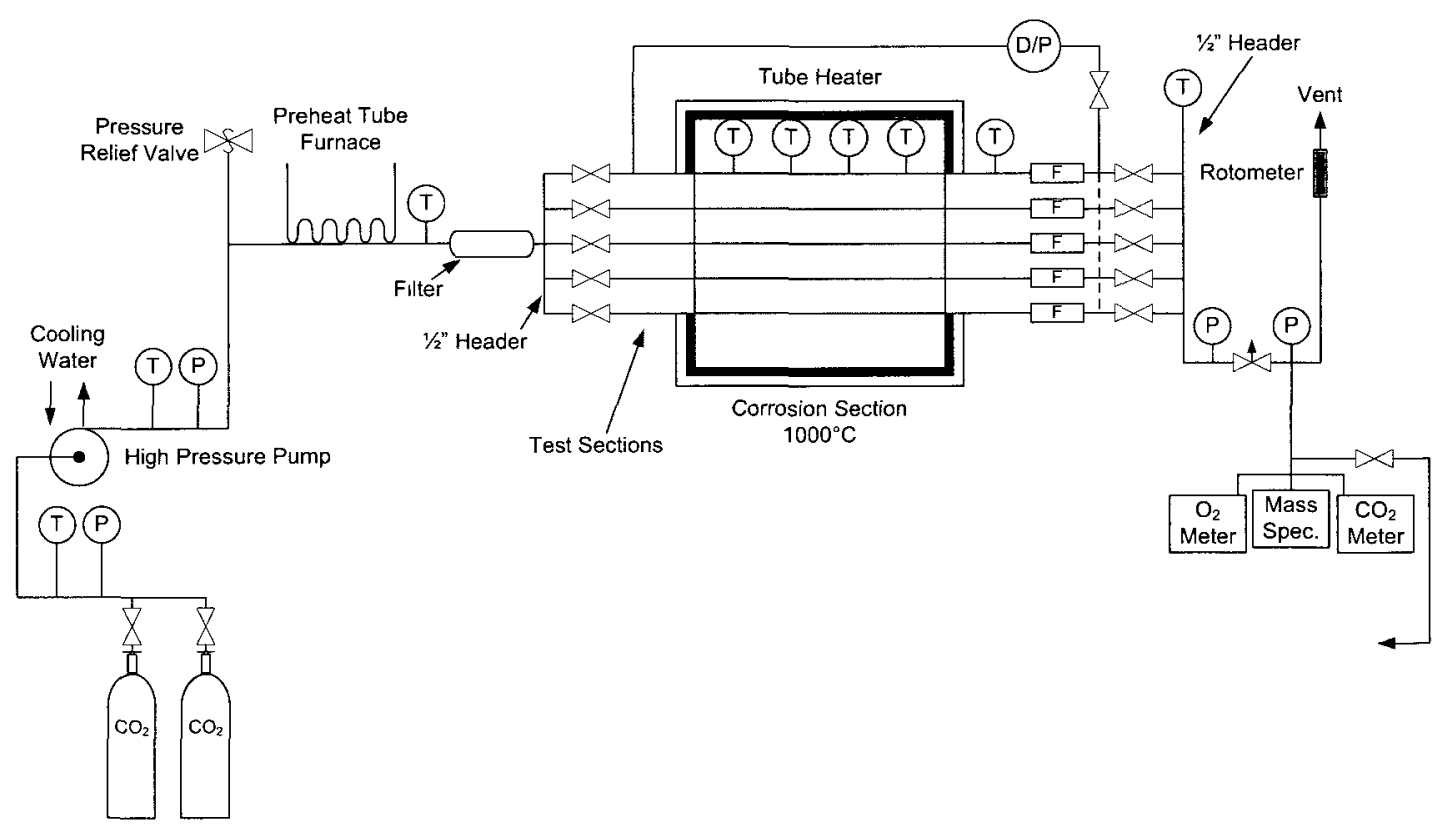

Figure 2-27: INL multi-specimen, $\mathrm{S}-\mathrm{CO}_{2}$ corrosion test rig. Adapted from [11] 
Almost concurrent with the INL initiative, the Tokyo Institute of Technology, in collaboration with the Japanese Atomic Energy Agency (JAEA), began the first stage of a very similar advanced energy system project in 2003 . The main objective of this project was to verify the performance and system design of a S-CO $\mathrm{CO}_{2}$ Brayton cycle for use with a fast breeder reactor (FBR) [75]. In addition to the compressor and heat recovery test loops that resulted, a high temperature, $\mathrm{S}-\mathrm{CO}_{2}$ corrosion test rig was also developed to investigate the corrosion resistance of 316-SS and 12\%-chromium steels. This corrosion test rig largely mirrored the multi-specimen design produced by the INL but, as depicted in Figure 2-28, was modified to function as a recirculating system. Two gas booster pumps pressurized a buffer tank to $22.0 \mathrm{MPa}$, where $\mathrm{CO}_{2}$ was regulated to $20.0 \mathrm{MPa}$ and sent to the five corrosion test sections at $1.2 \mathrm{~kg} / \mathrm{hr}$. Spent $\mathrm{CO}_{2}$ was then cooled from a maximum test temperature of $600^{\circ} \mathrm{C}$, reduced to $4.0 \mathrm{MPa}$, and returned to the booster pumps. Test sections in the furnace though measured only $12.7 \mathrm{~mm}(0.5 \mathrm{in}$.) in outer diameter, limiting the cross-sectional size of specimens that they could accept to just under $4 \mathrm{~mm}(0.16 \mathrm{in}$.).

In 2007, researchers at MIT constructed two, single vessel, $\mathrm{S}-\mathrm{CO}_{2}$ corrosion test rigs to expand upon the high temperature corrosion data assembled by both the INL and Tokyo Institute of Technology [38]. As Figures 2-29 and 2-30 would suggest, the general configuration of each test rig was the same, apart from the size of and flow path through their respective pressure vessels; a gas booster pump supplied an Inconel-625 (IN-625) pressure vessel with high pressure $\mathrm{CO}_{2}$, where it was heated by a split-tube furnace and later exhausted to atmosphere at $1.0 \mathrm{~L} / \mathrm{hr}$ through a gas bubbler. Residual 
gas analyzers (RGA) integrated into each test rig allowed gas compositions to be compared both prior to entering and after exiting the pressure vessel, although no discernible difference between the two streams was ever noted.

The smaller of the two pressure vessels (Figure 2-29) had an ID of $12.7 \mathrm{~mm}$ (0.5 in.), measured $304.8 \mathrm{~mm}$ (12.0 in.) in overall length (101.6 mm or 4.0 in. of which was heated), and was limited, on account of the compression ratio of its gas booster pump, to a maximum operating pressure of $12.5 \mathrm{MPa}$ at $650^{\circ} \mathrm{C}$. With only one opening in its shell, gas entry and egress was accomplished using $1.6 \mathrm{~mm}(0.0625 \mathrm{in}$.$) and 6.4 \mathrm{~mm}$ (0.25 in.) tubing, arranged in such a way that the annulus surrounding the smaller, inner tube delivered 'fresh' $\mathrm{CO}_{2}$ to the vessel while the inner tube itself provided a pathway to atmosphere. Conversely, the larger pressure vessel (Figure 2-30) had an ID of $25.4 \mathrm{~mm}$ (12.0 in.) and measured $1.52 \mathrm{~m}(60.0 \mathrm{in}$.$) in length, 0.61 \mathrm{~m}(24.0 \mathrm{in}$.$) of which was heated$ by a three-zone, $5.0 \mathrm{~kW}$ furnace. While this vessel could, according to American Society of Mechanical Engineers (ASME) standards, safely operate at any combination of pressure and metal temperature up to $27.0 \mathrm{MPa}$ and $750^{\circ} \mathrm{C}$, respectively, corrosion studies following its initial commissioning were restricted to below $22.0 \mathrm{MPa}$ and $700^{\circ} \mathrm{C}$. Furthermore, both vessels used carbon steel bolts to hold conical, IN-625 end seals in place, requiring additional thermal management (internal heat reflectors and heat sinks) to ensure that the bolts remained below their tempering temperature. 


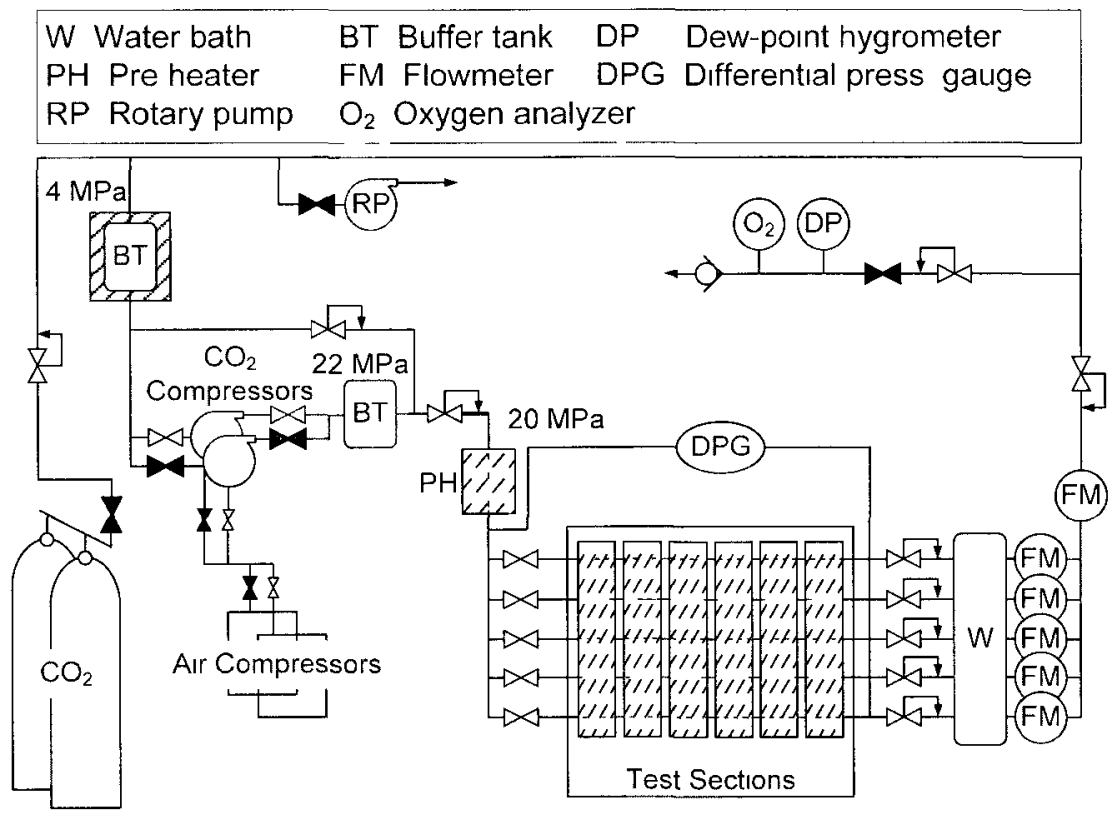

Figure 2-28: Tokyo Institute of Technology $\mathrm{S}-\mathrm{CO}_{2}$ corrosion test rig. Adapted from [33]

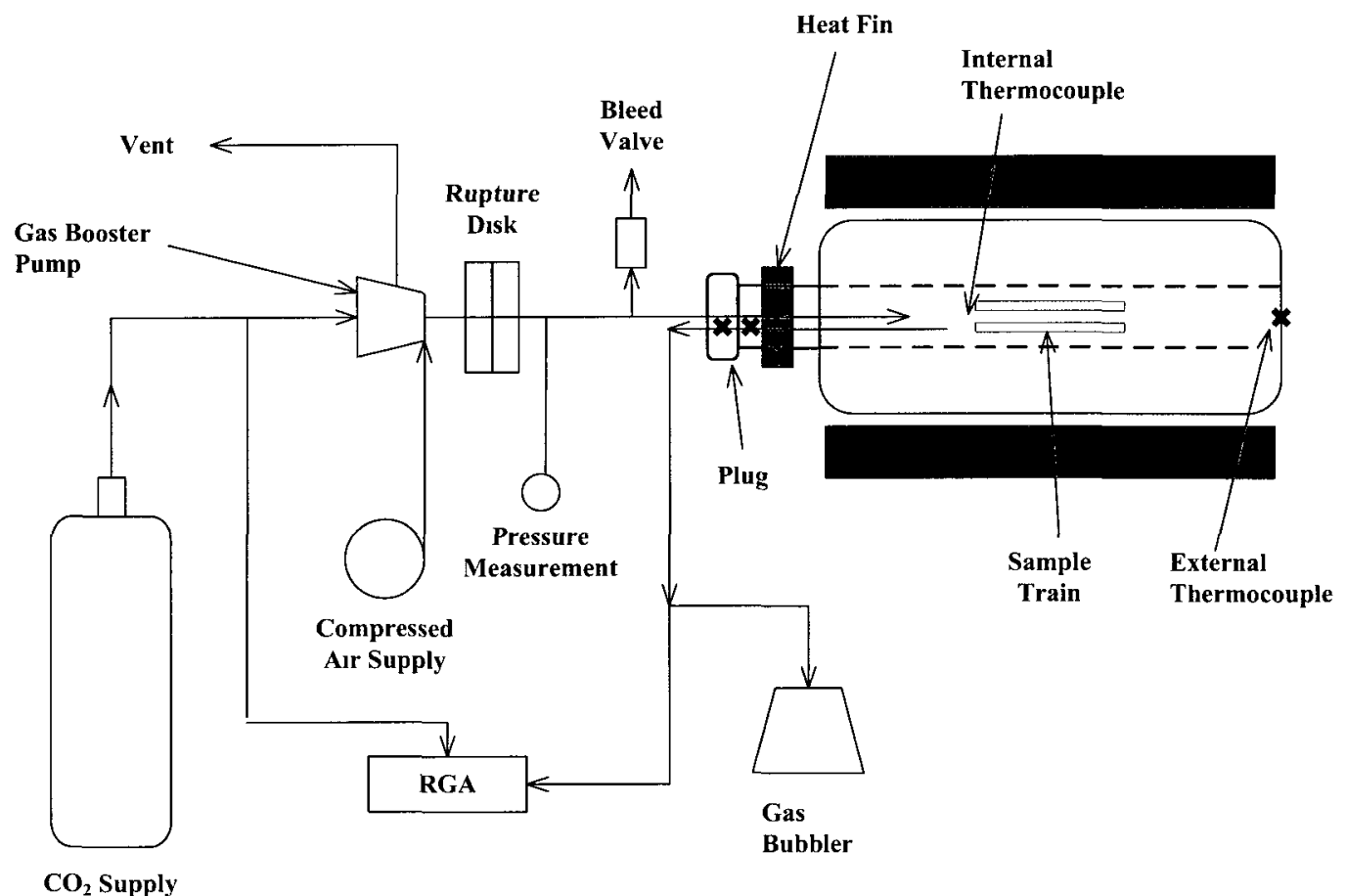

Figure 2-29: MIT low pressure S- $\mathrm{CO}_{2}$ corrosion test rig. Reproduced from [38] 


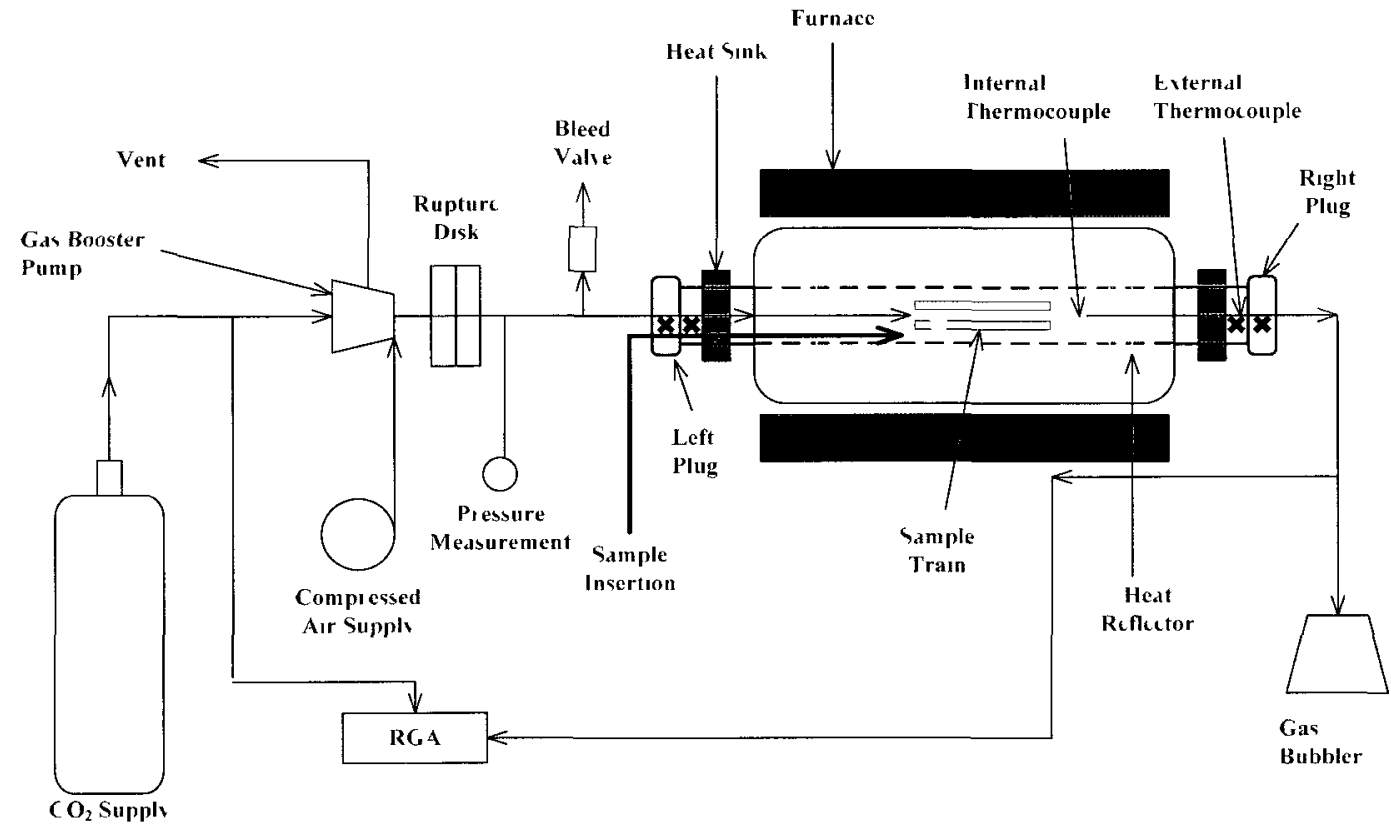

Figure 2-30: MIT high pressure S- $\mathrm{CO}_{2}$ corrosion test rig. Reproduced from [38]

No later than 2009, the UW-Madison built its own S-CO $\mathrm{CO}_{2}$ corrosion test rig, joining the likes of the INL, Tokyo Institute of Technology, and MIT, to assess materials that could be used in $\mathrm{S}-\mathrm{CO}_{2}$ power conversion systems [36]. As shown in Figure 2-31, this once-through test system used a syringe pump to deliver $\mathrm{CO}_{2}$, at 0.0 to $5.0 \mathrm{~g} / \mathrm{min}$, to an IN-625 pressure vessel. The pressure vessel, which was wrapped with three resistive heating cords instead of seated within a tube furnace, was designed to contain a maximum test pressure of $26.9 \mathrm{MPa}$ at $650^{\circ} \mathrm{C}$. Unlike the previous high temperature, $\mathrm{S}-\mathrm{CO}_{2}$ corrosion test rigs though, operation of this system was controlled entirely through a computer. 


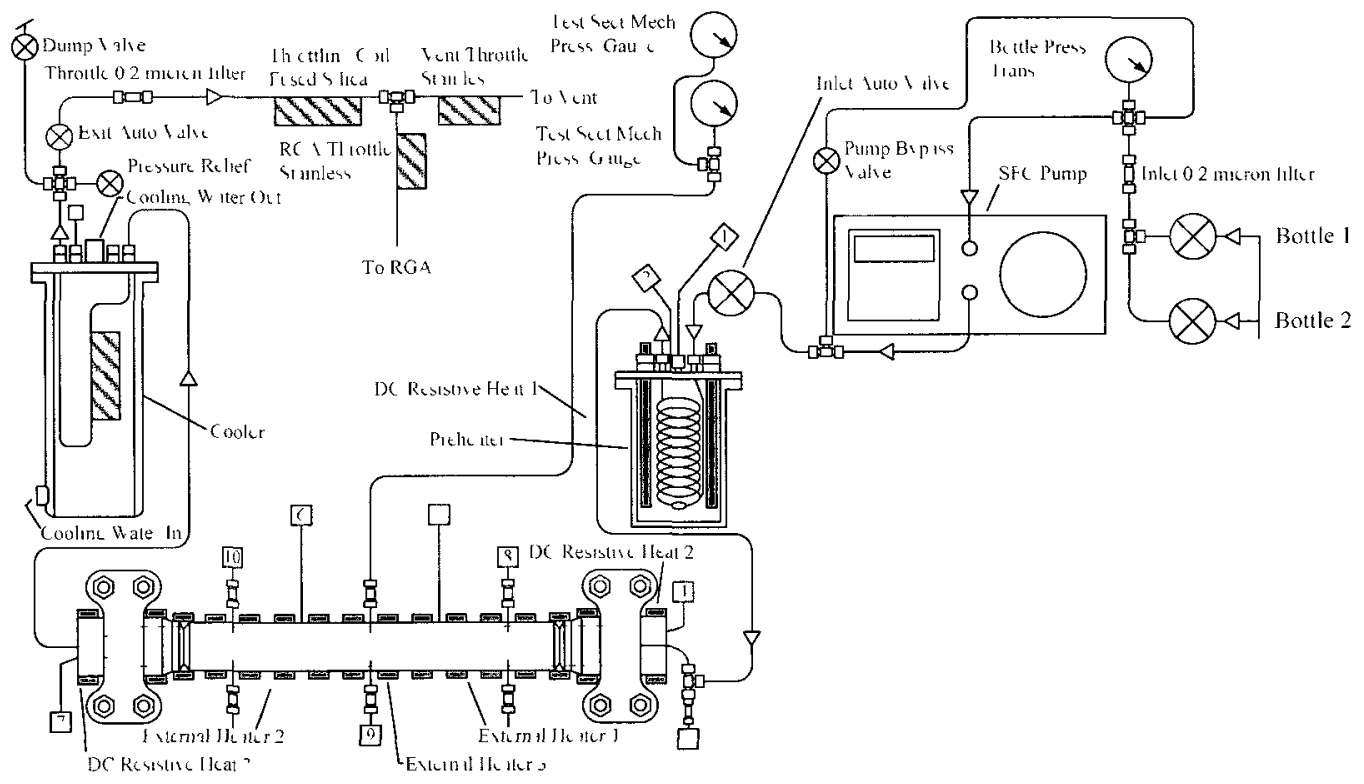

Figure 2-31: UW-Madison S-CO $\mathrm{CO}_{2}$ corrosion test rig. Adapted from [36]

The most recent high temperature, $\mathrm{S}-\mathrm{CO}_{2}$ corrosion test rig was fabricated by the CEA to support ongoing French research dedicated to the SFR [37]. Specimens were placed in a $1.0 \mathrm{~L}, 316 \mathrm{~L}-\mathrm{SS}$, agitated pressure vessel that could withstand $25.0 \mathrm{MPa}$ at $550^{\circ} \mathrm{C}$. Figure $2-32$ provides a schematic of this very modest, static test rig, whose only recorded variable was the temperature within the vessel.

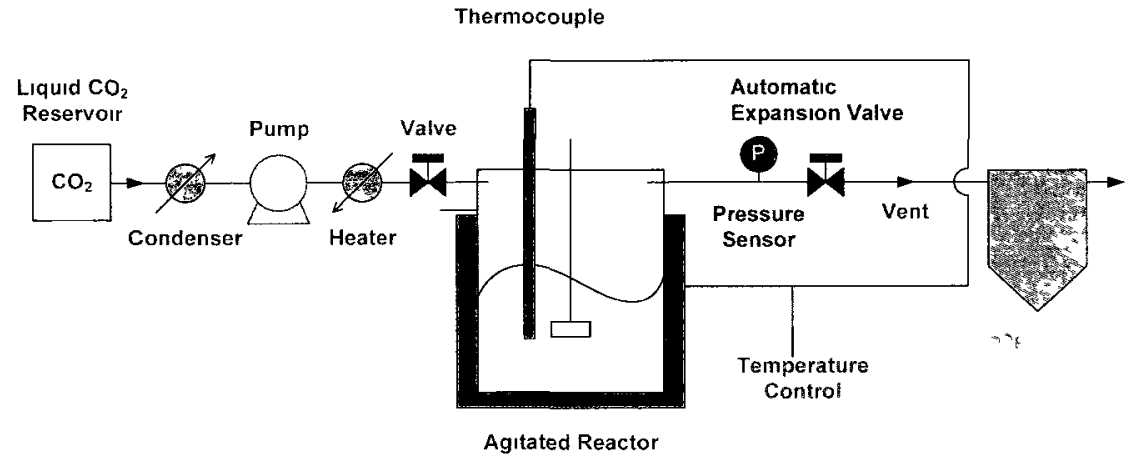

Figure 2-32: $\mathrm{CEA} \mathrm{S}-\mathrm{CO}_{2}$ corrosion test rig [78] 


\subsection{Methods of Corrosion Analysis}

Numerous analytical techniques can be employed both to measure the growth rate of the corrosion product as well as to characterize its structure and composition. While electrochemical methods are viable at high temperatures, a change in specimen mass is frequently used instead to assess reaction kinetics [66]. Additionally, the limitations presented by optical microscopy, such as the maximum attainable resolution and inability to generate elemental maps, are overcome with electron microscopy and electron- or ionbased spectroscopy [79]. This section will therefore outline aspects relating to gravimetric analysis as well as spatially resolved and surface analysis techniques.

\subsubsection{Gravimetric Analysis}

Gravimetric analysis can be performed either in-situ or ex-situ of the corrosion test environment, with obvious advantages to each approach. In-situ mass gain measurements provide the most accurate representation of reaction kinetics but, unsurprisingly, are expensive and usually less applicable to longer exposure times and at higher pressures $[47,53,66]$. A single specimen is suspended from a delicate silica fibre or platinum wire which in turn is attached to a continuous-recording microbalance. Moreover, an inert shielding gas of equal or slightly greater pressure than the test chamber must be used to protect the microbalance against corrosion [47,53]. In contrast, ex-situ measurements require minimal premeditative effort to carry out and allow multiple specimens to be tested simultaneously. Since specimens must be removed from the test chamber to be weighed, mass gain data is discontinuous and possibly erroneous if 
the thermal shock imposed on the specimens affects the stability of their corrosion product [66].

\subsubsection{Microscopic and Spectroscopic Analyses}

Lateral resolutions as low as $1.0 \mathrm{~nm}$ can be achieved with a scanning electron microscope (SEM), which uses a thermally-generated electron beam, under vacuum, to raster scan the surface of the specimen [79]. Figure 2-33 depicts the resultant electron and radiation emissions following the interaction of this incident electron beam with the surface. Typically, backscattered and secondary electrons energies are detected, amplified, and used in conjunction with a cathode ray tube to produce a topographical or cross-sectional image of the specimen $[79,80]$. These images can then be used to examine the morphology and total thickness of the oxide layer, in addition to the mode (e.g. uniform or intergranular) of corrosive attack.

Fitted with the appropriate detectors, the SEM can also perform Auger electron spectroscopy (AES) or X-ray photoelectron spectroscopy (XPS) concurrent to the imaging process. Both of these spectroscopic analyses have very limited depth resolution or penetration but can provide invaluable compositional information (i.e. the oxidation state of detected elements) of what is being viewed. Secondary ion mass spectroscopy (SIMS) is often used when a more precise surface characterization of the corrosion product is required. Ion sputtering replaces the electron beam and elemental mass concentrations are determined either on the surface or as a function of profile depth $[47,80]$. 


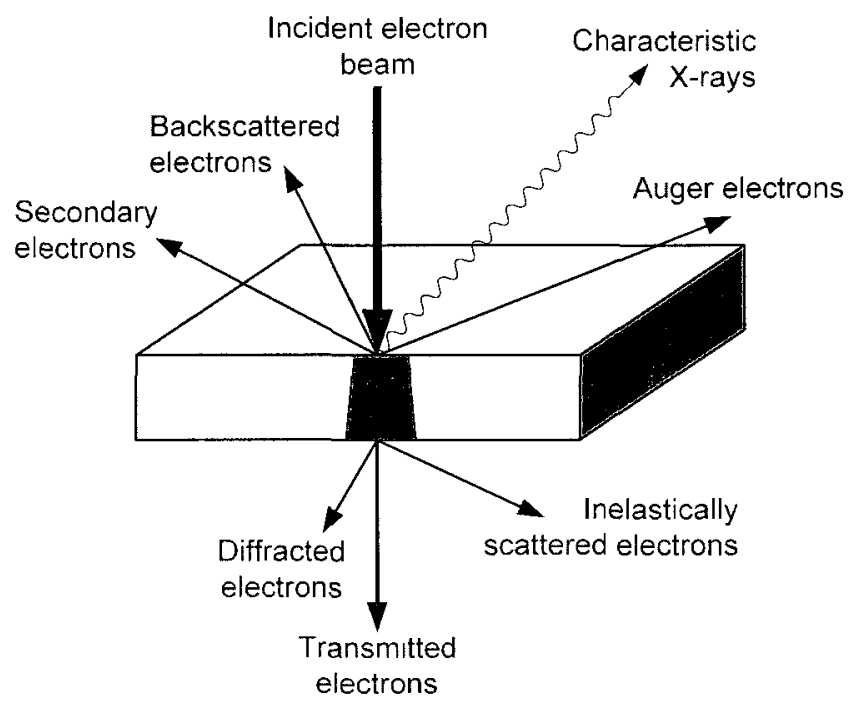

Figure 2-33: Surface interaction with an incident electron beam [47]

\subsection{Metallic Corrosion in High Temperature $\mathrm{CO}_{2}$ Environments}

Prior to the realization of the $\mathrm{S}-\mathrm{CO}_{2}$ Brayton cycle, the British AGR program was essentially the only motivating force for high temperature, $\mathrm{CO}_{2}$ corrosion testing. Fittingly, this testing was aimed to investigate the corrosion resistance of proposed superheater and fuel cladding materials - ferritic and austenitic stainless steels - at $\mathrm{CO}_{2}$ pressures up to 5.3 $\mathrm{MPa}$. While these tests helped to qualify the oxidation kinetics of steels in high temperature $\mathrm{CO}_{2}$, they could not substantiate whether similar behaviour would be observed at higher (supercritical) pressures and with nickel-base superalloys; such was the basis for the $\mathrm{S}-\mathrm{CO}_{2}$ corrosion test facilities presented in Section 2.3.2.1. This section will briefly review high temperature, $\mathrm{CO}_{2}$ corrosion studies conducted at both at subcritical and supercritical pressures. 


\subsubsection{Subcritical Pressure}

Corrosion studies carried out as part of the AGR nuclear program affirmed that the chromium content of an alloy was perhaps the most influential factor in determining its resistance to $\mathrm{CO}_{2}$ attack. Ferritic and austenitic steels were exposed to $\mathrm{CO}_{2}$ up to $700^{\circ} \mathrm{C}$ and 5.3 $\mathrm{MPa}$ and the morphology, kinetics, and composition of the resultant oxide layer(s) were examined. For chromium content characteristic of ferritic stainless steels (i.e. below $12 \%$ ), a Cr-partitioned, duplex oxide layer formed, consisting of a magnetite $\left(\mathrm{Fe}_{3} \mathrm{O}_{4}\right)$ outer layer and chromite spinel $\left(\mathrm{FeCr}_{2} \mathrm{O}_{4}\right)$ substratum [27-31]. This duplex oxide structure is shown in Figure 2-34. The growth mechanism of the $\mathrm{FeCr}_{2} \mathrm{O}_{4}$ substratum the rate controlling oxidation process [29] - was a result of the inward diffusion of the oxidant, opposite to the outward diffusion of $\mathrm{Fe}$ needed to sustain to the $\mathrm{Fe}_{3} \mathrm{O}_{4}$ layer. However as Figure 2-35 indicates, these steels became increasingly susceptible to breakaway oxidation above $550^{\circ} \mathrm{C}(823 \mathrm{~K})$, following a period of protective and then transitive behaviour; the incubation time to the onset of breakaway oxidation decreased predominately with increasing temperature, although surface finish, specimen geometry, prior cold working, and silicon content also had some effect [27,28].

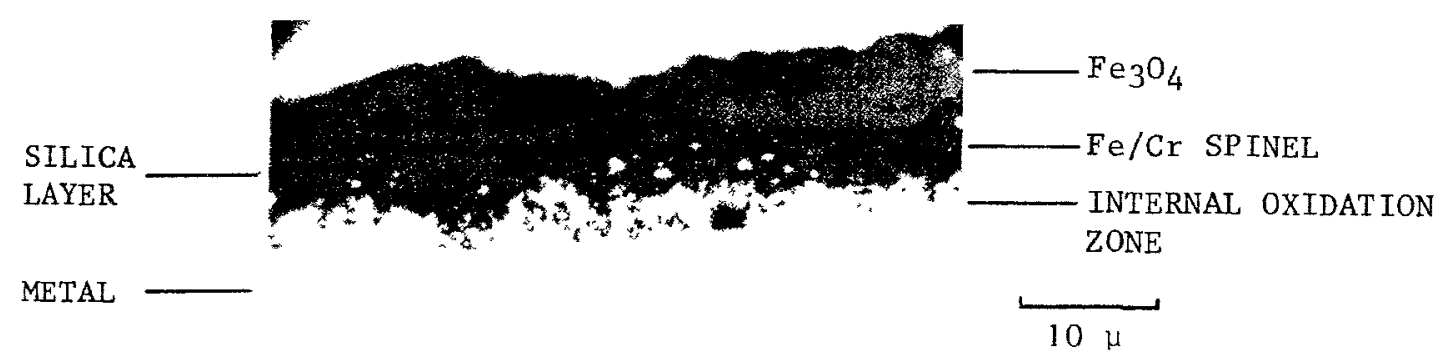

Figure 2-34: Multi-layered oxide $\left(\mathrm{Fe}_{3} \mathrm{O}_{4}\left|\mathrm{SiO}_{2}\right| \mathrm{FeCr}_{2} \mathrm{O}_{4}\right)$ that formed on a ferritic stainless steel following 1060 hour exposure to $\mathrm{CO}_{2}$ at $520^{\circ} \mathrm{C}$ and $4.0 \mathrm{MPa}$ [31] 


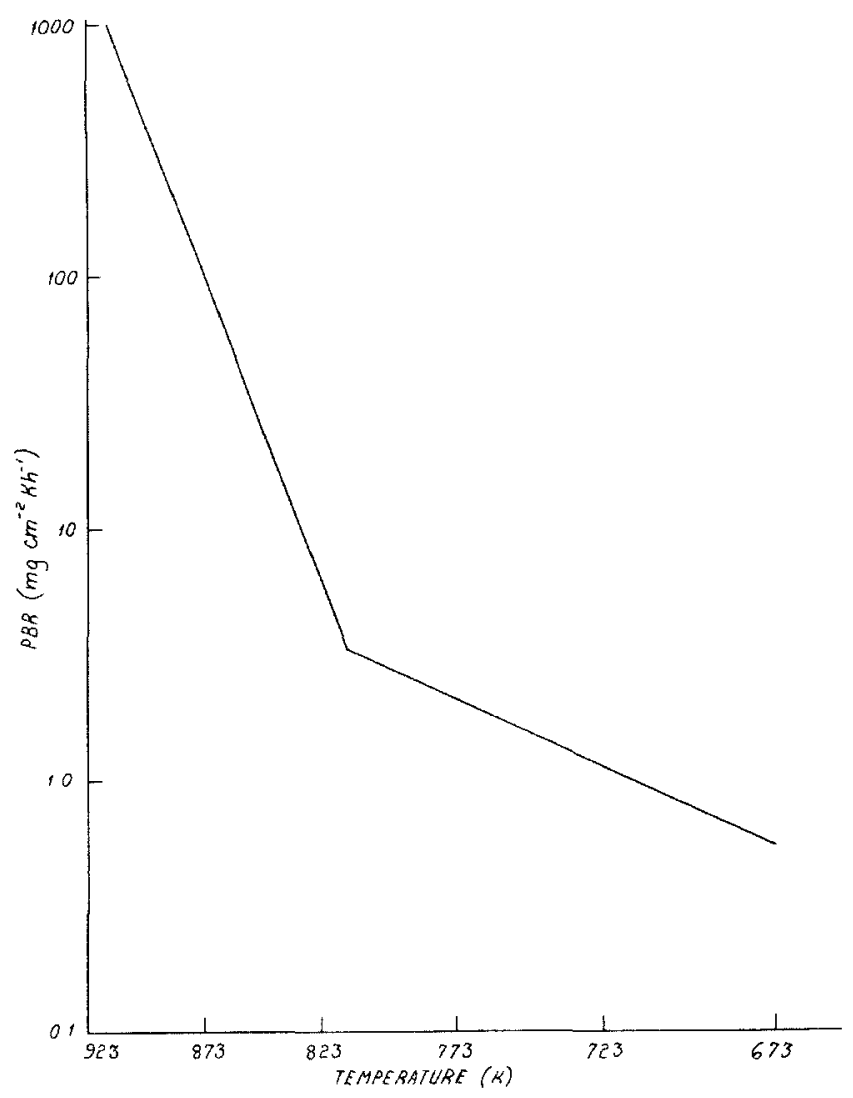

Figure 2-35: Post-breakaway oxidation rate as a function of temperature [27]

Breakaway oxidation was attributed to the underlying metal becoming saturated with carbon, to the point that oxide grains were encapsulated by carbides or graphite and, as a result, removed any adherence between the oxide and metal [29]. Furthermore, the vacancies left in the ferritic matrix by chromium depletion created new short-circuit diffusion pathways to the oxide-gas interface, increasing the overall oxidation rate. Higher levels of $\mathrm{CO}$ in the ambient atmosphere were also found to be conducive to breakaway oxidation because of the increase in carbon activity and hence tendency for carburization [28]. With chromium content above $18 \%$, austenitic stainless steels were disposed to form continuous, $\mathrm{Cr}_{2} \mathrm{O}_{3}$ oxide layers, in addition to the aforementioned 
duplex oxide structure. Unlike their ferritic counterparts though, these steels were unreceptive to breakaway oxidation and their higher chromium content conferred a 'selfhealing' feature to the oxide, if damaged [32].

While limited in number, similar corrosion studies were also conducted using pure nickel [81] and nickel-base superalloys [26]. As expected, pure nickel performed poorly between 700 and $1100^{\circ} \mathrm{C}$, relative to the superalloys, due to its inability to form $\mathrm{Cr}$ - or Al-based oxide layers. At lower temperatures, the corrosion resistance of nickel-base superalloys in $\mathrm{CO}_{2}$ was comparable to that of austenitic stainless steels, although the former seemed to be more affected by internal oxidation. Nevertheless, Hastelloy X appeared, at the time, to be the most stable of all the superalloys in $\mathrm{CO}_{2}$, albeit this was prior to 1976 [26]. Recent work has also shown IN-617 to have a propensity for intergranular attack in $\mathrm{CO}_{2}$ but only at extreme temperature; i.e., $1000^{\circ} \mathrm{C}$ [11]. Figure 2-36 illustrates the ingress of corrosion product into the base metal after 175 hours of testing, suggesting that long-term material stability may eventually be compromised.

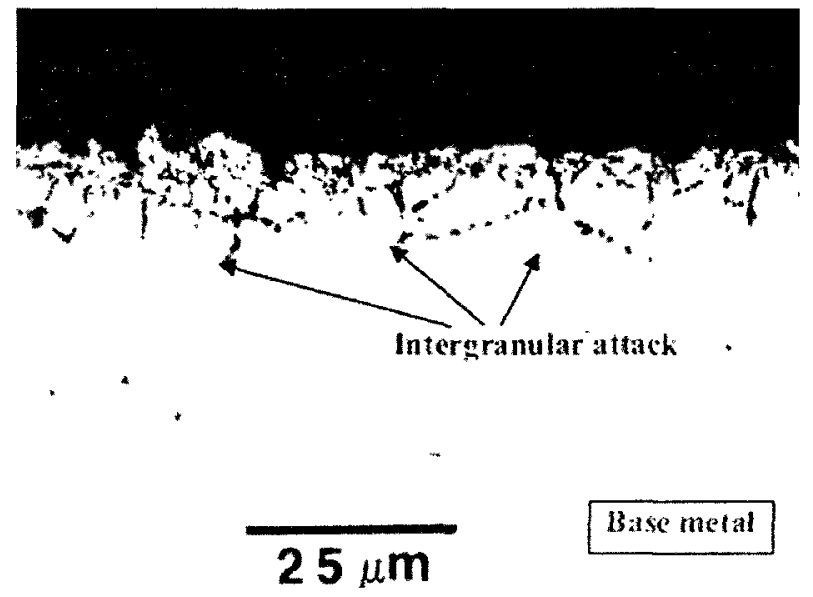

Figure 2-36: Intergranular attack of IN-617 following 175 hour exposure to $\mathrm{CO}_{2}$ at $1000^{\circ} \mathrm{C}$ and $7.0 \mathrm{MPa}$ [11] 


\subsubsection{Supercritical Pressure}

While testing in the high temperature, $\mathrm{S}-\mathrm{CO}_{2}$ regime is still in its infancy, early results would suggest that the larger pressures have a relatively minor influence on corrosion behaviour. Hejzlar et al. [76] liken this to the fact that the density of $\mathrm{CO}_{2}-$ which determines the solubility and dissociation of both corrosive species and subsequent corrosion products - does not markedly increase with pressure at temperatures so far above its critical point $\left(31.03^{\circ} \mathrm{C}\right.$ and $\left.7.38 \mathrm{MPa}\right)$. Additionally, austenitic steels $-304-\mathrm{SS}$ and 316-SS - tested at temperatures nearer the critical point of $\mathrm{CO}_{2}$, where density is the greatest, showed no discernable evidence of corrosion, even with significant impurity (water, methanol, or sulphur) content added [23-25]. Table 2-3 summarizes the various test conditions (e.g. pressure, temperature, and duration) used by researchers with the high temperature, $\mathrm{S}-\mathrm{CO}_{2}$ corrosion facilities described in Section 2.3.2.1.

Much of what was learnt from the AGR program regarding the surface response of ferritic and austenitic stainless steels to $\mathrm{CO}_{2}$ exposure is equally applicable at supercritical pressures. Ferritic stainless steels - 410J3-SS, F91, HCM12A, HT-9, and T91 - exhibited the same breakaway oxidation behaviour due to their inability to form a continuous $\mathrm{Cr}_{2} \mathrm{O}_{3}$ layer and susceptibility to carburization [33-37]. Apart from the silica inner layer, Figure 2-37 shows a near identical $\mathrm{Fe}_{3} \mathrm{O}_{4}$-chromite spinel, duplex oxide morphology to that which was depicted in Figure 2-34. In fact, $\mathrm{S}-\mathrm{CO}_{2}$ corrosion tests that included ferritic stainless steels were intentionally limited to below 500 hours to minimize the extent of spallation and avoid potential cross-contamination with other specimens. 
Table 2-3: Test conditions used for high temperature, $\mathrm{S}-\mathrm{CO}_{2}$ corrosion studies

\begin{tabular}{|c|c|c|c|c|c|}
\hline \multirow{3}{*}{ Researcher } & \multirow{3}{*}{ Institution } & \multicolumn{3}{|c|}{ Test Conditions } & \multirow{3}{*}{ Ref. } \\
\hline & & Pressure & Temperature & Duration & \\
\hline & & (MPa) & $\left({ }^{\circ} \mathrm{C}\right)$ & (hrs) & \\
\hline Oh et al. & INL & $7.0 / 10.0$ & 1000 & 500 & [11] \\
\hline \multirow{4}{*}{ Furukawa et al. } & \multirow{4}{*}{$\begin{array}{c}\text { Tokyo } \\
\text { Institute of } \\
\text { Technology } \\
\text { and JAEA }\end{array}$} & \multirow{4}{*}{20.0} & 400 & \multirow{4}{*}{1991} & \multirow{4}{*}{ [33] } \\
\hline & & & 500 & & \\
\hline & & & 550 & & \\
\hline & & & 600 & & \\
\hline L1 et al. & \multirow{8}{*}{ MIT } & 12.8 & 660 & 230 & [76] \\
\hline \multirow{3}{*}{ Dunlevy } & & 20.0 & 714 & \multirow{2}{*}{500} & \multirow{3}{*}{ [38] } \\
\hline & & \multirow{2}{*}{12.5} & 650 & & \\
\hline & & & 750 & 1000 & \\
\hline Gibbs & & 20.0 & 610 & 3000 & [34] \\
\hline \multirow{3}{*}{ Lim et al. } & & 12.5 & \multirow{3}{*}{650} & 230 & \multirow{3}{*}[35]{} \\
\hline & & 12.0 & & 1032 & \\
\hline & & 22.0 & & 194 & \\
\hline Sridharan et al. & UW-Madison & 20.7 & 650 & 3000 & [36] \\
\hline Roulllard et al. & CEA & 25.0 & 550 & 310 & [37] \\
\hline
\end{tabular}

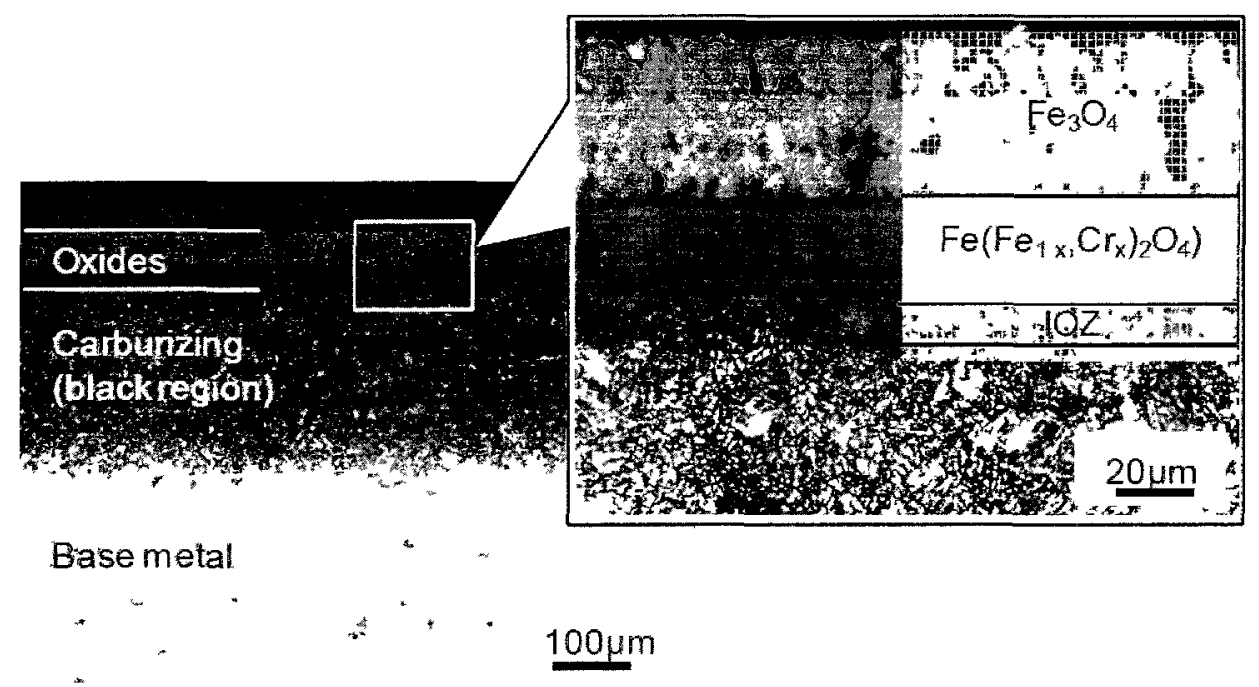

Figure 2-37: Characterization of 410J3-SS oxide structure following 1000 hour exposure to $\mathrm{S}-\mathrm{CO}_{2}$ at $600^{\circ} \mathrm{C}$ and $20.0 \mathrm{MPa}$ [33] 
Excluding 316/316L-SS, austenitic stainless steels - 310-SS, 800/800H, and AL-6XN - had mass gains that were indistinguishable from most of the nickel-base superalloys examined [34,36]. Figure 2-38 plots the cumulative mass gains for these steels as well as the other alloys tested at UW-Madison. The poor corrosion performance of $316 / 316 \mathrm{~L}-\mathrm{SS}$ above $650^{\circ} \mathrm{C}$, while not as severe as what was observed with the ferritic stainless steels, was again ascribed to oxidant eventually permeating through the duplex oxide layer and reacting with the chromium-depleted, austenite matrix. Seemingly counterintuitive, the corrosion rate of $316 / 316 \mathrm{~L}-\mathrm{SS}$ was also found to decrease with increasing temperature - from $0.11 \mathrm{mg} / \mathrm{cm}^{2}$.day at $650^{\circ} \mathrm{C}$ to $0.06 \mathrm{mg} / \mathrm{cm}^{2} \cdot$ day at $750^{\circ} \mathrm{C}$ [38]. At higher temperatures, the lattice diffusivity of chromium within this alloy was believed to increase, allowing for the formation of an underlying chromite spinel layer to occur much sooner [76].

Ten nickel-base superalloys constitute the preliminary high temperature, $\mathrm{S}-\mathrm{CO}_{2}$ corrosion database that has been openly established for this class of high-performance material: IN-625, IN-690, IN-693, IN-718, IN-725, IN-740, IN-740+, Haynes 230, MA754, and PE-16. With sufficient chromium content to promote the growth of a thin, external $\mathrm{Cr}_{2} \mathrm{O}_{3}$ layer, all of these superalloys displayed excellent corrosion resistance and consistency amongst one another [34,36,38]. The slight differences in mass gain that were noted correlated directly to the $\mathrm{Al}$ content of the alloy - the growth of a $\mathrm{NiAl}_{2} \mathrm{O}_{4}$ substratum or continuous $\mathrm{Al}_{2} \mathrm{O}_{3}$ external layer both served as a more effective barrier to the outward diffusion of cations than a $\mathrm{Cr}_{2} \mathrm{O}_{3}$ oxide layer could alone. 


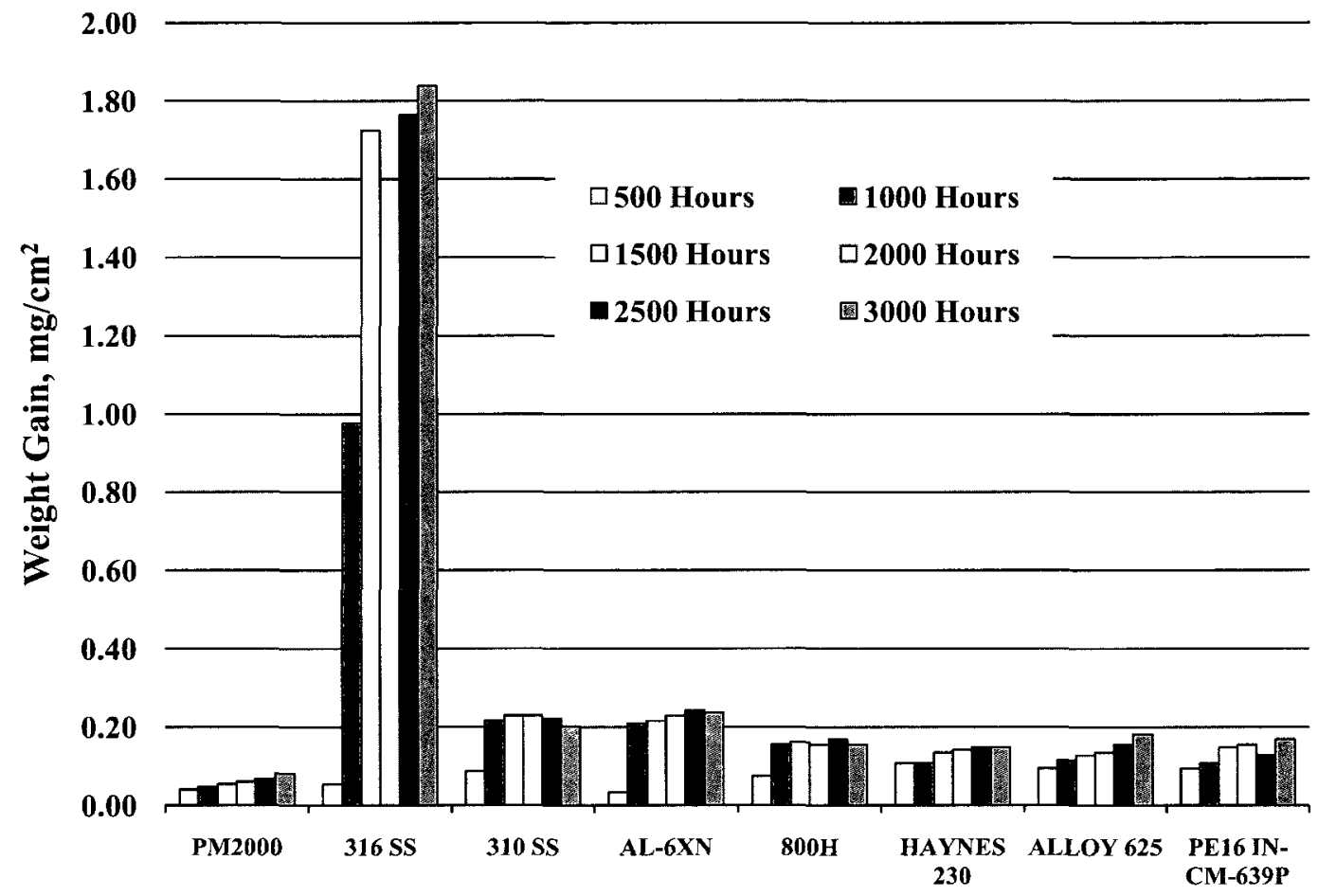

Figure 2-38: Cumulative mass gains of various alloys following a 3000 hour exposure to $\mathrm{S}-\mathrm{CO}_{2}$ at $650^{\circ} \mathrm{C}$ and $20.7 \mathrm{MPa}$ at UW-Madison. Reproduced from [36]

Figure 2-39 shows the cumulative mass gains for the various nickel-base superalloys tested at MIT by Dunlevy [38]. For select materials (IN-718 and IN-725), samples were also cut parallel to the rolling direction of the supply stock, under the assumption that exposed end grains (EG) would facilitate the uptake of oxidant and result in increased corrosion rates; however, the formation of a protective oxide layer was likely so quick that these short-circuit diffusion pathways were covered over almost immediately. Similarly, no connection between pressure and corrosion behaviour was firmly established - in some instances the increase in pressure at higher temperature appeared to suppress oxidation but the variance in test data at $650^{\circ} \mathrm{C}$ was too large to corroborate this. Protrusions from the external oxide layer indicated that transitional 
elements in the alloy $(\mathrm{Nb}, \mathrm{Ti}$, and $\mathrm{Zr}$ ), in addition to $\mathrm{Cr}$, were also diffusing to the surface and forming carbides. While these carbide precipitates had no bearing on the stability of the oxides in this study, Dunlevy [38] suggested that they could serve as eventual sites for crack initiation within the oxide layer.

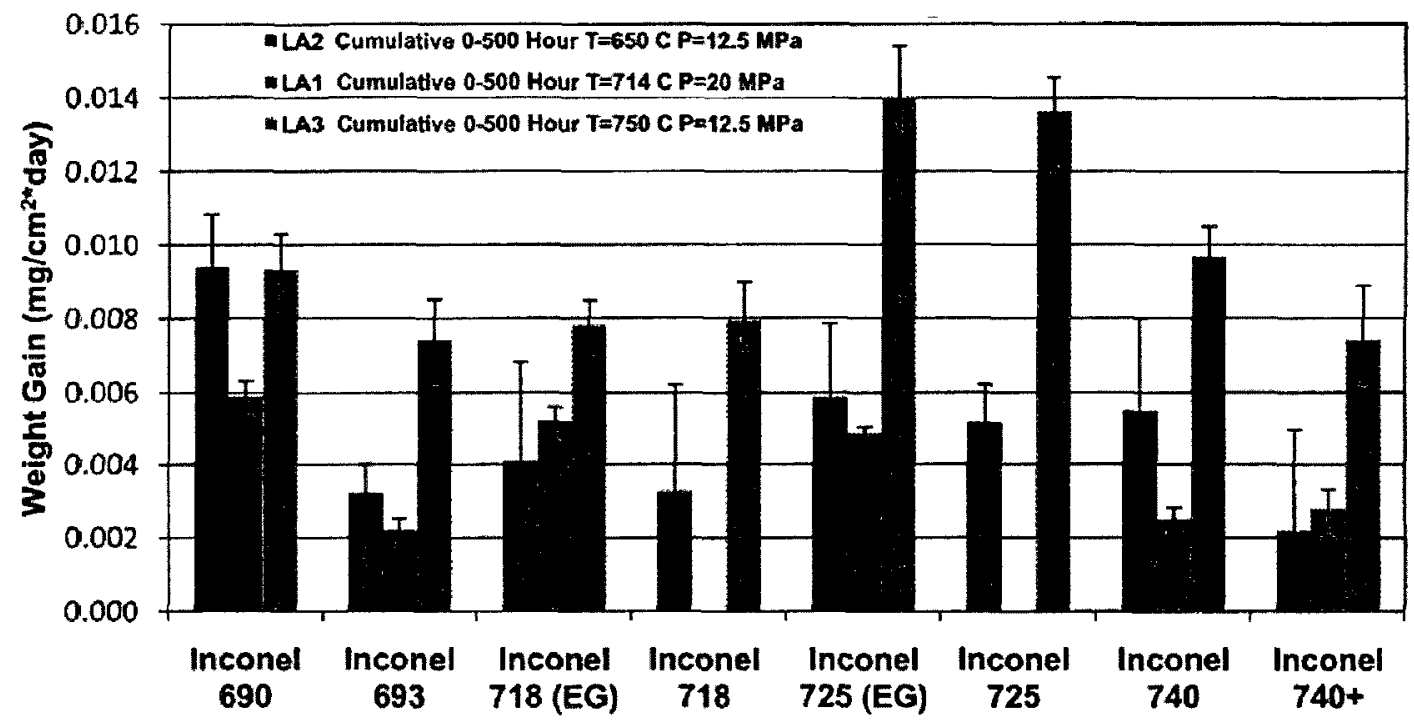

Figure 2-39: Cumulative mass gains of nickel-base superalloys following exposure to $\mathrm{S}-\mathrm{CO}_{2}$ at various test conditions [38]

Lastly, iron-base, oxide-dispersion strengthened (ODS) alloys, and particularly those with high Al content (MA957 and PM2000), demonstrated superior corrosion resistance to even that of the nickel-base superalloys; an adherent but wavy $\mathrm{Al}_{2} \mathrm{O}_{3}$ layer formed on the surface of these alloys [34-36]. While they seem like a logical choice for the structural materials of a S-CO $\mathrm{CO}_{2}$ Brayton cycle, ODS alloys are currently expensive to process and unfavourable to conventional welding techniques [82]. Until these issues are resolved, nickel-base superalloys represent the best alternative. 


\subsection{Summary}

The foregoing sections emphasize just how complex and potentially disastrous material interaction with a high temperature, $\mathrm{CO}_{2}$ environment can be. Moreover, the reader should now have an appreciation for the current state of corrosion research related to the $\mathrm{S}-\mathrm{CO}_{2}$ Brayton cycle and why the development of a dedicated $\mathrm{S}-\mathrm{CO}_{2}$ corrosion testing facility is justified. Summarized below are the key points that should be taken from this literature review:

1. Multi-step chemical processes allow for the release of $\mathrm{O}$ and $\mathrm{C}$ atoms from a carbon-rich oxidant to initiate and sustain oxidation, carburization, and potentially metal dusting corrosion mechanisms.

2. While limited in number, all the $\mathrm{S}-\mathrm{CO}_{2}$ corrosion facilities that have been built to date utilize a metallic pressure vessel to either contain test specimens or to function as one. Static, once-through, and recirculating configurations have been used.

3. Preliminary results from high temperature, $\mathrm{S}-\mathrm{CO}_{2}$ corrosion studies correlate well with what was observed at subcritical pressure as part of the British AGR nuclear program; i.e., the ability to form a continuous, adherent $\mathrm{Cr}_{2} \mathrm{O}_{3}$ oxide layer is an effective, but not the best, means to protect against $\mathrm{CO}_{2}$ attack.

4. Corrosion rates of nickel-base superalloys and ODS alloys that were able to form $\mathrm{Al}_{2} \mathrm{O}_{3}$-based oxide layers are the lowest of any of the materials studied in high temperature, $\mathrm{S}-\mathrm{CO}_{2}$ environments. 


\section{$3 \quad$ Thesis Objectives and Outline}

This thesis contributes to one of the deliverables identified in an ongoing research partnership between Carleton University and CanmetENERGY of NRCan involving the design of a $100 \mathrm{MW}_{\mathrm{e}}, \mathrm{S}-\mathrm{CO}_{2}$ advanced Brayton cycle. As was noted in the literature review, $\mathrm{S}-\mathrm{CO}_{2}$ corrosion data exists only for a limited number of materials and at specific pressure and temperature combinations - none of which are expected to be identical to the operating conditions of the cycle that results. Thus, to properly fulfil this deliverable and support the selection of suitable materials under relevant test conditions, a dedicated $\mathrm{S}-\mathrm{CO}_{2}$ corrosion test facility is required. Consequently, the main objectives of this thesis include:

1. The comprehensive design and assembly of a high temperature, $\mathrm{S}-\mathrm{CO}_{2}$ corrosion test rig, from the definition of its test conditions to the layout, selection, and procurement of its components.

2. Commissioning this test rig through calibration trials and baseline operation to fully understand and optimize its operation.

These objectives purposely coincide with what is necessary to see the development of such a corrosion test rig to completion. In the two chapters to follow, both objectives will be discussed in greater detail. 


\section{Design of the Carleton-NRCan S-CO $\mathrm{O}_{2}$ Corrosion Test Rig}

From the outset of its design, the Carleton-NRCan $\mathrm{S}-\mathrm{CO}_{2}$ corrosion test rig was to offer a testing envelope that, at the very least, matched the pressure and temperature capabilities established at MIT and UW-Madison. While safety considerations would ultimately influence the final design of this test rig, low implementation costs and a high level of usability were also regarded as important design criteria. This section first states the requirements of the Carleton-NRCan $\mathrm{S}-\mathrm{CO}_{2}$ corrosion test rig and details such fundamental components as the pressure vessel, pump, furnace, integrated safety features, and specimen boat. The rationale behind how these and other auxiliary components were arranged to form this test rig is then elucidated.

\subsection{Design Criteria}

Summarized below in bullet form are the compulsory design requirements of the Carleton-NRCan S- $\mathrm{CO}_{2}$ corrosion test rig:

- A primary operating point of $25.0 \mathrm{MPa}$ at $700^{\circ} \mathrm{C}$, with potential to test as high as $750^{\circ} \mathrm{C}$ but only at $15.0 \mathrm{MPa}$;

- The capability to sustain a continuous $\mathrm{CO}_{2}$ flowrate of at least $1.0 \mathrm{~L} / \mathrm{hr}$ (at standard conditions) and allow for intermittent static periods;

- Near-autonomous operation during testing;

- A pressure vessel that could readily accommodate test specimens with a maximum cross-sectional diameter of $12.7 \mathrm{~mm}(0.5 \mathrm{in}$.) and do so without restricting flow; 
- The use of $\mathrm{CO}_{2}$ whose purity is close to or above $99.9 \%$;

- A method of specimen support that itself would be unreceptive to corrosion and relatively inert, so as to not serve as a catalyst for any chemical reaction;

- The incorporation of both passive and active safety systems to protect against and quickly remedy any inadvertent overpressurization or thermal runaway;

- All applicable components to be registered with the Technical Standards and Safety Authority (TSSA) in Ontario as pressure-retaining devices.

\subsection{Pressure Vessel}

The proposed operating conditions of this test rig removed the applicability of any commonly available pressure vessel and demanded that one be custom designed and fabricated from a suitable, high temperature material. Figure 4-1 shows maximum allowable stress versus temperature curves of three nickel-base superalloys - IN-617, IN-625, and Haynes 230 - initially considered for the construction material of the pressure vessel; for comparison, 316-SS is also included to exhibit its rapid deterioration of mechanical properties above $550^{\circ} \mathrm{C}$. Despite all three candidate nickel-base superalloys having comparable strengths above $700^{\circ} \mathrm{C}, \mathrm{N}-625$ was selected as the pressure vessel body material because of its recent (but favourable) service experience at MIT $[34,38]$ and UW-Madison [36] with high temperature $\mathrm{S}-\mathrm{CO}_{2}$. Much like those used in prior $\mathrm{S}-\mathrm{CO}_{2}$ corrosion test rigs, this pressure vessel was to be tubular in shape, however an ID larger than $12.7 \mathrm{~mm}$ (0.5 in.) suggested that round bar stock would need to be bored through to give the minimum required wall thickness. 


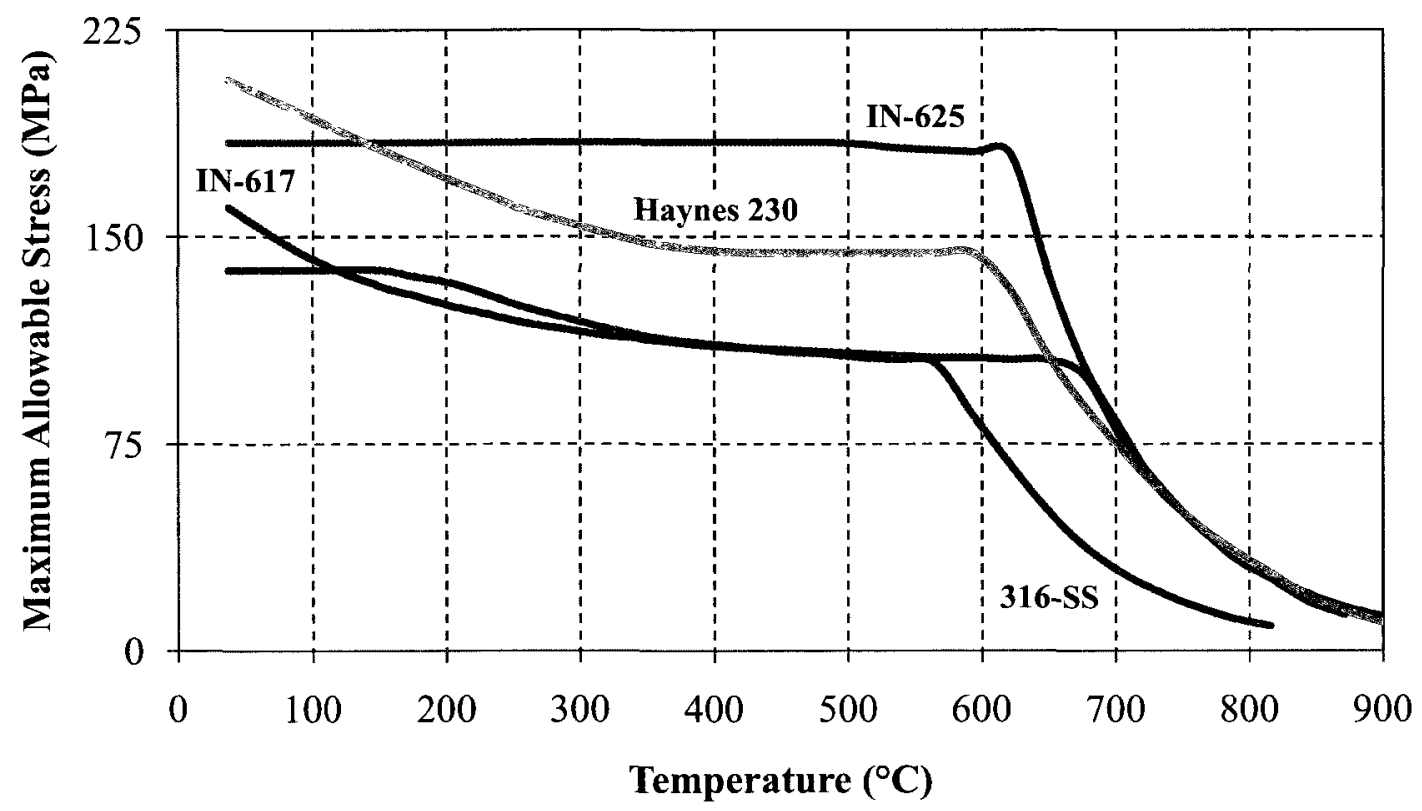

Figure 4-1: Stress-temperature curves for pressure vessel material candidates. Generated with ASME data provided by Moore [83]

Initial sizing calculations were performed in accordance to the ASME B31.3-2008 Process Piping standard and later verified by Moore [84] at Pressure Vessel Engineering Ltd. of Waterloo, Ontario for Canadian Registration Number (CRN) designation. Given the two proposed operating conditions, design points of $29.41 \mathrm{MPa}$ at $750^{\circ} \mathrm{C}$ and $17.65 \mathrm{MPa}$ at $800^{\circ} \mathrm{C}$ were chosen for the pressure vessel, with its final crosssectional geometry based on whichever condition represented the limiting case. For each point, the design pressure was equated to the burst pressure of the rupture disks; similarly, design temperatures were made $50^{\circ} \mathrm{C}$ higher than their respective operating temperatures - as determined from simulations conducted by Schuegraf [85] - to account for the higher furnace set points that would be needed to offset heating losses. Moreover, considering the very nature of this facility, a conservative corrosion allowance of 
$6.35 \mathrm{~mm}(0.25 \mathrm{in}$.) was also applied to the bore of the vessel. Failure of the pressure vessel would inevitably be dictated by its circumferential stress, and thus the minimum required wall thickness $\left(t_{\min }\right)$ was calculated from:

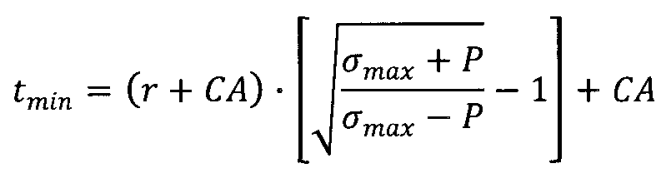

where $\mathrm{CA}$ and $\sigma_{\max }$ denote the specified corrosion allowance and temperature-dependent yield stress, respectively. With a fixed ID of $25.4 \mathrm{~mm}(1.0 \mathrm{in}$.), an OD of $88.9 \mathrm{~mm}$ (3.5 in.) was found to provide an acceptable wall thickness for both operating conditions. Figure 4-2 depicts the anticipated operating pressure and the maximum internal pressure this vessel can withstand at metal temperatures ranging from 650 to $875^{\circ} \mathrm{C}$, inclusively.

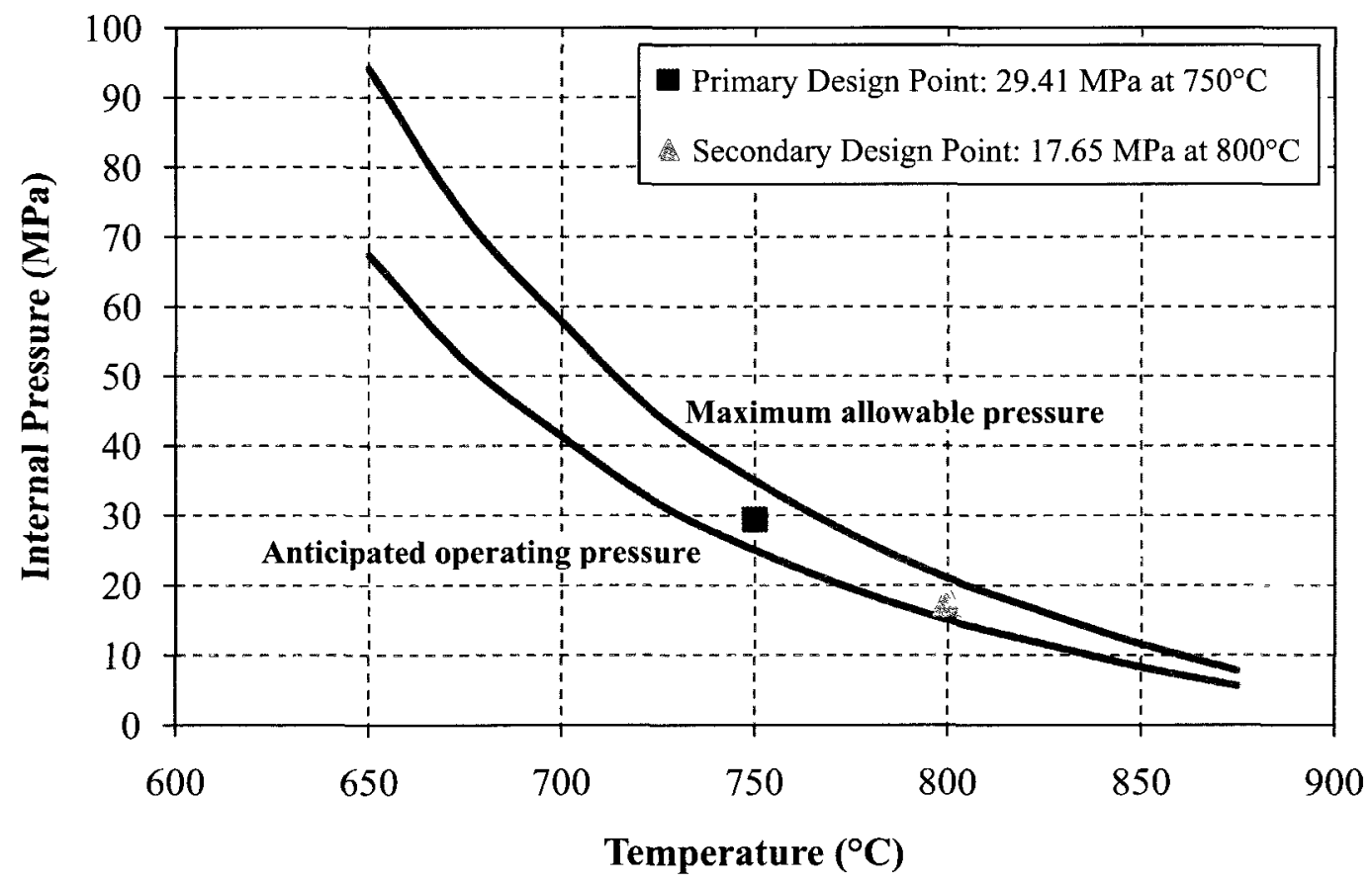

Figure 4-2: Maximum allowable internal pressure-metal temperature curve for the pressure vessel as per the ASME B31.3-2008 Process Piping code 
Both ends of the pressure vessel were sealed using 316-SS Grayloc $\AA$ connectors (CRN: 0B2790.5), each of which consisted of three components: (i) accompanying 3-GR20 blind hubs; (ii) a 2-1/2-3 clamping assembly; and (iii) a polytetrafluroethylene (PTFE)-coated, GR20 sealing ring. One 3-GR20 hub was welded to either end of the IN-625 section with its complement serving as the closure to the pressure vessel. The 2-1/2-3 clamping assembly brought both hub faces together as it was tightened, causing the GR20 sealing ring to elastically deform and conform to the shrinking cavity between them. A schematic of this metal-to-metal sealing arrangement is illustrated in Figure 4-3 and deemed an improvement over the carbon steel bolts used by MIT to retain their seal.

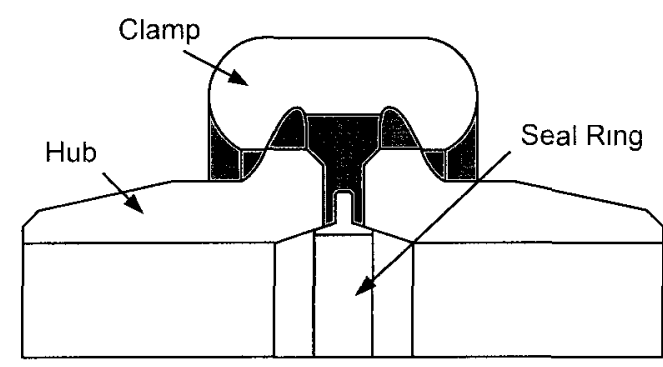

Before Tightening

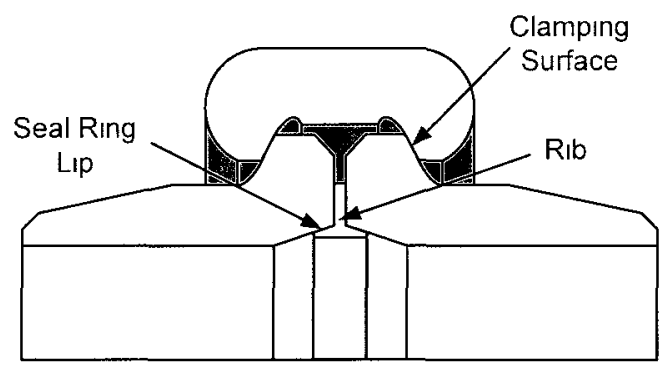

After Tightening

Figure 4-3: Grayloc $®$ connector prior to (left) and following (right) tightening. Adapted from [87]

To assist in determining an appropriate length for the IN-625 section, a thermal analysis of the entire vessel was also carried out by Moore [84] of Pressure Vessel Engineering Ltd. using Finite Element Analysis (FEA) software. The intention was to use the superior, high temperature properties of IN-625 to dissipate as much heat as possible - via free convection and radiative heat transfer mechanisms - before interfacing 
with the 316-SS hubs. As a result, the overall length of the pressure vessel, including the Grayloc ${ }^{\circledR}$ connectors, was $1727.2 \mathrm{~mm}(68.0$ in.), with $1460.5 \mathrm{~mm}(57.5 \mathrm{in}$.$) of that length$ constituted by the IN-625 section. These dimensions, in addition to those pertaining to the cross-section, are summarized below in Figure 4-4. Construction, radiographic inspection of the welds, and finally hydrostatic pressure testing of the vessel were all executed by Price-Schonstrom Inc. in Walkerton, Ontario, allowing it to be registered as a type $\mathrm{H}$ fitting with TSSA (CRN: $0 \mathrm{H} 14040.5)$.

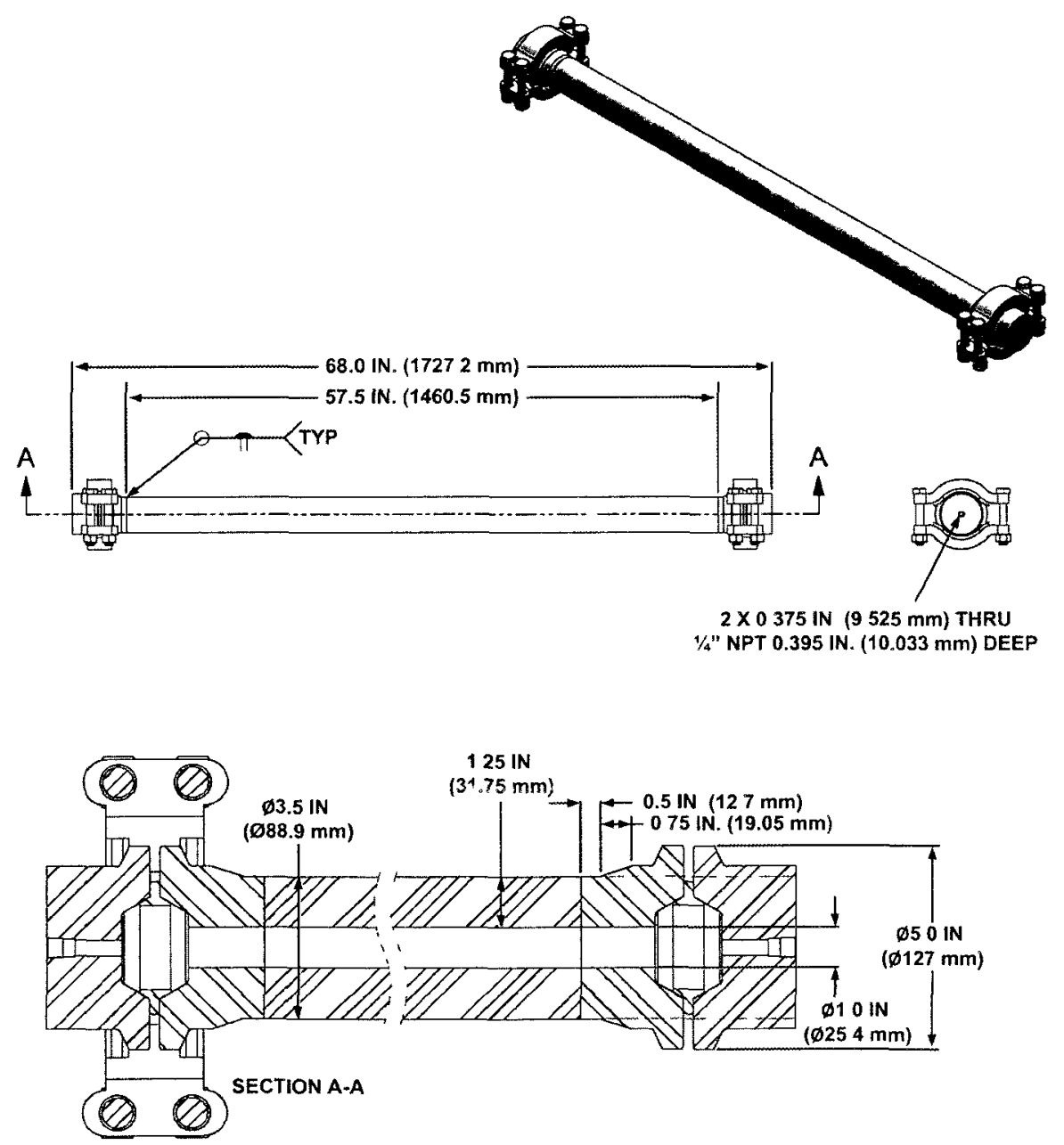

Figure 4-4: Working drawing of the IN-625 pressure vessel [84] 


\subsection{Gas Booster}

Sacrificing precise control over flowrate in favour of minimizing costs, high pressure $\mathrm{CO}_{2}$ was generated using an SC Hydraulic Engineering Corp. GBT-15/30 gas booster rather than a syringe pump. This two stage-double acting gas booster required only compressed air and gas supply sources to operate; hence, the outlet parameters of the booster were governed by its own inherent gas amplification factor and the pressures and flow capacities of these sources. Provided by the manufacturer, an approximate correlation between the compressed air $\left(\mathrm{P}_{\mathrm{A}}\right)$ and gas supply source $\left(\mathrm{P}_{\mathrm{S}}\right)$ pressures needed to produce a particular static outlet stall pressure $\left(\mathrm{P}_{\mathrm{O}}\right)$ was:

$$
P_{O}=30 \cdot P_{A}+2 \cdot P_{S}
$$

Below $\mathrm{P}_{\mathrm{O}}$ though, pressure perturbations were introduced into the outlet gas flow because of the intrinsic reciprocating action of the gas booster. Methods employed to mitigate this problem are discussed as part of the conceptual layout of the test rig in Section 4.7.

\subsection{Furnace}

The pressure vessel was centered within a Thermcraft Inc. XST-6-0-24-3V furnace, whose split-tube design facilitated the initial loading and positioning of the vessel. Three, independently controlled, heated zones gave this furnace a total heated chamber length of $609.6 \mathrm{~mm}(24.0 \mathrm{in}$.) and a cumulative power output of $6800 \mathrm{~W}$; zones 1,2 , and 3 measured $152.4 \mathrm{~mm}$ (6.0 in.), $304.8 \mathrm{~mm}$ (12.0 in.), and $152.4 \mathrm{~mm}$. (6.0 in.) in length, respectively. Figure 4-5 identifies the location of each heated zone and its corresponding Platinel II thermocouple. Temperature set points were inputted to and regulated by a 
Thermcraft Inc. 3-1-40-230-E15SP control system, however were only indicative of the air temperatures inside the heated chamber. The basis of Section 5.2 was therefore to find, through trial and error, the necessary set points of each heated zone that would give - with an approximately uniform distribution - the desired temperature inside the vessel. Upon its reception, the control system was also reconfigured to limit the maximum set point of any heated zone to $800^{\circ} \mathrm{C}$ (in agreement with the maximum design temperature of the pressure vessel).

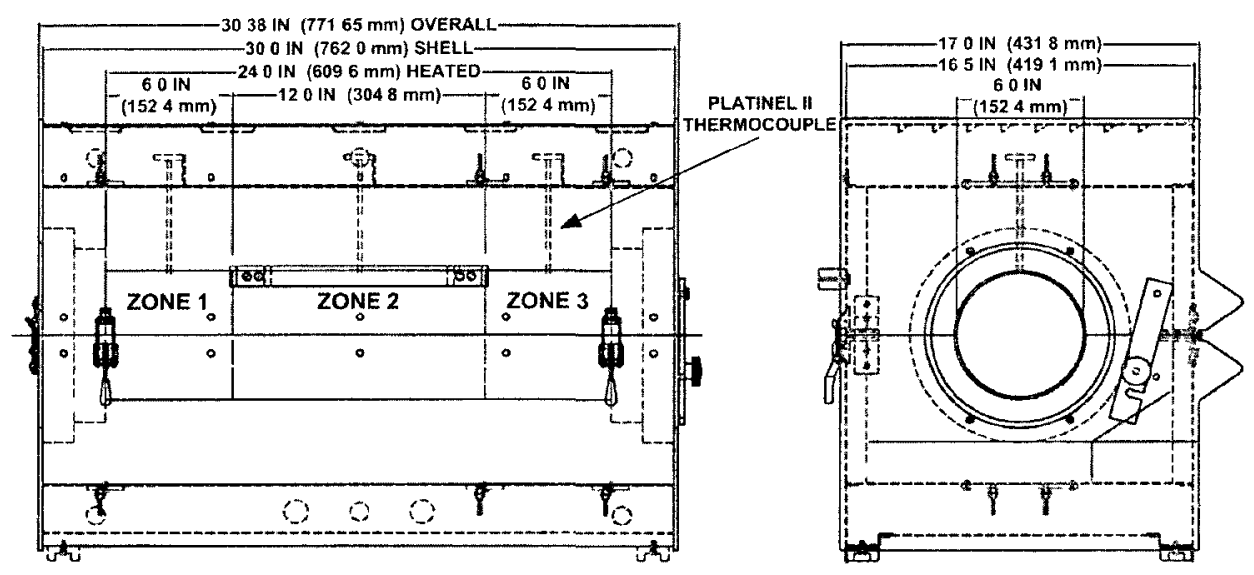

Figure 4-5: Furnace dimensions and heated zone locations

\subsection{Integrated Safety Features}

Again, due to the pressures and temperatures involved in operating this corrosion test rig, the implementation of measures to safeguard the user against serious injury or even death was indisputable. The resulting safety features consisted of several preventative (passive) and protective (active) components, some of which could be interchanged to specifically tailor to each operating condition. This section elaborates on how these safety features influenced the design of the test rig. 


\subsubsection{Passive Elements}

The passive safety elements ensured that the integrity of the corrosion test rig would not be compromised even under the most unexpected of conditions. A conscience effort was made throughout the design process that involved the selection of both tubing and valves whose pressure ratings were still above $29.41 \mathrm{MPa}$ (the higher of the two burst pressures), even at temperatures they would likely never encounter. For example, the $6.35 \mathrm{~mm}(0.25 \mathrm{in}$.) OD tubing that was used extensively throughout the test rig had a wall thickness of $0.89 \mathrm{~mm}(0.035 \mathrm{in}$.), allowing for safe operation at prolonged exposure up to $430^{\circ} \mathrm{C}$. The thicker walls also had the added effect of providing for some corrosion allowance at normal operating temperatures. For an added level of assurance, and to have the test rig registered as a whole with TSSA, components containing pressures above $204.77 \mathrm{kPa}$ (excluding the gas booster and those part of the compressed air system) were required to have a CRN. The CRN denoted that the designs and their specified maximum pressure rating were in fact validated by a regulatory agency.

\subsubsection{Active Elements}

Unlike their passive counterparts, the active safety elements of the test rig were intended to relieve pressure or block all inlet flow to the gas booster. These elements - a safety relief valve (SRV), solenoid valve relay circuit, and rupture disk - comprised the redundant overpressurization protection system represented schematically in Figure 4-6. The activation pressure of each component was purposely chosen such that each was triggered in sequence, rather than simultaneously, with increasing pressure and in order 
of increasing impact on system operation. Accordingly, the relief pressure $\left(\mathrm{P}_{\mathrm{R}}\right)$ was set midway between the operating $\left(\mathrm{P}_{\mathrm{OP}}\right)$ and burst $\left(\mathrm{P}_{\mathrm{B}}\right)$ pressures and, in turn, the relay circuit activation pressure $\left(\mathrm{P}_{\mathrm{RC}}\right)$ was set midway between the relief and burst pressures. Table 4-1 summarizes the magnitudes of each activation pressure at both specified operating points.

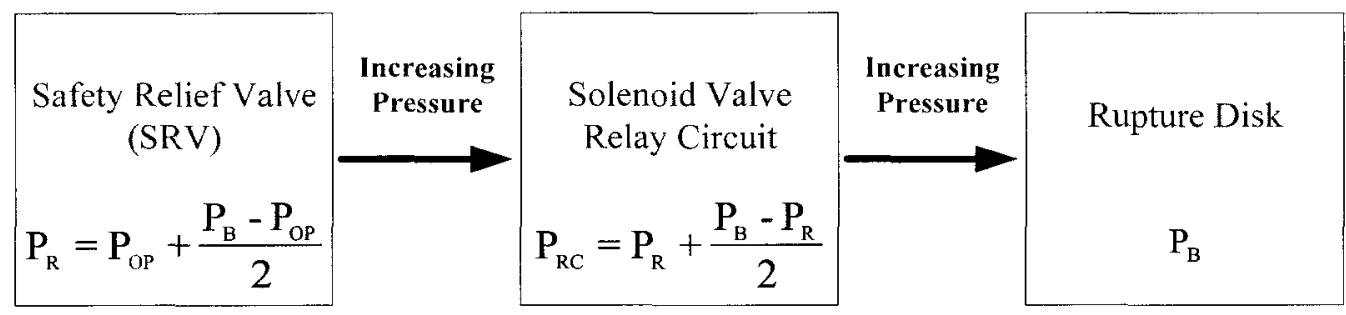

Figure 4-6: Overpressurization protection flowchart

Table 4-1: Activation pressures to remedy an overpressurization

\begin{tabular}{|c|c|c|c|}
\hline \multirow{2}{*}{$\begin{array}{c}\text { Operating } \\
\text { Pressure }\end{array}$} & \multicolumn{3}{|c|}{ Activation Pressure } \\
\cline { 2 - 4 } & $\mathbf{P}_{\mathbf{R}}$ & $\mathbf{P}_{\mathbf{R C}}$ & $\mathbf{P}_{\mathbf{B}}$ \\
\hline $\mathbf{M P a})$ & \multicolumn{3}{|c|}{$\mathbf{( M P a )}$} \\
\hline 25.00 & 27.21 & 28.31 & 29.41 \\
\hline 15.00 & 16.32 & 16.99 & 17.65 \\
\hline
\end{tabular}

Flowsafe Inc. F84-M safety relief valves (CRN: 0G10498.5), the first of the two pressure relieving devices used, were sized according to American Petroleum Institute (API) Recommended Practice 520, Part I [89]. Even with their different set pressures, an orifice area of $1.94 \mathrm{~mm}^{2}\left(0.003 \mathrm{in}^{2}\right)$ in each $316-\mathrm{SS}$ valve was found to provide sufficient flow capacity to atmosphere. Conversely, the 316-SS, SFAZ series rupture disks and their attendant 304-SS, FS-2U holder were purchased from ZOOK Canada Inc. (CRN: 0G8483.5CADD1). At the recommendation of ZOOK, these scored, forward- 
acting disks were produced with a $0 \%$ manufacturing range so that the proposed operating pressures would constitute $85 \%$ of their respective burst pressures. This higher burst tolerance, despite being almost $170 \%$ the cost of a standard model, was specified to ensure that the rupture disk would, in fact, be the last relieving device to activate.

In the event that the SRV failed closed, the solenoid valve relay circuit was designed to isolate the gas booster from its supply feeds; i.e. stop the addition of further $\mathrm{CO}_{2}$ to the corrosion test rig. To achieve this, the alarm signal output of a Graphtec Corp. GL820 midi logger was connected to the control side $\left(12 \mathrm{~V}_{\mathrm{DC}}\right)$ of a normally-open relay to serve as a circuit interrupter. Likewise, normally-closed solenoid valves - Asco® $8264 \mathrm{Cyro} / \mathrm{LCO}_{2}$ - and 8210 General Service-series (CRN: 0C12239.5) - were connected in parallel on the load side $\left(120 \mathrm{~V}_{\mathrm{AC}}\right)$ of this relay and to both the $\mathrm{CO}_{2}$ and air supplies. Alarm trigger conditions (discussed in Section 4.7) were assigned to specific input channels of the logger and, if they were exceeded, forced the alarm output to act as if it were an open circuit; subsequently, the relay was de-energized and both solenoids were closed. Figure 4-7 depicts the circuit diagram for this solenoid valve relay. 


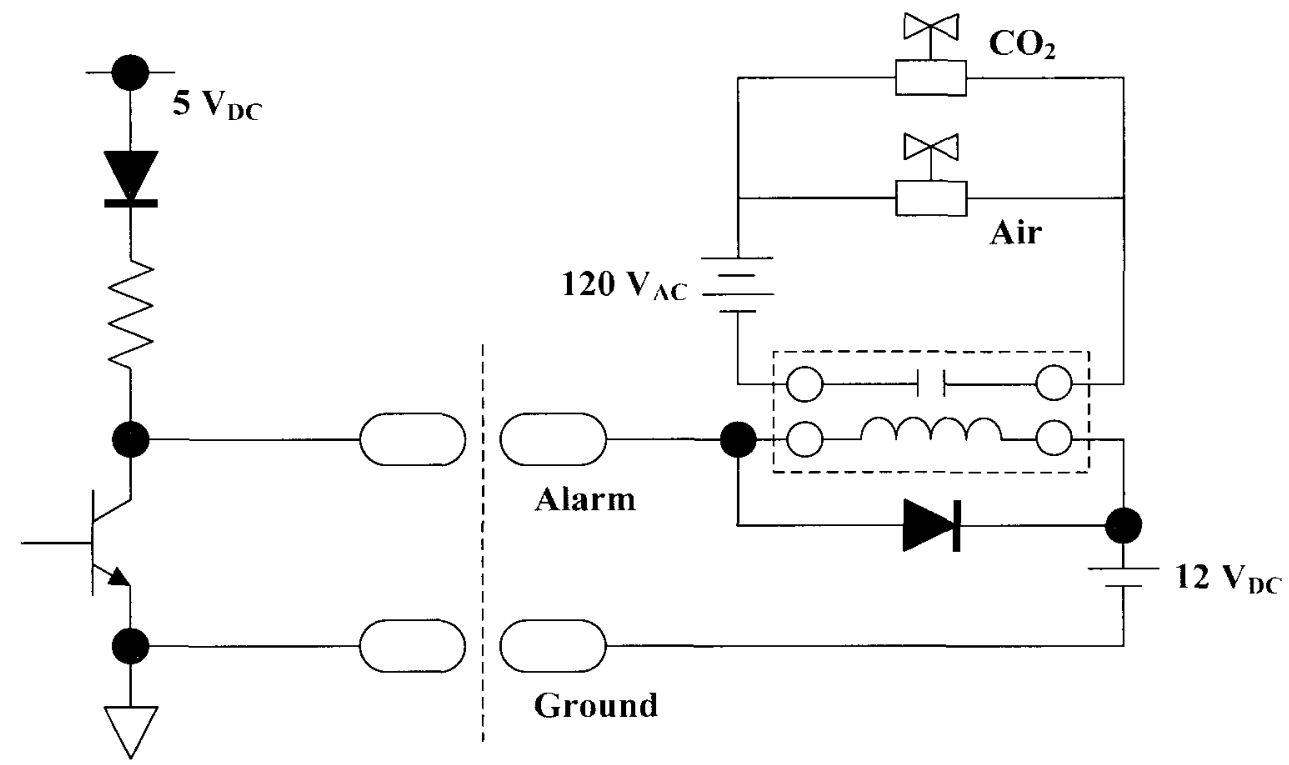

Data Logger

Alarm Output

Figure 4-7: Circuit diagram of solenoid valve relay

\subsection{Specimen Boat}

Test specimens were electrically isolated from the pressure vessel and suspended inside it using a custom-built, alumina specimen boat. Rather than machine this specimen boat entirely from a solid cylindrical rod, it was assembled from four components, which required little to no material removal: a grooved, $22.2 \mathrm{~mm}(0.875 \mathrm{in}$.) OD tube; two, stepped, semi-circular end caps; and a $3.2 \mathrm{~mm}$ (0.125 in.) diameter, solid support rod. This boat - fabricated by Elan Technology ${ }^{\mathrm{TM}}$ of Midway, Georgia measured $266.7 \mathrm{~mm}$ (10.5 in.) in length and used the semi-circle void in each of its ends to encourage $\mathrm{CO}_{2}$ flow. Figure 4-8 shows this specimen boat following its assembly, along with the alumina spacers that will be used to separate adjacent specimens. 


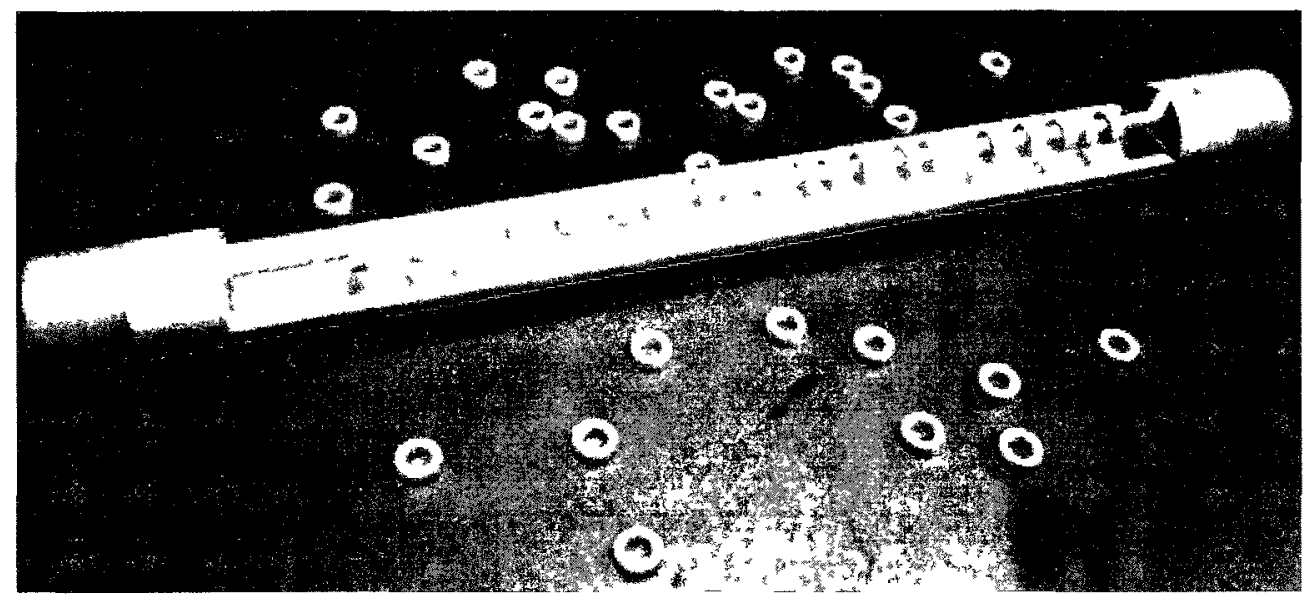

Figure 4-8: Alumina specimen boat

\subsection{Conceptual Layout and Assembly}

After much deliberation, the NRCan Bells Corners complex (BCC) was chosen over Carleton to house this $\mathrm{S}-\mathrm{CO}_{2}$ corrosion test rig; their telemetrically-monitored, $\mathrm{CO}_{2}$ bulk tank, comprehensive leak detection system, and dedicated technicians to assist both with assembly and routine maintenance were all influencing factors in this decision. As provided by BOC Canada Ltd., $\mathrm{CO}_{2}$ within this bulk tank had a minimum guaranteed purity of $99.85 \%$, with maximum impurity levels listed in Table $4-2$. The final design of this test rig was to utilize a once-through arrangement with static testing capabilities, as opposed to being a recirculating system. While a recirculating system would be most representative of the closed cycle, $\mathrm{S}-\mathrm{CO}_{2}$ Brayton cycle, excessive contaminant, in either solid or gaseous form, could potentially limit the life of the gas booster. Figures 4-9 and 4-10 illustrate the complete process and instrumentation diagram (P\&ID) and physical arrangement of this corrosion test rig; its accompanying bill of materials (BOM) is found in Appendix A. 


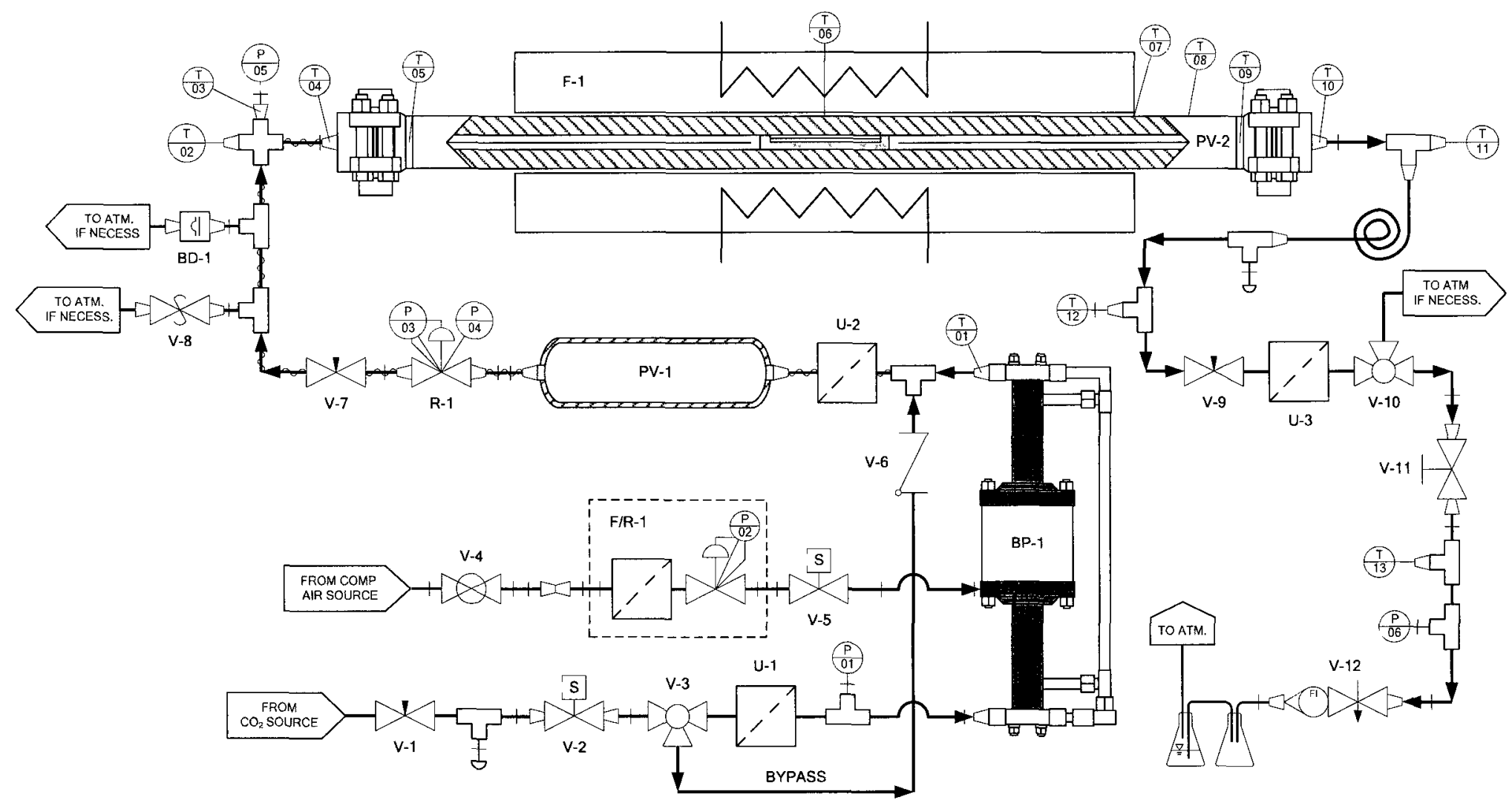

Figure 4-9: $\mathrm{P} \& \mathrm{ID}$ for Carleton-NRCan high temperature $\mathrm{S}-\mathrm{CO}_{2}$ corrosion test rig 
Table 4-2: Maximum impurity content of BOC Canada Ltd. standard grade bulk $\mathrm{CO}_{2}$

\begin{tabular}{ccccccccccc}
\hline & \multicolumn{10}{c}{ ppm (vol.) } \\
Inerts & $\begin{array}{c}\mathrm{C}_{\mathrm{x}} \mathrm{H}_{\mathrm{y}} \\
\text { (volatıle) }\end{array}$ & $\mathrm{H}_{2} \mathrm{O}$ & $\mathrm{O}_{2}$ & $\mathrm{NH}_{3}$ & $\mathrm{CO}$ & $\begin{array}{c}\mathrm{C}_{\mathrm{x}} \mathrm{H}_{\mathrm{y}} \\
\text { (non-volat1le) }\end{array}$ & $\mathrm{NO}_{\mathrm{x}}$ & $\mathrm{SO}_{2}$ & $\mathrm{COS}$ & $\mathrm{H}_{2} \mathrm{~S}$ \\
\hline 1000 & 50 & 32 & 30 & 25 & 10 & 10 & 5 & 5 & 0.5 & 0.5 \\
\hline
\end{tabular}

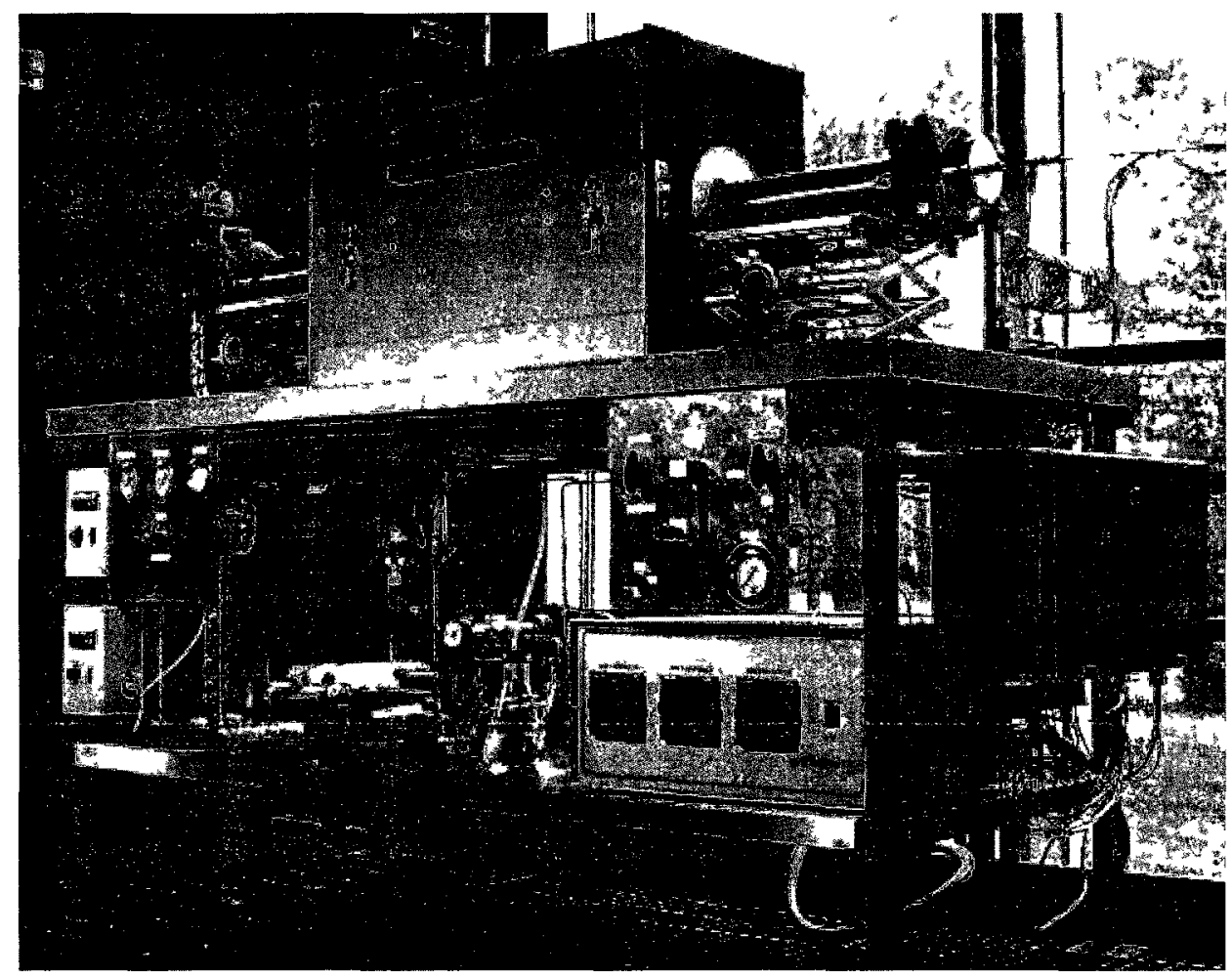

Figure 4-10: Carleton-NRCan high temperature $\mathrm{S}-\mathrm{CO}_{2}$ corrosion test rig

Carbon dioxide was supplied to the gas booster at $1.59 \mathrm{MPa}$ after first passing through the $\mathrm{Asco} \otimes 8264 \mathrm{Cyro} / \mathrm{LCO}_{2}$ solenoid valve and a $15.0 \mu \mathrm{m}$ particulate filter. The use of a three-way needle valve and check valve (located at the booster outlet) also allowed for $\mathrm{CO}_{2}$ to bypass the gas booster altogether and purge the test rig at this lower pressure. Similarly, compressed instrument air flowed through a Norgren Excelon $\mathbb{B}$ 
B74G filter-regulator assembly and the $A s c o ß 8210$ General Service solenoid valve before entering the booster. Apart from the check valve, Figure 4-11 shows where each of these components is located in relation to the GBT-15/30 gas booster. To simplify control over the outlet pressure of the gas booster, only the pressure of the compressed air feed could be adjusted. Furthermore, it was determined from Equation 4.2 that, given the maximum available $\mathrm{CO}_{2}$ and compressed air pressures, the stall pressure of the gas booster was limited to approximately $25.92 \mathrm{MPa}$.

Upon leaving the gas booster, compressed $\mathrm{CO}_{2}$ was filtered through a $7.0 \mu \mathrm{m}$ particulate filter and stored in a $316-\mathrm{SS}, 300 \mathrm{~mL}$ buffer tank. The buffer tank was one part of a two-stage system aimed to remove the inevitable pressure pulsations from the $\mathrm{CO}_{2}$; its complement was a GO-Regulator PR-57 series regulator. Stored energy in the $\mathrm{CO}_{2}$ would first serve as a rudimentary dampener to smooth out these pulsations before entering the PR-57 regulator, where the $\mathrm{CO}_{2}$ would then leave at essentially constant pressure. The addition of the buffer tank, kept at a slightly higher pressure than the intended operating pressure, was to prolong the life of the regulator's diaphragm. GO-Regulator had also recommended that ethylene propylene be substituted for the standard Viton seals to prevent any chance of explosive decompression with $\mathrm{S}-\mathrm{CO}_{2}$. Moreover, an Endress+Hauser Cerabar S PMP71 transmitter was used in conjunction with the PR-57 regulator to help in regulating the $\mathrm{CO}_{2}$ to the desired test pressure. 

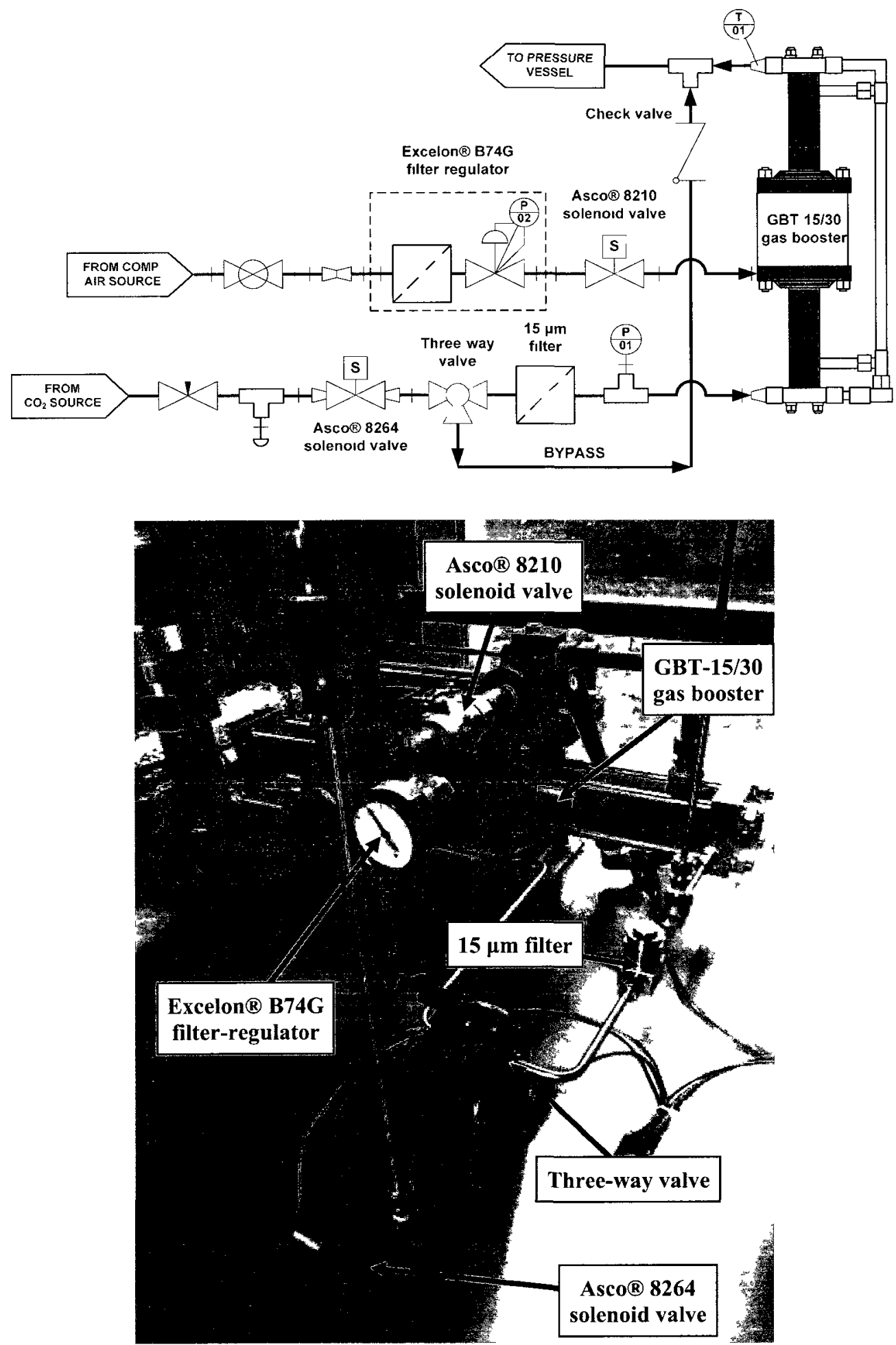

Figure 4-11: Inlet connectıons to the GBT-15/30 gas booster 
Figures 4-12 and 4-13 depict the layout of various components downstream of the GBT-15/30 gas booster, both at its immediate outlet and at the inlet to the pressure vessel. As each figure clearly shows, all tubing leading from the outlet of the gas booster to the inlet of the pressure vessel was wrapped with OMEGA ${ }^{\circledR}$ HTC heating cords and Aeroflex $\left(\right.$ tube insulation to keep the $\mathrm{CO}_{2}$ in a supercritical, rather than liquid, state; the pressure vessel, in turn, was supported by adjustable laboratory jack stands, which were aimed to facilitate its initial positioning and possible future removal. Two needle valves also allowed this corrosion test rig to function as a static system by completely isolating the pressure vessel. Consequently, both the FlowSafe F84-M SRV and ZOOK SFAZ rupture disk had to be located between these valves so as not to remove their protective role when operating at static conditions. Once testing commences, the specimen boat will sit inside the pressure vessel and temperature will be measured on both sides of it using OMEGA® KQIN thermocouple probes.

As a provision to accommodate higher flowrates, $6.1 \mathrm{~m}(20 \mathrm{ft}$.) of $3.175 \mathrm{~mm}$ (0.125 in.) OD, 316-SS tubing was coiled and added at the outlet of the pressure vessel to provide additional surface area for cooling - either by free convection or by submersing the coil in a water bath. Downstream of this cooling coil, a $7.0 \mu \mathrm{m}$ filter removed any particulate entrained within the $\mathrm{CO}_{2}$ before reaching the TESCOM ${ }^{\mathrm{TM}} \mathrm{CC}$-series metering valve. This particulate filter was situated between one of the static isolation valves and another three-way valve so that it could be taken out and replaced without interfering with a corrosion test. Similar to what was done upstream of the pressure vessel, all 
pertinent valves and measuring instruments were mounted onto stainless steel plating to make controlling the test rig as efficient as possible.
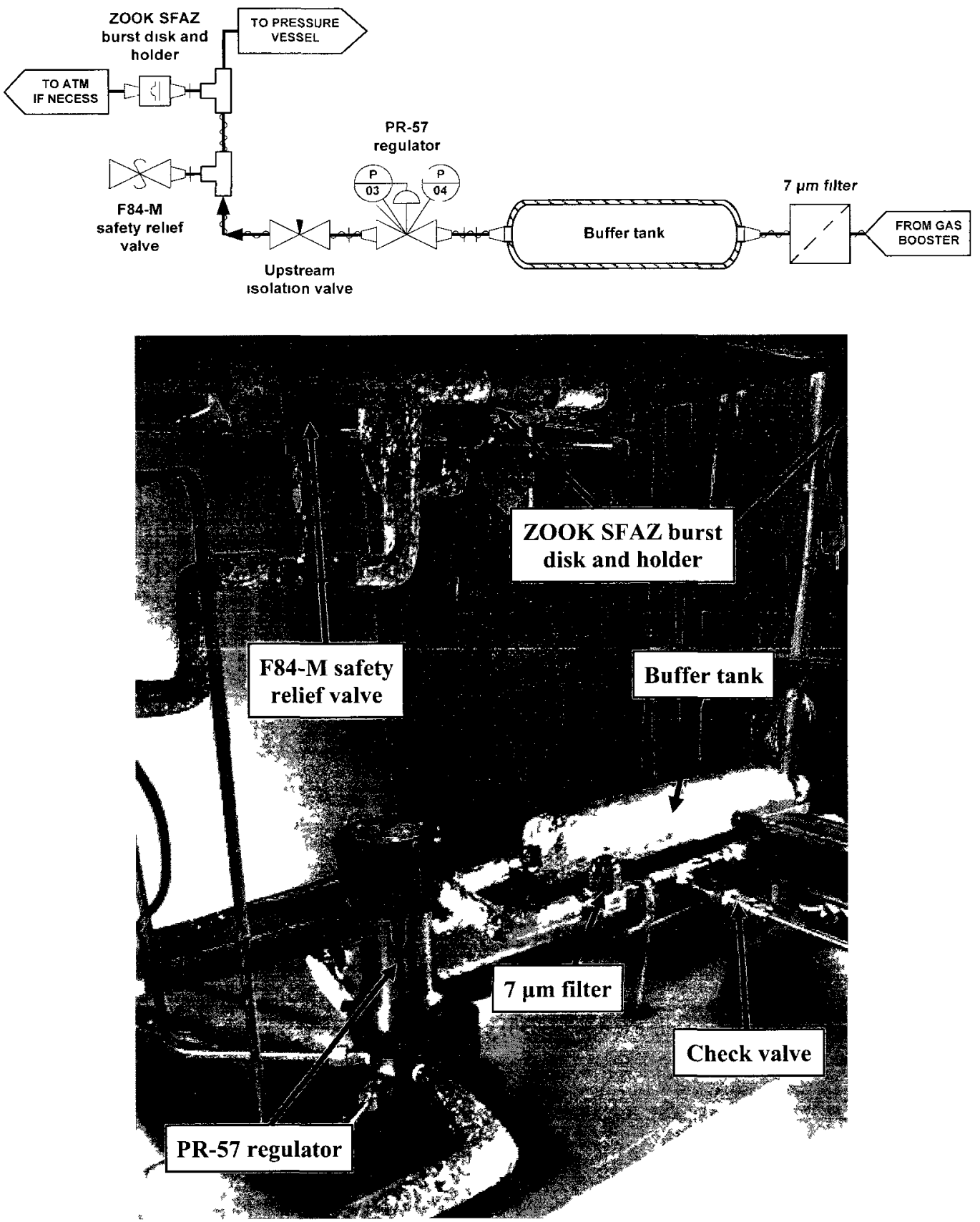

Figure 4-12: At the outlet of the GBT-15/30 gas booster 


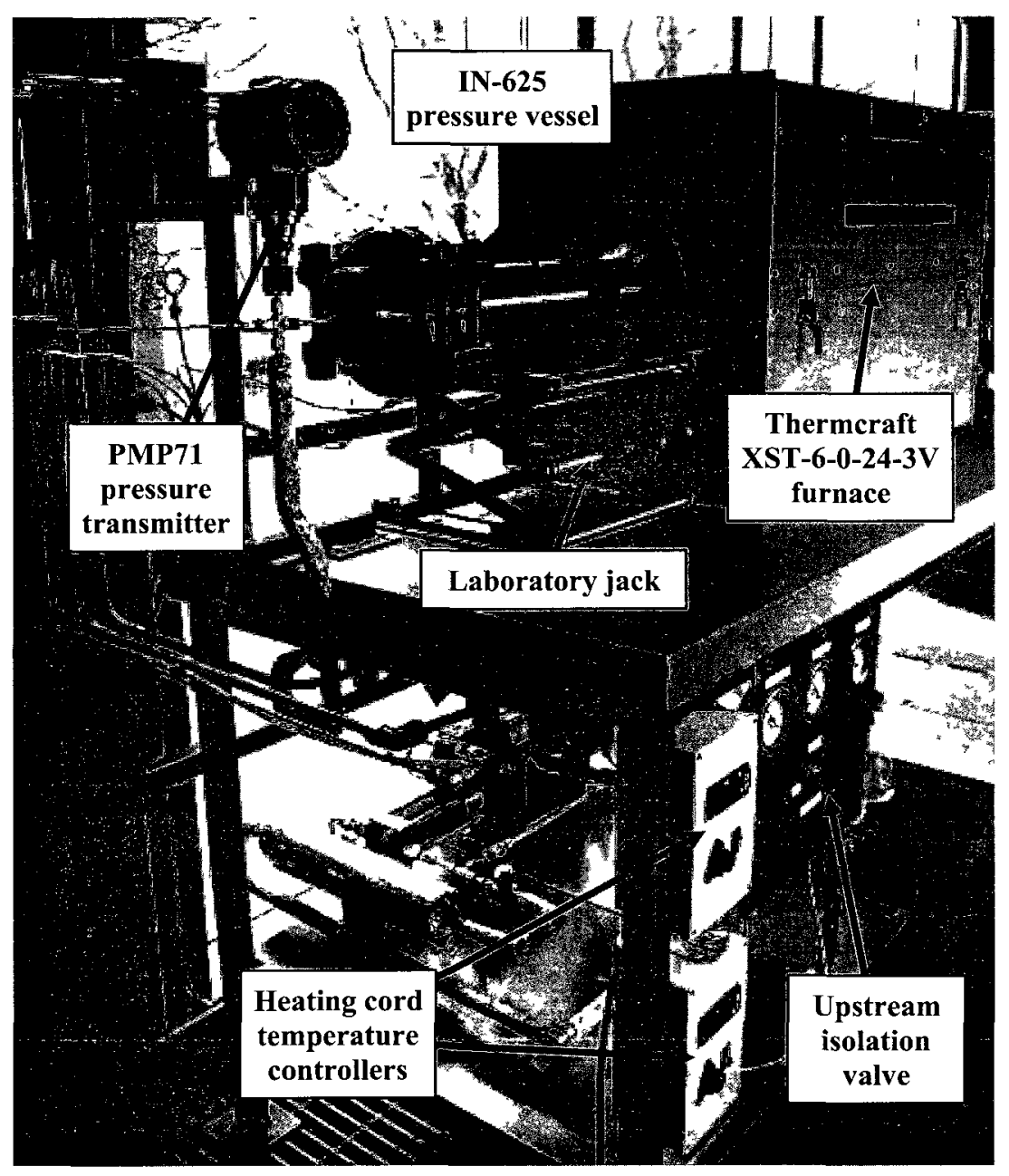

Figure 4-13: At the inlet to the pressure vessel

Pressure drop and hence flow control was achieved using the CC-series metering valve, with both temperature and pressure measured at its outlet to monitor against freeze-ups and indirectly quantify higher flowrates. Flowrates lower than $5.0 \mathrm{~L} / \mathrm{hr}$ at standard conditions were read off of a Swagelok rotameter, which, because of the precise control afforded by the metering valve, was converted into a passive flowmeter. Spent $\mathrm{CO}_{2}$ was finally exhausted to atmosphere after first passing through a simple gas scrubber 
configuration - two, $500 \mathrm{~mL}$ Erlenmeyer flasks arranged in series. Figure 4-14 illustrates how the corrosion test rig was configured downstream of the pressure vessel.

Type-K thermocouples were used exclusively throughout this test rig and, like the pressure transducer, had their output sampled and recorded by the Graphtec GL820 logger. This logger, as well as the solenoid valve relay circuit and OMRON DC power supply, were all mounted inside the electrical enclosure shown in Figure 4-15. In addition to those located inside and downstream of the pressure vessel, thermocouples were also permanently adhered to its exterior to measure metal temperature. Figure 4-16 depicts the relative locations of these thermocouples along the length of the pressure vessel - thermocouples T-4 and T-10 were fixed to both Grayloc $($ blind hubs; T-5 and T-9 were attached to each weld joining the blind hub to the IN-625 section; T-6 was positioned at the midpoint inside the furnace; and $\mathrm{T}-7, \mathrm{~T}-8, \mathrm{~T}-9$, and $\mathrm{T}-10$, collectively, gave a discrete thermal profile of the pressure vessel - outside the furnace - in the axial direction. 

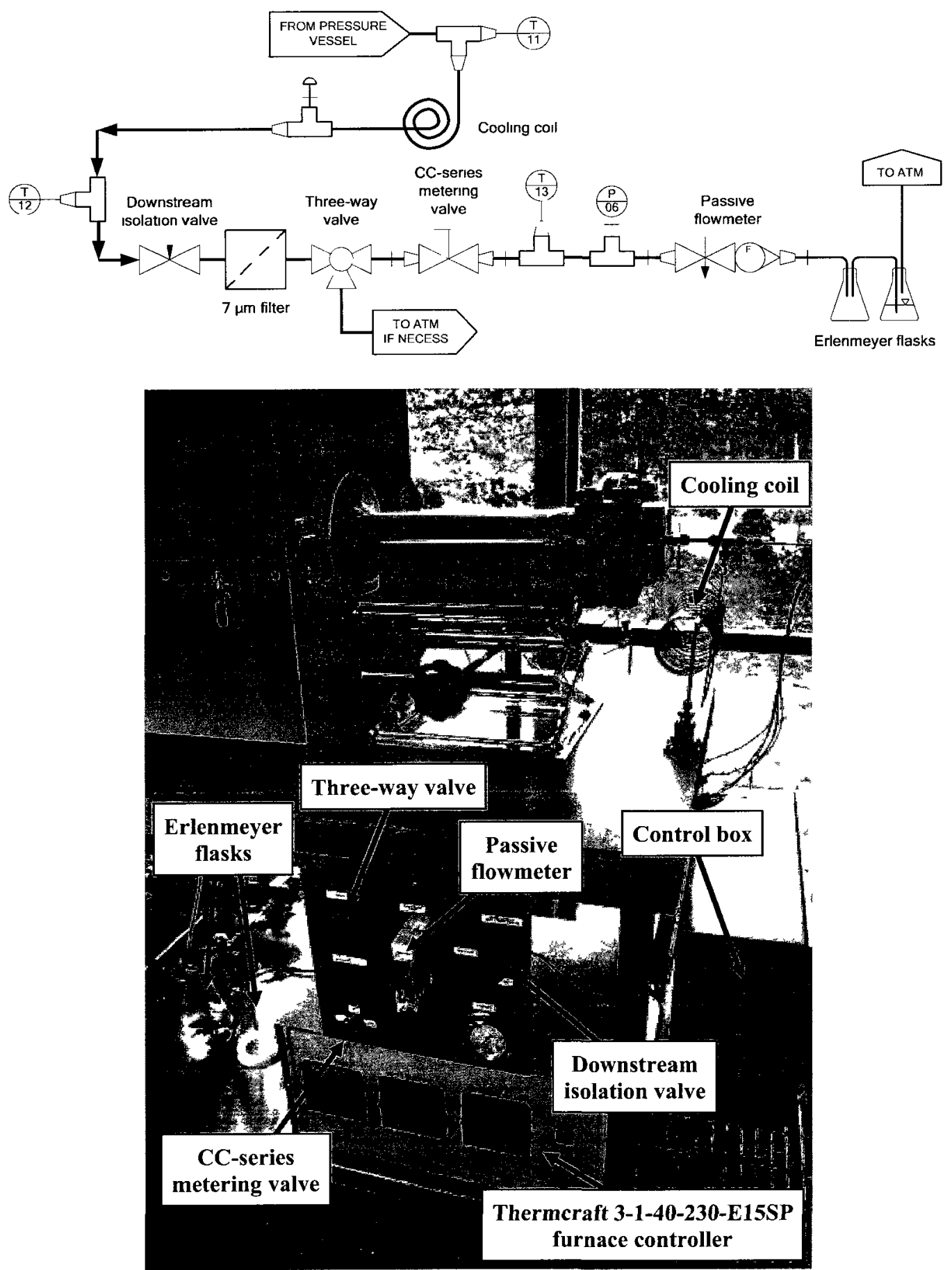

Figure 4-14: Downstream of the pressure vessel 


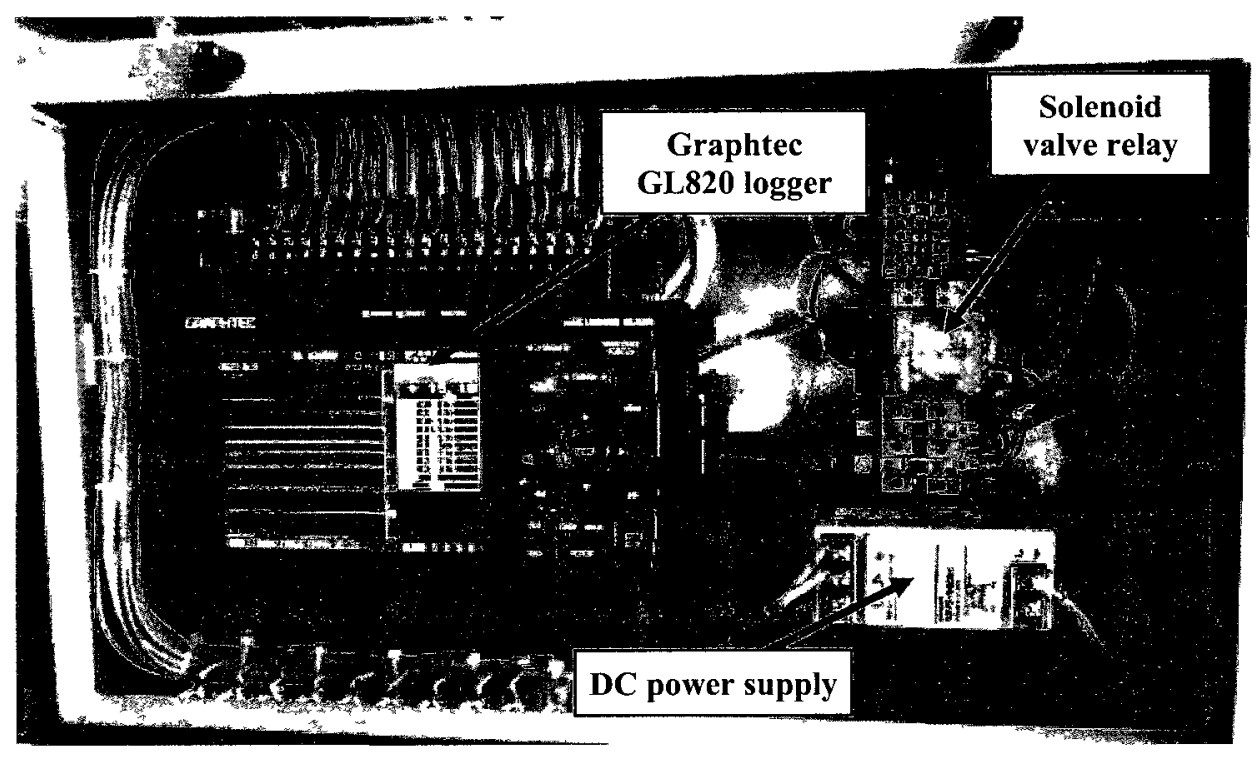

Figure 4-15: Electrical enclosure

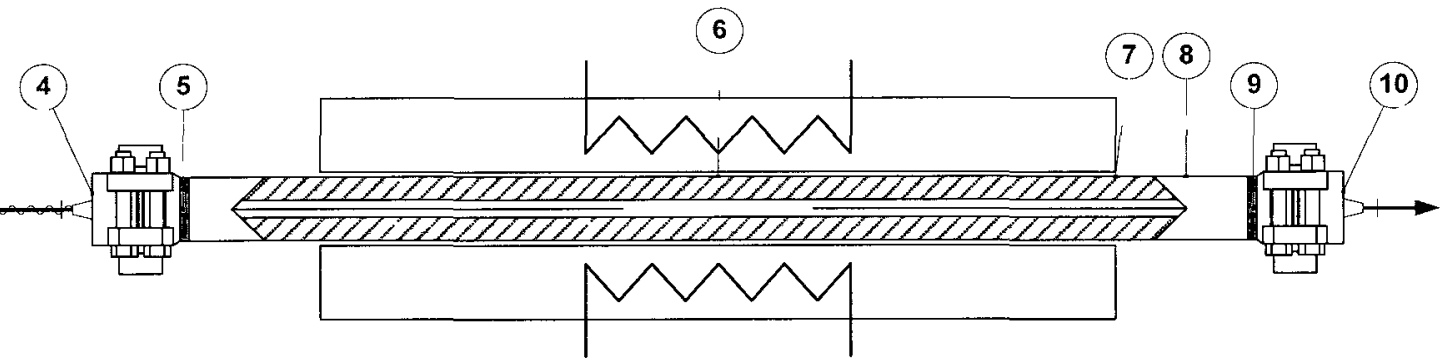

Figure 4-16: Thermocouple locations along the length of the pressure vessel

As part of the solenoid valve relay circuit discussed in Section 4.5.2, seven of the fourteen (nineteen during commissioning) analog inputs that fed into the GL820 logger were assigned upper threshold alarm triggers. Only four unique trigger conditions (one pressure- and three temperature-related) were actually defined though, leaving some input channels to serve in a duplicate or redundant capacity; the magnitudes of two of these alarm triggers were also dependent on which operating point was selected. Table 4-3 identifies the values of each of the four alarm trigger conditions and which input 
channel(s) they applied to. The first and second alarm triggers listed in Table 4-3 represent the predetermined solenoid valve relay circuit activation pressures and the design temperatures of the pressure vessel. Similarly, the remaining two trigger points were conservative maximum limits for both the process temperature of the PMP71 transmitter and the exposure temperature of the thread sealant used in the Grayloc $₫$ blind hubs - the actual maximum temperature ratings of each were $125^{\circ} \mathrm{C}$ and $288^{\circ} \mathrm{C}$, respectively.

Table 4-3: Assigned upper threshold alarm triggers

\begin{tabular}{|c|c|c|}
\hline $\begin{array}{c}\text { Alarm } \\
\text { ID }\end{array}$ & Applicable Channel Inputs & $\begin{array}{c}\text { Assigned } \\
\text { Value }\end{array}$ \\
\hline $1^{\mathbf{A}}$ & PMP71 pressure transmitter & $\begin{array}{c}28.31 \mathrm{MPa} \text { or } \\
16.99 \mathrm{MPa}\end{array}$ \\
\hline \multirow{2}{*}{$2^{\mathbf{A}}$} & $\begin{array}{c}\text { Internal temperature of the pressure vessel }(2 \text { signals }) ; \\
\text { Metal temperature of the IN-625 section inside the furnace }\end{array}$ & $\begin{array}{c}750^{\circ} \mathrm{C} \text { or } \\
800^{\circ} \mathrm{C}\end{array}$ \\
\hline 3 & Metal temperature of the PMP71 process connection & $100^{\circ} \mathrm{C}$ \\
\hline 4 & Metal temperature of the left and right Gralyoc $(\mathbb{R}$ blind hubs & $250^{\circ} \mathrm{C}$ \\
\hline
\end{tabular}

${ }^{\mathrm{A}}$ Value depends on the particular operating point chosen $-25.0 \mathrm{MPa}$ at $700^{\circ} \mathrm{C}$ or $15.0 \mathrm{MPa}$ at $750^{\circ} \mathrm{C}$ 


\section{$5 \quad$ Commissioning}

Following its assembly, functional testing of the Carleton-NRCan high temperature $\mathrm{S}-\mathrm{CO}_{2}$ corrosion test rig was conducted to evaluate its performance against the original design criteria. Time constraints only allowed for comprehensive thermal profiling inside the pressure vessel to be completed at $15.0 \mathrm{MPa}$; nevertheless, two furnace set points established at 15.0 $\mathrm{MPa}$ were used to investigate what effect operating at a higher pressure (e.g. 25.0 MPa) would have on heating the $\mathrm{S}-\mathrm{CO}_{2}$. This section describes what was observed during the initial start-up of this corrosion test rig and summarizes the results of its commissioning process.

\subsection{Initial Start-up and Modifications}

To characterize the temperature distribution of $\mathrm{S}-\mathrm{CO}_{2}$ within the pressure vessel, a custom OMEGA ${ }^{\circledR}$ profile probe was acquired with six thermocouples incorporated into a $381 \mathrm{~mm}(18.0 \mathrm{in}$.$) portion of its overall length. Figure 5-1 illustrates how this profile$ probe, in addition to a secondary, single-point OMEGA ${ }^{\circledR}$ KQIN probe, were arranged relative to the heated zones of the furnace; the thickness of the single-point probe has been exaggerated to differentiate between the two. Starting at the leftmost edge of zone 2, temperature was measured at successive, $76.2 \mathrm{~mm}$ (3.0 in.) intervals across its entire length; temperature was also measured at the rightmost edge of zone 3.

Initial functional testing was performed at $15.0 \mathrm{MPa}$ and with $\mathrm{CO}_{2}$ leaving the test rig at a constant flowrate of $2.0 \mathrm{~L} / \mathrm{hr}$ at standard conditions. Temperature in each heated zone of the furnace was also increased at a linear rate of $200^{\circ} \mathrm{C} / \mathrm{hr}$ to a final set point of 
$600^{\circ} \mathrm{C}$ to lessen the thermal shock that the pressure vessel would be subjected to. Figure 5-2 shows the temperature distribution both of the pressure vessel itself and the S- $-\mathrm{CO}_{2}$ inside it, once a steady state was reached. Data points used to generate Figure 5-2 and, likewise, all figures to follow were averaged from steady state data that was sampled every $5.0 \mathrm{~s}$ for a total duration of two hours (i.e. a sample size of 1440 data points).

Overall, the heating process was found to be quite inefficient, with fluid temperatures averaging approximately half the value of the furnace set points. Additionally, duplicate temperature measurements at the tips of each probe (T-2 and $\mathrm{T}$-13) differed by approximately $25^{\circ} \mathrm{C}$, with the single-point probe measuring the lower of the two. Although difficult to confirm, the radial positioning of each probe tip was most likely asymmetrical; the greater, unsupported length of the profile probe would have attributed to a larger deflection under its own weight, causing this thermocouple to actually be closer to the bottom of the pressure vessel. Testing was stopped though when the original, PTFE-based thread sealant used to interface with the pressure vessel began to discolour and melt to the Grayloc $®$ hubs.

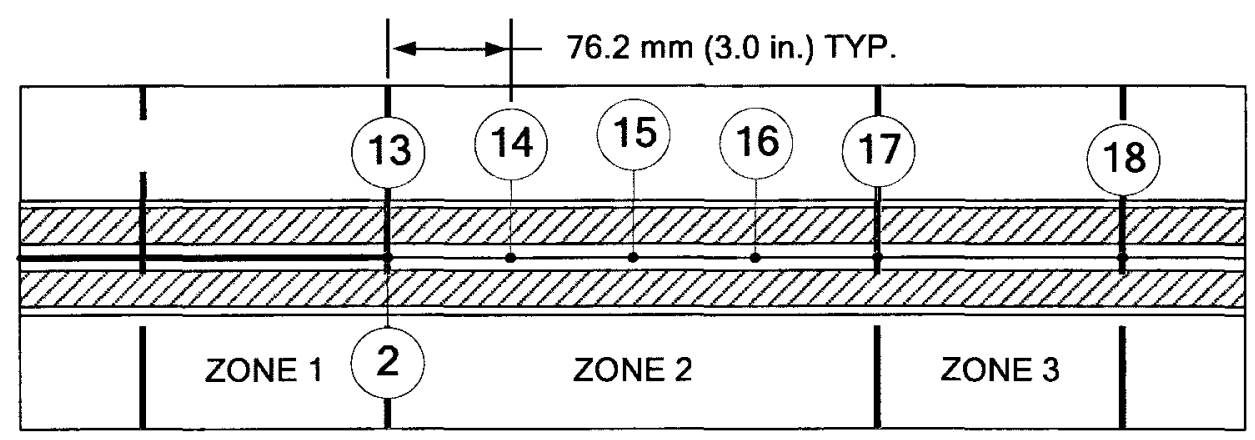

Figure 5-1: Location of thermocouples within the pressure vessel (hatched) 


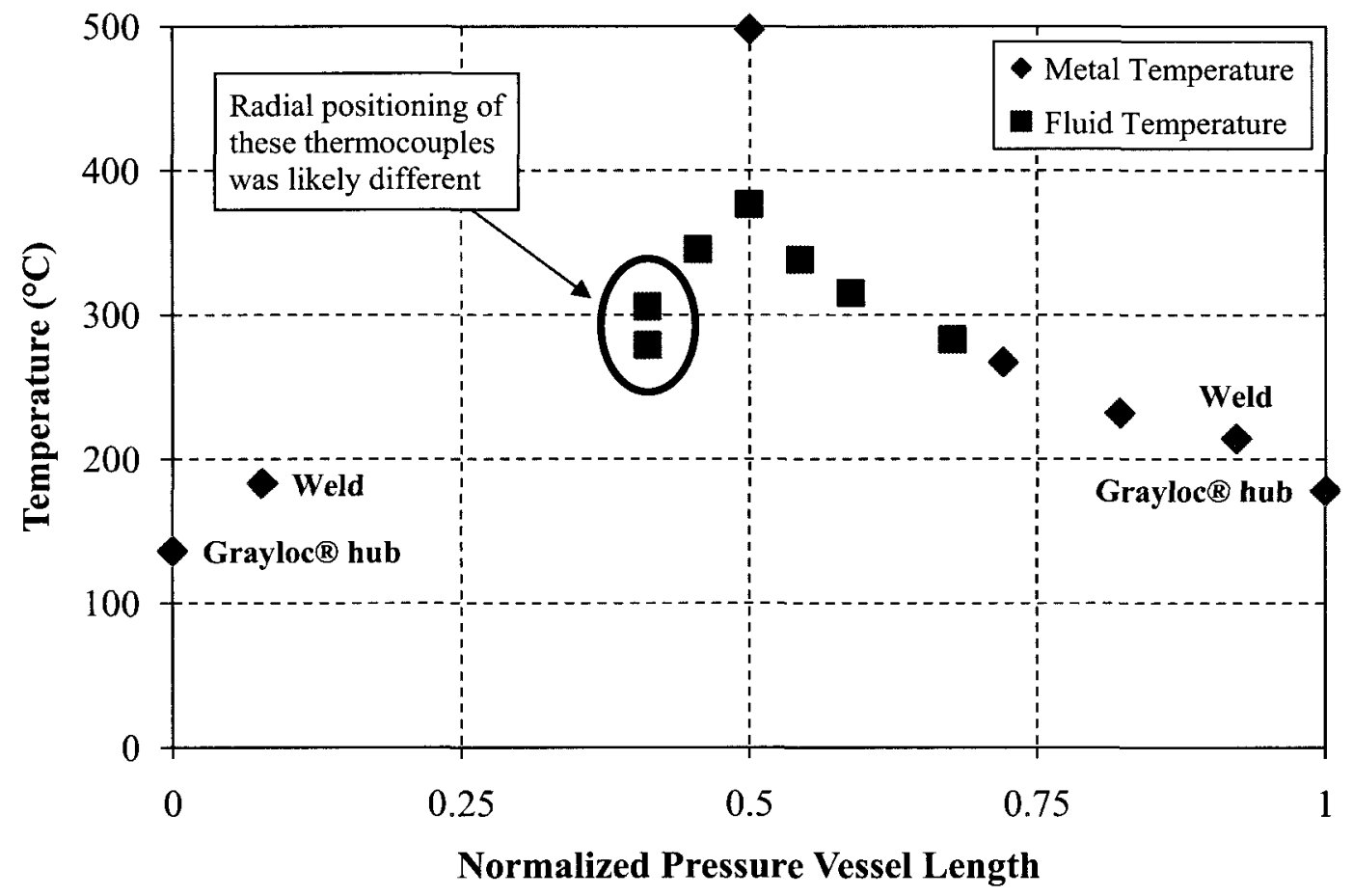

Figure 5-2: Initial temperature distribution at $15.0 \mathrm{MPa}$ for furnace set points of $600^{\circ} \mathrm{C}$

Similar to what was realized by Dunlevy [38], metallic reflectors were added inside the bore of the pressure vessel in an attempt to concentrate heat within the confines of the furnace. Molybdenum (Mo) sheeting was cut into six, $19.05 \mathrm{~mm}$ (0.75 in.) diameter disks and each disk was perforated with four equidistance holes about its axis to encourage flow. As shown in Figure 5-3, reflector placement was symmetric about the centre of the furnace, with the first of three reflectors positioned $63.5 \mathrm{~mm}(2.5 \mathrm{in}$.) from the outermost edge of zones 1 and 3; subsequent reflectors were spaced $25.4 \mathrm{~mm}$ (1.0 in.) apart from one another, moving towards the ends of the furnace. Furthermore, high purity nickel wire was crimped onto both probe sheaths, on either side of each Mo heat reflector, to ensure they remained fixed as the vessel was pressurized. Figure 5-4 depicts 
the arrangement of Mo reflectors on the profile probe sheath prior to being inserted into the pressure vessel. Following its reassembly, a metallic-based thread sealant, capable of withstanding temperatures up to $288^{\circ} \mathrm{C}$, was used instead on the process connections with the pressure vessel.

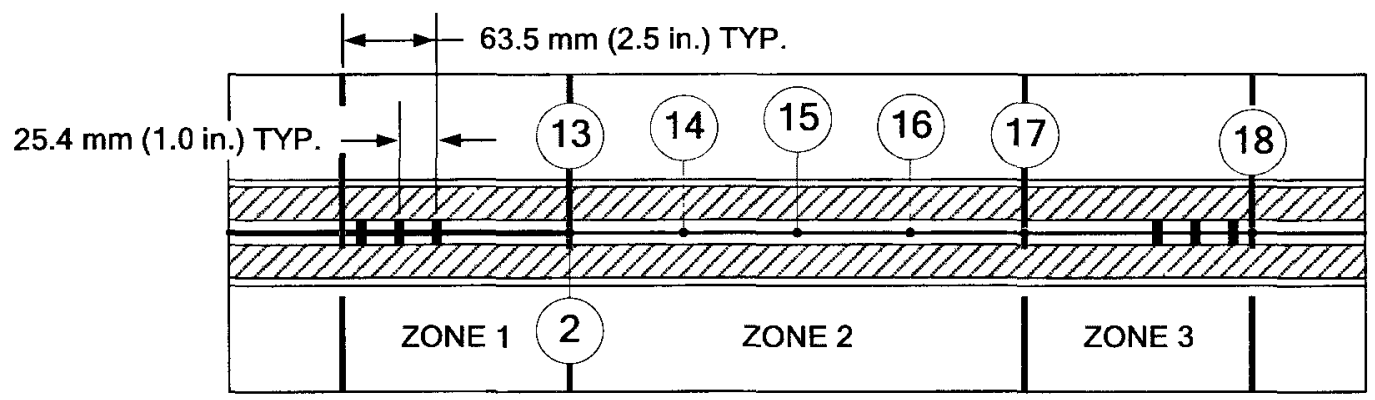

Figure 5-3: Heat reflector positioning within the pressure vessel (hatched)

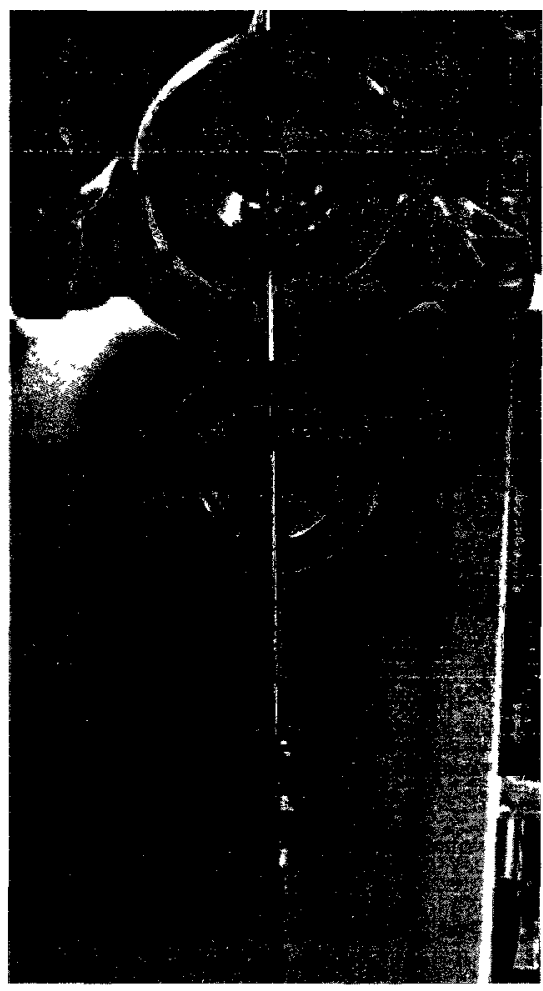

Figure 5-4: Heat reflectors attached to the profile probe sheath 
At identical conditions $\left(15.0 \mathrm{MPa}\right.$ with $600^{\circ} \mathrm{C}$ furnace set points) to the previous functional test, Figure 5-5 illustrates a marked increase - by as much as $150^{\circ} \mathrm{C}-$ in $\mathrm{S}-\mathrm{CO}_{2}$ temperature with the addition of these heat reflectors. However, the effectiveness of the heat reflectors is perhaps best exemplified by the significant temperature difference between adjacent thermocouples positioned within (T-17) and outside of (T-18) of their boundaries. The presence of the heat reflectors would also appear to minimize the temperature disparity between T-15 and T-17, skewing the nearly symmetric, bell-shaped distribution that was observed before, slightly right of centre. Moreover, temperatures measured by $\mathrm{T}-2$ and $\mathrm{T}-13$ should have been in closer agreement with each other, as the heat reflectors were also acting to centre both probes within the bore; however, unlike the earlier test in which T-2 was roughly $25^{\circ} \mathrm{C}$ cooler, $\mathrm{T}-2$ was now $30^{\circ} \mathrm{C}$ warmer. When the pressure vessel was disassembled again, the single-point probe was found to have a sharp bend along its length, which could have been incurred from misalignment during its initial insertion. Similarly, Figure 5-6 depicts the change in metal temperature following the addition of the heat reflectors. As the causal effect of the increased fluid temperatures observed in Figure 5-5, metal temperature within the furnace experienced the most pronounced change - an increase of approximately $85^{\circ} \mathrm{C}$. While not as noteworthy, the heat reflectors also served some purpose in keeping the Grayloc $®$ hubs cooler.

Since the alumina specimen boat can only accommodate metal coupons in $228.6 \mathrm{~mm}$ (9.0 in.) of its overall length, temperature need only be held constant over an equivalent length inside the pressure vessel. For each thermal profile conducted hereafter, furnace set points were adjusted to give an approximately uniform temperature 
distribution across T-14 to T-17, inclusively. Thus, when the specimen boat is to be inserted into the pressure vessel, it will be centred $38.1 \mathrm{~mm}(1.5 \mathrm{in}$.$) to the right of the$ midpoint of the furnace.

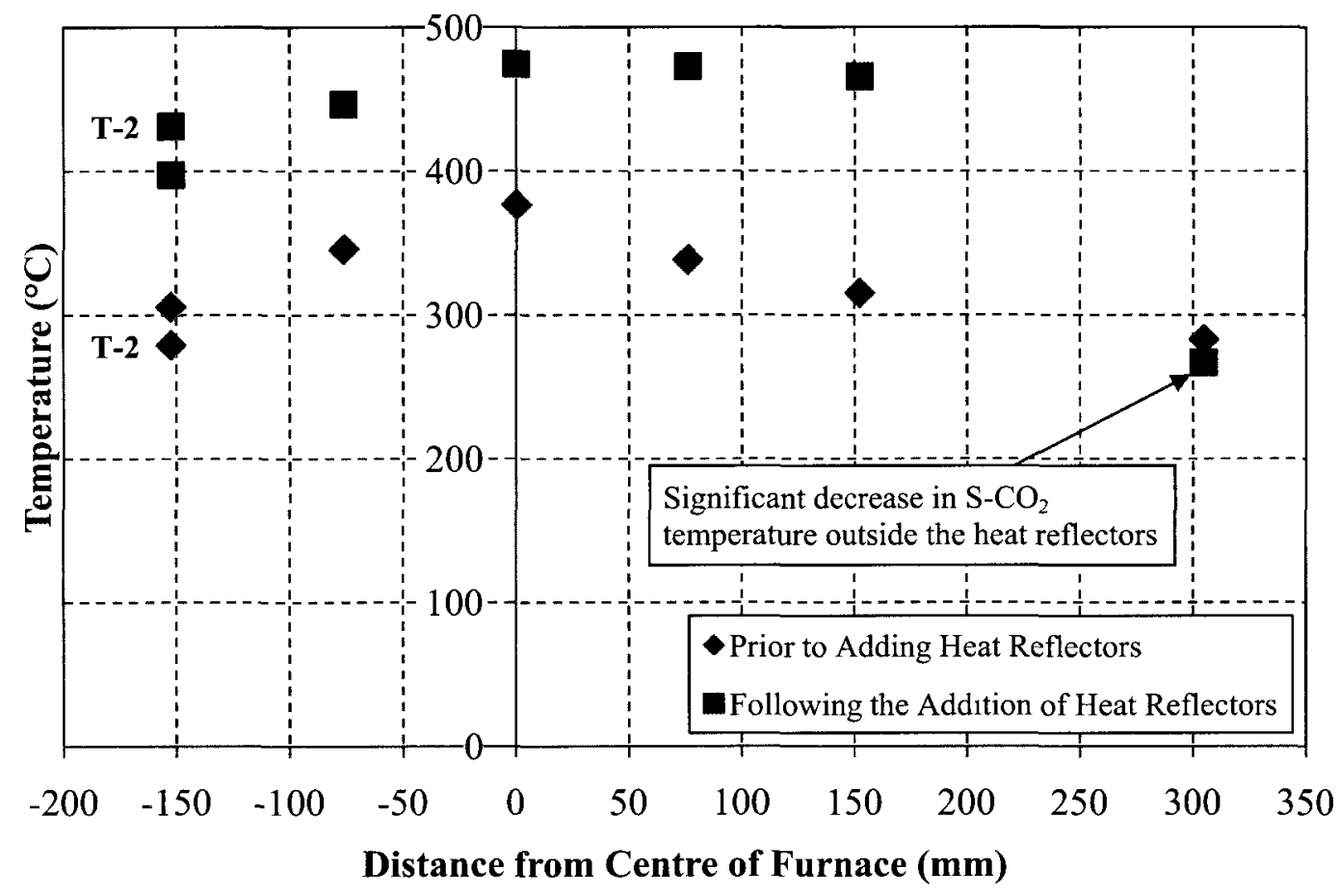

Figure 5-5: Effectiveness of the heat reflectors on raising fluid temperature at $15.0 \mathrm{MPa}$ for furnace set points of $600^{\circ} \mathrm{C}$ 


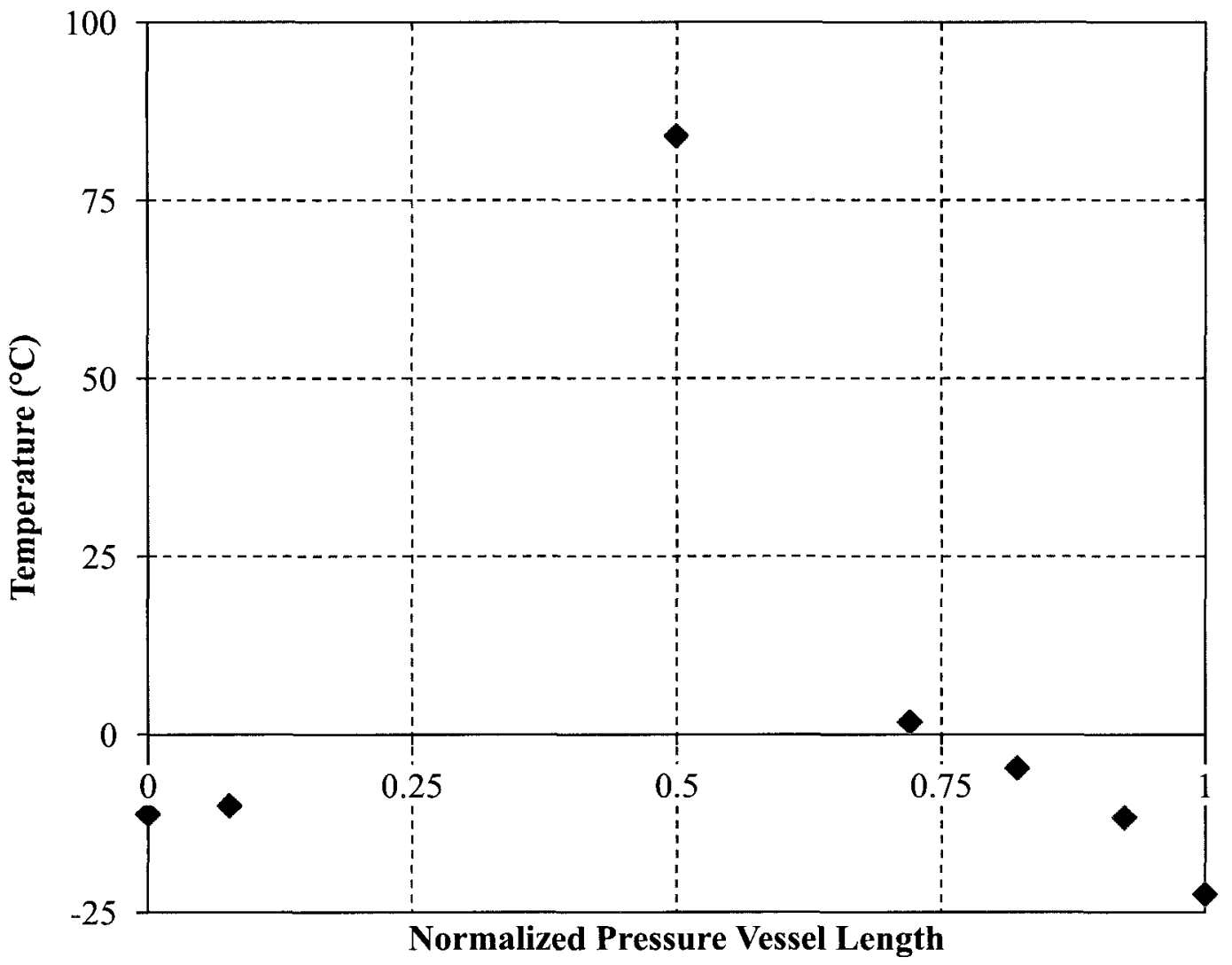

Figure 5-6: Change in metal temperature following the addition of the heat reflectors at 15.0 MPa for furnace set points of $600^{\circ} \mathrm{C}$

\subsection{Thermal Profiling at 15.0 MPa}

Two separate profiling trials were carried out at $15.0 \mathrm{MPa}$ to first establish furnace set points that would give uniform temperature distributions at $550,600,650$, and $700^{\circ} \mathrm{C}$ (i.e. temperatures that could serve as the TIT for the $\mathrm{S}-\mathrm{CO}_{2}$ Brayton cycle) and then, using the same series of set points, to confirm the repeatability of the initial results. This validation trial was also used to refine the original furnace set points, if needed, and further reduce the maximum temperature difference over the defined heated length. Similarly, the highest possible $\mathrm{S}-\mathrm{CO}_{2}$ temperature that would allow for a uniform 
distribution was also determined; however, the furnace set points required to achieve this were not validated like those at lower temperatures and were ultimately limited to the design temperature $\left(800^{\circ} \mathrm{C}\right)$ of the pressure vessel. While this section focuses solely on the internal temperature distribution of the pressure vessel, specifically over the $228.6 \mathrm{~mm}$ (9.0 in.) length spanning between T-14 and T-17, complete thermal profiles (at the aforementioned temperatures) are made available in Appendix B.

Furnace set points that would produce the desired fluid temperatures were determined by progressively increasing their values and monitoring what effect this had on the overall temperature distribution within the pressure vessel. Temperature was increased at a linear rate of $200^{\circ} \mathrm{C} / \mathrm{hr}$, regardless of the magnitude of the temperature rise, but only once pressure had stabilized at $15.0 \mathrm{MPa}$. To allow the $\mathrm{S}-\mathrm{CO}_{2}$ time to properly acclimatize itself to any increase in temperature, two hours - if the temperature increase was equal to or greater than $15^{\circ} \mathrm{C}$ - had to have elapsed before the next change to a specific furnace set point could be made; temperature increases less than $15^{\circ} \mathrm{C}$ were only given an hour. Table 5-1 details the succession of furnace set points beginning at a universal starting point of $580^{\circ} \mathrm{C}$ and clearly identifies the final set points needed to attain each of the four internal temperatures. As the overall temperature was increased, the difference between zone 1 and 3 set points (needed to counteract forced convection) was found to decrease, most likely as the effects of radiation heat transfer became more significant. From the outset of thermal profiling, the following convention was also adopted to summarize the set points of each heated zone in the furnace:

[ZONE 1 | ZONE 2 | ZONE 3] 
Table 5-1: Heated zone set points to give uniform temperature distributions

\begin{tabular}{|c|c|c|c|}
\hline \multirow{3}{*}{$\begin{array}{c}\text { Desired S-CO } \\
\text { Temperature }\end{array}$} & \multicolumn{3}{|c|}{ Heated Zone Set Point } \\
\hline & 1 & 2 & 3 \\
\hline & \multicolumn{3}{|c|}{$\left({ }^{\circ} \mathrm{C}\right)$} \\
\hline \multirow{8}{*}{$550^{\circ} \mathrm{C}$} & 580 & 580 & 580 \\
\hline & 620 & 620 & 620 \\
\hline & 650 & 620 & 620 \\
\hline & 665 & 620 & 620 \\
\hline & 680 & 620 & 635 \\
\hline & 680 & 620 & 650 \\
\hline & 690 & 620 & 650 \\
\hline & 695 & 620 & 655 \\
\hline \multirow{4}{*}{$600^{\circ} \mathrm{C}$} & 695 & 645 & 680 \\
\hline & 710 & 650 & 690 \\
\hline & 720 & 650 & 700 \\
\hline & 725 & 650 & 700 \\
\hline \multirow{4}{*}{$650^{\circ} \mathrm{C}$} & 725 & 675 & 725 \\
\hline & 740 & 675 & 725 \\
\hline & 750 & 685 & 725 \\
\hline & 750 & 690 & 725 \\
\hline \multirow{8}{*}{$700^{\circ} \mathrm{C}$} & 750 & 715 & 750 \\
\hline & 765 & 725 & 750 \\
\hline & 775 & 735 & 755 \\
\hline & 780 & 735 & 760 \\
\hline & 780 & 735 & 765 \\
\hline & 785 & 735 & 765 \\
\hline & 785 & 735 & 770 \\
\hline & 785 & 735 & 775 \\
\hline
\end{tabular}




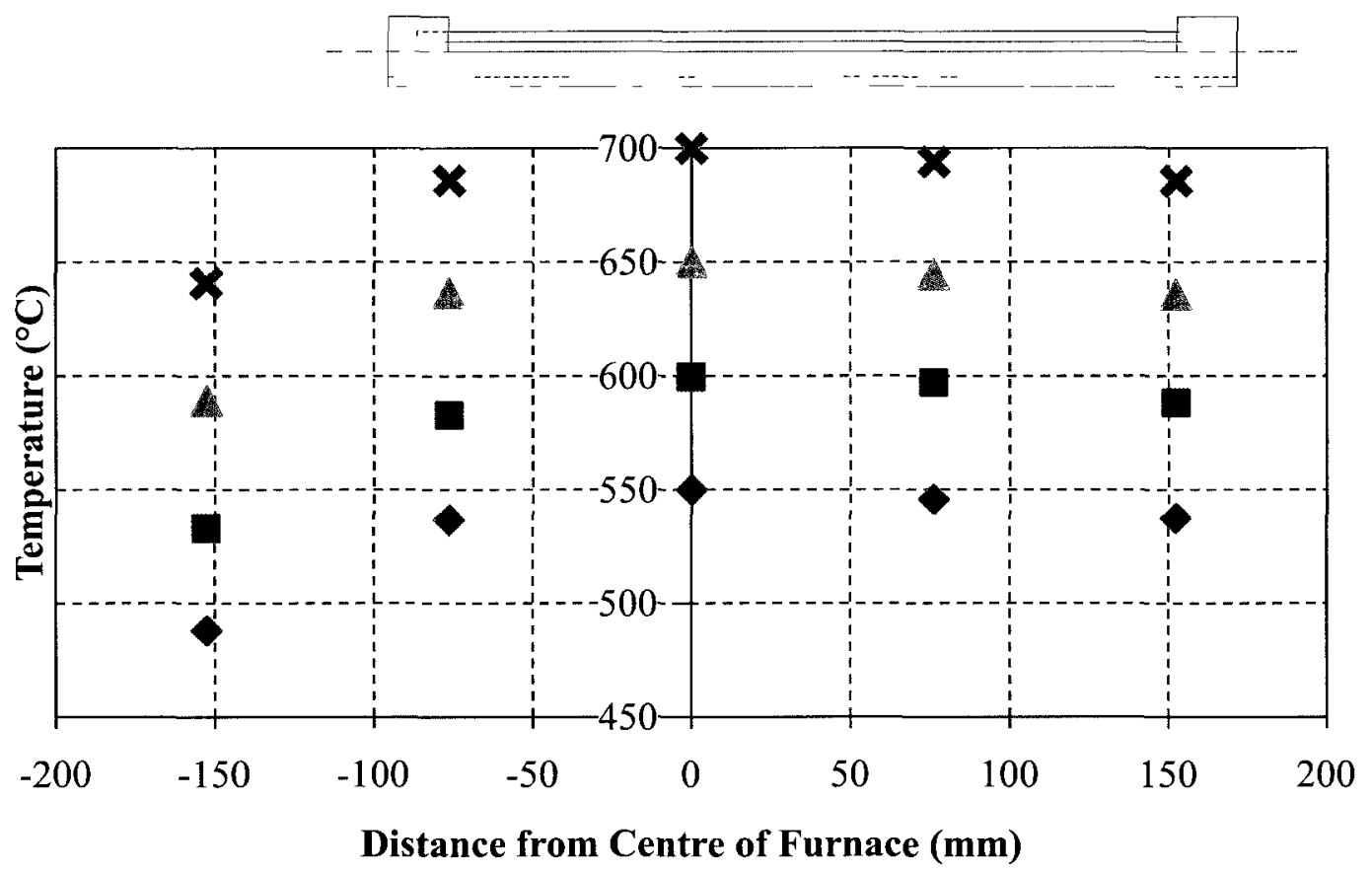

$$
\begin{array}{ll}
\bullet\left[695^{\circ} \mathrm{C}\left|620^{\circ} \mathrm{C}\right| 655^{\circ} \mathrm{C}\right] & \square\left[725^{\circ} \mathrm{C}\left|650^{\circ} \mathrm{C}\right| 700^{\circ} \mathrm{C}\right] \\
-\left[750^{\circ} \mathrm{C}\left|690^{\circ} \mathrm{C}\right| 725^{\circ} \mathrm{C}\right] & \mathbf{x}\left[785^{\circ} \mathrm{C}\left|735^{\circ} \mathrm{C}\right| 775^{\circ} \mathrm{C}\right]
\end{array}
$$

Figure 5-7: Temperature distributions for $550,600,650$, and $700^{\circ} \mathrm{C}$ using the established furnace set points

Figure 5-7 shows the expected temperature distributions over the usable length of the specimen boat at $550,600,650$, and $700^{\circ} \mathrm{C}$. Of these four temperatures, the average maximum temperature deviation between the respective peak and the lesser of the two ends was approximately $14.7^{\circ} \mathrm{C}$ or $2.36 \%$ of the peak temperature. Results of the validation trial are plotted in Figures 5-8 through 5-11 and, generally, show less variation with the original data set at higher temperatures. However, for each case, uniformity of temperature across the $228.6 \mathrm{~mm}$ (9.0 in.) length was marginally improved. Table 5-2 summarizes the furnace set points and thermocouple readings that were used to generate these plots, as well as the maximum temperature differences that were observed. 
At both 550 and $600^{\circ} \mathrm{C}$, Figures 5-8 and 5-9 illustrate that specific furnace set points actually had to be reduced by as much as $15^{\circ} \mathrm{C}$ to replicate the same temperature distribution as before; a small discrepancy in flowrate between the two trials was likely the cause. Although flowrate was visually confirmed to be $2.0 \mathrm{~L} / \mathrm{hr}$ at standard conditions for each trial, a more accurate means of flow measurement (i.e. a coriolis flowmeter) than what is currently in place would have substantiated this claim. These discrepancies in flowrate are less influential on heat transfer to the $\mathrm{S}-\mathrm{CO}_{2}$ above $650^{\circ} \mathrm{C}$, as the radiative heat transfer mechanism becomes more dominant. Figures 5-10 and 5-11 show that the temperatures obtained as part of the validation trial were nearly identical to those first measured in establishing furnace set points for 650 and $700^{\circ} \mathrm{C}$. In an effort to flatten these initial temperature distributions even more, individual furnace set points were increased by $5^{\circ} \mathrm{C}$ and the maximum temperature difference at both 650 and $700^{\circ} \mathrm{C}$ was reduced by roughly $0.5^{\circ} \mathrm{C}$. Overall, the average maximum temperature difference resulting from the validation trial was $13.1^{\circ} \mathrm{C}$ or $2.09 \%$ of the peak temperature; consequently, it was decided that the slightly modified furnace set points obtained from this trial would replace their original counterparts. 


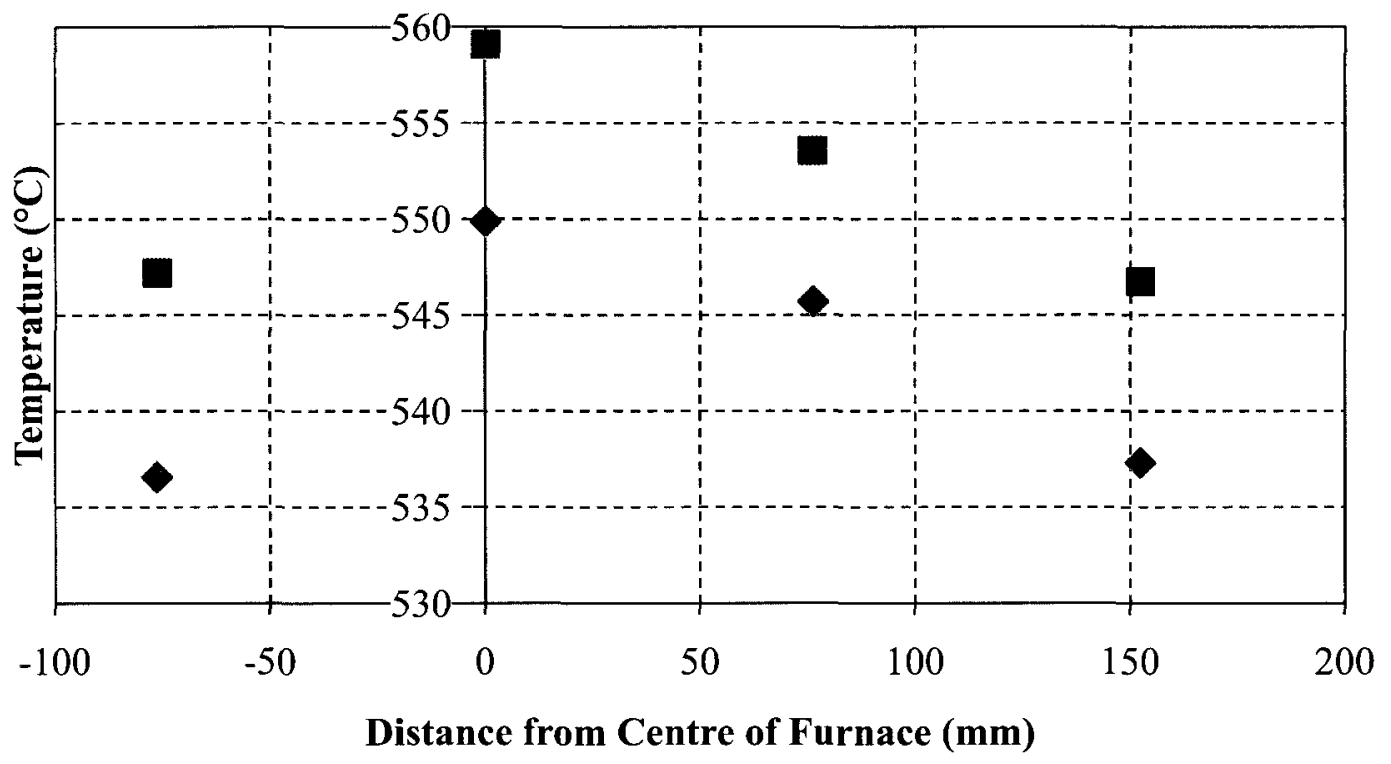

$\bullet\left[695^{\circ} \mathrm{C}\left|625^{\circ} \mathrm{C}\right| 655^{\circ} \mathrm{C}\right]$ Initial Run $\quad\left[685^{\circ} \mathrm{C} / 610^{\circ} \mathrm{C} \mid 645^{\circ} \mathrm{C}\right]$ Validation Run

Figure 5-8: Validation of the furnace set points to give $550^{\circ} \mathrm{C}$ at $15.0 \mathrm{MPa}$

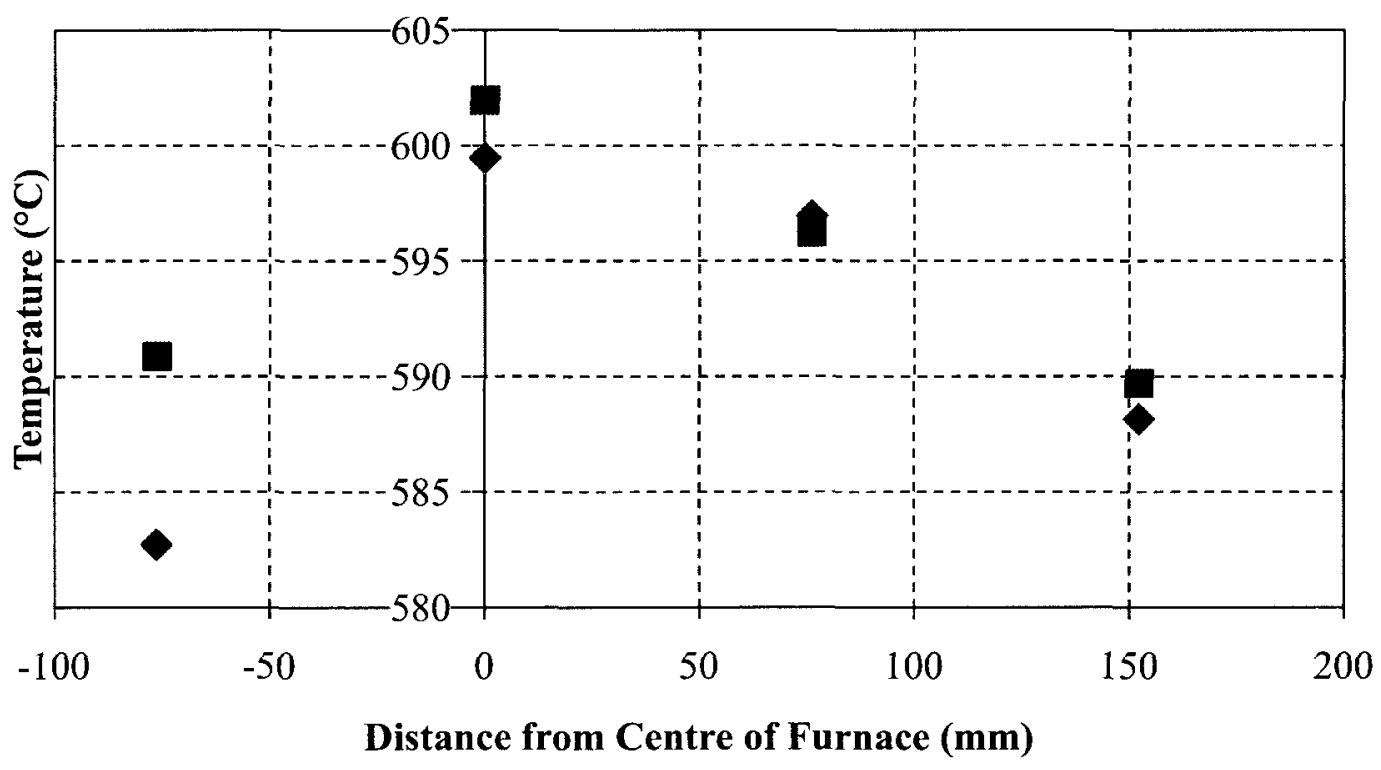

- $\left[725^{\circ} \mathrm{C}\left|650^{\circ} \mathrm{C}\right| 700^{\circ} \mathrm{C}\right]$ Initial Run $\quad\left[725^{\circ} \mathrm{C}\left|640^{\circ} \mathrm{C}\right| 690^{\circ} \mathrm{C}\right]$ Validation Run

Figure 5-9: Validation of the furnace set points to give $600^{\circ} \mathrm{C}$ at $15.0 \mathrm{MPa}$ 


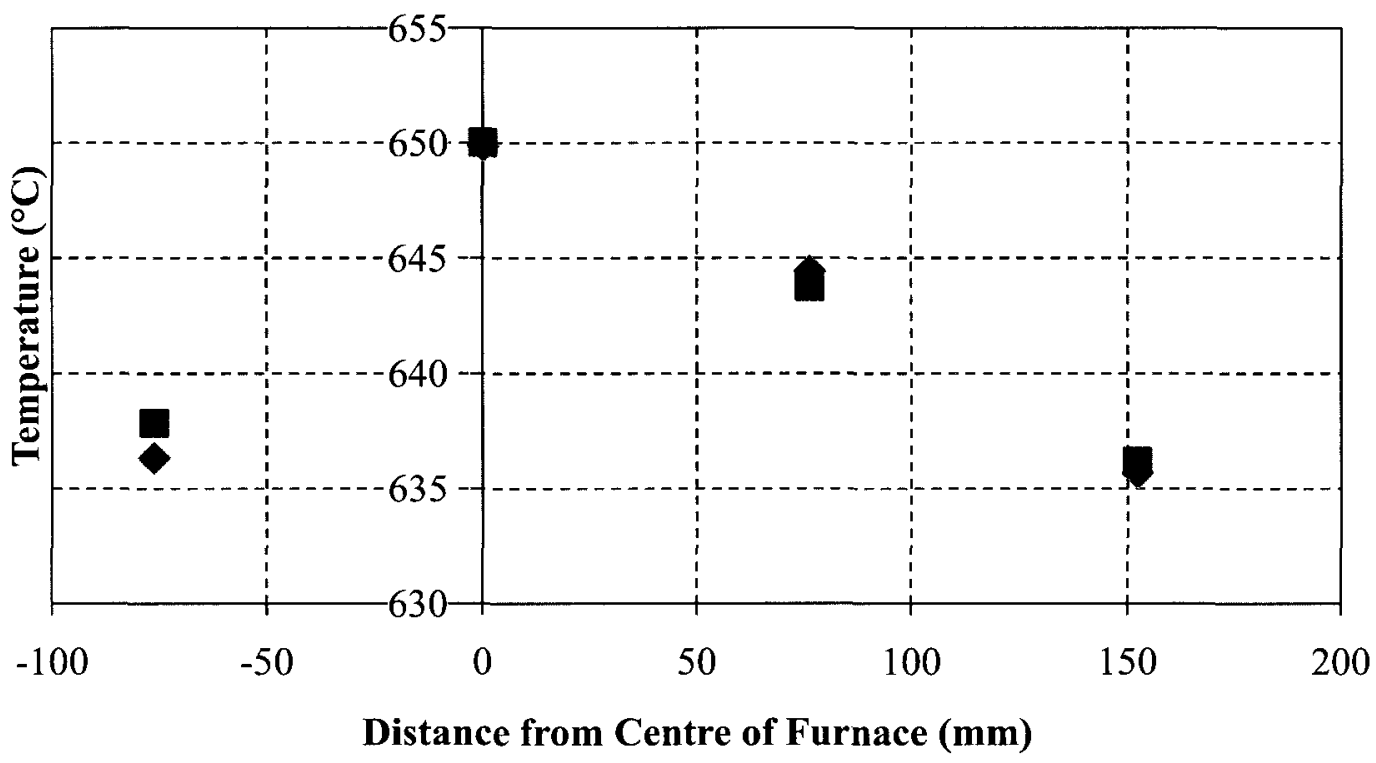

$\bullet\left[750^{\circ} \mathrm{C}\left|690^{\circ} \mathrm{C}\right| 725^{\circ} \mathrm{C}\right]$ Initıal Run $\quad \square\left[755^{\circ} \mathrm{C}\left|695^{\circ} \mathrm{C}\right| 725^{\circ} \mathrm{C}\right]$ Valıdation Run

Figure 5-10: Validation of the furnace set points to give $650^{\circ} \mathrm{C}$ at $15.0 \mathrm{MPa}$

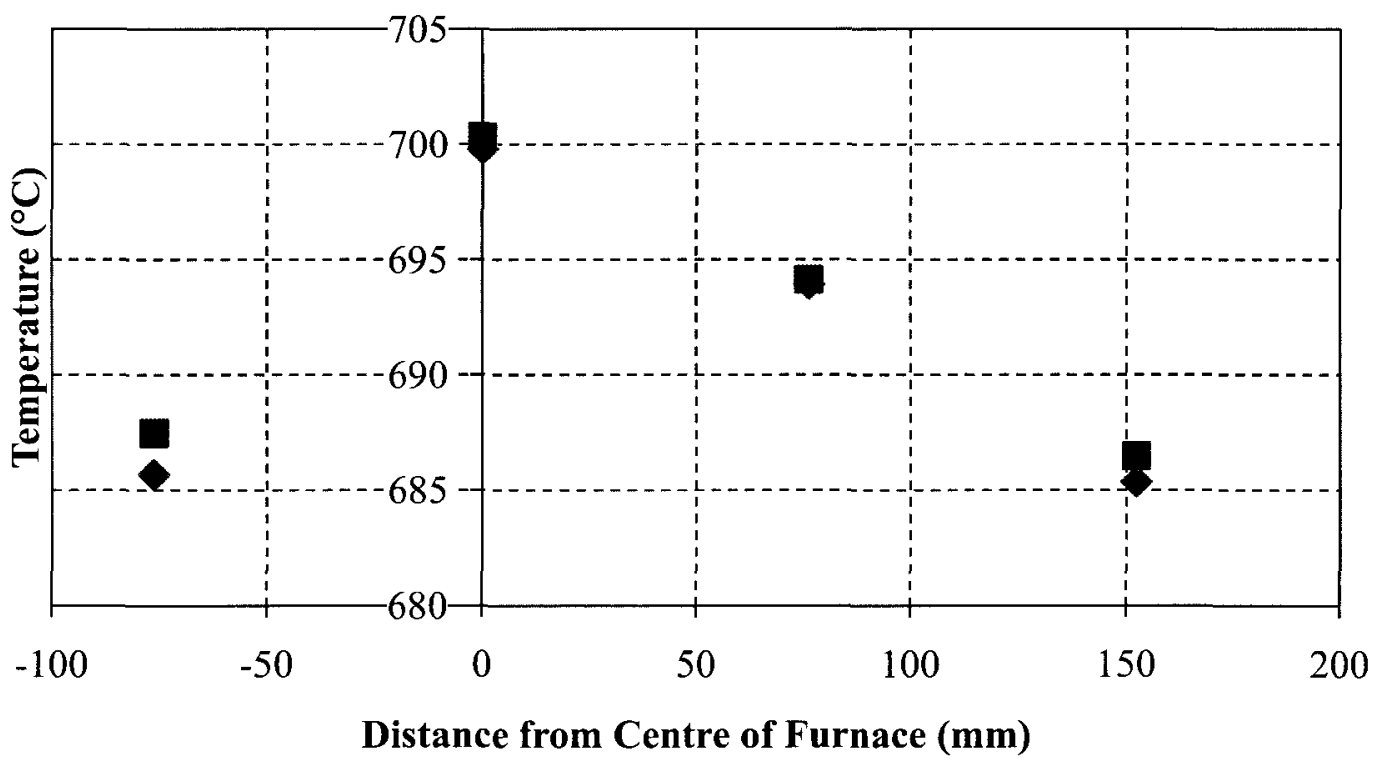

- $\left[785^{\circ} \mathrm{C}\left|735^{\circ} \mathrm{C}\right| 775^{\circ} \mathrm{C}\right]$ Initial Run $\quad \mathbf{a}\left[785^{\circ} \mathrm{C}\left|735^{\circ} \mathrm{C}\right| 780^{\circ} \mathrm{C}\right]$ Validation Run

Figure 5-11: Validation of the furnace set points to give $700^{\circ} \mathrm{C}$ at $15.0 \mathrm{MPa}$ 
Table 5-2: Summary of the thermal profiling trials conducted at $15.0 \mathrm{MPa}$

\begin{tabular}{|c|c|c|c|c|c|c|c|c|}
\hline \multicolumn{3}{|c|}{ Heated Zone Set Point } & \multicolumn{4}{|c|}{ Thermocouple Reading } & \multirow{2}{*}{$\Delta T_{\text {MAX }}$} & \multirow{2}{*}{$\frac{\Delta \mathbf{T}_{\text {MAX }}}{\mathbf{T}_{\text {MAX }}}$} \\
\hline 1 & 2 & 3 & T-14 & T-15 & T-16 & T-17 & & \\
\hline \multicolumn{3}{|c|}{$\left({ }^{\circ} \mathrm{C}\right)$} & \multicolumn{4}{|c|}{$\left({ }^{\circ} \mathrm{C}\right)$} & $\left({ }^{\circ} \mathrm{C}\right)$ & $(\%)$ \\
\hline 695 & 620 & 655 & 536.6 & 549.9 & 545.7 & 537.3 & 13.3 & 2.42 \\
\hline 685 & 610 & 645 & 547.2 & 559.1 & 553.5 & 546.7 & 12.3 & 2.21 \\
\hline 725 & 650 & 700 & 582.7 & 599.5 & 597.0 & 588.1 & 16.8 & 2.79 \\
\hline 725 & 640 & 690 & 590.9 & 602.0 & 596.2 & 589.7 & 12.3 & 2.04 \\
\hline 750 & 690 & 725 & 636.3 & 649.9 & 644.4 & 635.7 & 14.2 & 2.18 \\
\hline 755 & 695 & 725 & 637.8 & 650.0 & 643.7 & 636.2 & 13.8 & 2.13 \\
\hline 785 & 735 & 7775 & 685.7 & 699.8 & 693.9 & 685.4 & 14.4 & 2.06 \\
\hline 785 & 735 & 780 & 687.5 & 700.3 & 694.1 & 686.5 & 13.8 & 1.98 \\
\hline 800 & 750 & 800 & 708.2 & 721.5 & 715.5 & 708.2 & 13.3 & 1.84 \\
\hline & & & & & \multicolumn{2}{|c|}{ AVERAGE } & 13.8 & 2.18 \\
\hline
\end{tabular}

As an exploratory exercise, the furnace set points of zones 1 and 3 were set to the design temperature of the pressure vessel at $15.0 \mathrm{MPa}\left(800^{\circ} \mathrm{C}\right)$ and zone 2 was adjusted until a uniform temperature distribution was achieved. Thus, at $\left[800^{\circ} \mathrm{C}\left|750^{\circ} \mathrm{C}\right| 800^{\circ} \mathrm{C}\right]$, Figure 5-12 shows that S- $\mathrm{CO}_{2}$ could be heated to approximately $721^{\circ} \mathrm{C}-$ only $29^{\circ} \mathrm{C}$ less than the envisioned maximum testing capability of this facility - and maintained to within $13.3^{\circ} \mathrm{C}$ over the usable length of the specimen boat. Achieving a uniform fluid temperature of $750^{\circ} \mathrm{C}$ is certainly plausible, especially since the metal temperature at the midpoint of the furnace was $765.6^{\circ} \mathrm{C}$. However, a greater number of thermocouples - as a minimum, one in each heated zone of the furnace - should be mounted to the pressure vessel to ensure its safe operation as the set points are increased beyond $800^{\circ} \mathrm{C}$. In the meantime, a more optimal placement or greater number of heat reflectors within the bore of the pressure vessel should be investigated to increase fluid temperature. 


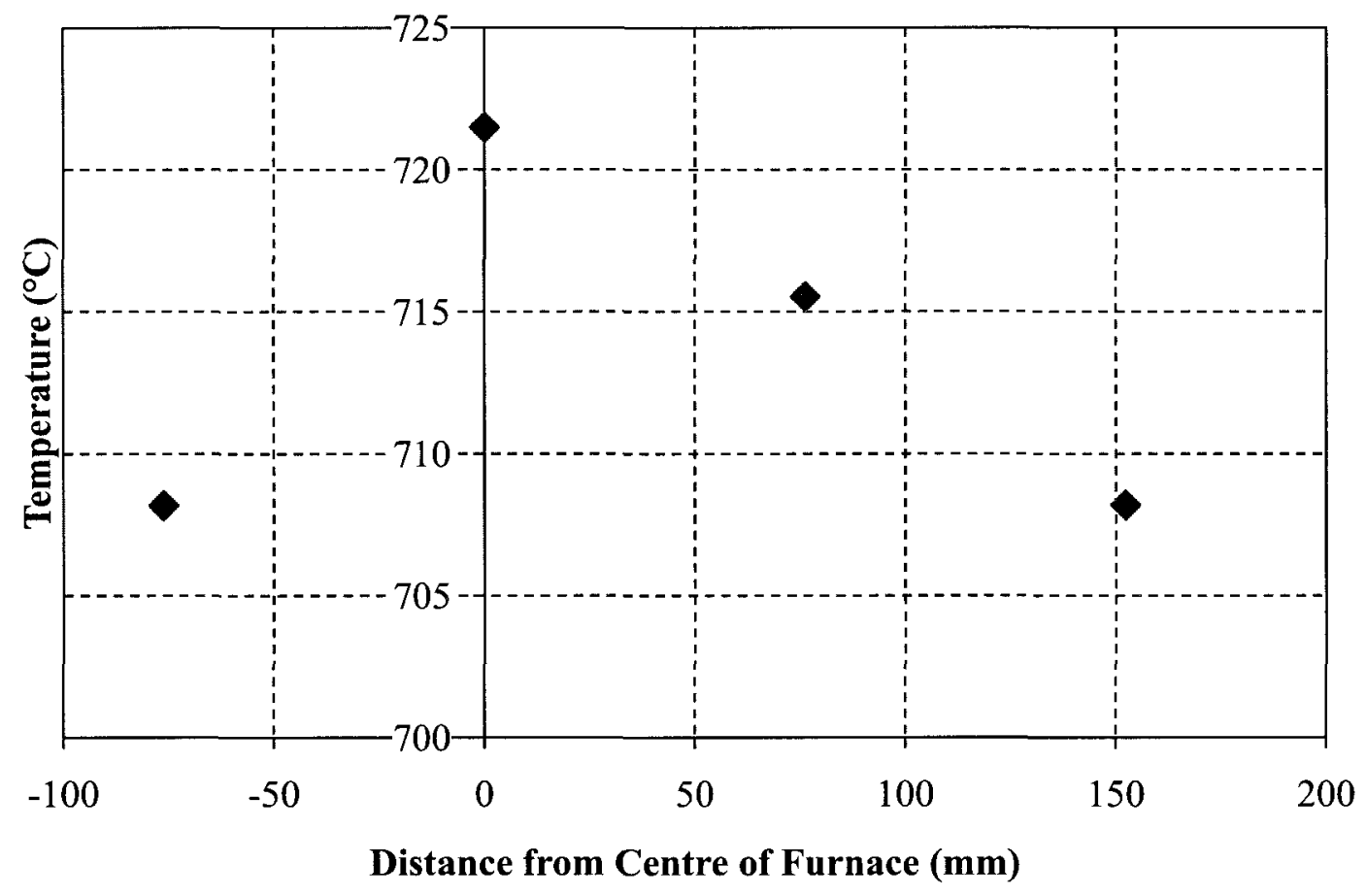

Figure 5-12: Temperature distribution using furnace set points of $\left[800^{\circ} \mathrm{C}\left|750^{\circ} \mathrm{C}\right| 800^{\circ} \mathrm{C}\right]$ at $15.0 \mathrm{MPa}$

Although not shown explicitly in any of the previous plots, the standard error associated with each thermocouple is $\pm 0.75 \%$ of its measured value; at $721.5^{\circ} \mathrm{C}$ (the largest recorded temperature), this amounts to $\pm 5.4^{\circ} \mathrm{C}$. Additionally, fluctuations in pressure at $15.0 \mathrm{MPa}$ are largely attributed to the duty cycle of the furnace and can be controlled to approximately $\pm 0.2 \mathrm{MPa}$, not including the maximum $\pm 0.02 \mathrm{MPa}$ reference accuracy of the transmitter. Figure 5-13 shows a representative sampling of pressure over a 10 hour window at $650^{\circ} \mathrm{C}$, with the average, maximum, and minimum recorded pressures being 14.97 $\mathrm{MPa}, 15.16 \mathrm{MPa}$, and 14.82 $\mathrm{MPa}$, respectively. For the same 10 hour window, Figure 5-14 illustrates the variation in both fluid temperature across zone 2 (T-2, T-13 through T-17) and metal temperature inside the furnace boundary (T-6). 


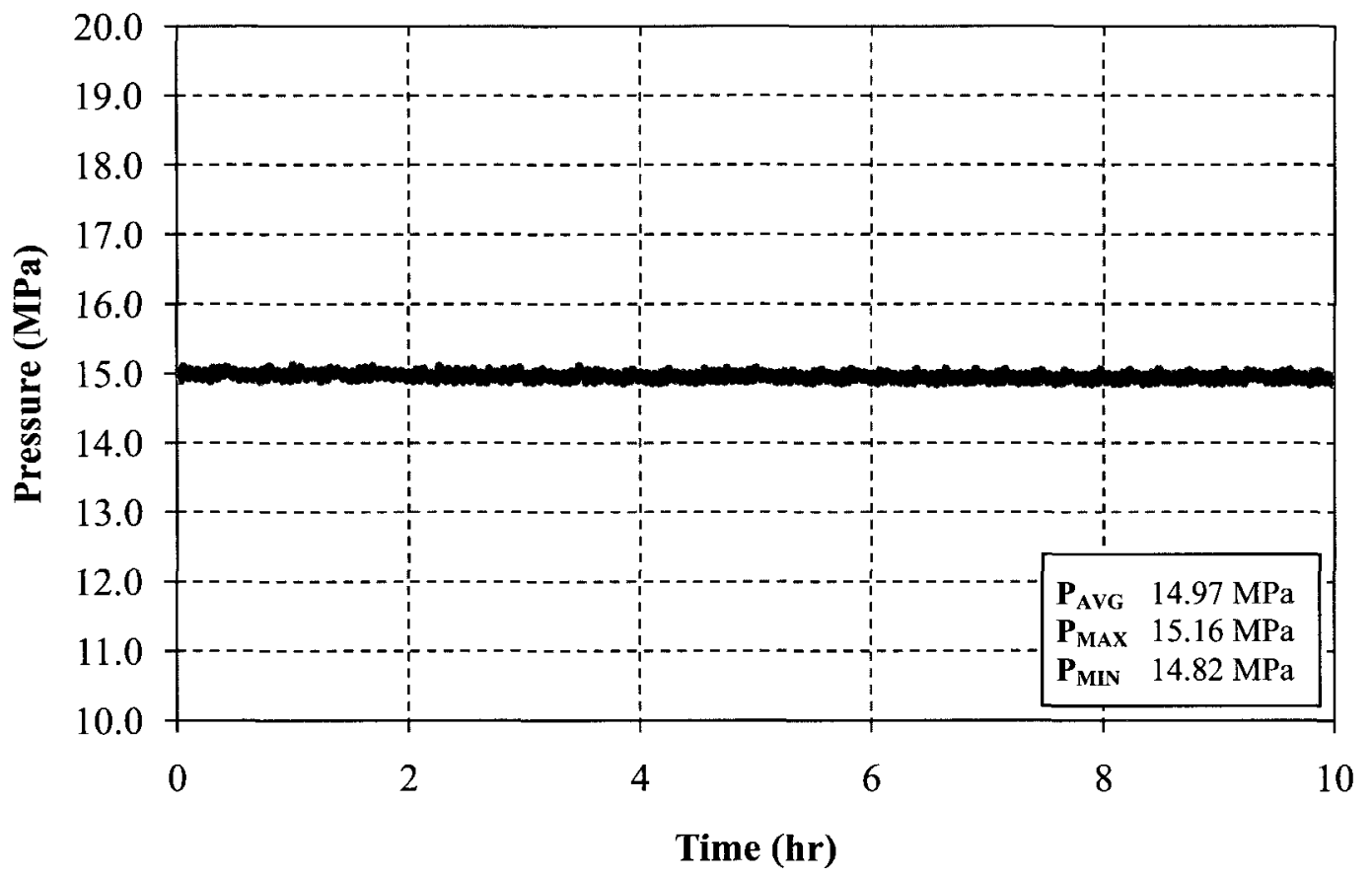

Figure 5-13: Pressure variations at $15.0 \mathrm{MPa}$ over a 10 hour period at $650^{\circ} \mathrm{C}$

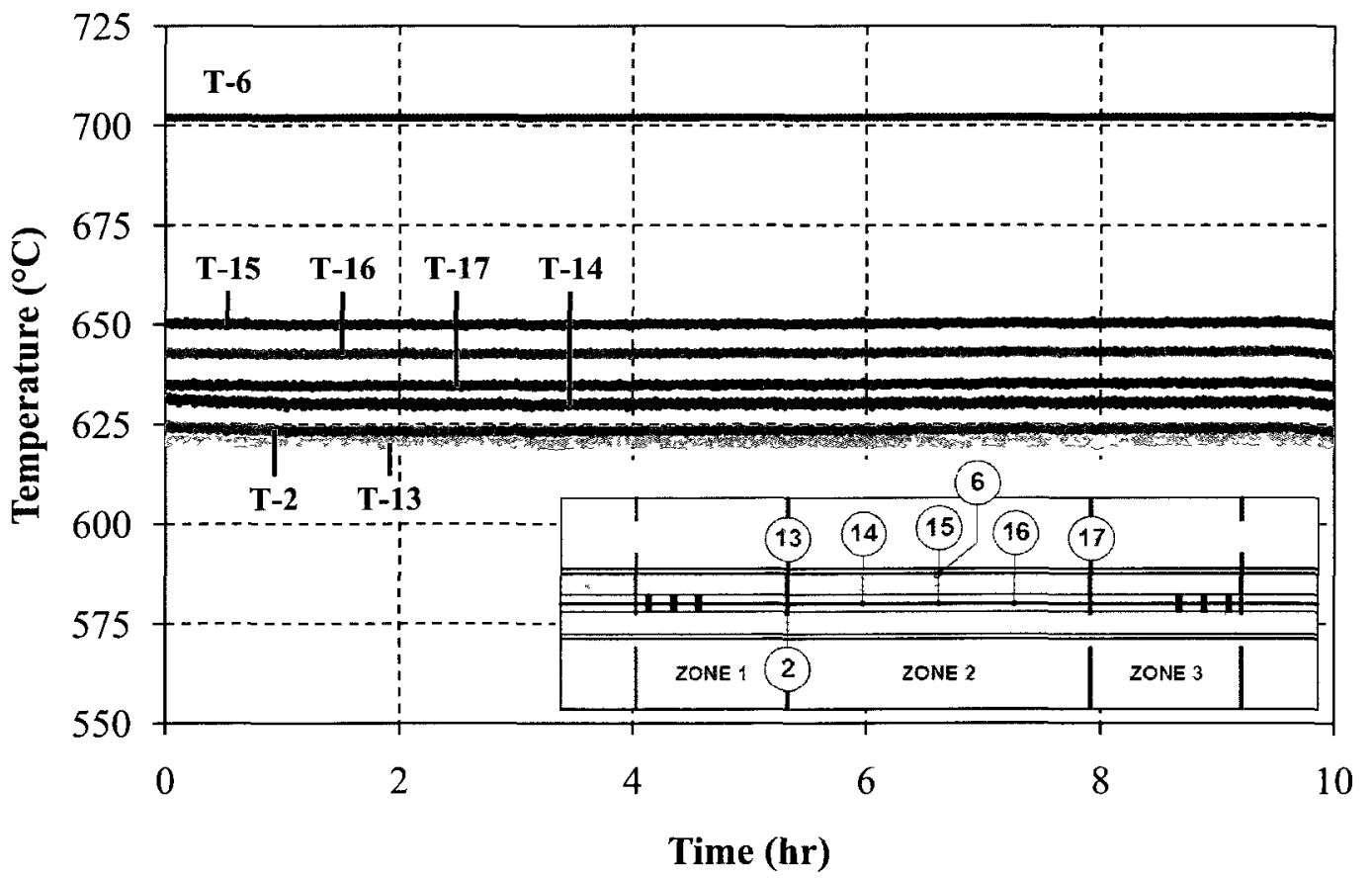

Figure 5-14: Temperature variations at $650^{\circ} \mathrm{C}$ over a 10 hour period at $15.0 \mathrm{MPa}$ 


\subsection{Pressure Effects on Performance}

Two additional thermal profiling trials were performed for 550 and $600^{\circ} \mathrm{C}$ but at 25.0 $\mathrm{MPa}$ to assess what effect operating at a higher pressure would have on the heating characteristics of this corrosion test rig. Intuitively, an increase in pressure, and hence an increase in density, should result in a lower fluid temperature for fixed furnace set points; just how much lower was unknown. As density increases, conductive heat transfer becomes more efficient [90] through the $\mathrm{S}-\mathrm{CO}_{2}$ and heat loss through the walls of the pressure vessel is expected to be greater. Figure 5-15, in fact, confirms this assumption, illustrating an increase in metal temperature outside the furnace for furnace set points of $\left[685^{\circ} \mathrm{C}\left|610^{\circ} \mathrm{C}\right| 645^{\circ} \mathrm{C}\right]$ and $\left[725^{\circ} \mathrm{C}\left|640^{\circ} \mathrm{C}\right| 690^{\circ} \mathrm{C}\right]$. Accordingly, Figures 5-16 and 5-17 both show an approximate $40^{\circ} \mathrm{C}$ reduction in fluid temperature at $25.0 \mathrm{MPa}$.

Only after this pressure investigation was completed was it realized that the using the same normalized flowrate at both pressures $(2.0 \mathrm{~L} / \mathrm{hr})$ would have produced fluid velocities at $25.0 \mathrm{MPa}$ that were approximately half of what they were at $15.0 \mathrm{MPa}$. However, the improved conduction mechanism at $25.0 \mathrm{MPa}$ seems to have a more pronounced effect on temperature distribution than velocity, shifting the entire profile to the right; i.e., the maximum temperature is observed at $\mathrm{T}-16$ rather than $\mathrm{T}-15$. Despite this noted shift in the $\mathrm{S}-\mathrm{CO}_{2}$ temperature distribution, Figure 5-18 suggests that the thermal time constant of this test rig is independent of its operating pressure. Increasing at a linear rate of $200^{\circ} \mathrm{C} / \mathrm{hr}$ from room temperature to furnace set points of $\left[685^{\circ} \mathrm{C}\left|610^{\circ} \mathrm{C}\right| 645^{\circ} \mathrm{C}\right]$, the time needed for $\mathrm{T}-15$ to reach a steady state is nearly identical at both 15.0 and $25.0 \mathrm{MPa}$. 


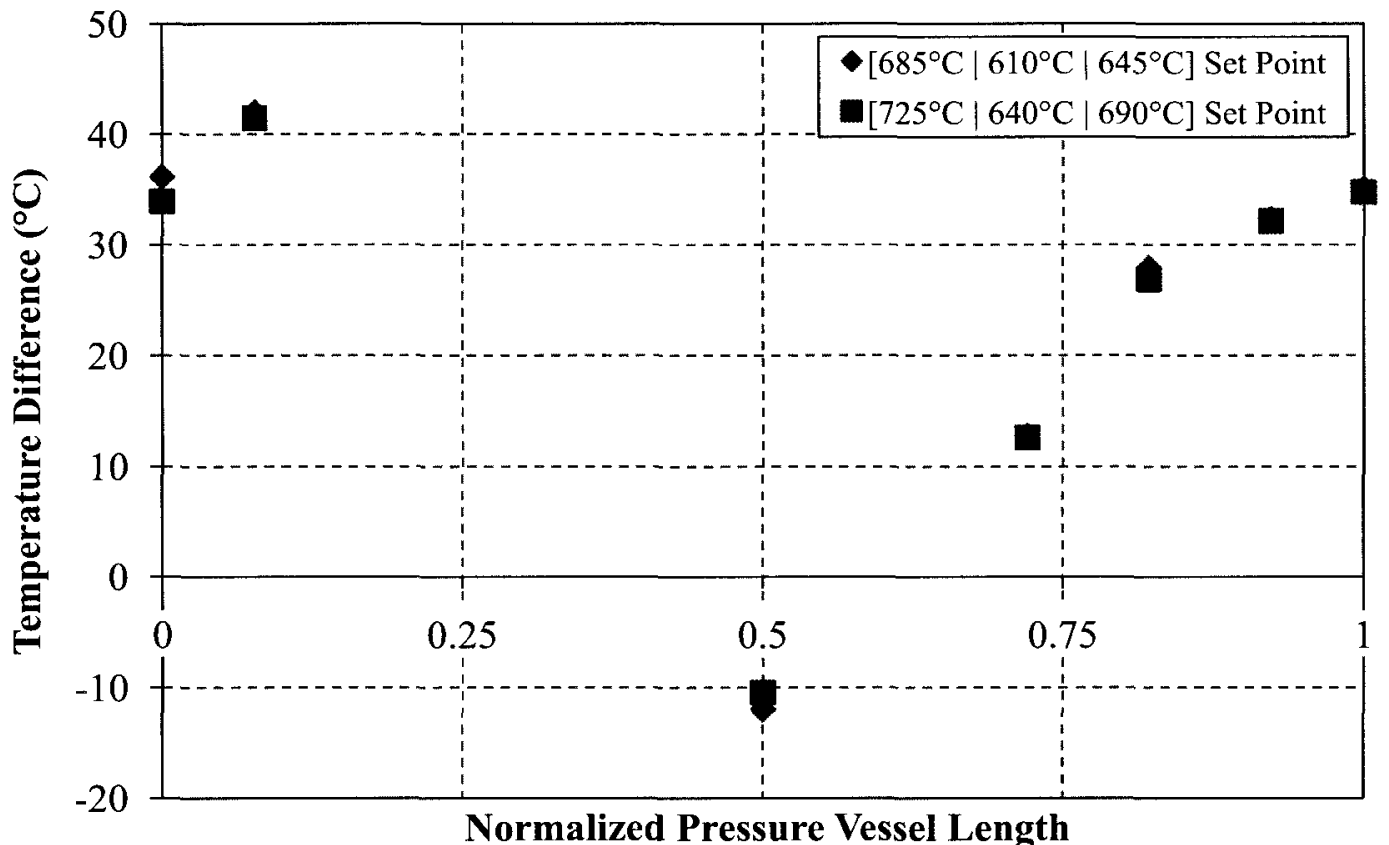

Figure 5-15: Differences in metal temperature at 25.0 MPa from 15.0 MPa for equivalent furnace set points

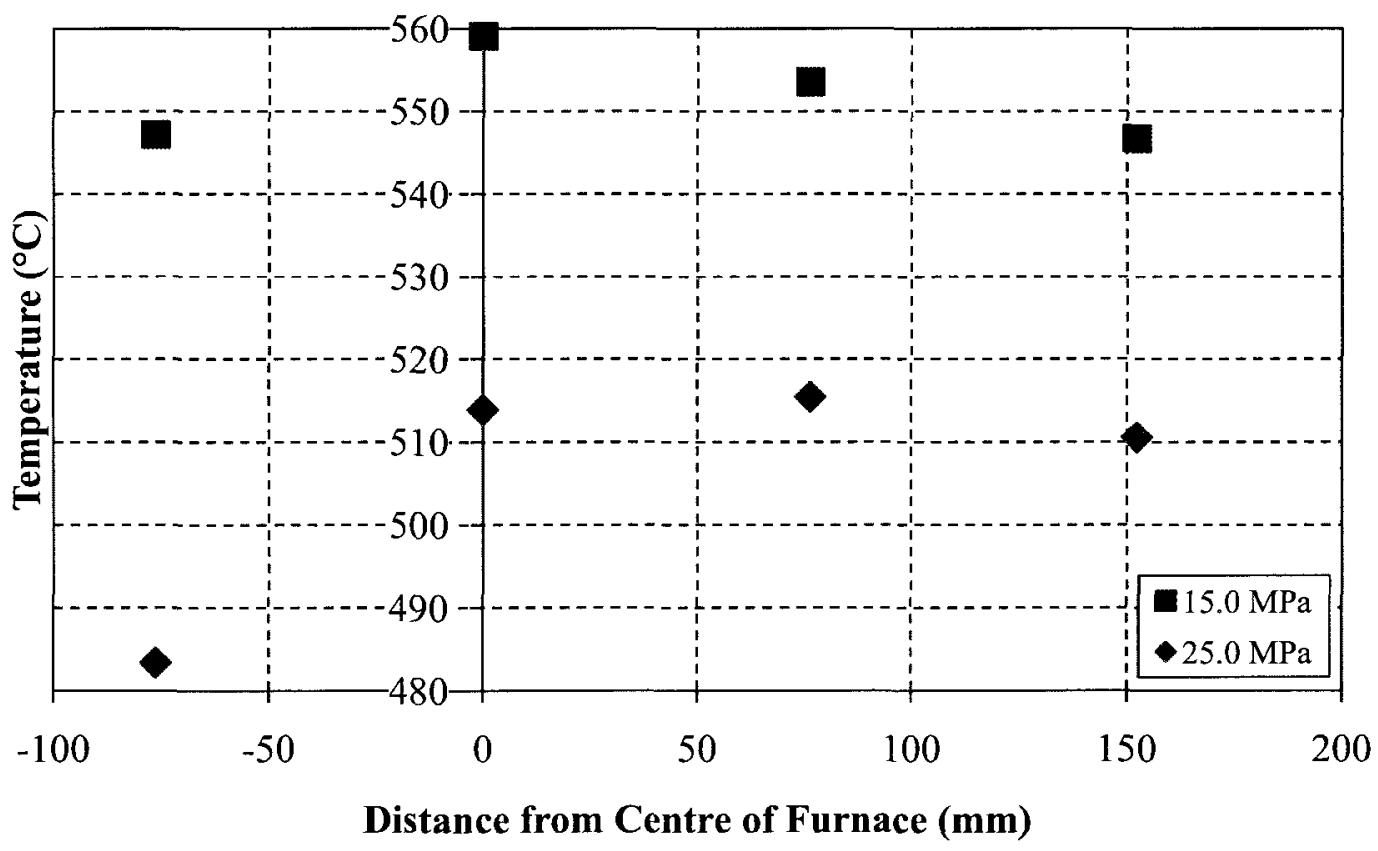

Figure 5-16: Temperature distributions using fixed furnace set points of $\left[685^{\circ} \mathrm{C}\left|610^{\circ} \mathrm{C}\right| 645^{\circ} \mathrm{C}\right]$ at 15.0 and $25.0 \mathrm{MPa}$ 


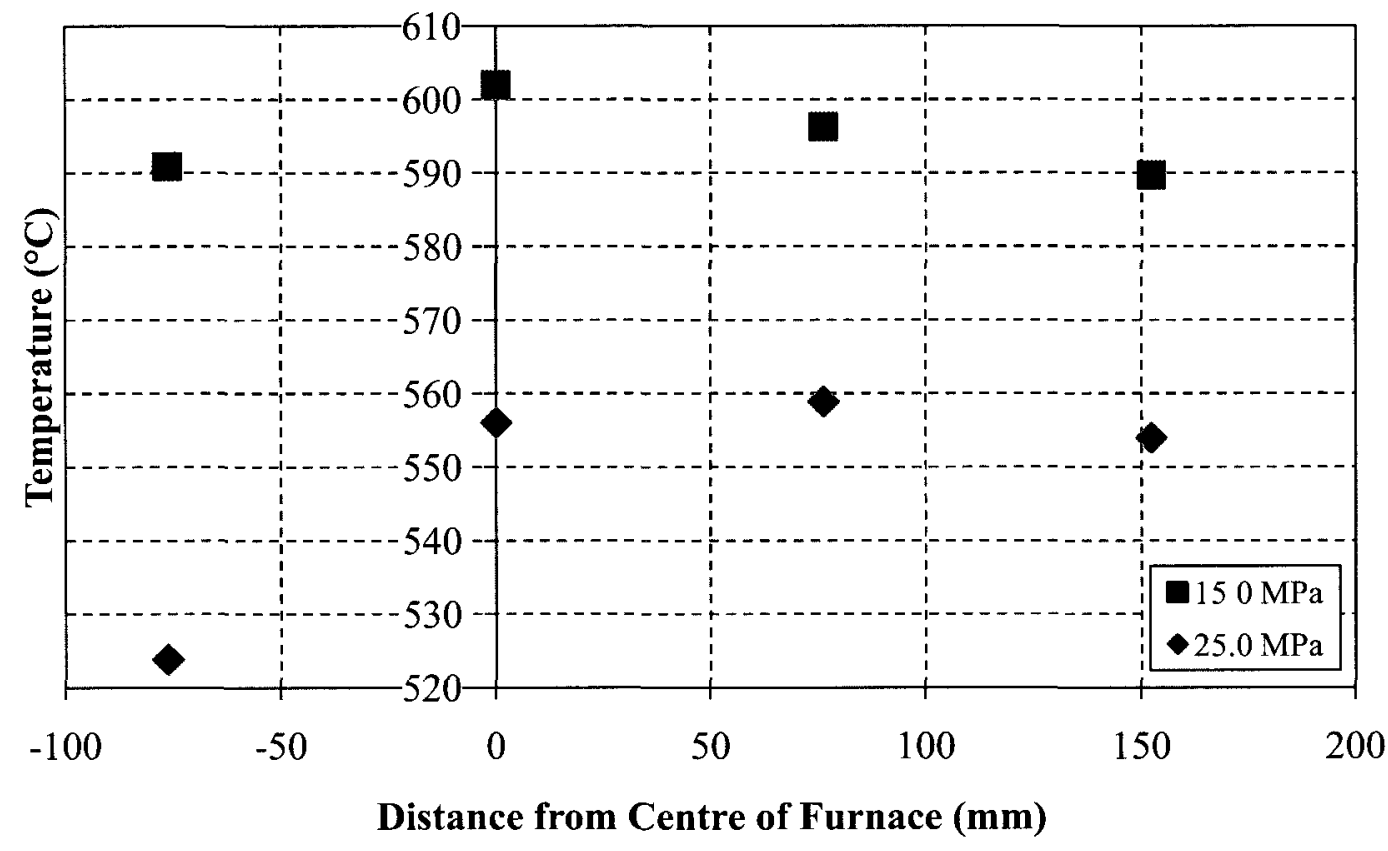

Figure 5-17: Temperature distributions using fixed furnace set points of $\left[725^{\circ} \mathrm{C}\left|640^{\circ} \mathrm{C}\right| 690^{\circ} \mathrm{C}\right]$ at 15.0 and $25.0 \mathrm{MPa}$

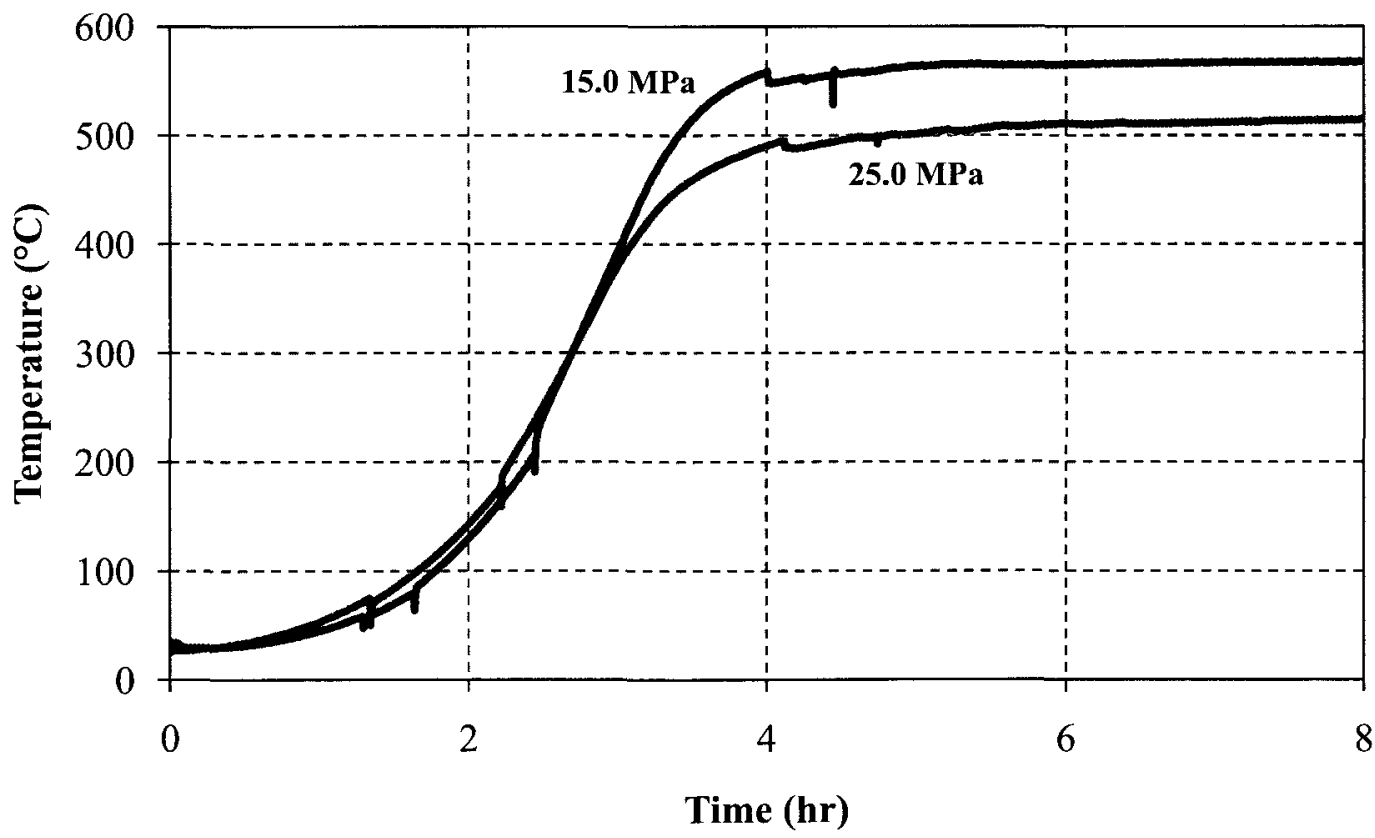

Figure 5-18: Thermal response of $\mathrm{T}-15$ from room temperature to fixed furnace set points of $\left[685^{\circ} \mathrm{C}\left|610^{\circ} \mathrm{C}\right| 645^{\circ} \mathrm{C}\right]$ at 15.0 and $25.0 \mathrm{MPa}$ 


\section{Summary and Conclusions}

Representing the first facility of its kind in Canada, the Carleton-NRCan $\mathrm{S}-\mathrm{CO}_{2}$ corrosion test rig was developed to satisfy two anticipated operating points: (i) $700^{\circ} \mathrm{C}$ at 25.0 MPa, or (ii) $750^{\circ} \mathrm{C}$ at $15.0 \mathrm{MPa}$. These operating points and the ability to accommodate test specimens measuring $12.7 \mathrm{~mm}$ ( $0.5 \mathrm{in}$.) in diameter give the CarletonNRCan facility testing capabilities comparable to those at MIT and UW-Madison using a relatively modest budget. On a global scale, the Carleton-NRCan corrosion test rig will undoubtedly contribute to the growing demand to evaluate the corrosion behaviour of various structural materials in high temperature $\mathrm{S}-\mathrm{CO}_{2}$. A better understanding of such corrosion mechanisms will assist in selecting or potentially developing alloys that will offer long-term reliability to the $\mathrm{S}-\mathrm{CO}_{2}$ Brayton cycle. The major conclusions that resulted from this thesis include:

1. The initial start-up of this test rig revealed the fluid temperature within the confines of the furnace to be approximately half that of the furnace set points. Consequently, the heating efficiency of the furnace was improved by adding three, equally-spaced, molybdenum heat reflectors on opposite sides of the furnace but inside the bore of the pressure vessel to mitigate the heat loss along its length.

2. Furnace set points that would yield a near-uniform temperature distribution across the usable length of the specimen boat were established and validated at 15.0 MPa for $550,600,650$, and $700^{\circ} \mathrm{C}$; similarly, limiting the maximum of any of furnace set points to $800^{\circ} \mathrm{C}$ (the design temperature of the pressure vessel) a 
uniform temperature was $721^{\circ} \mathrm{C}$ was attained. Of the nine trials conducted at 15.0 $\mathrm{MPa}$, temperature and pressure variations could be controlled to within 12.3 to $16.8^{\circ} \mathrm{C}$ and $\pm 0.2 \mathrm{MPa}$, respectively, once a steady state had been reached.

3. Preliminary functional testing at $25.0 \mathrm{MPa}$ indicated an approximate $40^{\circ} \mathrm{C}$ decrease in average $\mathrm{S}-\mathrm{CO}_{2}$ temperature from $15.0 \mathrm{MPa}$ for equivalent furnace set points.

\subsection{Future Work}

Given that this corrosion test rig is now operational, commissioning needs to be completed at 25.0 MPa to ascertain what maximum $\mathrm{S}-\mathrm{CO}_{2}$ temperature can be uniformly achieved within the pressure vessel. Once this maximum temperature is defined, furnace set points that will give uniform distributions at lower temperatures - presumably 500, 550,600 , and $650^{\circ} \mathrm{C}$ - will need to be determined and validated as was done at 15.0 MPa. Likewise, the commissioning envelope can be further expanded to include 10.0 MPa and 20.0 MPa; this will ultimately provide a catalogue of furnace set points to use for any conceivable combination of test conditions.

A thorough investigation should also be carried out to confirm if the current placement and number of heat reflectors inside the bore of the pressure vessel is indeed the optimal arrangement. Affixing the heat reflectors to the sheaths of each thermocouple probe was found to have the unwanted effect of shifting the maximum temperature inside the pressure vessel slightly right of its centre. One option to remedy this effect would be to provide a fluid path into and out of the pressure vessel that is not directly influenced by 
the presence of the heat reflectors. The 316-SS tubing that surrounds each thermocouple probe, prior to interfacing with the pressure vessel, could be extended inside the pressure vessel and the heat reflectors attached to this tubing instead. Another option to increase the heating efficiency of the furnace is to wrap the surface of the pressure vessel immediately at its boundary with the furnace - with insulation. This would undoubtedly require that another detailed FEA be performed to verify that: (i) sufficient length of the IN-625 is still exposed to dissipate heat, and (ii) thermal stresses are not too severe.

Ideally, the commissioning process would have been conducted with the specimen boat in-situ to give the most representative conditions of an actual corrosion test. However, excess weld slag from joining the Grayloc $($ hubs to the $\mathrm{N}-625$ section prevented the specimen boat from actually being inserted into the pressure vessel. This problem needs to be addressed and resolved before a more detailed thermal characterization can be executed, but, most importantly, before corrosion testing can begin. Price-Schonstrom Inc. has indicated that this work will be done at their expense but leaves the test rig inoperable while it is carried out. Once this work is completed though, a preliminary corrosion test at $650^{\circ} \mathrm{C}$ and $15.0 \mathrm{MPa}$ for 500 hours will be initiated; five stainless steels - 15-5, 17-7, 316-SS, 416-SS, and 420-SS - and one nickelbase superalloy - IN-738LC - have been acquired for this very purpose.

Corrosion testing that will inevitably result from this facility should distinguish what effect pressure has on the corrosion response of suitable construction materials nickel-base superalloys - in $\mathrm{S}-\mathrm{CO}_{2}$, even more so than what was done by Dunlevy [38]. The corrosion mechanism of these same materials should also be investigated at several 
temperatures to determine what, if any, effect the dissociation of $\mathrm{CO}_{2}$ to $\mathrm{CO}$ above $700^{\circ} \mathrm{C}$ will have on the corrosion rate. Lastly, each corrosion trial that is performed should be done so at durations (i.e. 3000 hours) that will either confirm or refute the long-term stability of the various oxide layers. However, to successfully achieve all of the abovementioned would require several test rigs to be operated concurrently or a compromise be made between the number of test points evaluated and the duration of each test. 


\section{References}

[1] International Energy Agency, World Energy Outlook, R. Priddle, Ed. Paris, France, 2009.

[2] T. Yokoyama, "Japanese $\mathrm{R} \& \mathrm{D}$ on $\mathrm{CO}_{2}$ Capture," in Proc. of the 6th International Conference of Greenhouse Gas Control Technologies, vol. I, Kyoto, Japan, 1-4 Oct. 2002, pp. 13-18.

[3] "A Technology Roadmap for Generation IV Nuclear Energy Systems," U.S. DOE Nuclear Energy Research Advisory Committee and the Generation-IV International Forum, GIF-002-00, Dec. 2002.

[4] "GIF R\&D Outlook for Generation IV Nuclear Energy Systems," Generation IV International Forum, Aug. 2009.

[5] J. Lillington, The Future of Nuclear Power. Oxford, UK: Elsevier Ltd., 2004.

[6] V. Dostal, "A Supercritical Carbon Dioxide Cycle for Next Generation Nuclear Reactors," Massachusetts Institute of Technology, Cambridge, MA, Ph.D. dissertation, Jan. 2004.

[7] T. Schulenberg, H. Wider, M.A. Fütterer, "Electricity Production in Nuclear Power Plants - Rankine vs. Brayton Cycles," in ANS/ENS International Winter Meeting (GLOBAL 2003), New Orleans, LA, 16-20 Nov. 2003.

[8] Y. Kato, T. Nitawaki, Y. Muto, "Medium Temperature Carbon Dioxide Gas Turbine Reactor," Nuclear Engineering and Design, vol. 230, no. 1-3, pp. 195207, 2004.

[9] M.L. Corradini, "Transport Phenomena in Supercritical Fluids in GENIV Reactor Designs," in Proc. of the 12th International Meeting on Nuclear Reactor Thermal Hydraulics (NURETH-12), Pittsburgh, PA, 30 Sept.-4 Oct. 2007.

[10] A. Moisseytsev, J.J. Sienicki, "Extension of the Supercritical Carbon Dioxide Brayton Cycle for Application to the Very High Temperature Reactor," in Proc. of the International Congress on Advances in Nuclear Power Plants (ICAPP '10), San Diego, CA, 13-17 June 2010.

[11] C.H. Oh et al, "Development of a Supercritical Carbon Dioxide Brayton Cycle: Improving VHTR Efficiency and Testing Material Compatibility," Idaho National Laboratory, Idaho Falls, ID, INL/EXT-06-01271, Mar. 2006. 
[12] C.S. Turchi, "Supercritical $\mathrm{CO}_{2}$ for Application in Concentrating Solar Power Systems," in Proc. of Supercritical $\mathrm{CO}_{2}$ Power Cycle Symp. 2009, Troy, NY, 2930 Apr. 2009.

[13] D.J. Chapman, D.A. Arias, "An Assessment of the Supercritical Carbon Dioxide Cycle for Use in Solar Parabolic Trough Power Plant," in Proc. of Supercritical $\mathrm{CO}_{2}$ Power Cycle Symp. 2009, Troy, NY, 29-30 Apr. 2009.

[14] G.A. Johnson, M. McDowell, "Issues Associated with Coupling Supercritical $\mathrm{CO}_{2}$ Power Cycles to Nuclear, Solar and Fossil Fuel Heat Sources," in Proc. of Supercritical $\mathrm{CO}_{2}$ Power Cycle Symp., Troy, NY, 29-30 Apr. 2009.

[15] National Institute of Standards and Technology (NIST). (2010, Sept.) Carbon Dioxide Gas Phase Thermochemistry Data. [Online]. http://webbook.nist.gov/cgi/ cbook.cgi?ID=C124389\&Units=SI\&Mask=4\#Thermo-Phase

[16] M.A. Jacobs, "Measurement and Modeling of Thermodynamic Properties for the Processing of Polymers in Supercritical Fluids," Technische Universiteit Eindhoven, Eindhoven, Netherlands, Ph.D. dissertation, Sept. 2004.

[17] National Institute of Standards and Technology (NIST). (2010, September) Helium Gas Phase Thermochemistry Data. [Online]. http://webbook.nist.gov/cgi/ cbook.cgi?ID $=$ C7440597\&Units=SI\&Mask=4\#Thermo-Phase

[18] V. Dostal, P. Hejzlar, M.J. Driscoll, "High-Performance Supercritical Carbon Dioxide Cycle for Next-Generation Nuclear Reactors," Nuclear Technology, vol. 154, no. 3, pp. 265-282, June 2006.

[19] V. Dostal, P. Hejzlar, M.J. Driscoll, "The Supercritical Carbon Dioxide Power Cycle: Comparison to Other Advanced Cycles," Nuclear Technology, vol. 154, no. 3, pp. 283-301, June 2006.

[20] J. Sarkar, "Second Law Analysis of Supercritical $\mathrm{CO}_{2}$ Recompression Cycle," Energy, vol. 34, no. 10, pp. 1172-1178, September 2009.

[21] J. Ashcroft, K. Kimball, M. Corcoran, "Overview of Naval Reactors Program Development of the Supercritical Carbon Dioxide Brayton System," in Supercritical $\mathrm{CO}_{2}$ Power Cycle Symposium 2009, Troy, NY, USA, 2009.

[22] V. Dostal, M. Kulhanek, "Research on the Supercritical Carbon Dioxide Cycles in the Czech Republic," in Supercritical $\mathrm{CO}_{2}$ Power Cycle Symposium 2009, Troy, NY, USA, 2009. 
[23] F.W. Schremp, G.R. Roberson, "Effect of Supercritical Carbon Dioxide $\left(\mathrm{CO}_{2}\right)$ on Construction Materials," Society of Petroleum Engineers Journal, vol. 15, no. 3, pp. 227-233, June 1975.

[24] E.M. Russick et al., "Corrosive Effects of Supercritical Carbon Dioxide and Cosolvents on Metals," The Journal of Supercritical Fluids, vol. 9, no. 1, pp. 4350, Mar. 1996.

[25] W.A. Propp et al., "Corrosion in Supercritical Fluids," Idaho National Laboratory, Idaho Falls, ID, INEL-96/0180, May 1996.

[26] C. Tyzack, H.C. Cowen, "The Corrosion of Reactor Materials in Carbon Dioxide," Atomic Energy Review, vol. 14, no. 2, pp. 263-324, 1976.

[27] R.A. Brierley, "Studies of the Oxidation of 9 and $12 \mathrm{Cr}$ Steels in High Temperature, High Pressure $\mathrm{CO}_{2}$," in Proc. of the British Nuclear Energy Society International Conference at Reading University, Berkshire, UK, 23-24 Sept. 1974, pp. 165-179.

[28] P.C. Rowlands et al., "Oxidation of 9\% Cr Steels in High Pressure High Temperature $\mathrm{CO}_{2}$," in Proc. of the British Nuclear Energy Society International Conference at Reading University, Berkshire, UK, 23-24 Sept. 1974, pp. 193207.

[29] P.L. Harrison et al., "The Oxidation of 9Cr 1Mo Steels in Carbon Dioxide - A Discussion of Possible Mechanisms," in Proc. of the British Nuclear Energy Society International Conference at Reading University, Berkshire, UK, 23-24 Sept. 1974, pp. 220-233.

[30] M.G.C. Cox, B. McEnaney, V.D. Scott, "Structure and Growth of Oxide on IronChromium Alloys," in Proc. of the British Nuclear Energy Society International Conference at Reading University, Berkshire, UK, 23-24 Sept. 1974, pp. 247256.

[31] P.L. Surman et al., "Methods of Controlling the Oxidation of $9 \mathrm{Cr} / 1 \mathrm{Mo}$ Steel in High Temperature $\mathrm{CO}_{2}$," in Proc. of the British Nuclear Energy Society International Conference at Reading University, Berkshire, UK, 23-24 Sept. 1974, pp. 257-271.

[32] J.C.P. Garrett et al., "Some Factors in the Oxidation of Austenitic Stainless Steels," in Proc. of the British Nuclear Energy Society International Conference at Reading University, Berkshire, UK, 23-24 Sept. 1974, pp. 298-310. 
[33] T. Furukawa, Y. Inagaki, M. Aritomi, "Corrosion Behaviour of FBR Structural Materials in High Temperature Supercritical Carbon Dioxide," Journal of Power and Energy Systems, vol. 4, no. 1, pp. 252-261, 2010.

[34] J.P. Gibbs, "Corrosion of Various Engineering Alloys in Supercritical Carbon Dioxide," Massachusetts Institute of Technology, Cambridge, MA, M.S. Thesis June 2010.

[35] J.Y. Lim et al., "Corrosion of Materials in Supercritical Carbon Dioxide Environments," in Proc. of NACE International Corrosion 2008, New Orleans, LA, 16-20 Mar. 2008.

[36] K. Sridharan et al., "Corrosion of Candidate Alloys in Supercritical Carbon Dioxide," in Proc. of Supercritical $\mathrm{CO}_{2}$ Power Cycle Symp., Troy, NY, 29-30 Apr. 2009.

[37] F. Rouillard, F. Charton, G. Moine, "Corrosion Behaviour of Different Metallic Materials in Supercritical $\mathrm{CO}_{2}$ at $550^{\circ} \mathrm{C}$ and 250 bars," in Proc. of Supercritical $\mathrm{CO}_{2}$ Power Cycle Symp., Troy, NY, 29-30 Apr. 2009.

[38] M.W. Dunlevy, "An Exploration of the Effect of Temperature on Different Alloys in a Supercritical Carbon Dioxide Environment," Massachusetts Institute of Technology, Cambridge, MA, M.S. Thesis Sept. 2009.

[39] M. Donachie Jr., S. Donachie, Superalloys: A Technical Guide, 2nd ed. Materials Park, OH: ASM International, 2002.

[40] R.C. Reed, The Superalloys: Fundamentals and Applications. New York, NY, USA: Cambridge University Press, 2006.

[41] C.T. Sims, N.S. Stoloff, W.C. Hagel, Superalloys II. New York, NY, USA: Wiley-Interscience, 1987.

[42] M. Durand-Charre, The Microstructure of Superalloys. Amsterdam, The Netherlands: Gordon and Breach Science Publishers, 1997.

[43] T.M. Pollock, S. Tin, "Nickel-Based Superalloys for Advanced Turbine Engines: Chemistry, Microstructure, and Properties," Journal of Propulsion and Power, vol. 22, no. 2, pp. 361-374, March-April 2006.

[44] J.R. Davis, Nickel, Cobalt, and Their Alloys. Materials Park, OH: ASM International, 2000. 
[45] G.Y. Lai, High-Temperature Corrosion and Materials Applications. Materials Park, OH: ASM International, 2007.

[46] T.J.A. Richardson, Ed., Shreir's Corrosion, 4th ed. Oxford, UK: Elsevier Ltd., 2010, vol. I.

[47] N. Birks, G.H. Meier, F.S. Pettit, Introduction to the High-Temperature Oxidation of Metals, 2nd ed. Cambridge, UK: Cambridge University Press, 2006.

[48] P. Kofstad, High Temperature Corrosion. London and New York: Elsevier Applied Science Publishers Ltd., 1988.

[49] O. Toft Sørensen, Ed., Nonstoichiometric Oxides. London, UK: Academic Press, Inc., 1981.

[50] R. Prescott, M.J. Graham, "The Formation of Aluminium Oxide Scales on HighTemperature Alloys," Oxidation of Metals, vol. 38, no. 3/4, pp. 233-254, 1992.

[51] G.B. Gibbs, R.E. Pendlebury, M.R. Wootton, "Protective and Breakaway Oxidation of Mild Steel in $\mathrm{CO}_{2}$," in Proc. of the British Nuclear Energy Society International Conference at Reading University, Berkshire, UK, 23-24 Sept. 1974, pp. 59-72.

[52] A.M. Pritchard et al., "Some Investigations into the Mechanism of Breakaway Oxidation of Three Mild Steels in High Pressure $\mathrm{CO}_{2}$ at $500^{\circ} \mathrm{C}$," in Proc. of the British Nuclear Energy Society International Conference at Reading University, Berkshire, UK, 23-24 Sept. 1974, pp. 73-84.

[53] D.J. Young, High Temperature Oxidation and Corrosion of Metals. Oxford, UK: Elsevier Ltd., 2008.

[54] H.J. Grabke, I. Wolf, "Carburization and Oxidation," Materials Science and Engineering, vol. 87, pp. 23-33, Mar. 1987.

[55] M. Schutze H.J. Grabke, Ed., Corrosion by Carbon and Nitrogen - Metal Dusting, Carburization, and Nitridation. Cambridge, UK: Woodland Publishing Ltd., 2007.

[56] P. Szakalos, M. Lundberg, R. Pettersson, "Metal Dusting on an Alumina-forming Ni-base Alloy," Corrosion Science, vol. 48, no. 7, pp. 1679-1695, July 2006.

[57] S.R. Shatynski, "The Thermochemistry of Transition Metal Carbides," Oxidation of Metals, vol. 13, no. 2, pp. 105-118, Apr. 1979. 
[58] D. Farkas, "Corrosion of Nickel-Base Superalloys in Simultaneous Carburizing and Oxidizing Environments," in Proc. of Materials in Nuclear Energy, Huntsville, ON, 29 Sept.-2 Oct. 1982, pp. 227-233.

[59] M. Shindo, H. Nakajima, "Effects of Carburization and Aging on the Tensile Properties of an Experimental Ni-Cr-W Superalloy," Journal of Nuclear Materials, vol. 144, no. 1-2, pp. 20-28, Jan. 1987.

[60] J. Zhang, D.J. Young, "Kinetics and Mechanisms of Nickel Metal Dusting I. Kinetics and Morphology," Corrosion Science , vol. 49, no. 3, pp. 1496-1512, Mar. 2007.

[61] G.W. Stachowiak, A.W. Batchelor, Engineering Tribology. Oxford, UK: Elsevier Ltd., 2005.

[62] A.W. Batchelor, L.N. Lam, M. Chandrasekaran, Materials Degradation and its Control by Surface Engineering, 2nd ed. London, UK: Imperial College Press, 2002.

[63] I. Kleis, P. Kulu, Solid Particle Erosion: Occurrence, Prediction and Control. London, UK: Springer Ltd., 2008.

[64] D.M. Rishel, F.S. Pettit, N. Birks, "Some Principal Mechanisms in the Simultaneous Erosion and Corrosion Attack of Metals at High Temperatures," Materials Science and Engineering, vol. 143, no. 1-2, pp. 197-211, Sept. 1991.

[65] R. Baboian, Ed., Corrosion Tests and Standards: Application and Interpretation, 2nd ed. West Conshohocken, PA: ASTM International, 2005.

[66] D.B. Meadowcroft H.J. Grabke, Ed., Guidelines for Methods of Testing and Research in High Temperature Corrosion. London, UK: The Institute of Materials, 1995.

[67] J.R. Nicholls, "Laboratory Studies of Erosion-Corrosion Processes Under Oxidising and Oxidising/Sulphidising Conditions," Materials at High Temperatures, vol. 14, no. 3, pp. 289-306, 1997.

[68] N. Hayashi et al., "Development of a New Testing Method by Centrifugal Erosion Tester at Elevated Temperature," Wear, vol. 258, no. 1-4, pp. 443-457, Jan. 2005.

[69] F.H. Stott et al., "The Erosion-Corrosion of Alloys Under Oxidizing-Sulphidizing Conditions at High Temperature," Wear, vol. 186-187, no. 1, pp. 291-298, July 1995. 
[70] A.V. Levy, Solid Particle Erosion and Erosion-Corrosion of Materials. Materials Park, OH: ASM International, 1995.

[71] W.F. Adler, Erosion: Prevention and Useful Application. Baltimore, MD: ASTM, 1979.

[72] A.V. Levy, J. Yan, J. Patterson, "Elevated Temperature Erosion of Steels," Wear, vol. 108, no. 1, pp. 43-60, Mar. 1986.

[73] R. Flitney, Seals and Sealing Handbook, 5th ed. Oxford, UK: Elsevier Ltd., 2007.

[74] R. Viswanathan, "Boiler Materials for USC Plant," in 17th Annual NETL Conf. on Fossil Energy Materials, 22-24 Apr. 2003.

[75] Y. Kato, "Overview of Supercritical $\mathrm{CO}_{2}$ Cycle Studies at TokyoTech," in Proc. of MIT-TokyoTech Symp. on Innovative Nuclear Energy Systems, Cambridge, MA,

2-4 Nov. 2005.

[76] P. Hejzlar et al., "Supercritical $\mathrm{CO}_{2}$ Brayton Cycle for Medium Power Applications," Massachusetts Institute of Technology, Cambridge, MA, MITANP-PR-117, July 2007.

[77] INL Portal. (Dec. 2010) Fiscal Year 2010 Nuclear Energy University Program Research and Development Awards. [Online]. https://inlportal.inl.gov/portal/ server.pt/gateway/PTARGS_0_2_61553_0_0_18/10-872_Sridharan_lmp_5-610.pdf

[78] F. Rouillard, Private communication, Mar. 2011.

[79] T.J.A. Richardson, Ed., Shreir's Corrosion, 4th ed. Oxford, UK: Elsevier Ltd., 2010, vol. II.

[80] B.A. Sexton, R.St.C. Smart D.J. O'Connor, Ed., Surface Analysis Methods in Materials Science, 2nd ed. Heidelberg, Germany: Springer, 2003.

[81] J.E. Antill, J.B. Warburton, "Oxidation of Nickel by Carbon Dioxide," Journal of the Electrochemical Society, vol. 114, no. 12, pp. 1215-1221, Dec. 1967.

[82] US DOE. (Mar. 2011) Oxide Dispersion-Strengthened Alloys - Fossil Energy. [Online].

http://fossil.energy.gov/international/Publications/DECC_task_08_US_2page.pdf

[83] C. Moore, Private Communication, Mar. 2011 
[84] C. Moore, PVECalc-3786, unpublished.

[85] A. Schuegraf, Preliminary Heating Characteristics of IN-625 Pressure Vessel, unpublished.

[86] J.R. Farr, M.H. Jawad, Guidebook for the Design of ASME Section VIII Pressure Vessels, 2nd ed. New York, NY: ASME Press, 2001.

[87] (Mar. 2011) Oceaneering - Grayloc® Products. [Online]. http:// www.oceaneering.com/oceandocuments/brochures/subseaproducts/GRLC\%20$\% 20$ The $\% 20$ Ultimate $\% 20$ Connector.pdf

[88] SC Hydraulic Engineering Corporation. (Mar. 2010) GB Gas Boosters and Systems - Rev. 10-15-06. [Online]. http://www.schydraulic.com/documents/ GasBoosterREV10-15-06.pdf

[89] American Petroleum Institute, Sizing, Selection, and Installation of PressureRelieving Devices in Refineries, Part I. Washington, D.C.: API Publishing Services, Jan. 2000.

[90] J.P. Holman, Heat Transfer, 9th ed. New York, NY: McGraw-Hill, 2002. 


\section{APPENDIX A: Bill of Materials}

\begin{tabular}{|c|c|c|c|}
\hline ID & COMPONENT DESCRIPTION & PART NO. & QTY. \\
\hline $\mathrm{V}-1$ & $1 / 4$ in. tube fitting ball valve & SS-43S4 & 1 \\
\hline $\mathrm{V}-2$ & 1/8 in. NPT, normally-closed solenoid valve & $8264 \mathrm{G} 009$ & 1 \\
\hline $\mathrm{V}-3$ & $1 / 4$ in. tube fitting, three-way ball valve & SS-43GXS4 & 1 \\
\hline $\mathrm{U}-1$ & Tee-type, $15.0 \mu \mathrm{m}$ particulate filter & SS-4TF-15 & 1 \\
\hline V-4 & $1 / 2$ in. FNPT ball valve & 465499 & 1 \\
\hline F/R-1 & $3 / 4$ in. FNPT filter-regulator & B74G-6AK-QD3-RMG-F/R & 1 \\
\hline $\mathrm{V}-5$ & $3 / 4$ in. NPT, normally-closed solenoid valve & $8210 \mathrm{G} 95$ & 1 \\
\hline BP-1 & Double acting, two-stage gas booster pump & GBT-15/30 & 1 \\
\hline $\mathrm{V}-6$ & $1 / 4$ in. check valve; $10 \mathrm{psi}_{\mathrm{g}}$ cracking pressure & SS-CHS4-10 & 1 \\
\hline $\mathrm{U}-2, \mathrm{U}-3$ & Tee-type, $7.0 \mu \mathrm{m}$ particulate filter & SS-4TF-7 & 2 \\
\hline PV-1 & $1 / 4$ in. FNPT, $300 \mathrm{~mL}$ sample cylinder & 316L-50DF4-300-PD & 1 \\
\hline $\mathrm{R}-1$ & 0 to $4000 \mathrm{psi}_{\mathrm{g}} \mathrm{SS}$ regulator; $1 / 4 \mathrm{in}$. MNPT ports & PR57-1F11Q2N14F & 1 \\
\hline V-7, V-9 & 1/4 in. tube fitting, high-pressure ball valve & SS-83PS4 & 2 \\
\hline \multirow{2}{*}{$\mathrm{V}-8$} & F84-M safety valve; $2370 \mathrm{psi}_{\mathrm{g}}$ set pressure & \multirow{2}{*}{ 01-2183L-103SL } & \multirow{2}{*}{2} \\
\hline & F84-M safety valve; $3590 \mathrm{psi}_{\mathrm{g}}$ set pressure & & \\
\hline \multirow{3}{*}{ BD-1 } & 3/4 in. FNPT SFAZ-UT burst disk holder & $\mathrm{FS} 2 \mathrm{U}$ & 1 \\
\hline & $\begin{array}{c}1 / 2 \text { in. SFAZ-002 rupture disk; } \\
2560 \text { psi }_{\mathrm{g}} \text { burst pressure } \\
\end{array}$ & \multirow{2}{*}{ UD-SFAZ-UT-00-0013-02 } & \multirow{2}{*}{$\begin{array}{c}4 \\
\text { each }\end{array}$} \\
\hline & $\begin{array}{l}\text { 1/2 in. SFAZ-002 rupture disk; } \\
4266 \text { psi }_{\mathrm{g}} \text { burst pressure }\end{array}$ & & \\
\hline \multirow{2}{*}{$\mathrm{F}-1$} & Three-zone, $1100^{\circ} \mathrm{C}$ split tube furnace & XST-6-0-24-3V & 1 \\
\hline & Three-zone furnace controller & $3-1-40-230-E 15 S P$ & 1 \\
\hline \multirow{4}{*}{ PV-2 } & 1.0 in. ID X 1.25 in. wall IN-625 pressure vessel & & 1 \\
\hline & 316-SS machined blind hub & 3-GR20 & 2 \\
\hline & 316-SS Grayloc $(\mathbb{B}$ clamp assembly & $2-1 / 2-3$ & 2 \\
\hline & 17-4 PH SS sealing ring & GR20 & 3 \\
\hline $\mathrm{V}-10$ & $\begin{array}{l}1 / 4 \text { in. tube fitting } X 1 / 4 \text { in. tube fitting } X 1 / 4 \text { in. } \\
\text { FNPT, three-way high-pressure ball valve }\end{array}$ & SS-83XPS4 & 1 \\
\hline $\mathrm{V}-11$ & $1 / 8$ in. NPT metering valve; 0.00005 max. $C_{V}$ & CC-A16A21APE & 1 \\
\hline $\mathrm{V}-12$ & $\begin{array}{l}1 / 4 \text { in. FNPT variable area flowmeter; } \\
0.5 \text { to } 5.0 \mathrm{std} . \mathrm{L} / \mathrm{hr}\end{array}$ & VAF-G1-01M-1-0 & 1 \\
\hline
\end{tabular}




\begin{tabular}{|c|c|c|c|}
\hline \multicolumn{4}{|c|}{ FITTINGS, INSTRUMENTATION, AND MISCELLANEOUS COMPONENTS } \\
\hline \multirow[t]{18}{*}{ ID } & COMPONENT DESCRIPTION & PART NO. & QTY. \\
\hline & $\begin{array}{c}1 / 4 \text { in tube fitting } \times 1 / 4 \text { in tube fitting } \\
\times 1 / 4 \text { in FNPT Tee }\end{array}$ & SS-400-3-4TTF & 6 \\
\hline & $1 / 4$ in MNPT plug & SS-4-P & 2 \\
\hline & $1 / 4$ in tube fittıng X $1 / 4$ in MNPT straight & SS-400-1-4 & 12 \\
\hline & 3/4 in FNPT full flow, quick-connect body & SS-QF12-B-12PF & 1 \\
\hline & 3/4 in FNPT full flow, quick-connect stem & SS-QF12-S-12PF & 1 \\
\hline & $3 / 8$ in thermoplastic hose, $3 / 8$ in SS MNPT & SS-7R6-PM6-PM6-30 & 1 \\
\hline & $1 / 4$ in tube fittıng Tee & SS-400-3 & 4 \\
\hline & $1 / 4$ in tube fittıng X $1 / 4$ in FNPT elbow & SS-400-8-4 & 2 \\
\hline & $1 / 4$ in tube fittıng elbow & SS-400-9 & 1 \\
\hline & 1/4 in MNPT X $1 / 2$ in tube adapter straight & SS-8-TA-1-4 & 1 \\
\hline & $1 / 4$ in MNPT X $3 / 4$ in MNPT reducer & SS-12-HRN-4 & 1 \\
\hline & $1 / 2$ in tube fitting X $3 / 4$ in MNPT straight & SS-810-1-12 & 1 \\
\hline & $1 / 4$ in tube fittıng cross & SS-400-4 & 1 \\
\hline & 1/4 in tube adapter X $1 / 2$ in FNPT straight & SS-4-TA-7-8 & 1 \\
\hline & $\begin{array}{c}1 / 4 \text { in tube adapter } X 1 / 8 \text { in tube fitting straight, } \\
\text { bored through }\end{array}$ & SS-200-R-4BT & 4 \\
\hline & 1/4 in tube adapter $X 1 / 8$ in tube fittıng straight & SS-200-R-4 & 2 \\
\hline & $1 / 4$ in tube fittıng X 1/8 in MNPT straight & SS-400-1-2 & 2 \\
\hline P-01 & 0 to $300 \mathrm{pss}_{\mathrm{g}}$ gauge, $50 \mathrm{~mm}$ face, $1 / 4 \mathrm{in} \mathrm{MNPT}$ & PGI-50M-PG300-CAOX-BG & 1 \\
\hline $\mathrm{P}-03, \mathrm{P}-04$ & 0 to $6000 \mathrm{psi}_{\mathrm{g}}$ gauge, $25 \mathrm{in}$ face, $1 / 4 \mathrm{in} \mathrm{MNPT}$ & $\mathrm{G} 058113$ & 2 \\
\hline $\mathrm{P}-05$ & 0 to $6000 \mathrm{psi}_{\mathrm{g}}$ transmitter, $1 / 2 \mathrm{in} \mathrm{MNPT}$ & PMP71-WAC1W21RDAAA & 1 \\
\hline $\mathrm{P}-06$ & 0 to $5 \mathrm{psi}_{\mathrm{g}}$ gauge, $25 \mathrm{in}$ face, $1 / 4$ in MNPT & 33075 & 1 \\
\hline $\begin{array}{l}\text { T-01, T-03, } \\
\text { T-04, T-05, } \\
\text { T-07, T 08, } \\
\text { T-09, T-10 }\end{array}$ & Self-adhesive K-type thermocouple & SAl-K-SRTC & 8 \\
\hline \multirow[t]{2}{*}{$\mathrm{T}-02, \mathrm{~T}-11$} & $\begin{array}{l}\text { K-type, single-point thermocouple probe, } \\
\text { IN-600, } 1 / 8 \text { in diameter, } 41 \text { in length sheath }\end{array}$ & KQIN-18U-41 & 2 \\
\hline & $\begin{array}{l}\text { K-type, multt-point profile probe, } \\
\text { IN-600, } 1 / 8 \text { in diameter, } 53 \text { in length sheath, } \\
\text { thermocouples } 0,3,6,9,12 \text {, and } 18 \text { in from tip }\end{array}$ & EIPP6012 & 1 \\
\hline $\mathrm{T}-06$ & K-type, IN-600 over-braided thermocouple & XCIB-K-2-1-3 & 1 \\
\hline \multirow[t]{6}{*}{$\mathrm{T}-12, \mathrm{~T}-13$} & $\begin{array}{l}\text { K-type, single-point thermocouple probe, } \\
\text { 304-SS, } 1 / 8 \text { in diameter, } 3 \text { in length sheath }\end{array}$ & KTSS-18G-3 & 2 \\
\hline & $1 / 8$ in OD X 0028 in wall, SS-316/316L tubing & SS-T2-S-028 & $20 \mathrm{ft}$ \\
\hline & $1 / 4$ in OD X 0035 in wall, SS-316/316L tubing & SS-T4-S-035 & $50 \mathrm{ft}$ \\
\hline & $1 / 2$ in OD X 0065 in wall, SS-316/316L tubing & SS-T8-S-065 & $20 \mathrm{ft}$ \\
\hline & $1 / 4$ in OD X $1 / 16$ in wall, vinyl tubing & LT-2-4 & $10 \mathrm{ft}$ \\
\hline & $120 \mathrm{ft}$ heatıng cord, $250 \mathrm{~W}$ output & HTC- 120 & 2 \\
\hline
\end{tabular}




\begin{tabular}{|c|c|c|c|}
\hline \multicolumn{3}{|c|}{ FITTINGS, INSTRUMENTATION, AND MISCELLANEOUS COMPONENTS (CONT'D) } \\
\hline \multirow{4}{*}{ ID } & COMPONENT DESCRIPTION & PART NO. & QTY. \\
\hline \multirow{5}{*}{} & Portable temperature controller; 10 to $79^{\circ} \mathrm{C}$ range & CN-TOT-A-175JF-120V & 2 \\
\cline { 2 - 4 } & $3 / 8$ in. ID X 1/8 in. wall elastomeric insulation & M06010 & $24 \mathrm{ft.}$ \\
\cline { 2 - 4 } & Adjustable height support stand; $150 \mathrm{lb}$ capacity & $9967 \mathrm{~T} 45$ & 2 \\
\cline { 2 - 4 } & Alumina specimen boat assembly & & 1 \\
\cline { 2 - 4 } & Isolated input, multi-channel data logger & GL820 & 1 \\
\cline { 2 - 4 } & $24 \mathrm{~V}_{\mathrm{DC}} 60.0 \mathrm{~W}$ power supply & S8VS-06024 & 1 \\
\cline { 2 - 4 } & Hinged electrical enclosure & R201206 & 1 \\
\cline { 2 - 4 } & $500 \mathrm{~mL}$ Erlenmeyer flask & FLA204 & 2 \\
\cline { 2 - 4 } & Size \#6, two-hole rubber stopper & DPSTO3032 & 2 \\
\hline
\end{tabular}




\section{APPENDIX B: Representative Thermal Profiles of the Pressure Vessel}

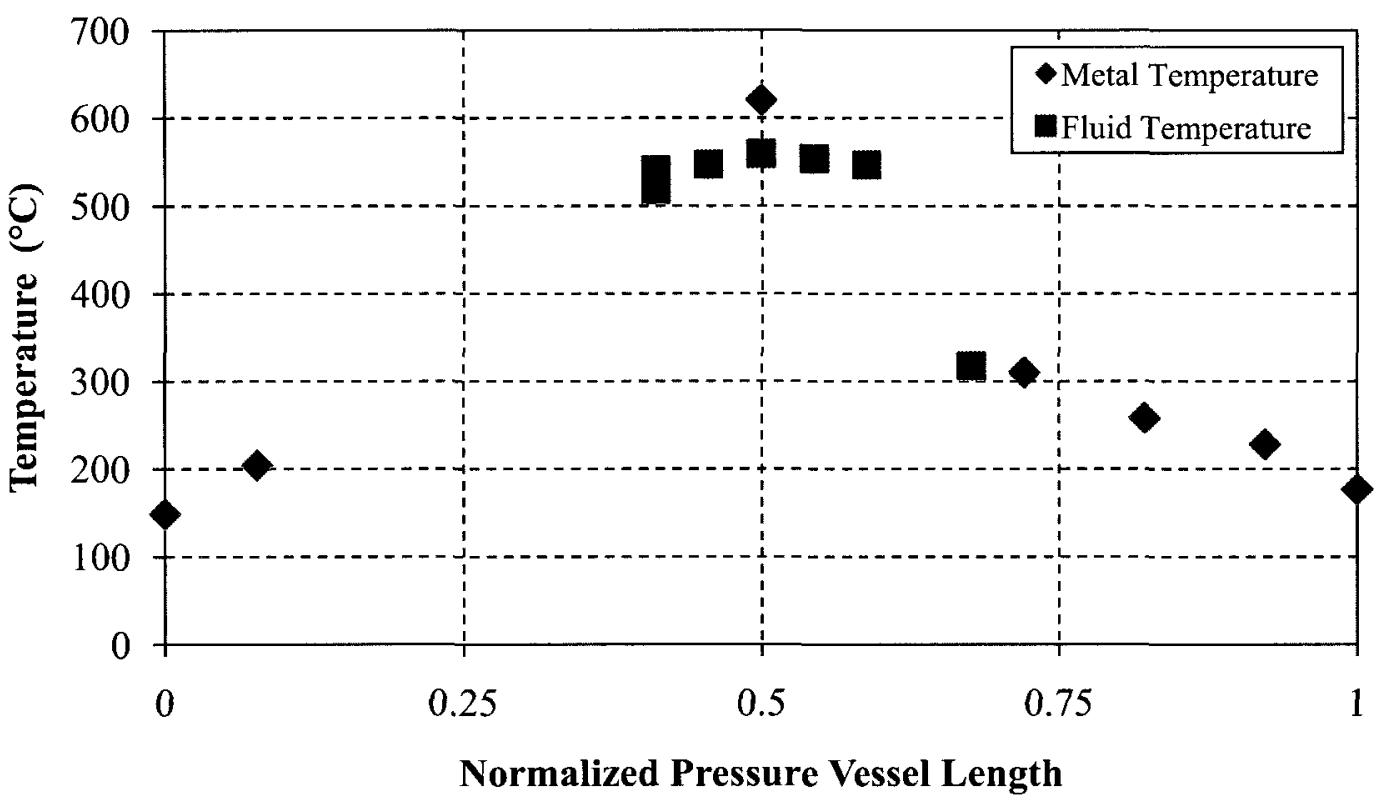

Figure B-1: Temperature distribution at $15.0 \mathrm{MPa}$ for $\left[685^{\circ} \mathrm{C}\left|610^{\circ} \mathrm{C}\right| 645^{\circ} \mathrm{C}\right]$

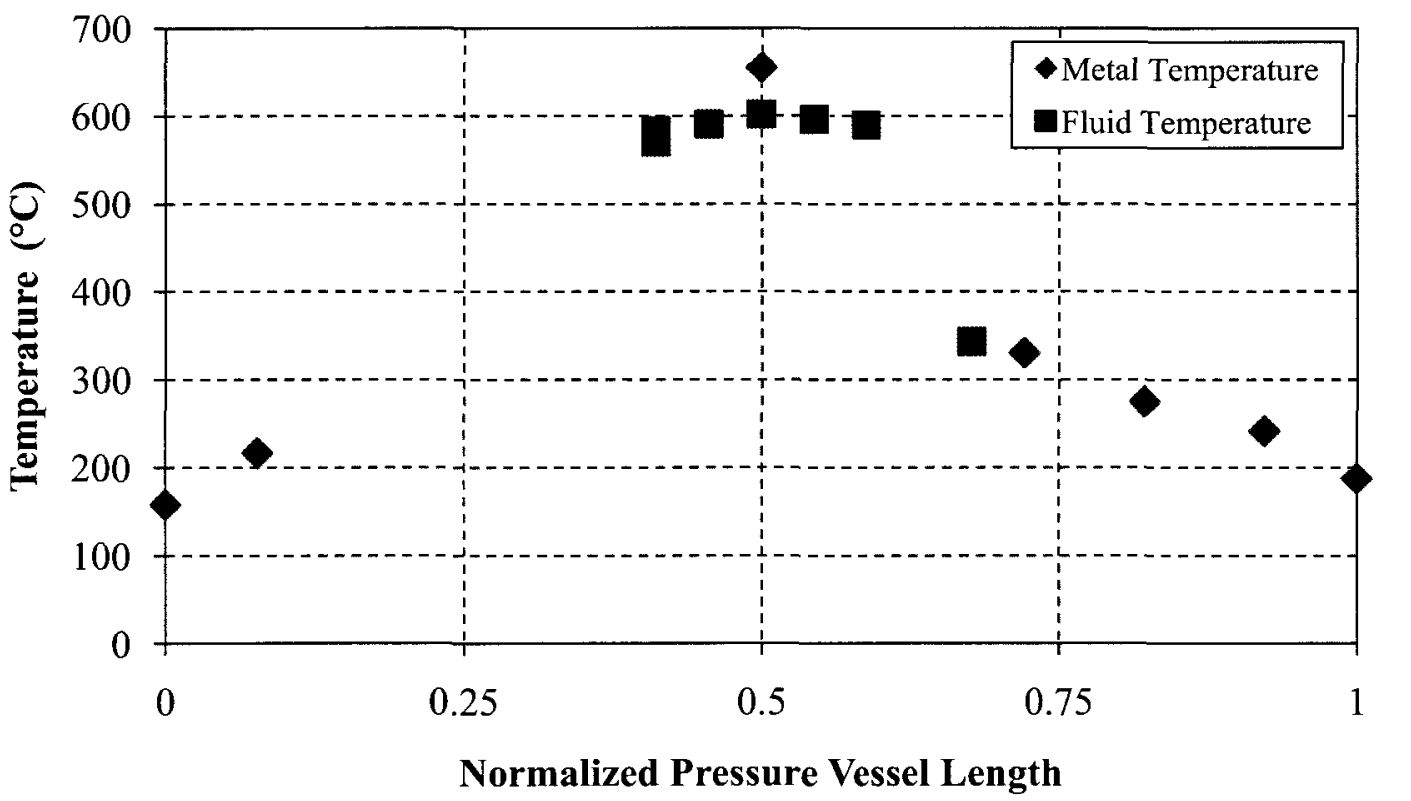

Figure B-2: Temperature distribution at $15.0 \mathrm{MPa}$ for $\left[725^{\circ} \mathrm{C}\left|640^{\circ} \mathrm{C}\right| 690^{\circ} \mathrm{C}\right]$ 


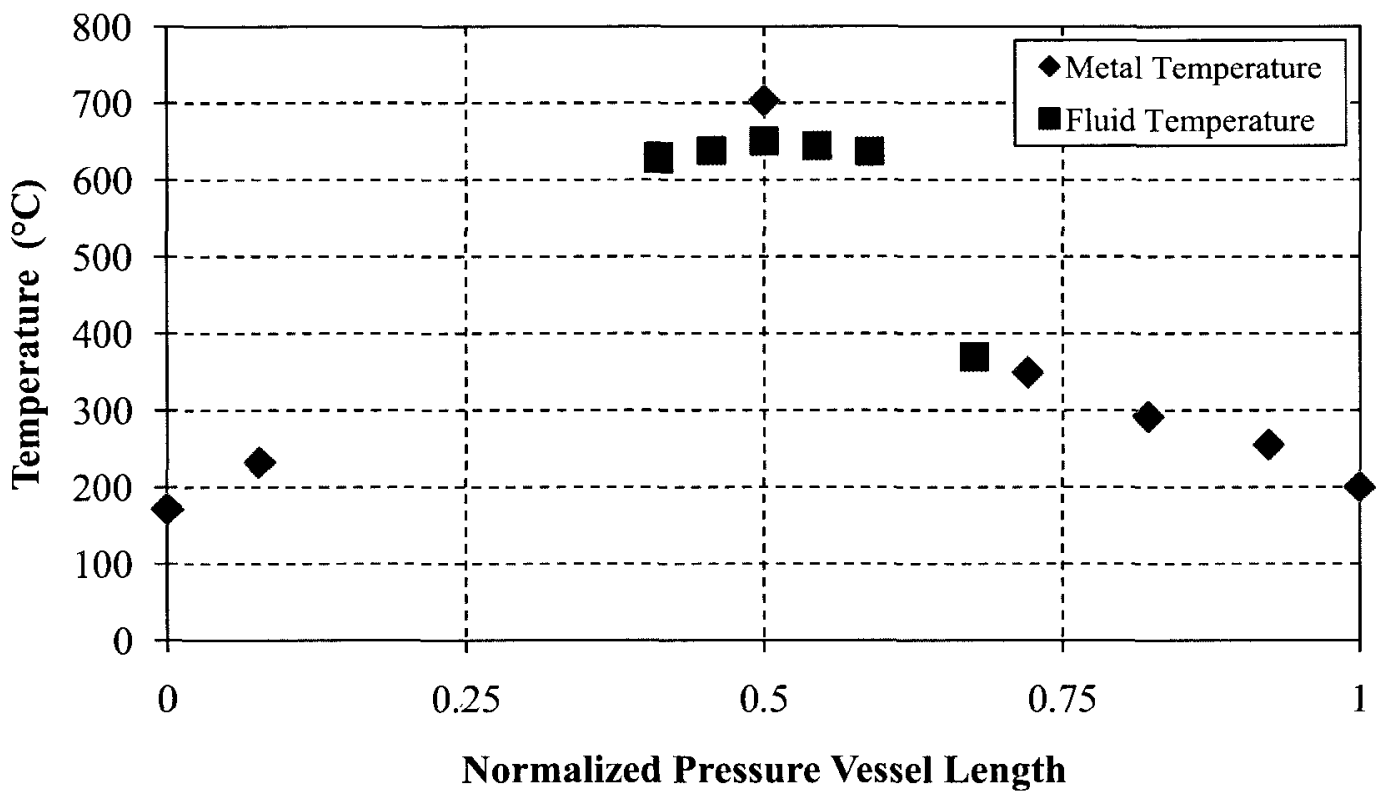

Figure B-3: Temperature distribution at $15.0 \mathrm{MPa}$ for $\left[755^{\circ} \mathrm{C}\left|695^{\circ} \mathrm{C}\right| 725^{\circ} \mathrm{C}\right]$

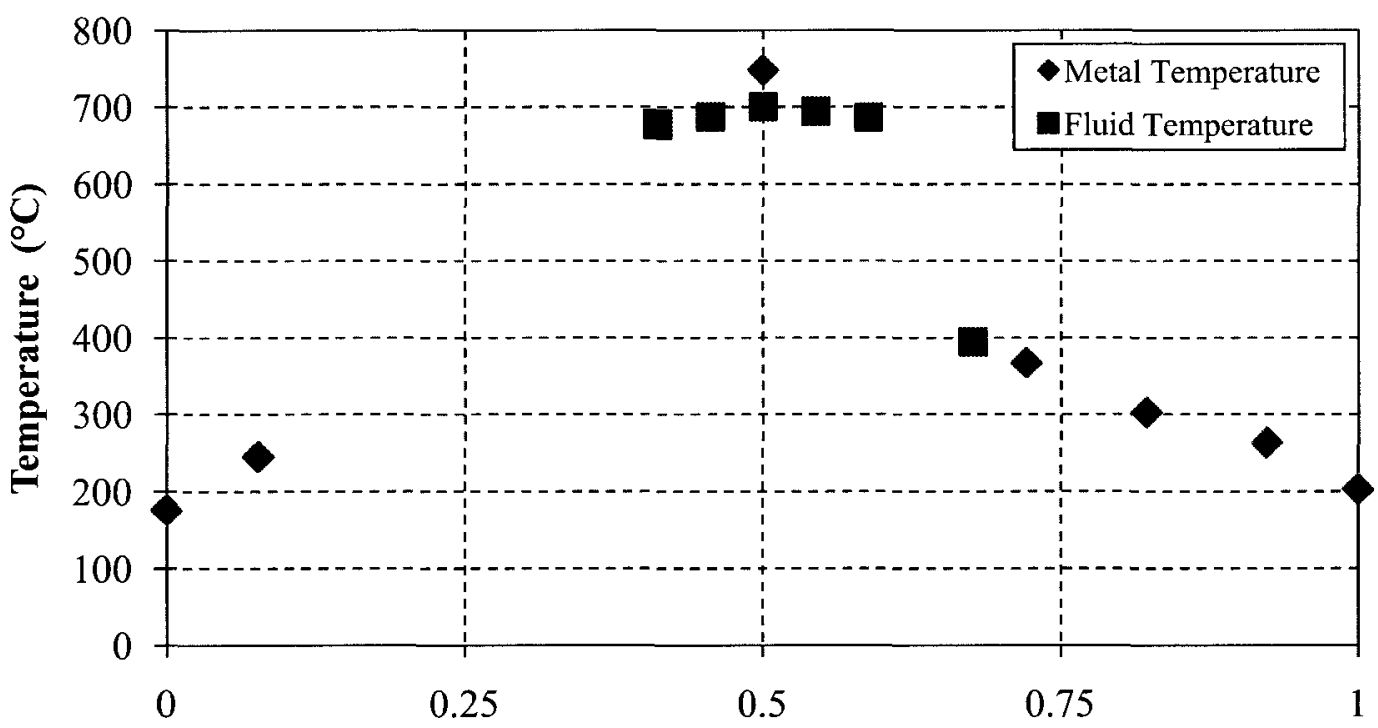

Normalized Pressure Vessel Length

Figure B-4: Temperature distribution at $15.0 \mathrm{MPa}$ for $\left[785^{\circ} \mathrm{C}\left|735^{\circ} \mathrm{C}\right| 780^{\circ} \mathrm{C}\right]$ 


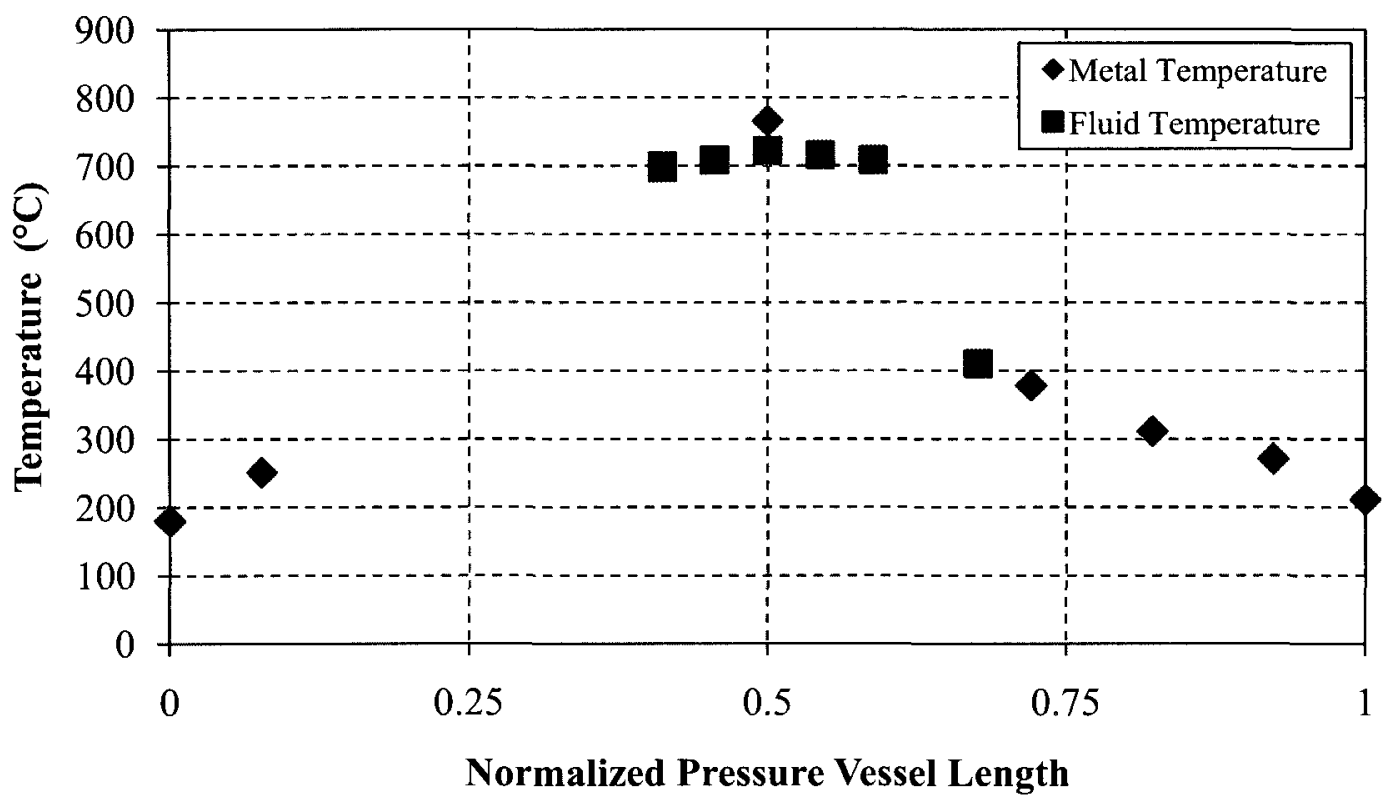

Figure B-5: Temperature distribution at $15.0 \mathrm{MPa}$ for $\left[800^{\circ} \mathrm{C}\left|750^{\circ} \mathrm{C}\right| 800^{\circ} \mathrm{C}\right]$

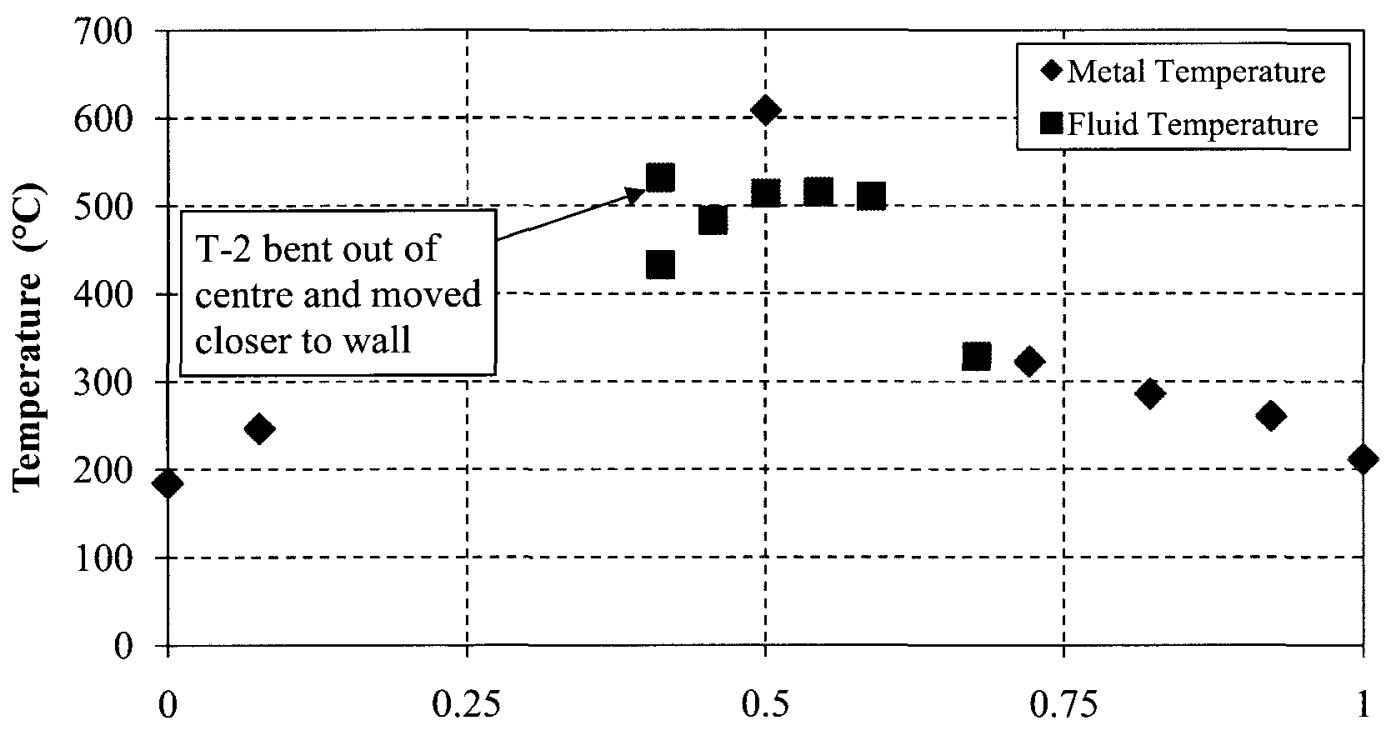

Normalized Pressure Vessel Length

Figure B-6: Temperature distribution at $25.0 \mathrm{MPa}$ for $\left[685^{\circ} \mathrm{C}\left|610^{\circ} \mathrm{C}\right| 645^{\circ} \mathrm{C}\right]$ 


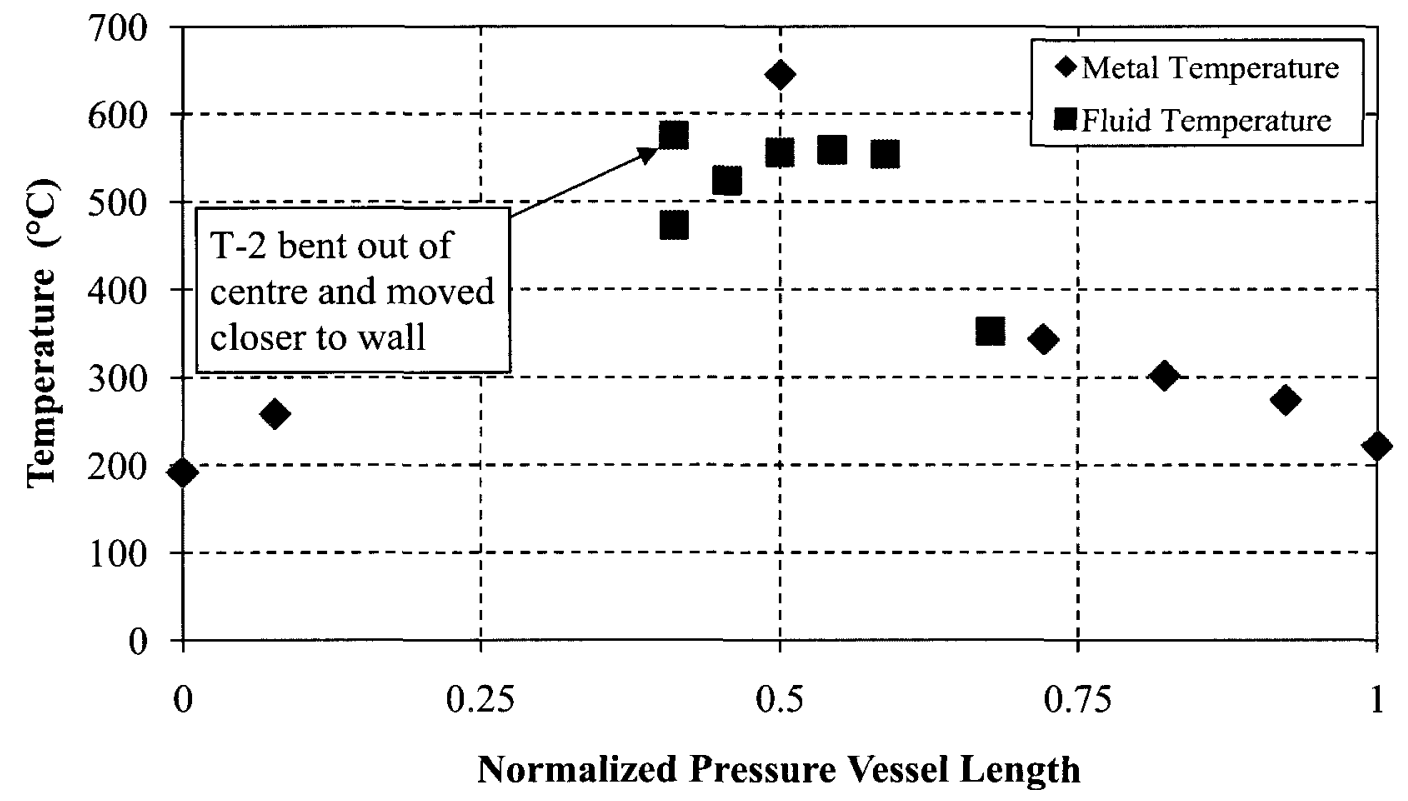

Figure B-7: Temperature distribution at $25.0 \mathrm{MPa}$ for $\left[725^{\circ} \mathrm{C}\left|640^{\circ} \mathrm{C}\right| 690^{\circ} \mathrm{C}\right]$ 